ILLUSTRATED

\title{
HoRsE BREAKING
}

CADT M. H. HAYES 


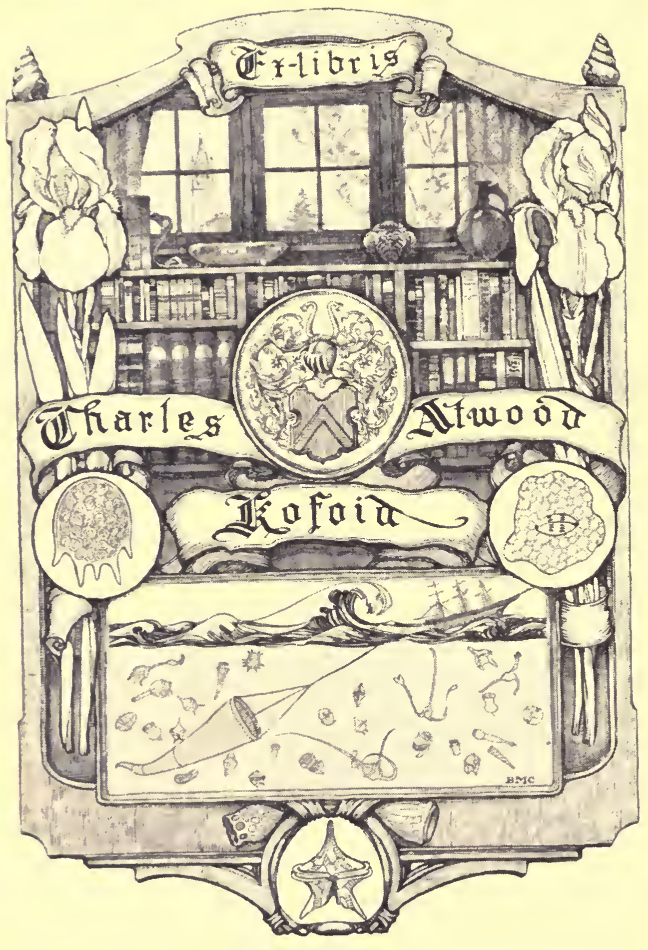




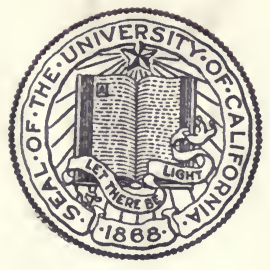

THE LIBRARY OF

\title{
THE UNIVERSITY OF CALIFORNIA
}

\author{
PRESENTED BY
}

PROF. CHARLES A. KOFOID AND MRS. PRUDENCE W. KOFOID 





\section{ILLUSTRATED HORSE - BREAKING}






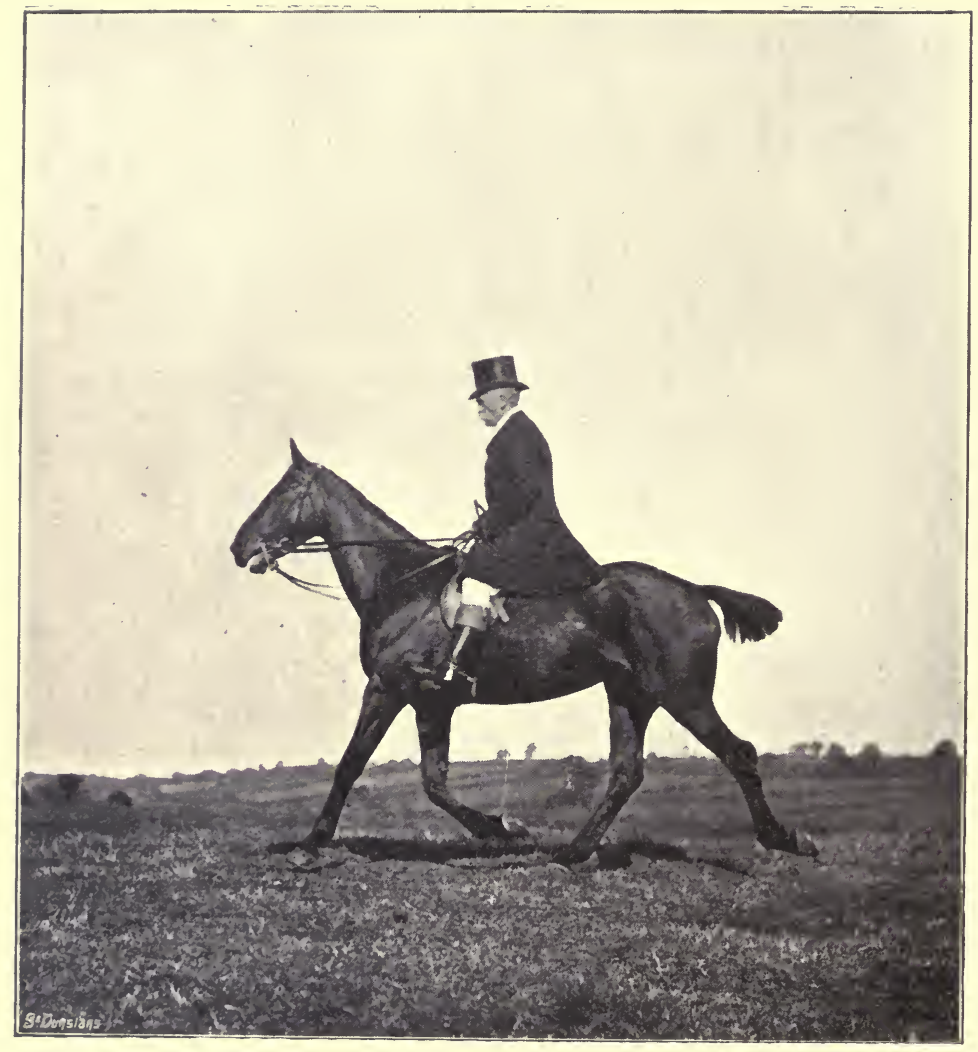

TROT'TING OFF TO COVERT. 


\section{ILLUSTRATED}

\section{HORSE-BREAKING}

BY

M. HORACE HAYES, F.R.C.V.S.,

Late Captain "The Buffs,"

AUTHOR OF

"POINTS OF THE HORSE," "VETERINARY NOTES FOR HORSE OWNERS,"

“ RIDING AND HUNTING," ETC.

ILLUSTRATED BY

J. H. OSWALD BROWN,

AND BY PHOTOGRAPHS SPECIALLY TAKEN

Third Edition (Revised and Enlarged)

LONDON

HURST AND BLACKETT, LTD.,

182, HIGH HOLBORN, W.C.

1908

All rights reserved 

$S F 287$
114
1905

To

IDU Dear Wuife

WHO HAS BEEN MY BEST HELPER AND SOUNDEST

ADVISER WHEN I HAVE BEEN BREAKING HORSES

IN VARIOUS PARTS OF THE WORLD 



\section{PREFACE TO FIRST EDITION.}

I OFFER this work to the favourable consideration of the public, as an attempt to describe a reasoned-out system of horse-breaking, which I have found, by practical experience, to be easy of execution, rapid in its effects, and requiring the possession of no exceptional strength, activity, pluck, or horsemanship by the operator, who, to become expert in it, will, as a rule, need only practice. It is in accordance with our English and Irish ideas on the subject; for it aims at teaching the horse "manners," and giving him a snafflebridle mouth; so that he will "go up to the bridle," and "bend" himself in thorough obedience to rein and leg.

As a personal explanation, I may mention that after having spent many years racing and training in India, during which time I practised the ordinary methods of breaking, I returned to England, where I learned the use of the standing martingale and long driving reins, as applied specially to jumpers, from Mr. John Hubert Moore, who was the cleverest "maker" of steeplechasers Ireland ever knew. $\mathrm{He}$, I may remark, obtained these methods, in his youth, from an old Irish breaker, named Fallon, who was born more than a century ago. I had also valuable instruction in "horse-taming " from Professor Sample. Having read an account of MM. Raabe and Lunel's hippolasso, as a means of control for veterinary operations, I conceived, with happy results, the idea of utilising this ingenious contrivance in breaking. I also learned, about the same time, how to balter a loose horse without running any danger of being kicked, or bitten.

Having thus acquired a fair amount of information, on what has always been to me a favourite subject, I naturally wished to put it into practice.

As I knew, judging from my former ignorance, how much men in India stood in need of instruction in horse-breaking. I determined to return to that country with the object of teaching this art; so as to acquire the experience I needed, and to "pay my expenses" at the same time. I am glad to say that I was successful in both respects. During a two years' tour, I held classes in all the principal stations of the Empire-from Trichinopoly to Peshawur, and from Quetta to Mandalay-and, having met a very large number of vicious 
animals and fine horsemen, I obtained experience, and greatly added to my stock of knowledge, which I shall now try to utilise for the benefit of my readers. As I proceeded through India, I felt the necessity of rejecting some methods I had formerly prized, altering others, and adopting new ones; so that the course of instruction which I was able to give to my more recent classes, was far more extensive, and of better proved utility, than what I had to offer at the beginning of my travels. The great want which I had at first felt, was a method by which a person could secure and handle, with perfect safety, any horse, no matter how vicious he might be. However, after many kicks, a few bites, and several lucky escapes, I was able to perfect the required method, which is so simple, that the only wonder is that I did not think of it before. I may explain that the Australian horses met with in India, where they form a considerable proportion of the animals used for riding and driving, are far more dangerous and difficult to handle and control than British stock. Had I remained in England all my life, I should not have acquired a quarter of the experience of vicious horses I was afforded, during the time I lately spent in India. It goes almost without saying, that the more difficult the pupil is to teach, the greater chance has the instructor of becoming expert in his business. I need hardly say, that I shall always be very grateful to any of my readers who may favour me with special information on this or kindred subjects.

I may mention, that, after returning from India, I held classes in England, Gibraltar, Malta, Egypt, Ceylon, Singapore, and Chına.

I have much pleasure in giving, in the body of this work, the sources from which I have taken various hints.

The chief claim I, here, make to originality, is, that in bringing together the results of experience in different countries, I have endeavoured to reduce the art of breaking horses to a more or less complete system, many of the principles of which, I venture to think, I have been the first to expound, and that I have made several improvements in existing methods. The new things which I have introduced need no special mention here.

My best thanks are due to Mr. J. H. Oswald Brown for the faithful and painstaking manner in which he has illustrated the letter-press of this book. The drawings speak for themselves.

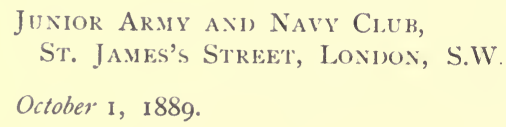




\section{PREFACE TO SECOND EDITION.}

Three years' horse-dealing in India, a horse-breaking tour through South Africa, a study of high-school riding in Paris and Berlin, and two seasons' hunting in Leicestershire taught me so many new things about horses, since writing the first edition, that the present one is practically a new book. Its letterpress is more than twice as much as that of its predecessor; the arrangement of the material has been entirely changed; and 75 new illustrations (reproductions from photographs) have been added to 49 old ones. I have given greatly increased prominence to mounted work for the breaking in of horses; and have added a description of the most modern developments of school breaking, for further information on which subject I would beg to refer my readers to the writings of Fillis and Barroil.

While writing for practical men, I have kept in view the fact that by working on the principles of equine psychology and equine locomotion, we can make horse-breaking a science as well as an art.

I have been obliged to say so much about work in the saddle that this second edition trenches to a large extent on what I had supposed to be the special province of the subject of my book, "Riding and Hunting." Riper experience shows me that breaking and riding should be studied conjointly; for we cannot break in a horse properly to saddle unless we know how to ride him; nor can we ride him to the best advantage unless we know how he has been broken in. Therefore, instead of writing these two works separately, I ought to have brought out one book of two volumes on their respective subjects. Although it is too late now to make the alteration, I shall bear this fact in mind, when, at some future time, I shall have to write a new edition of "Riding and Hunting"; and shall avoid a good deal of repetition by being able to refer to "Illustrated Horse-Breaking."

I may mention that Messrs. Champion and Wilton, 457, Oxford Street, W., keep patterns of the breaking gear I use.

All the photographs in this book have been done either by my wife or by myself.

The sad and untimely death of Mr. J. H. Oswald Brown has deprived me, when preparing this edition, of the invaluable help of a friend to whom I owe the greater part of the success attained by the books which he illustrated for me. 



\section{INTRODUCTORY NOTE TO THIRD EDITION.}

This edition of "Illustrated Horse-Breaking" is identical with the previous one, except for the addition of some ideas which the Author mentioned to me a short time ago, and a few others which have seemed to me helpful during much practical work.

As an old pupil, and a friend of Capt. Hayes, I feel that I have lost much by his death, for I have the pleasantest recollection of time passed in his genial company, when he has enthusiastically entertained me with some of his many interesting experiences, and has never tired of explaining to me things concerning horses, which he has thought might help me. I used to find his clear reasoning a pleasure to follow, and I was always greatly impressed by the broad-minded way in which he would discuss new ideas.

I have enjoyed re-reading the second edition of "Illustrated Horse-Breaking" greatly, and now more than ever have I been impressed by the excellence of the book, but I must say I have a higher opinion of the horse's intelligence than that expressed by the Author. I also think that some people possess a much better influence on animals than others, and that Capt. Hayes was helped greatly in educating horses by his gentle, perceptive and determined nature.

R. HAROLD MEADE.

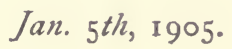





\section{O N TENTS.}

\section{CHAPTER I.}

PAGF

\section{MENTAL QUALITIES OF THE HORSE.}

Mind-Consciousness, ideas, memory, habit, and instinct-Intelligence and reason-Special instincts and senses-Vice

\section{CHAPTER II.}

\section{THEORY OF HORSE-CONTROL.}

Objects and scope of horse-breaking-Requirements in the breaker-Desirability of early training-Gaining the horse's attention-Accustoming a horse to his surroundings-Making a horse understand our ordersPunishment and reward-Effect of the voice-Emulation and imitation - Fatigue-Necessity for exacting implicit obedience from the horseSafety in breaking-Rapid methods of breaking-On the possibility of overcoming any form of vice-Personal influence in breakingAdvisability of possessing various methods of breaking-Selection of breaking methods-Permanency in the effect of breaking-Summary of the principle of making horses docile . . . . . .

\section{CHAPTER III.}

\section{THEORY OF MOUTHING.}

"Mouth" and "aids"-Respective action of the aids-Suitability of the horse to the application of the aids-Making a horse obey the aids-Combined action of fore and hind legs, and distribution of weight on them-Carriage and action of the head and neck of the horse when he is in motion- "Collecting" the horse-Requirements of a good mouth - Combined action of the aids in forming the mouth-Respective action of the snaffle and curb-Direction of the pull of the reinsTurning, circling and lunging the horse-Reining back-The standing martingale-Bearing reins, running reins, side reins, and nosebands"'Tying horses up," "reining," dumb jockeys, and the pillars . . 


\section{METHODS OF HORSE-CONTROL.}

The breaking enclosure-Gentling the horse-Holding and leading a comparatively quiet horse-Making a rope halter-Haltering a loose horse - Teaching a loose horse to come up and to follow--Lifting up a fore leg-Holding up a fore leg-Tying up a fore leg-Blindfolding a horse - The halter-twitch--The rope-twitch - The noose-twitch-The headstall-twitch-The bridle-twitch-The Indian war bridle-The Comanche bridle-The Cavesson-The strait-jacket-Lifting up a hind leg-Improvised hobble-The wooden gag-Making a horse lie down and keeping him on the ground-Major Woods' method of throwing horses-Throwing a horse with a strait-jacket-The head and tail method-Rareyfying a horse--Sample's horse-taming machine -South African method of breaking .

\section{CHAPTER V.}

BKEAKING ON FOOT.

Catching a horse and making him quiet to handle-Mouthing a horse with the long reins on foot-Teaching a horse to turn on his forehandTeaching a horse to lead

\section{CHAPTER VI.}

\section{ORDINARY MOUNTEI) BREAKING.}

General remarks-Mounting a horse for the first time-Turning a horse on the forehand at the halt when mounted-Reining back-The walk - The trot-Turning a horse during movement-Teaching a horse to carry his rider in a collected and well-balanced manner-The canter - The halt - Whip and spurs - Time required for ordinary breaking to saddle

\section{CHAPTER VII. \\ TEACHING HORSES TO JUMP.}

General instruction-Jumping faults-The hunter-The chaser-The hurdle racer-The show jumper-Time required to teach a horse to jump

\section{CHAPTER VIII.}




\section{CHAPTER IX.}

\section{SCHOOL BREAKING.}

General remarks on school breaking-The school horse-Collecting the horse at the halt-Collecting the horse at the walk and trot-Teaching the horse to strike off correctly into the canter-Changing the leg at the canter-Figure of eight at the canter-Cantering falsely-Turn on the forehand-Turn on the hind-quarters-The passage-The passage with head to wall-The passage with tail to wall-Change of hand by the passage-Counterchange of hand by the passage-Circling at the passage-The halt-Change from one pace to another-Shoulder in-Course of school instruction-Additional school movementsExtension of a fore-leg-The Spanish walk-The Spanish trot-Turn on the fore-hand on three legs-The canter on three legs-Changes of leg at the canter-A circus high-school act.

\section{CHAPTER X.}

\section{BREAKING FOR SPECIAL WORK.}

The race-horse-The lady's horse-The cavalry horse-The polo ponyThe park hack-The fashionable harness horse-The shooting pony -Mules and zebras

\section{CHAPTER XI.}

\section{FAULTS OF MOUTII.}

Boring-Pulling and running away-Throwing up the head and star-gazing - Jibbing-Rearing-Shying-Running out to one side and difficult to turn-" Keeping behind the bit," prancing, and "breaking " when wanted to walk or trot-Teaching pacers (amblers) to trot-Carrying the hind quarters, in the canter or gallop, outside the line of progression, and refusing to lead except with a particular fore-leg"Putting too much weight on the fore-hand" when mounted-Plunging forward when starting in harness-Pulling away from and hanging against the pole when in double harness

\section{CHAPTER XII.}

\section{FAULTS OF TEMPER.}

Difficult to catch-Difficult to handle, bridle, saddle, mount or dismount from-Difficult to ball or drench-Unsteady with the whip, under fire, when drawing swords, when touched with the heel, etc.-Difficult to lead into a doorway, horse-box, etc.-Difficult to shoe-Buck-jumping -Biting and savaging-Kicking and striking out in front-Pawing at 
PAGE

night-Pawing lack the litter-Rubbing the tail-Sleeping standing -Difficult to harness and unharness-Getting the tail over the rein and kicking when in harness-Lying down in harness-Hanging back in the stall

\section{CHAPTER XIII.}

\section{CIRCUS TRICKS.}

General remarks-“Begging"-Bowing and shaking the head-Circling steadily at liberty-Teaching a horse to follow-Handkerchief work -Jumping over another horse, etc.-Kicking-Kissing-Kneeling down-Laughing-Liberty work-Limping-Lying down-Obeying without reins-Polka, dancing the-Pushing a man out of the ringRearing and walking on the hind legs-See-sawing on a plank, etc.Shaking hands-Waltzing. 


\section{LIST OF ILLUSTRATIONS.}

FiG.

PAGE

I. Horse running out at a fence (A B), on account of refusing to bring his hind quarters round in answer to the pull of the reins; although he bends his neck to it

2. Horse going straight at his fence $(\mathrm{A} B)$, on account of having answered the pull of the reins with his hindquarters as well as with his forehand . . . 65

3. Trotting . . . . . . . . . 69

4. Cantering . . . . . . . . 70

5. Walking at ease . . . . . . . . . . 7 I

6. Collected walk . . . . . . . . . 73

7. Reining-back . . . . . . . . 85

8. " , . . . . . . . . 86

9. Maximum length for a standing martingale . . $\quad 88$

г. Front view of leather-covered, unjointed snaffle . $\quad$. 89

I I. Leather-covered, unjointed snaffle, in horse's mouth 89

I 2. Jumping with standing martingale . . . . 9 I

13. Holding horse . $\quad$. $\quad$. $\quad$. $\quad . \quad 97$

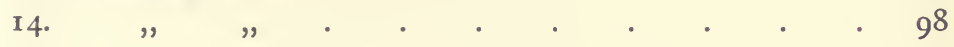

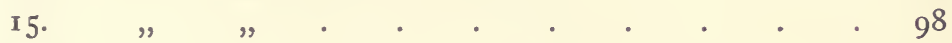

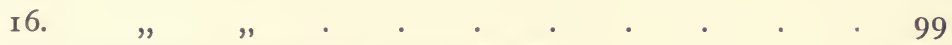

I 7. First loop in making a rope-halter . . . . 100

I8. Rope-halter completed . . . . . . Iо०

I9. Rope-halter ready to put on . . . . . Iо I

20. Rope-halter with knot to prevent it pinching the horse's jaws . . . . . . . . . 102

2 I. Rope-halter, put on pole to halter horse . . . IC3 
2 2. Haltering loose horse . . . . . . . 104

23.,$"$. . . . . . . 105

24. Rope-halter on horse . . . . . . . 106

25. Pratt's method of putting halter on pole to halter horse. Io7

26. Noosing horse's fore leg . . . . . . 1 108

27. Pulling up horse's fore leg with rope . . . . . 109

28. Tying up horse's fore leg with rope . . . I Io

29. Lifting up a fore leg . . . . . . . I I I

3०. Wrong way of holding up horse's fore leg . . . I I 2

3I. Proper way to hold up unshod horse's fore leg . . II2

32. Proper way to hold up fore leg of shod horse . . II3

33. Rarey's leg-strap . . . . . . . . II4

34. A stirrup-leather utilised for tying up a fore leg . . I I 5

35. Tying up fore leg with stirrup-leather . . . . II 7

36. Suspending horse's fore leg to surcingle . . . II 7

37. Halter-twitch . . . . . . . . II8

38. Halter-twitch applied . . . . . . . I I9

39. ," . . . . . . . . I 20

40. Noose which will not run . . . . . . I 2 I

4I. Pratt's twitch, first portion . . . . . . 122

42. Pratt's twitch, completed . . . . . . 123

43. Pratt's twitch on horse's head . . . . . I 24

44. Noose-twitch . . . . . . . . I 24

45. Head-stall twitch on horse . . . . . . 125

46. Bridle-twitch, front and near-side view . . . . I 26

47. , , off-side view . . . . . . 1 27

48. Indian war bridle . . . . . . . 128

49.,$\quad$. . . . . . . . . $\quad$ I 29

50. First part of Comanche bridle . . . . . $\quad$ I 29

5 I. Comanche bridle, off-side . . . . . . I30

52. Comanche bridle, near-side. . . . . . I $3^{\mathbf{I}}$

53. Strait-jacket . . . . . . . 132

54. Horse with strait-jacket on . . . . . . 133

55. Lifting up horse's hind leg . . . . . . I34

56. $, ", \quad$. . . . . . . . . 135

57.,$\quad$, $\quad$. . . . . . . . 136

58. Holding up horse's hind leg . . . . . 137

59. First step in lifting up hind leg without assistance . I $3^{8}$ 
FIG.

6o. Second step in lifting up hind leg

6r. Third step in lifting up hind leg .

62. Hobble

63. Holding up horse's hind leg

140

64. Gentling horse's hind leg .

140

64A. Padded slip hobble

I 4 I

64B. Leg fastened with slip hobble

142

65. Double sheet bend on horse's tail

142

66. Pulling up horse's hind leg .

143

67. Hind leg pulled up with one rope on tail . . . I45

68. Method of fastening a rope to a short tail . . . 146

69. Rope attached to short tail . . . . . . 147

70. Hobble improvised with stirrup-leather and iron . . 148

7 I. Wooden gag . . . . . . . . 149

72. Horse ready to be made lie down . . . . 150

73. Horse on ground . . . . . . . 151

74. Making horse lie down . . . . . 152

75. Horse on ground with head pulled round . . . 153

76. Holding horse down on ground . . . . . 153

77. Horse tied head and tail . . . . . . I55

78. Horse tied down on ground. . . . . . 167

79. Side view of bearing-rein . . . . . . . $\quad$ r 69

80. Front view of bearing-rein . . . . . . I7 I

80.. Standing martingale shortened . . . . . I72

81. Horse with bearing-rein . . . . . . 173

82. Front view of driving-pad . . . . . . I74

$82 \mathrm{~A}$. Horse circling . . . . . . . . $\mathrm{r} 75$

83. Side view of driving-pad $\quad . \quad$. $\quad . \quad . \quad . \quad$. $\quad$ I75

84. Wooden driving-pad . . . . . . . I76

85. Driving-pad, crupper, and rein-bearers on horse . . 176

86. Driving horse on foot with reins through stirrup-irons . $\quad$ I 77

87. Rein under cantle of saddle . . . . . $\quad$ I 78

88. Circling horse on foot to the right . . . . I79

89. Circling horse on foot to the left . . . . I80

90. Position from which to circle horse (to left, for instance) r $8 \mathrm{I}$

91. Outward rein on driving pad . . . . . 182

92. Turning horse with rein on driving-pad . . . 183

93. Removing head-stall without displacing bridle . . 190 
Fig.

94. Driving horse with running reins through stirrup-irons .

95. Making horse, on foot, turn on his forehand to left with whip

96. Crupper leading-rein . . . . . . . . r96

97. Knot in crupper leading-rein . . . . . 197

98. Teaching horse to "come up" by tapping him on chest with whip

99. Off rein passed through near ring of snaffle for leading horse

ıо०. Horse mounted for first time . . . . . 203

Ior. Horse ready to be mounted for first time . . . 205

I02. Mounting horse for first time . . . . . 206

ı०3. Buckjumping saddle . . . . . . . 209

104. " " . . . . . . . 2 10

105. Rein and whip in each hand . . . . . 2 II

ıо6. Rein and whip in hand . . . . . . 2 I 3

107. Teaching the horse to turn to the right on his forehand

by the whip . . . . . . . 214

I 08. Leg drawn back in turning horse . . . . 2 I5 5

ro9. Cantering with near fore leading . . . . 225

I ro. Period of canter or gallop when weight of horse and rider is borne by leading fore leg . . . . 227

I I I. Leicestershire cut and laid hedge . . . . . ${ }_{2}^{2} 8$

I I 2. Teaching horse to jump with long reins . . . 239

I I3. " , , , , . . 24I

I I 4. Boots for protecting horse's legs when jumping . $\quad 244$

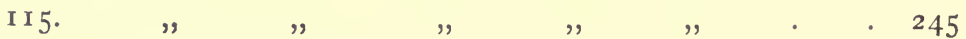

I 6. Driving horse in harness on foot . . . . 254

I I 7. A jingle . . . . . . . . . 255

I 7 A. Double hobble in use . . . . . . 258

I r8. Passage to the right . . . . . . 274

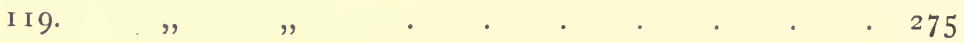

I 20. Cantering with near fore leading . . . . $\quad 279$

I 2 I. The Spanish walk . . . . . . $\quad{ }^{285}$

I22. The mountain zebra . . . . . . . 297

I 22A. A mountain zebra . . . . . . . . 299

I 23. Pulling kicker's head round . . . . . . 335

I24. Tail tied with tape to prevent horse rubbing it . $\quad 33^{6}$ 


\section{ILLUSTRATED HORSE-BREAKING.}

CHAPTER I.

\section{MENTAL QUALITIES OF THE HORSE.}

Mind-Consciousness, ideas, memory, habit, and instinct-Intelligence and reason-Special instincts and senses-Vice.

MIND.

An animal is distinguished from a vegetable by, among other things, the possession of a nervous system, the development of which appears to regulate that of the mental capacity of the individual. In the lowest grades of animal life, the nervous matter, instead of having a definite form, is diffused generally throughout the body, which, in this case, is gifted only with the power of contracting on being touched and of absorbing nourishment from its surroundings. In the next few upward steps, we find the nerves arranged in a system of conducting nerves and nerve centres by which the animal can receive and combine impressions from without, and can transmit to its muscles the stimulus for the movements which are necessary to its welfare. By the nerves on the surface of the body becoming modified by use, the senses of sight, hearing, taste, and smell were gradually established. Advance in nervous development is brought about chiefly by the principles that use strengthens a function; that offspring more or less resembles the parent or parents, 
according as there has been, respectively, one or two engaged in its reproduction; and that those beings which are best fitted to their surroundings are the most likely to survive in the struggle for existence. Thus, as we ascend the scale of life, we find that the nervous system, in becoming developed, endows the animal with many faculties. Consciousness, memory, and instincts appear early; but the power of drawing conclusions latest of all. As all these faculties, instinctive as well as intellectual, are, as far as we can find out, manifestations of the nervous system, it may not be unreasonable to regard what is called mind and the nervous system as one and the same thing. Degree of development seems to be the only difference between the mind of man and that of brutes.

CONSCIOUSNESS, IDEAS, MEMORY, HABIT, AND INSTINCT.

Many of the actions of animals are performed in direct response to stimuli applied to sensory nerves (those of feeling, seeing, hearing, tasting, and smelling), as, for instance, when we draw our hand back in the event of one of our fingers being accidentally pricked, or when we blink our eyes on some unexpected object suddenly approaching them. These automatic movements may be comparatively simple, such as the two I have just cited; or complex, as when the touch, smell, and no doubt sight, of its dam's teat stimulate the newly-dropped foal to suck, or when a sleeping man brushes off a fly which is irritating the nerves of the skin of his face. As consciousness plays no part in automatic actions, we may infer that if the actions of any animal were wholly automatic, such animal would be devoid of consciousness ; in fact, it would be an unconscious automaton. We know from observation that in all the higher animals, actions which at first were automatic, become in many cases largely modified by 
consciousness, by which impressions of past nervous stimuli produce a more or less lasting impression on the brain (or mind). I may point out that ideas are the effects left on the mind by impressions. By being conscious, an animal associates in its mind the idea of pleasure or pain with past impressions; and, consequently, in the future seeks after impressions which it has learned by experience to be pleasurable, and tries to avoid those which are painful. For example, we may daily note that the young of the higher animals, from experience, gradually increase their ability to obtain and select their food, and to save themselves from their enemies. We see in ourselves how greatly experience in boxing and fencing perfects the automatic movements which are necessary to guard us from hurt by fist or sword-point. The necessary retention of ideas (or memory) appears to be due to a modification of the brain substance by which an impression of an original idea is produced by means of another idea that has been associated with it. Professor Lloyd Morgan aptly compares this modification of brain substance to that undergone by a used phonograph, the cylinder of which has become indented in such a way by the voice, that it is capable of reproducing similar wave-sounds at a subsequent time. Ideas, we must remember, are no more retained in the mind than are sounds in the phonograph. Habits are thus formed in the individual, and by the principle of heredity are transmitted to the offspring as instincts. We may define an instinct as a habit which has become hereditary and automatic, and which can consequently be exercised without teaching, imitation, or experience. Or we might regard instinct, in its collective sense, as hereditary memory. Granting, as we can scarcely help doing, the truth of the principle of evolution, we must admit the existence of mental progress by means of con- 
sciousness and association of ideas among the lowest forms of animal life, if we prove it; as we can amply do, among the higher animals.

While giving full weight to the respective influences of the principle of the survival of the fittest, and that of selection, I think we must admit that instinct may become greatly modified through generations by the influence of the association of ideas. Thus, there have been frequent instances of the wild birds of recently-discovered islands evincing extremely little fear of man on his first appearance; although they gradually acquired it as an instinct under new influences later on. The Samoan tooth-billed pigeon, which, before that island was brought under the influence of Western civilization, used to sleep and breed on or close to the ground, has, by the presence of its imported enemies, acquired the habit of taking refuge in trees, in which it now possesses the instinct of roosting and building its nest. The fear of man, which we have made instinctive in many animals, may by disuse be rendered so slight as not to merit the title of an instinct, as we may see by the difference in tameness between the young of our domestic animals and the offspring of their respective wild representatives of common ancestry. The influence of use and selection on instinct gives us, in the dog, members of the same species with such widely differing instincts as those of the foxhound, greyhound, pointer, collie, and retriever, for example. The progeny of wild horses, taken up young and reared under civilised conditions, are far more difficult to break in and render far less willing and less intelligent service than the offspring of horses which have been bred for many generations in close companionship with man. The semi-wild ponies of the Himalayas (Spiti, for instance) being constantly exposed, when grazing, to injury from falling snow, ice, stones 
\&c., and to the attacks of wild beasts, exhibit such extreme watchfulness against danger, that, even in safe places, they shy at the slighest provocation in a manner which is highly unpleasant to the rider. This instinctive shying, apart from fulness of "beans," "shortness" of work, or love of displaying power, is a faculty which has become comparatively dormant among highly civilised horses.

As instincts are in the species, so are habits in the individual. The power of a habit in diminishing or strengthening the force of instinct is, as we have seen, well marked. In fact, a large portion of the art of horsebreaking consists in establishing in the animal habits which are opposed to his instincts, especially that of selfpreservation. Thus we have the habit of obedience to man, under the influence of which the well-trained charger will have lost his instinctive timidity to such an extent that he will go through flames, or gallop up to a tiger or other terrifying wild beast, on receiving the signal to do so from the hand and leg of his rider. With age, the instincts of every-day life grow stronger in the horse which is in a wild state. He becomes more and more watchful and difficult to capture; and his love of freedom and impatience of control increase with his years. Hence, the later his education is attempted, the harder will it be to impart.

A habit, to be fully established, must have become automatic, in which process memory (or the power of connecting ideas) plays a large part. The 'bus horse which has learned to associate the sound of the bell or of the conductor's foot on the platform, with the idea of going on, will have acquired the habit of starting forward the moment he hears the well-remembered signal.

Memory, as I have indicated, co-exists with consciousness, and is possessed by all animals which are capable of 
learning by experience. The study of animal life leads us to the conclusion, I venture to think, that animals are able to associate in their minds only concrete ideas; and that the association of abstract ideas is confined to mankind. Perhaps a more correct division of memory would be : memory of facts, and memory of chains of reasoning. Even fish possess good concrete memory. If we make a practice of feeding fish which are kept in a pond, these animals of low nervous development will quickly learn to connect the impression which our appearance makes on them, with the idea of food, and, on seeing us, will hasten to place themselves in position to receive our gifts. In fact, the fish will remember us; and, furthermore, if we select a particular hour of the day at which to feed them, they will apparently bear it in mind. Although many men of great intellectual capacity possess extraordinary good fact-memory; we find this faculty equally well developed among persons of feeble mental grasp, and sometimes even among idiots. Horses have extremely good fact-memories, and, as remarked by Dr. Le Bon, would win all the competitive examinations if they were able to talk and write. On the other hand, there are many men who have great power of keeping in remembrance long and complicated problems, but are singularly deficient in fact-memory.

The vividness with which an event is retained in the memory of man or beast depends on the intensity of the impression, or repetition, or on both. Without intensity, repetition has but little effect in fixing an impression on the mind. For example, lessons which we have conned over, perhaps, hundreds of times during our school days, are often completely forgotten long before our hair turns grey; and yet some painful accident in our eally childhood may remain permanently vivid in our remembrance. The ordinary system of horse-breaking, by which repetition 
(without intensity) is chiefly relied upon for the formation of habits of discipline, is defective; because the nature of the obedience thus obtained is too weak to oblige the animal to yield himself absolutely to its influence. The old, tedious methods of gradually inducing a horse to obey the rein, take months to produce an effect which at any moment is liable to be nullified by disturbing circumstances of no great force. When, however, obedience to the rein is taught (as I shall explain further on) in a manner which it is impossible for the horse to resist, the intensity of the impression produced will be superior to that of almost any opposing agency. Here the action, which is the result of the strongest motive, will, in almost all cases, be in accordance with the teaching of the discipline which the horse had previously found to be irresistible. We must disabuse our minds of the old fallacy (which has done much to retard progress in the art of horse-breaking) that quick methods are necessarily less permanent in their effects, than those which demand a much longer time for their carrying out. In saying this, I in no way wish to convey the idea that repetition is useless. On the contrary, it will be needed in almost all cases to confirm a habit, no matter how strong the first impression may have been. Acting on the principle of intensity of impression, with suitable repetition, we shall obtain far better breaking results in a tenth of the time required by those who depend chiefly on repetition.

The power of memory is, like instinct, susceptible of cultivation.

Connected with memory, there are three points to which I would wish to direct the attention of my readers: (I) With age, the power of making new associations of ideas becomes diminished; (2) fatigue, either mental or physical, impairs this power; and (3) the greater the 
number of associations made with the same idea, the weaker do each of them become. From this we learn, that in teaching horses we should begin with them when they are young; that we should not continue our instruction so long as to fatigue their mind; and that we should restrict, as far as possible, the associations which we bring about in the mind of the horse to their own respective results. Some men hit a horse with the whip, "job" him in the mouth with the rein, or speak to him in exactly the same way for whatever fault he may commit, and then wonder why they fail to keep him in control.

\section{INTELLIGENCE AND REASON.}

Consciousness is the beginning of intelligence, which culminates in reasoning power. The intelligence of the horse appears to me to be limited to the power of profiting by experience obtained by association of ideas formed from pleasurable or painful trial. When the association of ideas is more or less complex, there is hesitation and apparent reflection. Self-control being a necessary consequence of consciousness, animals sometimes control the promptings of instinct by association of ideas gained from experience. Thus the civilized dog or cat, on observing forbidden food, will often appear to be in a dilemma; on the one side being urged to obey its instinct of hunger; on the other, being restrained, probably, by the idea that punishment will follow the commission of theft. In obeying pure instinct, there would be no hesitation. The dog that has sinned in secret will often betray himself by his guilty look and abashed behaviour. We may assume that he, just as a man might do, yielded to the temptation of instinct, and afterwards associated in his mind the idea of chastisement with that of his $\sin$. We may note, to a certain-though far slighter-extent, this feeling in a 
friendly disposed horse, who inadvertently gives his groom or master a "nip," and then starts back in trepidation at what he has done. The experienced horseman will have frequently remarked in the horse he is riding or driving, hesitation to act according to his instincts, especially if the animal be in doubt if his rider or driver will stand "nonsense." The horse's tentative efforts in this direction seem to be controlled by a certain amount of reflection. The apparently thoughtful manner in which some goodtempered, intelligent horses will refrain, under great provocation, in cases of accident, from obeying their instinct of self-preservation to the detriment of their rider or driver, points to the fact of their being gifted with the power of control. Most of us can call to mind instances of high-couraged horses which, having fallen with their rider in such a way, that if they had not remained perfectly still while he was being extricated out of his difficulty, he would in all probability have been killed. I have known such animals, even during a run out hunting, and without any special training, stop "dead" on their rider falling off and getting hung up by the stirrup. In fact, I have owned and known horses which, if they got into any serious difficulty, out of which they could not safely extricate themselves, would wait patiently for their rider or driver to render them the necessary assistance. Other horses which, on the contrary, appear to be guided solely by instinct, will struggle and dash themselves about with the utmost fury on finding themselves in any awkward "fix." In this respect, mules, I think, generally show more sense, as I shall point out on page I6, than most horses.

A not very uncommon vice among horses is refusal to go through a comparatively low doorway, on account of the animal having knocked its head on some previous 
occasion, against the top of such an entrance. Although the man in charge may show the horse that by lowering its head (which on such occasions it generally keeps raised as high as possible), it can easily go under the supposed obstruction, it will display an obstinate disbelief in the efficacy of any such expedient. Other horses, wise from experience, though not from having reasoned out the problem, will display great intelligence in crawling under bars employed to keep them prisoners, and even in opening doors by lifting up the latch.

As intelligence restrains the action of instinct, it follows that when these two faculties exist in an animal, they will as a rule be in an inverse proportion to each other. Thus, the bee and the spider have more highly developed instinct, though less intelligence than the dog; and vice vers $\hat{x}$. The same remark would hold good when comparing civilised nations with Bushmen or Australian blacks; and English and Arab horses with bronchos and zebras.

Although the horse has generally great difficulty in associating cause and effect, unless the connection be particularly easy of perception, and the interval of time between the two be extremely short; he may be fully alive to the fact, in particular cases, that the one circumstance follows the other. For example, we may every day see horses which are accustomed to jump and prance about immediately after making a stumble, and thus betray the fact that they are old offenders in this respect. Their alarm is evidently due to the remembrance that punishment follows the making of a false step; but they have not intelligence enough to understand that the former was the penalty of the latter; for in no case which I have seen, does the infliction of such chastisement render the horse less liable to stumble. I have often remarked among racehorses which I have been training, that plaiting the 
mane previous to a race made some of the old ones so excited, that they would refuse to eat after their mane had been arranged in strands. They evidently connected the idea of racing with this portion of their toilet. We shall see further on how to induce the horse to make the required mental connection, and even to teach him, for our own ends, how to draw wrong conclusions as to cause and effect.

I have been unable to trace any indication of reasoning power in the horse, whose highest displays of intelligence seem (to me, at least) to be the outcome of tentative or accidental experience. He, like many human beings, appears to lack the ability of acquiring new knowledge by drawing conclusions from that which he already possesses. If I am correct in this statement, association of ideas is, therefore, the only means by which we are able to teach him. Respecting the brain power of apes, Frank Buckland says : "No monkey of any species, where the experiment has been tried, would even put a stick or coal on to an expiring fire; he would sit down and shiver by the fire till it goes out. His mind is not sufficiently acute to see the connection between cause and effect, so as to put coal on to keep the fire going." Cuvier, however, tells us of an ourang-outang which, when at meals, if it was unable to fill its spoon, would pass it on to the person next to it, in order to get it filled. This clever ape, seeing, on one occasion, that the glass which it had placed on the table was on the point of toppling over, put out its hand and prevented it from falling. I have noticed and admired the intelligence with which dogs in charge of children have sometimes prevented the little ones from going too near the edge of a precipice, or the brink of deep water. Newfoundland and other water dogs will often recognise the fact of persons drowning, and will go to their assistance ; 
although such animals might view with unconcern an ordinary swimmer in the water. The Indian elephant can be easily taught to pile up logs of timber with almost mathematical precision. Probably one of the best instances of what we might call reasoning power in animals is furnished by the fact that the sight of a dog being tied behind a moving carriage is an almost irresistible temptation to other dogs to attack him, no matter how inferior they may be to him in strength and size. The assaulting parties appear to understand that an animal thus pulled along by the head, is at a very serious disadvantage in defending himself against an attack from behind.

Most of us, no doubt, have observed the artifice grooms adopt, of showing a sieve of corn to a horse which is loose in a field, and which they wish to entice within catching distance. Although we may laugh at the simplicity of the horse in this instance, we must not therefore conclude that he is altogether wanting in sense; for we may often notice that if the groom presumes too far on the credulity of the animal, and leads him off to the stable without allowing him to eat some of the oats, he will in future see through the imposition, and refuse to be caught. Here, the sight of the man forms in the mind of the horse a stronger association with the disagreeable idea of capture than with the pleasurable one of food. The groom can generally, however, restore the desired association by judicious concessions. To explain the action of the horse in this case, we in no way require to suppose that he is guided by reason.

In many hilly countries where the mountains are high, the bridle paths narrow and the cliffs precipitous, the pack animals (horses, ponies, mules, and donkeys) which are accustomed to carry bulky loads that overhang a good deal to right and left, acquire the habit of travelling on the 
extreme edge of the outside of the roadway, so that they may not knock their burden against a jutting-out rock or other prominent obstacle. I may explain that such an accident might cause them to lose their balance and fall over the precipice. We might accept the adoption of this prudent precaution as a proof of forethought, were it not for the fact that all practisers of this habit will adhere to it when no such precaution is necessary. I have ridden many ponies of this kind on wild mountain paths, with a considerable amount of trepidation; for do what I could to keep them away from the dangerous edge of the cliff, they would rigidly adhere to it, seemingly under the impression that the load on their back (myself) projected at least three feet on each side of them. Their prudence, therefore, is the result of experience, and not of reason. Most of my readers will no doubt recall many similar cases among the horses of their acquaintance. I have never seen a loose horse with a trap behind him refrain from trying to go through a narrow gateway, because it was not wide enough to admit the carriage.

While giving animals full credit for their manifestations of intelligence, we should not forget that some of their instinctive actions often simulate those due to reflection. The extraordinary uniformity which animals of the same species observe in performing actions that at first sight appear to be prompted by reflection, would lead us to ascribe them to blind instinct, rather than to thoughtful intelligence, as, for instance, the ruses of the hare when trying to baffle her pursuers.

To illustrate the manner in which we may mistake the results of experience for those of reasoning, Professor Lloyd Morgan cites the following case: "Some years ago I was with a friend watching a horse which was dragging a heavy load, zigzagging up a steep hill. 'How well,' said 
my companion, 'that horse appreciates the principle of the inclined plane.' I begged him to explain exactly what he meant by this expression. 'He sees,' said my friend, 'that the less the slope, the less intense, if more prolonged; the labour to raise the load through a given height.' I told him that my own view was that the poor animal was quite unable to perceive the relation between the slope and the labour, and to think, 'the less the slope the less the labour.' Now I have noticed that when I am breasting a steep grassy mountain slope, I have a tendency to slew off to right or left, and thus to lighten my labour." We all, no doubt, can easily call to mind many other instances of mechanically advantageous results being obtained, even by ourselves, automatically, and, consequently, without the exercise of reasoning power.

Experience proves that the intelligence of the horse is small as compared to that of the ape, monkey, dog, or elephant; although his memory is as good, if not better than theirs. Our great difficulty in teaching the horse arises from his dulness in associating cause and effect.

The chief difference between the mind of the horse and that of man, is that instinct is far more highly developed, and intelligence proportionately less developed, in him than in us. His mind has, not very correctly, been compared to that of a young child, whose instinct, however, is greatly inferior to that of the horse, even if the child be in no way superior to the horse in the matter of intelligence.

\section{SPECIAL INSTINCTS AND SENSES.}

The term, instinct of self-preservation, is used to express a large number of instincts which serve to nourish the animal's body and to protect it from danger, for which duty we have love of freedom or impatience of control, fear of surroundings, anger or resentment against inflicted or 
threatened injury, hostility, revenge, \&c. As a horse's chief defence against foes, when in a wild state, is flight; one of the easiest signals to make him understand is that of threatening him from behind, with a driving whip, for instance, in order to induce him to go forward.

A horse shows his love of freedom by his tendency to revert to a wild state. In this, he acts in marked contrast to the ass, who seems to accept his lot of servitude with resignation, probably on account of his having been longer under the influence of domestication.

A horse may be easily excited to anger by the infliction of pain, by threat, and by acting in a suspicious manner, as a person might do even by running away from the animal in real or assumed fear. A horse may display his anger by active resentment or hostility, or by stubbornness, which is of all faults the most difficult to overcome. His memory of the successful indulgence of such feelings is particularly long. I remember the case of a cavalry horse which had incurred the dislike of the Colonel of the regiment on account of jibbing and refusing to jump. The commanding officer had on several occasions vainly used the driving whip with the utmost severity in the endeavour to make the animal clear the obstacles in the riding-school. At last, the Colonel gave the delinquent up as hopeless, and had him "cast." He was bought for a very small sum by a friend of mine, who is a capable horseman, and who in a short time converted him into a willing and reliable harness horse. Five years passed by without incident as far as the horse was concerned, until it happened that my friend drove him in his dog-cart to the neighbouring railway station to meet the Colonel, who got into the trap, and, as they drove off, began to express his thanks for the "lift." The moment the horse heard the well-remembered and hated voice, he instantly stopped and refused to pro- 
ceed. My friend laughingly asked the Colonel to kindly dismount, to go in front of the horse while continuing to talk, then to cease speaking, and, when the horse moved off again, to get into the dog-cart without uttering a word. As soon as the horse thought that the owner of the detested voice had gone away, he started on his journey in obedience to the signal of his driver, and carried the two gentlemen to their destination in his usual orderly manner.

When a horse is under the influence of either fear or anger, he will often act with total disregard to his own safety. I knew a case of a pony mare who, on getting by accident over her head a bag which prevented her from seeing, started off in a mad gallop, and dashed out her brains against the first lamp-post she encountered. Some jibbers have been flogged and spurred in the most cruel manner, without being induced to proceed in the required direction ; and others, which have thrown themselves down in their sulky fit, have had fires lighted under them without making them get up. From anger as well as from fear, horses have kicked so violently against hard objects, that they have not alone inflicted severe wounds on their legs, but have even broken them. A dog, unless he was mad, would do none of these things; because he has intelligence enough to recognise the folly of needlessly hurting himself. I have observed that if a kicking mule, when in harness, gets a hind leg over a shaft or trace, he will, unlike what a horse would usually do under similar conditions, keep quiet and allow himself to be released as speedily as possible. This, I think, is a valid argument in favour of the idea that mules are, as a rule, more intelligent than horses.

Horses will sometimes treasure up the feeling of revenge against those who have injured them, whether the offenders be men or animals of their own kind. I once owned a 
particularly inoffensive charger who never did anything wrong for the three years I had him, until one day he got bitten by the horse of a friend of mine who had come out for a ride with me. As I had both hands on the reins, and as the two animals were side by side, my horse was not able to return the assault for the time being. After the lapse of about an hour, during which time I had forgotten all about the "nip" received by my mount, something or the other obliged me to take the lead, when, just as I was drawing clear, my horse kicked the other animal most viciously and hurt him severely. I continued to own this horse for about two years after that; but on no subsequent occasion did he show the slightest tendency to use his heels against either man or horse.

The instinct of gregariousness in the horse, namely, that which prompts him to herd with his fellows, causes him to share the feelings of his companions, and is closely connected with the instinct of imitation. He often copies his mates in rearing and in other forms of "playing up," as well as in the familiar stable vices of crib-biting, windsucking, and weaving. We may often notice, when riding in company, that if one horse, the leader as a rule, starts at some object, which is frequently so trivial as to escape our notice, that the others will follow suit with such quickness that we might almost suppose that there was some kind of electrical communication between them; the fact, however, being that their thoughts are chiefly devoted to watching the movements of those in front of them.

As the horse is a gregarious animal, the breaker will be able to engage his attentions far better when he has him alone-in a riding-school, for instance-than when other horses are present. The teacher may utilise the imitative instinct by giving a "reluctant" one a lead over a fence, or by placing an unruly pupil alongside a steady break-horse. 
The habit of galloping about in herds has probably developed the instinct of emulation, which in horses is almost entirely confined to trying to outstrip each other in trials of speed. A horse's affection towards his kind, irrespective of sexual relations, or perhaps more correctly, his love of companionship with them, is a form of the instinct of gregariousness, and is often strongly developed. When parted from his equine friend (no matter what the respective sexes may have been), he will frequently display his sorrow by dejection and refusal to eat. I have known a horse, in such a plight, die apparently from grief: I have seen a horse "chum" with a cow, which was the only other quadruped in the field in which the two used to graze. In obeying his instinct in this instance, he no doubt mistook the ruminant for a kind of soliped. I have known dogs and even goats become attached to horses; but could obtain no proof that the horse reciprocated the devotionat least, to judge by the sound test of the effect of separation on appetite. Cats sometimes select a horse as a companion; probably on account of the mice or rats which come after the spilt grain, or because the horse's back forms a warm couch for pussy. In such cases I have seen no demonstration of love, beyond curiosity or good-natured forbearance, for his feline companion on the part of the horse. Mares without their young at foot, or when barren, not unusually adopt orphan foals if they get the opportunity of doing so. As a horse's affection, apart from sexual or maternal motives, seems to be dependent on his instinct of gregariousness, and as mankind can in no way become objects of this instinct, his fondness for us rarely exceeds cupboard love, or mere tolerance. Unless he be influenced by fear, he will take the proffered carrot or other dainty as readily from the hand of a stranger as from that of his master or mistress, separation from whom has never been 
known to injuriously affect his appetite. I think we must accept the fact that his affection towards man, however highly it might be cultivated, is too slight to admit of its being utilised in our service. I have observed that horses in whom the instinct of gregariousness is strongly developed, are frequently sulky, or at least have their hearts somewhat "behind their work" when alone, evidently on account of their thoughts being with their absent-companion or companions, instead of with the business at which they are engaged. The horse exhibits little or no lave for the admiration of.man, which in the dog is a valuable means of education. We may often find a dog striving to win our approval by bringing us a stone to throw away, and thus to give him an opportunity of showing his cleverness by retrieving it.

The sexual or reproductive instinct is often a great hindrance to the success of equine education. Some mares are always more or less "in season," or are liable to become so if anything rubs against their hind quarters. When afflicted with this form of nymphomania, they are, as a rule, " jady," apt to kick, and otherwise unreliable. The entire, from combativeness engendered by sexual rivalry, sometimes shows a strong tendency to "savage." The experience I have had among wild and unbroken horses leads me to think that the vice of attacking with the teeth is either sexual or acquired; for geldings, which have been emasculated young, and which have not been brought under the influence of man, exhibit it to a very trifling extent; although, under provocation, they will freely lash out behind, cow-kick, or strike out with their fore legs.

Sense of hearing.-The horse, agreeably to the anecdote told on page 15, and as we might infer from observing the almost constant play of his ears when he is in the open, pays great attention to sounds, and is very quick to mark 
differences of tone, although he has extremely little ability to distinguish one word from another. As a rule, a loud, harsh sound of the human voice frightens the horse; but a soft one calms him.

Sense of sight.-The horse is greatly affected by objects which have to him a strange or suspicious appearance. It is easy to understand that the survival of an instinct which in former times helped to preserve him from his neighbouring foes, makes him start with terror when he sees, for instance, a bear skin in his path, or a trailing rope, the serpentine motion of which might suggest the idea of a snake. But I cannot fathom the motive for the fear with which the approach of a camel invariably inspires him. $\mathrm{He}$ will seldom take in good part the sight of a donkey (or even a pony) with a bulky load on its back. Water and white and glittering objects are generally sources of alarm to him. The expression of the human face appears to have no effect on the horse. "With respect to this subject I have made many experiments on young and old horses, and can certify that if the man moves only his eyes and the muscles of his face, without stirring his body or arms the horse will remain perfectly unconcerned. I have a hundred times tried the effect of anger in my look, of smiles on my lips, without the slightest result. You may make the most horrible grimaces at your horse, or you may stick your tongue out at them, bur none of them will show the smallest sign of being influenced by such means" (Fillis). The reason for the horse being insensible to the expression of the human face, however exaggerated it may be, although keenly observant of the slightest movement of the hand, for instance, appears to me to be that the special feature which the horse looks at, as an index to the mind, is the ears, which in man are too small and too little gifted with mobility to afford him any clue to our thoughts. 
They are, in the horse, his most expressive feature, and consequently he draws conclusions principally, in this respect, from the nature of their movements. That, under ordinary circumstances, an animal's ideas on facial expression are chiefly, if not wholly, derived from his studies on that subject among individuals of his own species. The mouth of the horse, as well as his ears, is capable of expressing his feelings to some extent; but it differs so much from that of man in its position on the face, in its power of laying bare the teeth, and in the mobility and size of the upper lip, that our possession of a mouth is a fact of which the horse is possibly unaware. In any case, its expression is nearly, if not quite, meaningless to him. With our organs of vision, the most threatening action is that of knitting the eyebrows; with those of the horse, that of "showing the white of the eye." As we habitually do the latter, but in a way different to that of the horse, and as the horse is practically incapable of the former; it is reasonable to suppose that the play of our eyes would be lost on him. The power of expression of a dog's features resembles that of man to a certain extent. I have seen dogs smile, wrinkle the skin on their noses when doing so, in a manner not very unlike that by which some persons show their pleasure at meeting an agreeable acquaintance. We all know that a dog makes a special study of the expression of his master's face.

Sense of feeling and smell.-Although the horse's sense of smell is acute, I have not observed that he, like the dog, uses it to recognise persons. I certainly think that, when a horse brings his muzzle up to anything he may wish to examine, he does so with the object of using it more as an organ of touch, than to smell the object in question. As a rule, a horse which is in a doubtful mood with respect to a person who wishes to approach him, will, as every horse- 
man knows, feel considerably reassured it he be allowed to touch with his muzzle the hand of the man, who, unless he sees the danger signal of drawn back ears, should on no account pull his hand abruptly away; for the fact of his doing so will usually be regarded by the horse as a menace. The smell of a camel is extremely distasteful to the horse, who, as a rule, does not at all object to that of the elephant, which is quite as peculiar a looking animal as "the ship of the Desert." The smell from a tannery inspires almost all horses with fear.

Scratching his mane is the form of caress most appreciated by the horse, especially if he be in a wild state, in which case his crest will be more or less itchy from the presence of scurf and insects.

As the actions of the horse are prompted far more by instinct than by intelligence; one of his chief characteristics is uniformity of conduct, which fact can be utilised with advantage by the breaker. What a horse does once, we may generally count upon him performing a second time under similar conditions. Hence, if his progress in education be slow, it will, as a rule, be sure. The treachery which is noticeable in many men and women, and even in a few monkeys and dogs, is almost absent in the horse. If we find that the horse which previously was quiet to handle and ride, suddenly wants to take one's life, or to "play up" in some outrageous fashion, we may be certain that his change of demeanour is not due to the fact of his having thought out some nefarious plan to gain his own ends by our discomfiture; but that it is the outcome of provocation which he has had just reason to resent on some previous occasion. The few treacherous horses which I have met were, I feel certain, rendered so by cruel or injudicious treatment.

The feeling of submission to superior power is the chief 
one by which we can obtain mastery over the horse, who, when he finds himself defeated, will generally "give in " completely. Here, his small amount of intelligence will not enable him to reflect that, although we have mastered him on one point, he may be able to turn the tables on us under different circumstances. The process of rendering a ferocious dog or savage tiger helpless for the time being, as we might do to the horse by Rareyfying him, or by other horse-taming methods, would not prevent either the dog or the tiger from flying at us the moment he was free from his trammels.

Courage or pluck in the horse.-A man, in the facing of danger, may, by a purely intellectual effort, overcome his instinct of self-preservation. Here we have the resultant of two opposing forces. Thus, brave men have often, even from motives of abstract right, faced certain death, the terrors of which they have keenly felt the whole time. Others have been equally self-sacrificing under the purely instinctive influences of anger, jealousy, emulation, or love of admiration. Although there are no words to exactly express these two kinds of feelings, we may, for convenience sake, apply valour or bravery to the former; courage or pluck, to the latter. This, I need hardly explain, is an arbitrary use of words on my part; yet the distinction is worthy of consideration. The facing of danger in the horse, as far as I have been able to observe, is entirely the result of instinct, of habit, or of a combination of the two; and has consequently no intellectual element. The term "courage," as used by horsemen, signifies that feeling (whether simple or compound), under the influence of which the horse will strain every effort to obey the orders of his rider or driver. In its transmission, the effect of heredity is often well marked. This most valuable quality can be easily lost by mismanagement. 


\section{VICE.}

The term vice in the horse is used in such various senses that I am unable to supply an exact definition of it. Perhaps I might be permitted, for convenience sake, to say that, from a saddle and harness point of view, it includes all unruly habits and tricks which militate against the safety or comfort of the ordinary rider or driver. We might therefore sub-divide it into deliberate vices, and those arising from impatience of control or nervousness. By deliberate vices, I mean those which the horse practises for the gratification of his own ends, in direct opposition to the well-understood and legitimate orders of man; and those which prompt him to make unprovoked and hostile attacks on man or other animals.

Stable vices I may define as those which produce injurious or unpleasant effects either on the horse or on his attendants, while he is in his stall or loose box, or while he is entering or leaving his abode.

What we are pleased, from our point of view, to call vice in the horse, is, as a rule, manifestations of his instinct of self-preservation, and has nothing to say to innate turpitude. In combating, therefore, so-called vice in the horse, we should not resent (as too many of us are inclined to do) his non-compliance with our wishes as a personal affront; for he owes no allegiance to us beyond that of the weaker mind to the stronger.

There is a pseudo form of nervousness which is a common vice among horses that are well fed, underworked, and are ridden or driven by timorous people. I may point to the far greater tendency these so-called nervous horses have to shy and "play up" when leaving their stable, than when returning to it after a long journey.

The distinction between nervous and deliberate vice may 
be easily made, if we observe how a horse acts after we have proved to him that he need have no fear of us. For instance, if we fix up a horse, say, in a "strait-jacket" (see page I29), so that he cannot kick, and continue to "gentle" him over with one hand until he has ample reason to believe that we have no intention of hurting him ; we might justly term him vicious if he kicked out at us, without our again touching him, the moment the restraint was removed. Fear of the near approach of man will often induce a purely nervous animal to kick out, if a person, and especially a stranger, ventures to come within reach. Although horses frequently kick from nervousness, they rarely bite from that cause alone. I think I might venture to define the more or less vicious form of nervousness as the exhibition by the horse of unfounded fear of surroundings which, however startling their effect on him might be in the first instance, he has proved by ample experience will not hurt him.

The more experience I acquire in the breaking of horses, the more convinced I become that the so-called "nervousness" of animals which have been handled some time, and which have always been treated with kindness, is largely made up of impatience of control, and, in many cases, of active hostility. I make bold to assert that many crafty dangerous brutes pose before their owners as ill-used victims of a too highly-strung nervous system. Take, for instance, an old saddle-horse, like many I have met, that snorts with apparent terror at anyone who approaches him, and is ready, on the slightest chance of reaching his mark, to strike out in front, or lash out behind, if saddling or mounting him be attempted. His nervous emotion the first time he was taken in hand, or the first time he performed his unpleasant tricks, may have been thoroughly genuine; but its exhibition enabled him more 
or less successfully to resist control. This act of insubordination having revealed to him the knowledge of his own power, which is a pleasurable sensation to every animal, was naturally repeated on every available occasion, until the vicious habit became confirmed; although its necessity may have been disproved to him scores of times by the fact that the saddling or mounting had been accomplished without the infliction of any pain or irritation to him, however great the trouble may have been to the groom or rider. As in horses, so do we find among dogs, that nervousness often degenerates into ferocity. The young dog who barks violently from nervousness, on seeing that the noise he makes causes persons in his vicinity to run away, is tempted to follow them, and, having discovered his own power, is apt to exercise it, with the usual result that he becomes bad-tempered and vicious.

I am inclined to think that nervous horses are not as "game" as their more placid fellows, and am thoroughly convinced that the majority of so-called nervous horses are sulky, treacherous brutes. Although there are exceptions to this rule, it would be most unwise to ignore the fact that the repetition of any trick which tends to render an animal difficult of control, whatever way it may have been contracted, has an increasingly bad effect on him the longer it is continued.

Sulkiness or obstinacy in the horse, which we may regard as the antithesis to "courage" (see page 23), is of various forms, is produced by many different causes, and is often complex in its nature. It may be entirely due to natural impatience of control, as I have frequently seen in freshlycaught animals, which, when haltered for the first time, on finding that they could not escape, have thrown themselves down on the ground and refused to move. In such cases, as indicated on page 7 , it increases with age, It may be 
acquired, as we may find any day on the racecourse among animals which have been rendered "faint-hearted" by "punishment." Many of these poor things show by the tumultuous beating of their hearts that fear-from the mental association of their surroundings with the idea of pain-and also, most probably, the feeling of injustice, are the causes of their not "trying." A tendency to "faintheartedness" is often inherited; stubbornness may be the result of a habit which, for instance, a timid rider or driver has allowed the horse to acquire by giving it too much of its own way. In jibbers, we may see many degrees of this particularly bad habit, which, other things being equal, is difficult to overcome in proportion to the severity and frequency of the successful contests which the horse has had with his would-be master. Here, the employment of ineffectual punishment or of unavailing force serves only to increase the horse's knowledge of his own power, which we should always strive to withhold from him. If horses could reason better than they do, the vice of jibbing would undoubtedly be more common among them than it is at present. Laziness is often akin to obstinacy, as we may find in some horses which, without actually jibbing, are always ready to slacken their speed, even if they do not stop entirely, the moment the rider or driver ceases to stimulate them; although the task required of them may be well within their compass. On the other hand, some of the "gamest" horses require a great deal of "rousing up " in order to make them exert themselves to the utmost. I may define jibbing as refusal to move or to go in a required direction by a horse which understands the order given, and which is well able to execute it if he wishes. Long-continued privation in youth renders a horse more or less spiritless and inclined to be sulky.

Aggressiveness.-By this term I wish to express the vice 
some horses have of attacking men or other animals without sufficient provocation. Horses are said to "savage" when they use their teeth as weapons of aggression. Entires are specially prone to this mode of assault, and, if they succeed in overthrowing their opponent, to increase their advantage by kneeling on him. Mares delight most in kicking. My experience-gained chiefly in South Africa -of absolutely unhandled horses is, that when caught for the first time, they will strike out freely in front, lash out behind, or cow-kick, but that they will very rarely attempt to bite. The acquisition of that fatal knowledge of his own power to injure or terrify his enemy, especially if resentment for the infliction of pain be added to it, is without doubt the chief cause of aggressiveness. A hereditary tendency to aggressiveness is often well marked. Teasing a horse is usually effective in developing that undesirable quality.

Treachery, as I have stated on page 22 , is a rare vice in the horse. It is fortunate for horse-owners that it is seldom met with; for of all equine failings, it is the most dangerous and the most difficult to cure. The treacherous horse, after having gained one's confidence by a more or less prolonged course of docility, may in a moment, without any warning and apparently without the slightest provocation, buck one off its back, kick the trap to pieces, bolt madly away in saddle or harness, savage one, or kick one. And yet, the instant it has effected its deliberately planned purpose, it may assume an air of innocence, and act as if it were the impersonification of virtue. I cannot help giving treacherous horses credit for the possession of a comparatively large amount of intelligence. 


\section{CHAPTER II.}

\section{THEORY OF HORSE-CONTROL.}

Objects and scope of horse-breaking-Requirements in the breaker-Desirability of early training-Gaining the horse's attention-Accustoming a horse to his surroundings-Making a horse understand our orders-Punishment and reward-Effect of the voice-Emulation and imitation-Fatigue-Necessity for exacting implicit obedience from the horse--Safety in breaking-Rapid methods of breaking-On the possibility of overcoming any form of vicePersonal influence in breaking-Advisability of possessing various methods of breaking-Selection of breaking methods-Permanency in the effects of breaking-Summary of the principles of making horses docile.

IN this chapter I shall limit myself chiefly to the theory of making horses quiet and obedient, without special reference to the formation of "mouth" and paces, which I shall consider in Chapter III.

\section{OBJECTS AND SCOPE OF HORSE-BREAKING.}

The objects of horse-breaking are: (I) to make the animal quiet, both in and out of the stable ; (2) to teach him to obey the orders of his rider or driver with promptness and precision ; and (3) to establish in him the habit of applying his powers to the best advantage.

The scope of breaking is wider than might generally be thought; for it includes not alone the education of the untutored animal, but also the correction of faults which, while seriously detracting from the horse's value, are usually looked upon as unavoidable dispensations that have to be 
borne with becoming resignation ; as, for instance, prancing, chucking up the head, star-gazing, boring, refusing to jump particular kinds of fences, refusing to jump in "cold blood," showing excitement in harness when the whip is cracked, shying off the ball at polo, disinclination to stand steady when being mounted, etc. The knowledge (which I shall endeavour to supply to my readers) of the way to give a horse a good "mouth," and to render him steady and reliable, is of infinitely more value to everyone, except a showman, than instruction (which I shall try to afford) in methods for taming man-eaters and other exceptionally dangerous animals. The art of mere "horse-taming" is of little practical use ; for the need of its application is of but rare occurrence, especially in countries where horses have been brought up under civilised conditions. Even the celebrated Rarey, after subduing three or four "savages," when in England, had to content himself with exhibiting them about the country as reformed characters, for lack of new subjects on which to show his skill. When wishing to form a class for practical instruction in horsebreaking, during my various tours, I have frequently met with the objection that there were no vicious horses in that particular place. But as I always replied that I needed animals with only common faults of mouth and temper, I have never been at a loss, on such occasions, for subjects to demonstrate the fact that there are but few horses entirely free from some riding or driving fault which more or less impairs their value, and which, as a rule, can be readily corrected. Besides the formation of "mouth" and "manners" in the unhandled horse, as well as in the "spoiled" one; breaking comprehends the special education of the horse in many different capacities. 
REQUIREMENTS IN THE BREAKER.

To break-in a horse properly, one requires to have knowledge, patience, readiness of resource, sympathy, skill, coolness, and pluck. Horse-breaking, I may state, is partly an art and partly a science. In its former relation, dexterity to carry out its mechanical details is necessary. In the latter, acquaintance with the laws which respectively govern the working of the animal's mind and body is needed. All such indispensable knowledge will, however, be in vain, unless the breaker has patience to apply it in an exact manner, and without allowing himself to be influenced in any way by feelings of impatience, anger, or resentment. Horses vary mentally as much as they do physically. Some are quick and docile; others, stupid and stubborn. If their lack of comprehension or wilful disobedience causes their teacher to lose his temper, the exhibition of his annoyance will assuredly frighten out of the timid ones whatever sense may have been in their heads, and will provoke the sullen ones to resistance, if not to retaliation. To be successful, he should adopt the maxim of patience, patience, and still more patience. Not alone are horses of infinite variety as regards their dispositions; but the çauses of their failings or vices differ so much that the breaker must be essentially a man of ready resource, and not a mere follower of routine. Again, he must have sympathy with weakness, and must be quick to appreciate and reward progress in learning and compliance with his wishes. Skill can be obtained, and "the magic touch" developed, only by long practice. The handling of bad horses in breaking, certainly demands a large amount of coolness and pluck, both of which can also be improved by practice. 


\section{DESIRABILITY OF EARLY TRAINING.}

As those instincts of the horse which are opposed to obedience to man, increase in strength with age, it is a great advantage to begin the education of a horse as early as possible. Horses which from their birth have roamed about in freedom for several years, have their instinct of independence so strongly developed, that it is proportionately difficult to make them learn that it is their duty to obey, and not to dictate. I have met many such cases among South African and under-bred Australian horses which had been "taken up" late in life. Although it is easy to make these old pupils lose their fear of man, it is often impossible to induce them to render willing service; in other words, if not actually sulky, their hearts, so to speak, are generally behind, instead of in front of, their work. Not alone do these rebellious instincts grow stronger with years, but their possessors become less capable of being influenced by new impressions.

GAINING THE HORSE'S ATTENTION.

Whether the pupil be a child or a horse, the first step which the teacher will have to take in imparting instruction is to make him attend to his lesson. As the horse is a gregarious and roving animal, whose instinct of selfpreservation prompts him, when in the open, to keep a sharp look-out against the attacks of enemies; the breaker will be able to keep him far more attentive and obedient in some convenient enclosure, such as a riding-school, which contains no other horses and men, and which is free from disturbing external influences, than in the open. When the habit of obedience has been confirmed (but not till then), the animal should be gradually accustomed to 
work outside, and in company. As horses in the army, owing to their large number, are broken in "rides" of several at a time, a certain proportion of them contract the vice of refusing to leave the ranks or to act independently, which, I need hardly say, is a form of jibbing. The same detestable vice is often met with in the hunting field, from the fact of timid or incompetent riders seeking for a lead. The instinct of imitation in the horse is far more of a hindrance than of an aid to the breaker who aspires to teach a horse to implicitly obey his rider or driver. Even the most experienced will require no argument to understand that a horse which will not take his own line, or will not, for instance, jump in "cold blood," is not half broken.

To many persons who regard horse-breaking as a purely empirical art, the mention of a riding-school as a place of instruction for a young hunter, race-horse, or chaser, is like the showing of a red rag to the proverbial bull. We must, of course, bear in mind, that mere personal opinions have no part in the science of horse-breaking. The prejudice against riding-school work has no doubt arisen from the fact, that as a rule, the manége has been used for the training of horses only for military, school, or circus purposes; and has not been hitherto utilised to any great extent for preparing them for the field or road. I can say from experience, that anyone who has used a suitable enclosure for the preparatory teaching of, for instance, 'cross-country horses and hacks, and has had subsequently to do the work without a school of this kind, will keenly appreciate the great advantage the use of a manége gives him in gaining the attention of his pupils, and in rendering them obedient.

I may here allude to the fact that over-stimulation of the nerves, whether in a mental or physical respect, tends to 
insensibility. Thus, the too frequently excited muscle ceases to contract; and the overwrought brain, to think. The miller remains unconscious of the din of the machinery around him ; and the horse, of the admonitions of the rider or driver who keeps constantly speaking to him. Continued pressure of the bit on the bars of the horse's mouth is far less effective in restraining the animal, than pressure which is judiciously intermitted. The stimulus of whip, spurs, or mouthpiece, if repeated in a monotonous manner, is at last more or less disregarded.

\section{ACCUSTOMING A HORSE TO HIS SURROUNDINGS.}

To render the horse capable of instruction, it is not sufficient to arrest his attention; but we must also gain his confidence by proving to him that he need not fear injury from anything we do to him, or from the surroundings in which we place him. To render him steady under future provocation, it is well to make him bear with equanimity all possible kinds of terrifying sights and sounds and to oblige him to endure being touched all over without flinching. The ligher we try him in these respects-it being of course understood that the causes of alarm do not entail pain-the quieter will he be if anything startling happens to him during actual work. The mere accustoming a horse to unfamiliar sights, sounds and feelings, is not a reliable method for making him steady; because, if permitted to do so, he will often, particularly when he is fresh, assume a frightened demeanour which may be pure affectation on his part, but which may be fraught with danger to his rider or driver. On the contrary, he should be taught to devote his entire attention to carrying out the orders of his master, and not to attempt to take the initiative, unless he receives the signal that he can act for himself for the time being. 


\section{MAKING A HORSE UNDERSTAND OUR ORDERS.}

We know from experience that the horse, to be well broken in, must not alone be quiet; but must also thoroughly understand the meaning of the various orders we give him. Although his intelligence is not developed highly enough to enable us to teach him our spoken language; we may by the establishment of certain signals render him capable of knowing our wishes, in the carrying out of which their clear comprehension is naturally the first step. Our conventional language or signals should be those which he can best understand. Hence, in this endeavour we should work on his most highly developed mental faculty, namely, his memory, in the exercise of which, association of ideas is the most effective stimulus. It is evident that we should give these signals in as clear and uniform a manner as possible, and that their effect should not be complicated by that of other influences, such as fear, anger, excitement, or desire to go to a companion. We shall see further on that almost the entire education of the horse depends upon association of ideas. I may give the following instance of the working of this principle:-A friend of mine had a horse which became so increasingly difficult to mount, that at last he was unable to get on him by ordinary means, on account of the animal "breaking away" the moment he attempted to put his foot into the stirrup. Living near a river, he hit on the expedient of placing the horse with his off side "broadside on," and close to, a steep part of the bank, and then made a feint of mounting on the near side. As usual, when the man's foot touched the iron, the horse swung round, and, on this occasion only, fell down twenty feet into the water. The mental effect of this lesson, which was harmless from a physical point of view, was 
to make the animal perfectly steady to mount, so long as he stood on the bank of the river and in a position similar to that from which he had had his tumble, but he was just as difficult as ever to mount anywhere else. It is evident that any such method to be perfect should be of universal, and not of local, application. No doubt this unruly horse would, by many, be deemed a nervous creature and a worthy recipient of a large amount of kindness and petting. I may state that probably the most effective means of applying the principle of association of ideas to the breaking of vicious horses, is one by which the animal arrives at the right conclusion from wrong premises, as with the rope-twitch (see page 324), when making a horse steady to mount. Evidently mistaking the cause of the pain inflicted on him, he connects the idea of punishment with the word "steady," and not with the application of the rope. Were he able to argue rightly on this subject, he would remain quiet only when the twitch was on, and would entirely disregard the verbal admonition, for which he entertains marked respect.

If a horse does not understand our signals, and we continue to force them on him, he will, as a rule, become impatient, violent or stubborn. In the horse world, we hear every day the remark that a horse knows when he has a timid rider on his back. My opinion, after long and careful investigation, is that the animal draws no conclusion whatsoever as to the state of mind of the man in the saddle; but that any unaccustomed "defence" which he may make in such a case is due to his becoming confused by the illregulated signals which the rider gives him. Although the unhappy man may be entirely unaware that he is transmitting these signals; it is impossible for him to avoid doing so, if he makes the slightest movement with hand, leg, or body. Every such movement is made by the accomplished 
horseman with the purpose of giving a definite and easily understood signal to his mount.

A horse's respect for signals which he understands, is well proved by the fact that many horses which are habitually "difficult" with ordinary riders, will obey with steadiness and precision the behests of a capable horseman. I have known horses which, after they left their breaker, became almost unrideable by the majority of people from having been "spoiled" by bad management; and yet whenever their breaker happened to ride them again, they appeared almost instantly to forget their lately-acquired tricks, and comported themselves as sedately as they had previously done with him.

\section{PUNISHMENT AND REWARD}

Are the two great means by which we can establish, for purposes of education, the required association of ideas in the mind of the horse, whose affection for us and whose love of our admiration are, as I have already said, too slight to be profitably utilised. Punishment is far more effective than reward, which, I regretfully feel compelled to say, might be altogether laid aside without any appreciable interference with the progress of a horse's instruction. I make this statement from practical experience, and not from sentimental considerations, with which I have at present no concern. In deference to long-established stable usage, I here employ the expression "punishment" for the infliction of pain, independently of its object. Thus, a race-horse is often said to run gamely under punishment, which in that case means the application of whip, or spurs, or of both, as a stimulus to increased exertion. We should bear in mind that humanity, as well as self-interest, enacts that the breaker is justified in 
inflicting suffering on the horse only as a means of education, but not as a penalty for wrong-doing, which is a question of morality that does not concern him. In breaking, the sole benefit to be derived from the infliction, or from fear of pain, is to induce the animal to mentally associate with it the particular idea which the breaker wishes to convey, either as a stimulus or as a warning. The horse, following his instinct of seeking safety from danger by flight, tries, as a rule, to escape from threatened or inflicted pain. Thus, the horse goes forward when we raise the driving whip behind him, or touch him on the quarters with it. If we threaten him with the whip in front, he will usually recoil from it. I think we may take for granted that if the horse yielded to instinct, uninfluenced by previous training, he would, on being struck on the front part of the body, be more inclined to go back than to go forward. By association of ideas, however, we can teach him to increase his pace almost as well by hitting him on the shoulder as on the hind quarters. The latter method is much to be preferred to the former, on account of its being more in harmony with the animal's instinct. If an irritating fly happens to pitch on the horse's side behind the girths, he will instinctively try to dislodge it by whisking it off with his tail, or, failing that, by kicking at it. As we wish him to employ neither of these means on being touched with the spur, we should teach him to regard its application as an indication of our wishes, and not as a cause of irritation. Pain as a warning may be illustrated by the use of the wooden gag (see page 329), to make the biter connect in his mind the idea of pain with the practice of his pet vice, which he will forsake as soon as the suggested thought becomes habitual to him.

The chief practical reasons against the employment of punishment in the breaking of horses are : that it is very 
liable to fail in its object; and that it is calculated to break the spirit of high-couraged animals, and to increase the sulkiness of stubborn ones. When the horse is under the influence of anger, to which he can be readily provoked by punishment, he will be incapable of instruction, and may exhibit dangerous resentment, or determined passive resistance, with utter disregard of painful or even fatal consequences to himself. A victory obtained by him when in this state of feeling will naturally produce a powerful effect on his excited mind, and will consequently aggravate any tendency to resistance far more than the exhibition of timidity or weakness on the part of the rider or driver. Of course I do not mean to say that a vigorous "shaking up," and a sharp cut or two with a stick (for preference) or whip, is not sometimes advisable with a "reluctant" horse, or to stop the "calfish" tricks of a youngster; but even in this we should carefully remember the danger we run in being unsuccessful in our attempted enforcement of discipline. The history of the Turf furnishes us with an appalling number of instances of race-horses which have had their tempers permanently spoiled, by jockeys or stable-lads punishing them severely for some act of disobedience which the thrashing and spurring was unable to prevent. Personally, I make it a rule never to hit a horse, so as to hurt him, when breaking. Mares are far more liable than entires or geldings to be spoiled by punishment. If the breaker be obliged to employ coercive measures, he should apply thém in such a manner (as I shall explain later on) that the horse will not connect him with the inflicted pain.

In making a horse quiet, or in regulating his movements, we should naturally avoid, as far as possible, the use of any kind of pain which, while accomplishing its special purpose, produces in other respects a bad effect on the horse. The ordinary twitch furnishes us with a good illustration; for 
although it may make the horse stand steady while it is being employed, its application, whether on upper lip or ear, will almost certainly render him subsequently more or less difficult to handle near the former seat of pain. The same object may be urged against the use of the cavesson (see page I3I) for inflicting blows on the horse's nose, with a like object. The practice of jerking the reins so as to hurt the "bars" of the animal's mouth, with the intention of punishing him for unsteadiness, is still more reprehensible; for as long as the reins are associated in his retentive mind with the idea of pain, so long will he receive with suspicion, fear, or resentment, all orders conveyed to him through the reins, and consequently his usefulness will be more or less impaired for any service that demands pluck and "cleverness." These remarks apply to the employment of the spurs, and to the whip in all its forms. In fact, the use of all such "aids" or indications, as we shall see more fully in the following chapters, should be reserved, as far as practicable, for their legitimate work of telling the horse what his master wishes him to do. If we accept the axiom that one of the chief duties as breakers is to establish a clearly understood code of signals between ourselves and the horse, we should not increase the difficulty which all horses have in comprehending these signals, by rendering their meaning ambiguous to him, as we would do, were we sometimes to use them as definite orders, and at other times, as the means of inflicting punishment for faults which the horse may or mav not know he has committed.

The fact that a horse, like a child, has a keen sense of injustice, fully accounts for the readiness with which his temper may be spoiled by punishment unconnected in his mind with the committal of a fault. Nothing can be more opposed to reason than to reward a horse for doing wrong, 
and to punish him for obedience, as we may frequently see done by the driver of a jibber, who pats the animal on the neck and speaks encouragingly to him when he stops, and flogs and rates him as soon as he starts.

In the judicious use of the voice as a punishment by threatening, or as a reward by the expression of approval, there need be no fear of ambiguity; for the horse is in no way likely to mistake a harsh tone for a caress, or a soft one for a rebuke. As I have previously pointed out, the horse's power of drawing conclusions is so small, that, as a rule, he is unable to associate in his mind one event with another, unless their connection is well marked and extremely close as regards duration of time. We all know that pain inflicted in the ordinary way with whip or spur, for, say, biting, or unsteadiness when being mounted, is far more likely to aggravate the particular fault than to cure it. But if the correction be carried out as explained respectively on pages II 8 and 329 , the horse as a rule will readily associate the idea of punishment with that of wrong-doing, on account of the sensation of pain instantly following the committal of the offence. The infliction of punishment for aggressiveness, such as "savaging," may be beneficial, provided always that it is rewarded only during the attack, and is not continued after the horse has ceased the assault.

Reward may be conveyed by the voice, by patting and caressing the animal with the hand, by giving him some favourite dainty, such as a carrot or lump of sugar, and by the cessation of discipline. The last mentioned means of gaining the good-will of the horse is particularly effective, and may be utilised with great advantage in the management of the reins, and in many cases in which we wish to inform him that he has done to our satisfaction the task we have set lim. 


\section{EFFECT OF THE VOICE.}

The horse's keen perception of sound makes the human voice a powerful means, by association of ideas, of controlling and guiding him. As he readily recognises change of tone (see page I9), but not of words; we should reserve a particular tone for each of our different orders, the number of which should, in this respect, be kept as small as possible, so that ambiguity may be avoided. Also, it is of course well to have only one unvarying word or expression for each order. M. James Fillis says :- "To teach a horse 'at liberty' [in a school or circus] to advance at the walk, trot, or canter, one says 'walk' in a comparatively low tone; 'trot,' while slightly raising the voice; and 'canter,' in a loud, commanding tone. If you utter the word 'canter' softly, the horse will remain at the walk; if loudly, he will immediately strike off into the canter." I have seen very dangerous animals approached and handled with impunity, merely by "shouting at" them, and terrified ones rendered tranquil by a few gentle words. To obtain the full effect of the voice, we should, while employing it, utilise the principle of association of ideas. As cases in point, I may mention teaching horses to halt (see page I82), and to stand steady (see page 324 ). As suggested on page 34, we should avoid wearying the attention of the animal by needlessly speaking to him. In fact, we should reserve the use of our voice for occasions on which it is needed to produce a definite effect.

\section{EMULATION AND IMITATION.}

In breaking, emulation may often be useful by, for instance, infusing "life" into a lazy pupil by "company." We find the benefit of imitation when a frisky youngster, on being put into double-harness, copies the staid demeanour 
of a well-broken companion. In giving a "reluctant" horse a lead over a fence, both these influences come into play.

The effect of imitation is particularly well seen in young horses, who love to copy the action of their companions. When riding in company, I have frequently noticed the newly-born colt or filly imitate the tricks or peculiarities of those near her. For instance, if a companion has the habit of throwing up his head, or boring it down, she will probably try to follow suit; though she will be more than usually circumspect in her demeanour when restricted to the society of a steady old horse. I recognise this principle so fully that I make a point of not having young horses which I am breaking-in, ridden in the company of unsteady ones.

\section{FATIGUE}

May be used as a valuable adjunct to other means of control, but should seldom be employed alone; for its effects usually are as transitory as the sensation itself. Thus, if we, while riding or driving a bolter, allow him, in order to cure him of his vice, to run himself to a standstill, we shall in all probability find the animal quite as ready, if not more so, to run away the next time he is "fresh." In such a case, the fact of the horse having been allowed to do the very thing he wanted to accomplish, in defiance of the wishes of his would-be master, can produce no good effect in forming in him the habit of obedience. Fatigue may often appear to be the sole cause of the quietness evinced by an animal under treatment of some of the breaking methods I shall describe; but this on examination will be found to be incorrect. Even the fatigue caused in, say, rendering an unruly horse quiet to shoe behind, by keeping him on the ground and "gentling" him (see page 
I53), is out of all proportion small compared to the amount of control obtained. One of the best examples of the fact that it is the feeling of powerlessness to rebel, and not the sensation of fatigue, which compels obedience by these methods, is furnished by the experiment of making a violent horse, like an Australian buckjumper, quiet to mount by tying him head and tail (see page 328); the effect produced being striking; the feeling of helplessness evident; and the amount of fatigue small.

At the same time, we must not forget that the effect of exercise is very useful in making a horse which is full of spirits and "beans," attend to the work we give him to do.

NECESSITY FOR EXACTING IMPLICIT OBEDIENCE FROM THE HORSE.

As the horse takes little, if any, delight in obeying the orders of man, who is his physical inferior, it is not sufficient for him to clearly understand them; but he must be made, if possible, to believe from the commencement of his instruction that he cannot resist them. The convenience and safety of the rider or driver may often require that the horse, in yielding himself absolutely to the guidance of man, shall perform actions which are opposed to the promptings of his instincts, particularly that of selfpreservation. The system of trying to induce a horse to obey merely by humouring and petting him is altogether wrong from a practical point of view; for the horse being a selfish animal as far as we are concerned, can, under such circumstances, be made compliant to our wishes only when they tally with his own.

While fully admiring the kindness of heart of those enthusiasts who regard a horse as a friend to be won by affection, I must say that the better plan for making him 
a useful member of society is to treat him as a servant who has to be taught his work, and from whom. implicit obedience has to be demanded. Until he does his work honestly and well, the less petting he gets the better; for he is apt to become headstrong and fractious by a small amount of indulgence in his own way. I entirely deprecate punishing a stubborn horse with whip or spur, which he can resist ; but I insist on the necessity-after proving to him that he has nothing to fear, and after teaching him to understand the meaning of our signals_of impressing on him the fact that he must obey. I shall endeavour, in due course, to explain how such obedience can be peremptorily enforced.

If we have a dispute as to discipline with a horse, we should not part company with him before making him yield, lest he may carry away the mischievous impression that he has got the best of the battle. The breaker need not attempt to do too much at any one lesson; but what he undertakes he should succeed in performing before quitting his pupil. For instance, with a horse that will not allow his hind legs to be touched, the breaker may reasonably content himself with making him quiet to handle about those parts, without insisting on his standing submissively to be shod "behind," which is an operation that might be attempted on the following day. Also, we should make use of our knowledge of the limited scope of the horse's reasoning powers, to change the subject of contention if we fear that there is any chance of our being worsted in a pitched battle with the animal, so that the victory, even if it does not affect the original cause of dispute, should always remain on our side. As an illustration, I may mention the advisability of forcibly making a determined runaway lie down until he thoroughly "gives in," in order to make him yield the more readily to the indications of the reins. 
As the teacher requires cheerful as well as implicit obedience to his commands, he should be careful to judiciously regulate their character and frequency, and to reward the pupil for complying with them.

In enforcing obedience, we should never employ a general effect when a particular one would answer our purpose, lest we might spoil the animal's pluck and "lightheartedness." Thus, instead of Rareyfying a high-couraged horse which had on previous occasions been made difficult to mount by a bad rider prodding him in the side with his toe when trying to get into the saddle; it would be better to attain our object by means of the rope-twitch (see page I 8 ), or by the head and tail method (see page I55), so as to prove to him that he need not in future fear being touched by the toe when being mounted. In fact, we should regard the application of irksome means of control as a necessary evil to be employed as little as practicable. The method of reducing a horse to discipline by getting on his back and sticking on until he gallops or bucks himself to a standstill is not scientific ; for no matter how plucky and adhesive the rider may be, the terrified or vicious horse may unseat him by running into some obstacle, falling down, or throwing himself back when rearing, in which case he will probably acquire the evil knowledge of his own strength, and will consequently be much worse than he was before. Even if the man gets the mastery ; the effect, to become permanent, has to be repeated several times, and, in many instances, is disregarded after a rest of a few days in the stable, or with a different rider. This rough style of breaking is, of course, good only as far as it goes, and has no claim to teach the manners which make the horse, as well as they do the man. 
SAFETY IN BRFAKING.

It is manifest that the methods adopted in breaking should not alone be free from physical danger to the horse, but should also be in no way calculated to spoil him. Judging by the large proportion of pullers, borers, refusers and one-sided mouthed animals there are to well-broken horses, we might not unreasonably conclude that more horses are marred than "made" in breaking.

In order to fulfil the necessary condition of safety for himself, the breaker should be able by the system under which he works-to quote the words of that clever horsetamer, "Professor" Sample-" to make the animal rideable and driveable before he is either ridden or driven." The breaker who employs the ordinary English method is not alone exposed to danger when mounting, or even when driving his pupils for the first few times, but also in the preliminary handling. The advice, which is freely tendered on such occasions, to go boldly up to the horse and show him that you are not afraid of him, should be treated by its recipient as a piece of "cheap swagger," or the outcome of mere ignorance; for even granting that such a proceeding would effectively soothe a terrified animal, or cow a treacherously disposed one-suppositions which are altogether absurd-such counsel should in no way supply the necessary foolhardiness for such an undertaking. My advice, to either amateur or professional, is never to give a horse a chance of doing wrong. Hence, in order to be consistent, I shall endeavour to describe in the following pages how any horse, no matter how wild or vicious he may be, can be brought under complete control with, practically, no risk to the breaker. 


\section{RAPID METHODS OF BREAKING.}

We are greatly indebted to American horse-tamers, from Rarey down to Sample, for having furnished us with laboursaving methods of breaking. If we examine the working of these methods, we shall note that they are founded on intensity of impression in the association of ideas (see page 6); on the principle of showing a horse his powerlessness to resist our orders; or on a combination of the two. The ordinary English, French, and German systems are based on repetition for the formation of a habit; but without special intensity of effect. Consequently, the desired result takes a long time (say, from six months to two years) to be obtained, and is liable under trifling provocation to be lost. The "horse-tamers" and their followers make three blunders: in claiming that their respective systems are infallible; in asserting that the effects are permanent; and in failing to recognise the great importance of a "good mouth" and obedience to the "aids." While fully admitting that no system of education is infallible, and that the best broken horse is capable of being spoiled at any moment by an incompetent attendant, rider, or driver, I must say that, with extremely few exceptions, any unhandled or spoiled horse, no matter low wild, vicious, or old he may be, can be made, by quick methods, quiet to ride and ready to obey the ordinary indications of the reins in from two to four hours. Such a horse, to become a reliable "conveyance," would probably require about twelve more lessons-two a day-of an hour's duration each. He ought by that time to have acquired a fairly good mouth, steady paces, and "cleverness" to jump any ordinary fence. Army remounts which have never had even a halter on them, might 
on an emergency be made fit for the riding-school in a couple of days. I need not dwell on the value of such expedition in military exigencies, and in all cases where time is an object. "Spoiled" horses which have learned to know their own power, would naturally take longer to break than entirely unhandled animals; although a limit of a week need not usually be exceeded even with them. The possibility of reclaimed horses going back to their old tricks should be provided against by a judicious repetition of the necessary discipline, which would rarely be needed after the first three or four days, if the animal be mouthed and suppled in the manner I shall hereafter describe. Without using any forcible methods, which, as a rule, would not be required with a valuable horse, the breaker ought not to need more than a week to make any ordinary horse fit for all the usual requirements of saddle or harness, as far as quietness and obedience go. His higher education, especially in the formation of his paces, and, if a cross-country horse, in teaching him to collect and extend himself properly when jumping, would probably ozcupy the breaker's time for another month or two.

"Spoiled" horses are not, as a rule, satisfactory subjects for a breaker to tackle; because although the instructor may succeed in reducing the large majority of them to submission, they will often revert to their old tricks when they leave his hands and find they can do so with impunity. The owners of "spoiled" and vicious horses are generally bad tempered, irritable men, who would be incapable of displaying the patience of a good breaker, however hard he might try to instruct them in his methods. My wife once saw a man dismount from his horse, tie up a fore-leg, and beat him most brutally. When she asked him what he was doing, he replied that he was "Hayesifying" the animal, and her indigna- 
tion was great on hearing that he had attended one of my breaking classes.

To those who might advance the argument that because the ordinary course of breaking takes more than ten times as long as the methods I advocate, it must therefore be more permanent in its influences, I would beg to submit that such a contention would hold good only on the untenable supposition that the effects of the respective processes were equal in force. I see no possible benefit, except the questionable one of giving the animal an exaggerated opinion of his own powers of resistance, in taking a month to accomplish what may be done quite as efficiently in an hour; as, for instance, making a fractious horse steady to mount, or quiet to shoe behind, or a sulky refuser to jump "kindly." We must surely admit that the intensity of an effect, and not the time occupied in its production, is the measure of its permanency.

ON THE POSSIBILITY OF OVERCOMING ANY FORM OF VICE.

Our problem here is to establish a new habit that will have a stronger influence on the vicious animal's mind than the old habit which had impaired his usefulness. If the "pain in the temper" is due to the horse failing to understand our wishes, we may easily eradicate the fault by utilising the principle of association of ideas. When, however, the dispute is one as to supremacy, our last and great resource is to impress on his mind the erroneous conviction that he cannot resist our orders. If, however, he finds out by experience that he need not obey our orders unless he chooses, our labour will be in vain; supposing that he makes up his mind, which he is fully capable of doing, not to "give in." Herein lies the whole question of success or failure, in making vicious horses docile. The fact of 
our gaining our point, by the application of whip or spurs, with some sulky horses, only proves that these particular animals had not the necessary amount of resolution to resist the coercion applied to them. There are, however, many other horses upon which the only effect of such punishment would be to still further increase the rebellious state of their minds. Man-eaters, like the historic Cruiser, the taming of whom made Rarey famous, being actuated almost entirely by instinctive hostility, yield far more readily to man's authority than the sulky animal, who, having found out a method by which he can thwart the wishes of his would-be master, craftily adheres to it, and thereby lays claim to the possession of a large amount of intelligence. From this we may see that the assertion made by many " horse-tamers," that they can cure any form of equine vice, is absurd. Youatt tells us that Cruiser was never actually "tamed," but had to be "Rareyfied" by a specially-trained breaker whenever he was required for use, a process which would be far too tedious and expensive for the ordinary horse-owner.

Of all kinds of vice, treachery and stubbornness are the most difficult to eradicate; for the horse who sets his will in deliberate opposition to ours, questions the validity of our erroneous assumption of physical supremacy, the acceptance of which is our strongest means of horse control. Or we may say that such an animal fights us with the weapons-those of intelligence-by which, alone, we can bring into subjection our physical superiors. Vices due to nervousness or impatience of control can be readily overcome, and as a rule, "refusing" and jibbing in the saddle. A jibber in draught, however, is apt to find out, although the breaker may be all-powerful in the absence of the cart, the advantage is all the other way as soon as the horse gets between the shafts. Besides, it is impossible in many cases 
to apply, on the spot, breaking methods to animals which have played up in harness. For instance, if a trapper be accustomed to jib as soon as he comes to a stiff incline, to back into the ditch or fence, and then to proceed to kick the vehicle to pieces, all the breaker can do is to take him out, and try to indirectly counteract the fault in some convenient place. He may apparently succeed; but the old association of ideas may influence the mind of the pupil more strongly than the new one, in the event of anything going wrong; as, for instance, an accidental halt the first time the horse is driven up a hill through a crowded thoroughfare. In such a case, if the animal "shows fight," he will gain the victory almost to a certainty, and the attempted association of ideas will become proportionately weakened. For vices unconnected with harness, the breaker can, on the contrary, generally find some suitable place in which to work his will on the disobedient one, under advantageous conditions. I say this with every reasonable reserve; for we may sometimes meet with cases of saddle vices, such as running away on a racecourse when galloped, or when close to hounds that are in full cry, to which it is difficult to directly apply efficient breaking remedies.

Vices caused by undue sexual excitement, defects of vision, pain in the legs or feet which might make a horse refuse to jump, and other infirmities and diseases, do not come within the scope of the breaker. Castration is, in both sexes, an admirable means for rendering quiet those animals which are vicious from sexual causes. Although I have had many hundreds of horses with various forms of "pain in the temper" pass through my hands, I have met with very few which, so far as I could judge, were incapable of being made serviceable on account of mental aberration, which, in the horse, usually takes the form of extreme and causeless excitability. I have known only one or two 
healthy horses which were so listless and stupid that they might be regarded as idiots. My good friend, Mr. Harry Abbott, of Calcutta, owned a horse called Echo, which appears to have been half idiotic. Of this animal, Mr. Abbott wrote:- "He was thrown out of training into a large paddock, where he was a source of amusement to everyone, for he appeared half cracked. He used to pick up sticks in his mouth, take them to a corner and make a pile of them; sometimes he would trot round with his head against his flank for half an hour at a stretch; he would run after crows or other birds that alighted in the paddock, and chase them with his mouth open." Despite his madness the horse won several races for his owner; but his wild excitement in trying to break out of his stable on being left behind, when he heard his stable companions going away to a race meeting, was the cause of his being shot as raving mad.

As the breaker has to work on the material at hand, and as he has no power to change the nervous organisation of the animal, however firmly he may establish the habit of implicit obedience, it is impossible for him to make a naturally sulky horse work with the gaiety of heart and pluck which an honest one will display. This is particularly true out hunting with "faint-hearted" horses, which, no matter how carefully they may have been broken, and how well they are ridden, are often apt to refuse if they get interfered with, or to hang back in a crowd, when we want them to go boldly forward and give a lead over some awkward fence.

\section{PERSONAL INFLUENCES IN BREAKING.}

I do not believe in the possession of any special power over horses, with which some people are supposed to be 
gifted, apart from skill, knowledge, pluck, and physical advantages.* The great objection to the practice of personal influence as a breaking agent is, that although the animal may be perfectly obedient to the man who has had the exclusive handling of him, he may be refractory with other people, and may even jealously resent interference from anyone else. I have frequently been struck with this fact when breaking savage horses who would not, if they could help it, allow anyone except their groom to meddle with them; and have always found that they were more vicious to approach when their stable attendant was near them, than when he was absent. We may often see the same feeling evinced by dogs which would fly at any stranger who dared to touch them, as long as they were with their master; although they might be fairly amiable if he were not present. However much we may admire to the abstract this fidelity to one, it is apt, in the horse, to detract from the animal's usefulness under civilised conditions; especially if the owner be not regarded as the confidential friend in question. When the groom is the object of this exclusive form of affection, it is generally advantageous to have him changed for a new man.

\section{ADVISABILITY OF POSSESSING VARIOUS METHODS OF BREAKING.}

As horses differ greatly in temper and intelligence, and as the removal of the cause is the best plan for the treatment of either disease or vice; the breaker, to be successful in the instruction of young horses, or in the reformation of "spoiled" ones, should be provided with various

* Despite this statement, the fact remains that Captain Hayes possessed an extraordinary amount of patience with difficult horses, and has been known to spend more than six hours with a jibber without showing the least display of temper. 
methods for enforcing his commands. Hence, we may rest assured that the horse-tamer who advertises his own particular "system" as a certain cure for all forms of disobedience or vice, is as arrant a quack as the man who tries to foist on the public a pill for the removal of every kind of disease. In the following pages I shall describe various breaking methods, from which my readers can select those which they deem most suitable for particular cases.

\section{SELECTION OF BREAKING METHODS.}

The most useful methods of breaking are those which we can readily and frequently apply, so as to establish the desired habit. Hence, the "indications" conveyed by the reins, voice, and whip, and also by the leg, in saddle, should be specially relied upon in forming the horse's " manners" and paces. In other words, the horse's " mouth" (using the expression in its most comprehensive meaning) should be the foundation of all good breaking. A horse which has been trained to obey the "aids" (see page $5^{8}$ ) with precision, can be relied upon to remain steady and obedient under very trying circumstances. As it is impracticable to be constantly repeating taming methods, such as Rareyfying, or tying a horse head and tail and making him go round (see page 155 ), and as they afford us no assistance in the guidance of the horse or in the formation of his paces; we must disregard them as means for the maintenance of a permanent state of discipline, however useful they may be for enforcing authority in the first instance. The " aids," on the contrary, are ever present, whether riding or driving, to keep the horse mindful of his duty.

PERMANENCY IN THE EFFECTS OF BREAKING.

The rôle of the breaker is to establish in the horse certain habits, which, being for the most part opposed to his in: 
stincts, can be easily subverted by accustoming him to practices opposed to them, or even by allowing his instincts to resume their former and natural sway over him. We must remember that, however firmly held in check by training instincts may be, their influence on the mind remains constant; and that the influence of discipline may become gradually effaced by the opposing action of these instincts, unless repeated from time to time. Consequently, in order that the effects of breaking may be permanent, the state of discipline induced by them should be rigidly preserved.

However well a horse may have been broken of a bad habit, he will be far more likely to acquire it again under injudicious management than he would have been had he been originally free from it; for no course of discipline, although it may keep him under perfect control, can efface out of his mind the memory of the practice of a former habit. Hence, a teacher of breaking will be wise to confine himself to showing "how it is to be done," and not risk his reputation in making the impossible attempt of "curing" a vicious horse for other people. Besides, it is only " human nature " for the owner, rider, or driver of a wayward horse which has reverted from a state of discipline to his former evil courses, to klame the breaker and not himself.

The correct method, as I have already explained, in establishing the habit of obedience, is first to make the horse obey, and then to repeat the process as may be needed. Although, in a few exceptional cases, one victory over a horse may produce a permanently good effect on his mind, as far as mere obedience or docility is concerned; the effect, however strongly it may have been enforced, will, in the vast majority of instances, soon wear off unless it be repeated. I have often, and I think unjustly, incurred blame after I had practically demonstrated to the members of a class I was teaching, the feasibility of making a confirmed jibber, 
obstinate refuser, or violent buckjumper, quiet and obedient in one lesson; because such an animal had afterrwards become just as bad as before, on account of his owner not taking the trouble, as advised by me, of repeating the lesson I had given. I may point out that the reason why men usually fail to subdue "difficult" horses, is because they do not know how to take the first step, namely, that of enforcing obedience. If they be supplied with this allimportant information, their task will be one of increasing facility after each repetition, and, if persevered in, will be rapidly completed. But to be successful, it must be repeated until the desired habit is established.

SUMMARY OF THE PRINCIPLES OF MAKING HORSES DOCILE may be stated as follows :-

I. To obtain control over the animal.

2. To prove to him that he has nothing to fear from us, or from the surroundings in which we place him; in other words, to give him confidence and to cure him of nervousness.

3. To teach him to understand the meaning of the signals by which we desire to convey our orders to him.

4. To make him obey our orders with promptness, precision and willingness.

5. To instruct him how to use his powers to the best advantage.

6. To convert by repetition those acts of obedience and "cleverness," thus taught, into confirmed habits, so that he may become a permanently useful servant. 


\section{CHAPTER III.}

\section{THEORY OF MOUTHING.}

"Mouth" and "aids"- Respective actions of the aids-Suitability of the horse to the application of the aids-Making a horse obey the aids-Combined action of fore and hind legs, and distribution of weight on them-Carriage and action of the head and neck of the horse when he is in motion"Collecting" the horse-Requirements of a good mouth-Combined action of the aids in forming the mouth-Respective actions of the snaffle and curb -Direction of the pull of the reins-Turning, circling, and lunging the horse - Reining back--The standing martingale-Bearing reins, running reins, side reins, and nosebands-“Tying horses up," " reining," dumb jockeys, and the pillars.

$$
\text { "MOUTH" AND "AIDS." }
$$

A HORSE may be said to have a good mouth when he obeys the aids with promptness and correctness. In riding, the aids-if I may be allowed to adopt the definition-are the signals afforded by the reins, whip, legs (and spurs), voice, and changes of position of the rider's weight. In driving, they are confined to the reins, whip, and voice. I am of course aware that the term "aids" is applied, in the manege, only to the action of the reins and legs for guiding and regulating the movements of the horse. As the other forces which I have mentioned, act in the same direction, and are valuable adjuncts to the reins and legs; I venture to include them in a definition which is as suitable to them, as it is to those whose recognition has obtained the sanction of custom. 
As the riding-school term, "aids," is not generally understood by horsemen in this country; I regret that I am forced to employ it (modified as I have explained) from the absence of any popular synonym. The stable expressions, "mouth" and "mouthing," are misleading; for they wrongly imply that the horse is to be controlled exclusively by his mouth, that is to say, by only one end of his body, instead of by both ends, as he ought to be, and as we shall see further on. In deference to custom I shall, however, use these expressions in the following pages; but with the understanding that "mouth" signifies capability of answering the aids ; and "mouthing," instruction in their application.

\section{RESPECTIVE ACTIONS OF THE AIDS.}

The reins can be used to bend the head and neck; to restrain the forward action of the horse by exerting pressure on the mouth in a direction opposite to that in which he is proceeding or in which he is placed; to turn the head and neck to the right or to the left; to lower them; to raise them; or to combine, when practicable, two or even three of these actions, as is done when the head is drawn to one side and lowered by the action of one rein, and when the movements of the horse are checked at the same time by the pressure of both reins.

The whip or stick may be used either as a local or as a general stimulant to movement. The local effect may be converted, by association of ideas, into a general one. Thus, although the purely instinctive result of a cut of the whip on the hind-quarter or on the shoulder might respectively be a kick or a bite at the supposed aggressor ; it will be taken by many saddle and harness horses as a signal to go on, independently of the position of the seat of pain, 
The same remark applies to the application of the legs, feet, or spurs, the effect of which may be the same, whether they prick the stifles, score the sides, or rip the shoulders. Here we have a manifest loss of useful power, in that, with either the whip or feet, we can obtain with the properly broken-in horse at least seven valuable indications (or signals) instead of only one. Thus, the application of the drawn-back foot, or of the whip when used in a similar manner, will, for instance, check the tendency of the hind-quarters from swinging round when a turn is being made to the opposite side (two indications, one for each side). When the rider's foot is advanced and the shoulder is touched by the front and inner edge of the boot, an indication similar to the one behind is given in front (two indications). The application of both drawn-back feet will cause the horse to bring his hind legs under him-that is, to the front (one indication). A similar use, in front, of both feet advanced will make him extend his fore legs to the front (one indication). The application of both heels or spurs at a point midway between the respective spheres of action of the fore and hind limbs may be fairly accepted as a stimulant to both (one indication). As I shall later on attempt to investigate the intelligent application of the aids, with illustrations, I shall abstain for the present from further discussing this subject, which I have here introduced, principally, with the object of impressing on my readers that it is not enough for them to know when they should touch their horse with whip or foot; but that they should also know where and why they should apply such aids.

The voice is a general stimulant. The rider's weight, by its change of position, is naturally a local indication. 
SUITABILITY OF THE HORSE TO THE APPLICATION OF THE AIDS.

The five following facts are the principal ones which render the horse amenable to control by the aids :-

I. His instinct of self-preservation prompts him to fly from the infliction of pain.

2. The "bars" of the lower jaw (that portion of the gums which is devoid of teeth, and which is between the molars and the tushes, or the place which the tushes usually occupy) being sensitive and smooth, readily lend themselves to the application of restraining pressure.

3. The lateral muscles of the neck are so weak that the ordinary rider or driver can easily pull the horse's head round to whichever side he likes.

4. When the horse carries his head in the best manner for facilitating his movements (see page 69), the mouthpiece, whether of snaffle or curb, will be in a good position for the rider or driver to control the animal by the reins. The breaker will therefore be under no necessity of trying, for bitting purposes, to make the horse carry his head and neck in any other way than a perfectly natural one.

5. When the saddle horse is in motion, the balance of his body is readily disturbed by changes in the position of the rider's weight. Hence, such changes, when appropriately made, are readily accepted by the horse as signals for altering the nature or direction of his movements.

MAKING A HORSE OBEY THE AIDS.

In teaching a horse to obey the aids, we should act on the principle advocated on page 44, of making our equine servant accord ready obedience to our commands, after he has learned to understand our wishes when they are ex- 
pressed by the proper signals. The breaker will do well to bear in mind the maxim, that a horse should never get the chance of pulling successfully against the reins, or unsuccessfully against the collar. As a man on foot has as thorough command over a horse, as the horse has over his rider (supposing that both know how to exercise their respective powers); the breaker should naturally commence his lessons on foot, and should, as a rule, refrain from giving the horse the advantage of having him in the saddle until the habit of obedience to the aids (or to their breaking substitutes, such as the pressure of the long rein on the quarter, for that of the rider's outward leg) be fully confirmed. In all this, we act on the principle of association of ideas in the mind of the horse to guard ourselves from the evil consequences which might ensue from the exercise of the animal's instinctive impatience of control.

With some horses, and especially with those which have learned to know their own power, the process of inculcating the habit of obedience to the aids by their mere application, may be ineffective, or may be too tedious for practical requirements on account of the impression produced being lacking in intensity (see page 6). In such a case, I would advocate the advisability of exacting obedience, in the first instance, by some ready method, for instance, making the horse lie down (see page I52), or keeping him on the ground (see page I53), so as to impress him with the idea of our supreme power, and to banish from his mind any thought of resisting our will, even on a point concerning which he would always prove victorious, had he sufficient intelligence to see through our artifice. Our power over the horse when we are on his back, being necessarily limited in extent, may, with all our teaching, fail us at times. I in no way wish to say that competent riding or driving cannot in time accomplish the object in view, in the case 
of ordinary horses, without the work on foot; but it will take very much longer to do so, and will require far more skill in the operator. According to my experience, the work on foot, which I shall describe later on, can produce on difficult horses good effects which, without its assistance, are unattainable by any rider or driver, however excellent his "hands," and however great his pluck may be.

COMBINED ACTION OF FORE AND HIND LEGS, AND DISTRIBUTION OF WEIGHT ON THEM.

The locomotive machinery of the horse should be viewed as a whole in its working, and not as made up of independent portions; and that, in all forms of useful movement, there should be perfect harmony between the respective action of both fore and hind limbs, and even of each separate limb. In the ordinary course of turning the saddle horse, for instance, it is therefore illogical to act only on the mouth ; for by doing so, the tendency will be to cause the hind legs to revolve round the pivot formed by the fore ones, which bear the greater proportion of weight, instead of the revolution being made by both pairs of legs on a pivot somewhere between them. Riders who attempt to guide the horse entirely by the reins treat him as if he had only one end, namely, the forehand. An admirable illustration of the evil results of this incapable method is afforded by the trick many horses have acquired, when they refuse or run out, of yielding only the head and neck to the pull of the reins, and not, as they ought to do, bringing their hindquarters round at the same time. It is manifest that the control of the head and neck which the rider has in Fig. I, is of no use to him in putting the horse straight to the fence, so long as the animal retains command over the action of his hind legs. The horse which has been taught to answer 
the pull of the rein with both ends of his body will, on the contrary, in the event of shying off or refusing to the left,

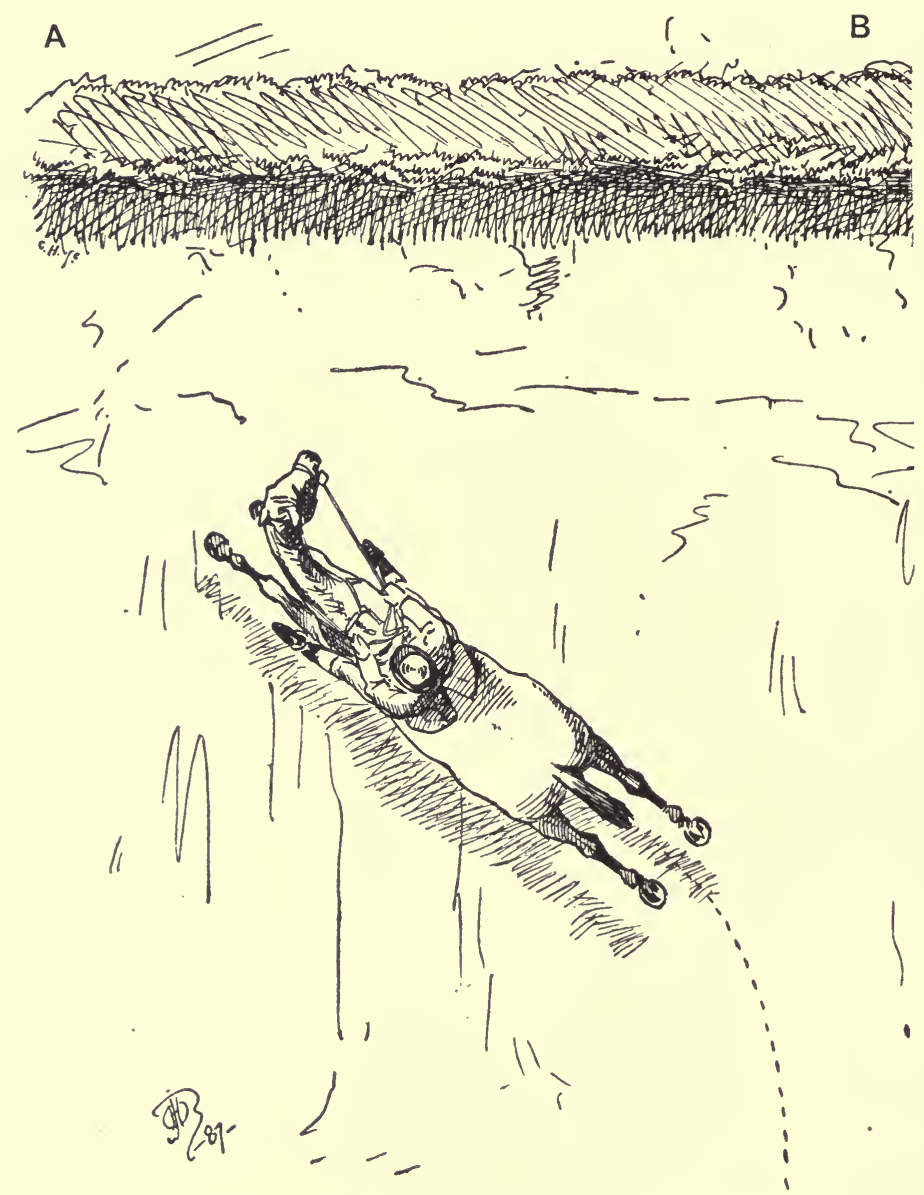

Fig. I. - Horse running out at a fence (A B), on account of refusing to bring his hind-quarters round in answer to the pull of the reins; although he bends his neck to it.

turn his hind-quarters round to the left at the same time as his head is pulled to the right by his rider, and will thus 
place the direction of his body at right angles to the obstacle, as in Fig. 2.

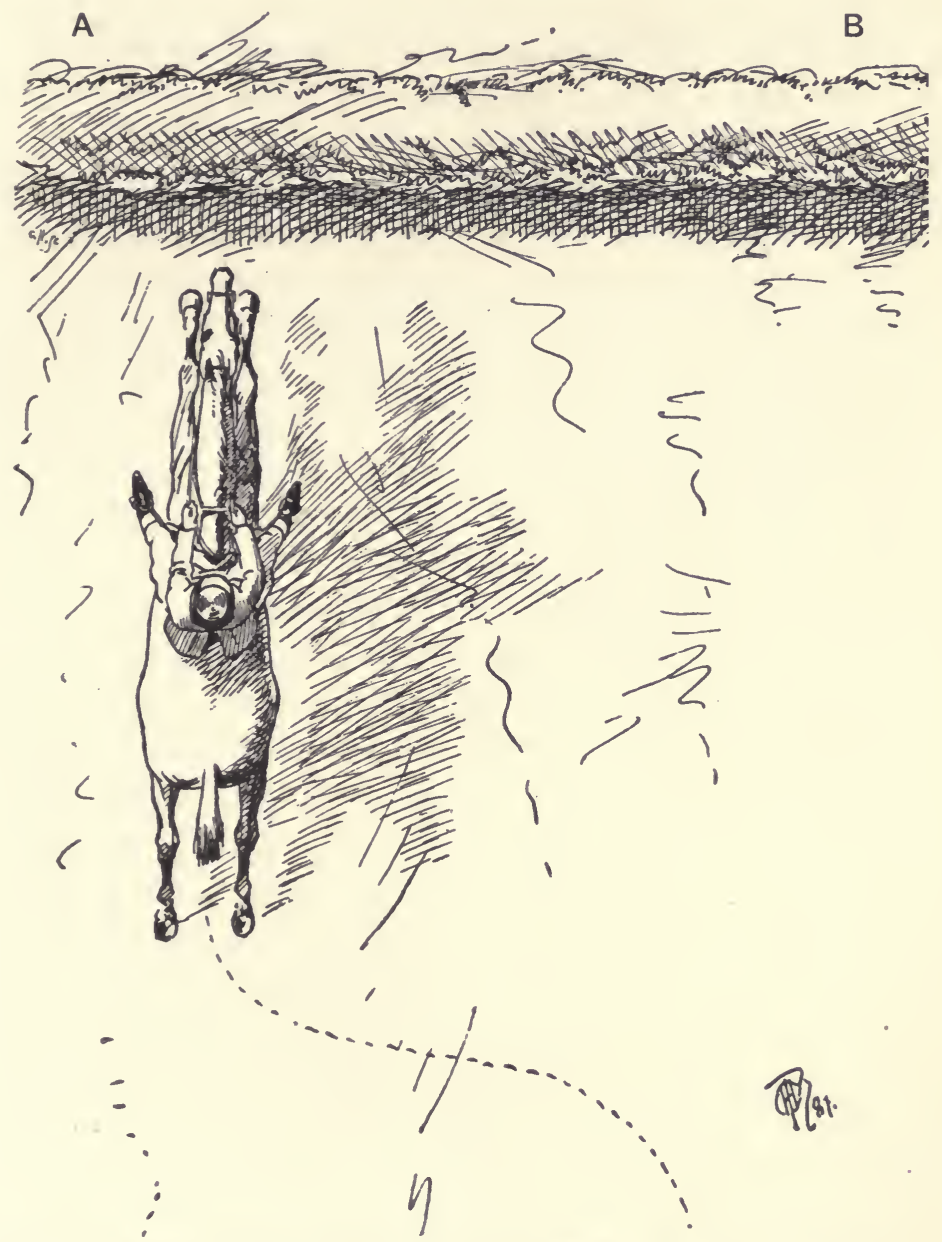

Fig. 2.-Horse going straight at his fence (A B), on account of having answered the pull of the reins with his hind-quarters as well as with his forehand.

As the conformation of the horse meets his grazing requirements as well as his locomotive ones; we find, as a 
rule, that for saddle purposes he is too heavy in front. The goat, being a browsing animal, appears to be much lighter in front than the horse, if we may judge by a comparison between their respective powers of rearing. I am inclined to think that the custom of feeding horses from a manger which is raised off the ground, tends to make a horse light in front. A prevalent idea among experienced men is that a young horse "fines down" about the withers and shoulders after he has been taken up from grass and has been stabled and worked under ordinary conditions. This "fining down" would, I think, chiefly consist in increased obliquity of the shoulder blade. I may remark that the conformation of boys and girls is usually susceptible of considerable change for the better by a course of judicious gymnastics and "setting up" drill.

However much or little the proportion of weight borne by the fore legs, as compared to that carried by the hind limbs, is in excess of that which would be most suitable for mere purposes of locomotion; experiment proves that the proportion of weight in front is considerably increased by the fact of a man being placed on the horse's back. Hence, in any case, the breaker should try to teach the horse which is intended for saddle work, to carry himself in such a way that, when mounted, the weight of horse and rider will be so distributed that the weight on the forehand, as compared with that on the hind legs, will be less in proportion to that borne under similar circumstances by the untaught horse when at liberty. Unfortunately it is impossible to give exact rules as to obtaining the most advantageous distribution of weight, which must be left to the judgment of the breaker, and which will evidently be different to that naturally adopted by the animal. I may point out that the expressions, "making a horse bring his hind-quarters under him," and "lightening his forehand," 
mean the act of increasing the weight on the hind limbs, by taking it off the fore ones. It follows from the fact that the presence of a rider alters the proportion of weight in the manner mentioned; that the heavier the intended rider, the more should the weight be brought back. The well "set up " soldier gives us an admirable illustration of the great influence which training has on gait.

We know from experience that muscles which are practised at one particular kind of work, gradually acquire the ability to perform it in the easiest possible manner. Thus, a man who has to carry heavy burdens on his back, will in time unconsciously acquire the action most surtable to his task. It might therefore be argued that any attempt to teach a horse to carry himself in the manner described, is useful merely for saving time, and that the horse would, after a while, automatically rectify matters. Even if this were true, which it might not be in the large majority of cases, we must remember that horses which are allowed to go " heavy in front," especially at fast paces, are particularly liable to become unsound from injuries to their fore legs, which injuries greatly exceed in number all the other accidents that incapacitate saddle horses, and especially racehorses, from "standing" work. In this country little or no attempt is made, except in the Army, to form the paces of riding horses. Despite the influence of careful selection in breeding, we cannot ignore the fact that the legs of the average horse are but ill adapted to bear, under ordinary conditions of work, the strain of a greater weight than that of his own body. The old adages that any horse is able to wear out four sets of limbs, and that a horse is as old as his legs, are unhappily too true. Therefore it behoves the careful horseman, by judicious breaking, to diminish as far as possible the chances of his animals becoming unsound.

As the preponderance of weight on the forehand increases 
as the speed, the liability of injury to the fore legs, as compared to that of the hind ones, will vary in the same proportion. Bringing too much of the weight back, especially when jumping (see page 243), is apt to throw an injurious amount of strain on the hind legs.

In rearing, there is extreme preponderance of weight on the hind legs; in kicking with both hind feet, on the fore ones. The rider can lighten the forehand: (I) by leaning back in the saddle; (2) by raising the horse's head; (3) by moderating the speed; and (4) by applying the drawn-back heels or spurs, so as to make the horse bring his hind legs well under him, and at the same time checking with the reins any increase of speed. When increased action of the fore legs is prevented from being utilised in a forward direction, it is expended in a more or less vertical one, as we may see in the case of fashionable harness horses which are broken on the " hit 'em and hold 'em " principle. As the instability of the centre of gravity increases proportionately to the speed (see Points of the Horse) ; the slower the pace, other things being equal, the lighter will be the forehand; and vice versa.

The rider can increase the weight on the forehand : (I) by leaning forward in the saddle; (2) by lowering the horse's head; (3) by increasing the speed; and (4) by applying the feet to the borse's shoulders.

As the effects of "work" show far more frequently in the fore legs than in the hind ones of our hunters, racehorses, chasers, troopers, and hacks, we may, I think, infer that our horses are as a rule too heavy in front. If the correct proportion of weight between the two sets of limbs was maintained more accurately, these horses would undoubtedly last longer. Consequently, the adoption of improved methods of breaking would effect a large saving of money to individuals, and also to the State. 
The harness horse has to put on his forehand an extra amount of weight proportionate to the load he has to draw.

CARRIAGE AND ACTION OF THE HEAD AND NECK OF THE HORSE WHEN HE IS IN MOTION.

When the horse takes a stride to the front, the fore limb is drawn forward and upward by certain muscles of the neck,

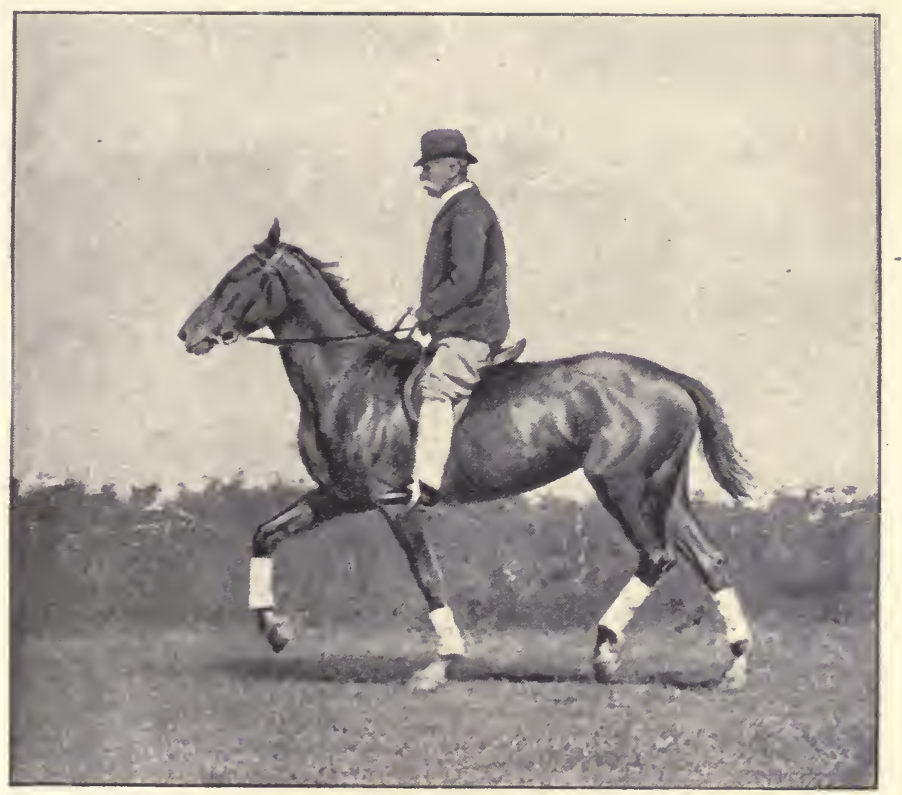

Fig. 3.-Trotting.

the action of which is regulated by the depression or elevation of the head. If the head be unduly raised, the forward reach of the fore legs will be curtailed by this high attitude, and the speed will consequently suffer. If, on the contrary, the head be brought down too low, the animal, if at the gallop or canter, instead of "going level," will have a more or less pitching motion, from too much weight being thrown 
on his forehand; and will lose time in his stride by excessive bending of the knees, which is necessary in that case to enable his feet to clear the ground.

Owing to the variety in the conformation of different horses, and in the work they are called upon to do, it is

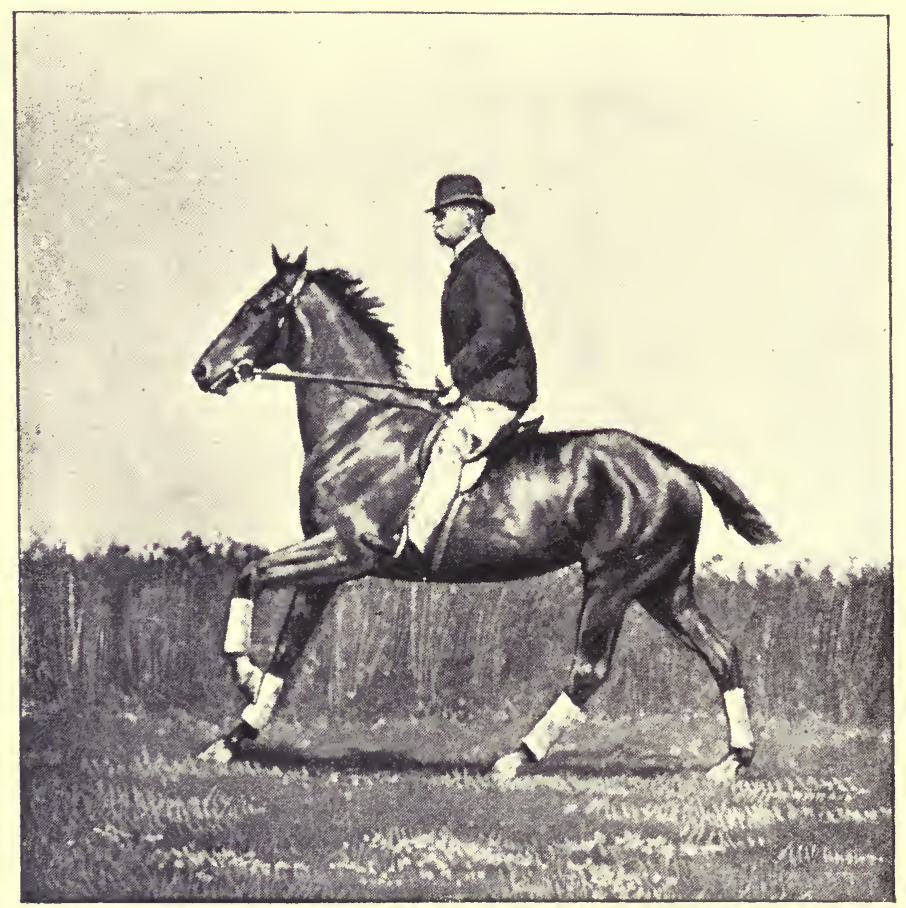

Fig. 4.-Cantering.

impossible to lay down any fixed rule as to the angle at which the head and neck should be carried; a fact that is of little moment, for experience will enable us to form a sufficiently near approximation for all practical purposes. The neck muscles which draw the fore limb forward, will act to the best advantage when the neck is held straight; 
for in that position the muscles are stretched out as much as possible, and, consequently, when they contract, they have their utmost forward pull.

The chief muscle which draws the fore limb to the front, is attached to the head in such a manner that it acts best during movement, when the head is carried more or less at

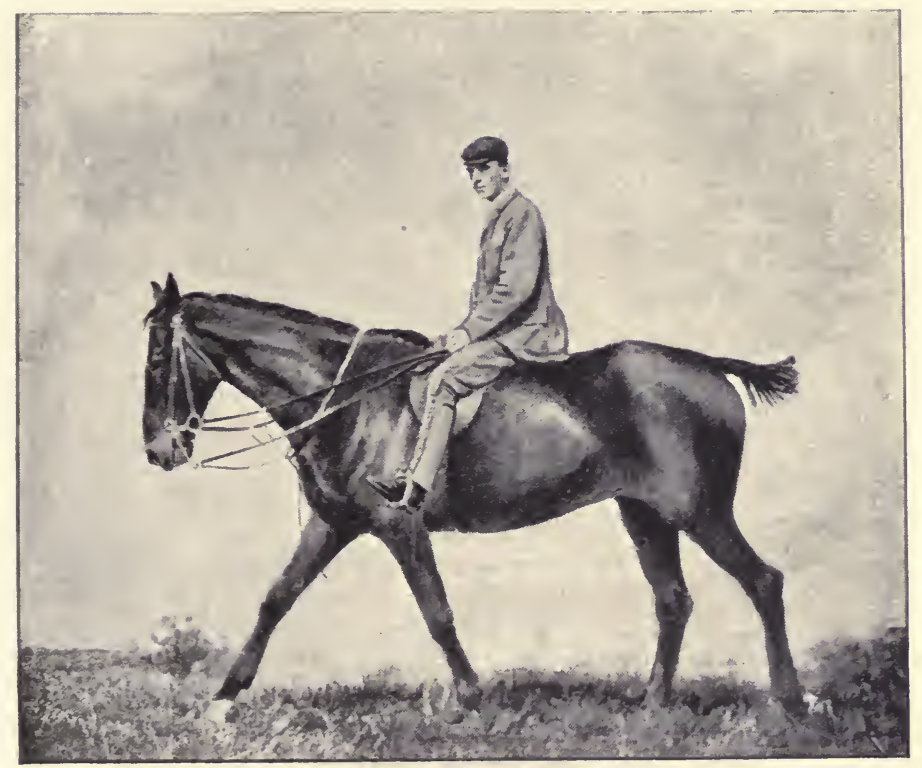

Fig. 5.-Walking at ease.

right angles to the neck. We may also assume that, as a rule, the head and neck are best placed for all ordinary requirements of paces faster than the walk, when the condition just stated is observed, and when the head is carried at an angle of about $45^{\circ}$ to the ground (see Figs. 3 and 4). When the horse walks at ease (see Fig. 5), the head will be lowered, and carried more perpendicularly. For mere purposes of control by the bridle, the most generally 
advantageous position is when the line of the face makes an angle of about $90^{\circ}$, or a little less, with the ground (see Fig. $6)$; because, in that case, the pull of the reins is more or less at right angles to the bars of the lower jaw against which the mouthpiece of the bridle presses, and the forward reach of the fore legs is somewhat checked by the legs being bent. Neither for control nor for movement, is it well for the head to be flexed to a greater extent than this. The more the chin is drawn in beyond this limit, the more will the pull of the reins be transferred (from the bars of the lower jaw) to the poll of the animal's head ; the more oblique will become the direction of the pressure of the mouthpiece on the bars ; and the more will the horse be obliged to lower his head, thereby unduly increasing the weight on the forehand. Thus, by bringing his chin into his chest, the horse (I) more or less deprives his rider of control over him ;

(2) disturbs the proper distribution of weight between his fore and hind legs; and (3) hampers the movements of his fore limbs.

\section{COLLECTING THE HORSE.}

By the somewhat ill-defined term, "collecting the horse," I wish to express the act by which the animal is made to bend his neck and bring his hind legs under him ; so that his spinal column will be more or less regularly arched, and his muscles will continue to contract and relax at short and regular intervals. He will then "play" with the bit by yielding his neck as well as his jaw, and will advance his hind feet more under his body than he usually does. When fully collected, he will be in the best possible state of general readiness to perform any legitimate form of work, such as going forward, reining back, turning, circling, or leaping. In fact, he will be "bent" 
before and behind, like a spring, with his forces collected together and ready to be applied in any legitimate manner which his rider may demand. As, by collecting the horse, we deprive him of taking the initiative; we find that the practice of frequently collecting him is the best possible

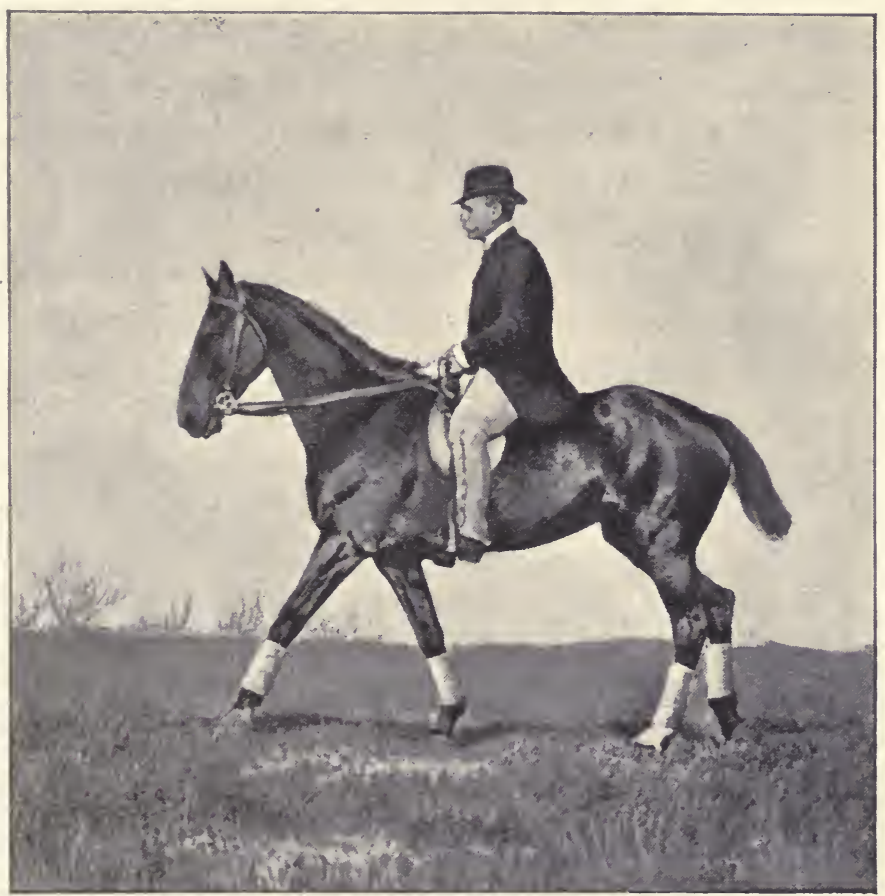

Fig. 6.-Collected walk.

means for curing him of hardness of mouth and stiffness of neck. A horse can be collected at any pace ; but if I may venture to say so, he should not be collected at the halt; for then there will be no harmony of action between the muscles of the head and neck, and those of the hindquarters; the former being in a state of alternate contraction and relaxation; the latter, motionless. In collecting 
the saddle horse, the reins bend the neck and check the advance of the fore limbs, while the pressure of the rider's legs, spurs, or whip makes the horse bring his hind legs under him. As I have already said, the line of the face, when the horse is fully collected, will be at right angles to the ground, or a little less; but the chin should not be drawn in more than this. We may accept the fact that teaching the horse to collect himself is the foundation of all good mouthing, whether for the formation of the mouth of a young animal, or for the correction of a puller or a borer.

It is manifest, that in checking a horse's speed, we should more or less collect him; the collection being proportionate to the alteration in the speed; for the faster the pace, other things being equal, the greater the weight on the forehand. Whether we make the horse adopt a slower gait, or bring him to a halt more or less abruptly, it is necessary that we should collect him so that he may be ready to apply his powers to the best advantage, either for stopping himself, or for moving on again in the same or in a new direction. If the preponderance of weight be on the forehand, the hind limbs will be more or less thrown out of action, and vice versa. Hence, when checking the speed of a horse, and especially when bringing him to a halt, the rider should close his Jegs and should lower his hands when taking a pull on the reins, so that the horse may bring his hind legs well under him, and at the same time bend his neck.

The popular expression "in hand" may be used for "collected." We must be careful to understand that a horse may be "light in hand" without being in any way "collected," as, for instance, a star-gazer which will not go up to his bridle. When a horse is galloping through heavy ground, the fact of his fore feet sinking more deeply into the soil than the hind ones, will make him unduly heavy in front. We should here try to more or less collect him. If, 
at the same time, we were coming up to a high fence, to safely negotiate which, the animal would require to have his neck straight, so as to have full freedom of action with his fore legs; he should, at least for the last few strides, be light in hand, instead of being collected. The expression, "getting a horse's hind legs well under him," appears to be used indiscriminately for collecting a horse, and for making him light in hand. The distinction I have indicated is, however, worthy of attention.

It is evident that when breaking the horse, we should teach him to collect himself according to the indications we give him, and to an extent which may be out of all proportion to the requirements under which he is receiving his lesson, although similar to those of actual work.

Note.-During breaking too much care cannot be taken in teaching collection and a willing obedience to the aids; for the more perfectly they are mastered, the more easily and harmoniously will the horse be able to move with us. The well-trained horse and horseman should be able to move together as harmoniously as two good dancers, the horseman moving with his "mount" and guiding it as easily and imperceptibly as the good waltzer with his partner. I wish that many horseowners understood this better, for by so doing they might be saved much disappointment with expensive purchases. How often do we not hear (especially at shows) charges of unfairness from a disappointed exhibitor who has become the owner of a horse, which previously was almost unbeaten, and afterwards passed over.

The discontented one, in many cases, possibly believes the judges are treating him unfairly, while in reality, he has ignorantly spoilt his horse's action and thrown the animal entirely out of balance by employing some severely unsuitable bit, or a groom, who by his bad riding causes the show animal nothing but discomfort. Horsemen are nowadays 
greatly handicapped, because riding schools usually teach only in the stiff uneasy military way to which the hunting man rightly objects, and boys are therefore allowed to pick up riding as best they can, being accompanied in many cases at first by some ungainly old coachman, who possibly gives them only a good illustration of what not to do. The young rider, unless he is naturally active, graceful, and observant, thus contracts bad habits, which cling to him for the rest of his riding days. Surely eating is a much more natural and easy thing for a boy than riding, yet most parents recognise the advisability of having a child taught how to use properly its knife, fork and spoon while they totally ignore the riding.

REQUIREMENTS OF A GOOD MOUTH.

A horse may be said to have a good mouth when he obeys the aids with promptness, accuracy, and precision, and when he carries himself in the manner most suitable to the work he has got to do. The combined weight of the body of the saddle horse and of his rider must, therefore, be properly distributed between the fore and hind legs. If the animal leans strongly on the mouthpiece of the bridle, he will be "heavy in front." If, on the contrary, he refuses to "go up to his bridle" (remains " behind his bridle"), he will have an undue proportion of weight on his hind legs. In order that the rider or driver may keep in touch with the horse, it is necessary that the animal shall allow him to maintain a certain amount of "feeling" on the reins, and of pressure by the legs, so that he may remain in communication with both ends of the horse. For ordinary requirements, and especially for 'cross country work, the amount of feeling on the reins which the animal should bear with equanimity, might naturally be somewhat in excess of that which would be needed for mere purposes of communication between horse and rider. It is evident that the more 
incapable the rider, the broader should be this margin, which is an evil, though a necessary one, with men of light seats and heavy hands. It must, however, in no case exceed the controlling power of the rider or driver. The habit of refusing to go up to the bridle not alone cuts off the communication which we should constantly maintain by means of the reins between ourselves and the horse; but is extremely liable to degenerate into the dangerous combined vice of rearing and jibbing.

A horse with a good mouth, as I have already indicated, will be capable of being readily collected; that is, while having his hind legs well under him, by the action of the rider's heels or spurs, he will freely bend to the rein with his head or neck. He will then keep the muscles which close his jaws more or less relaxed; but without losing touch with the reins, and will often show, at slow paces, this obedience to the rein by the familiar play of the lower jaw and champing of the bit. The relaxation of the jaw is useless, as we know from practical experience, unless the horse also yields with the muscles of his neck.

As the manner in which a horse moves under the guidance of his rider or driver, is the true test of the state of his "mouth"; it is evident that to have a good mouth, the horse should carry himself in well-balanced style, that is, with the weight distributed in due proportion between his fore and hind legs; with the line of his face, at an angle of about $45^{\circ}$ to the ground, unless we wish to "collect" him, or unless he is at a walk (see page $7 \mathrm{I}$ ); and with the direction of his neck favourably placed for the movements of the fore legs. For the same reason, we may infer that all mouthing instruction, or, at least, by far the greater part of it, should be given when the horse is in movement. If we seek to impart it while the animal is stationary, we shall, in doing so, have constantly to strive against the tendency of 
the horse to keep one part of his body fixed, while we are "suppling" the other end. The horse, as I have already said, should be taught to move as a whole, and not in parts.

Note.-When riding or driving a young horse in a field for mouthing instruction, decide in your own mind exactly where you wish him to go, and then try to take him over the ground you have chosen. By doing this you will accustom him to the aids and be able to see how his education is progressing. When a horse is exercised on a road or definite track, there is slight occasion for applying the aids, and the rider may think his mount most handy until he gets him into a field, and finds he cannot guide him where he wishes with any certainty.

COMBINED ACTION OF THE AIDS IN FORMING THE MOUTH.

From an examination of equestrian pictures, we may learn that " the knights of old," and in fact all European military horsemen up to the commencement of the present century, rode in such a position that they could use their legs as an aid only by means of the ends of their sharp and long spurs. Hence they controlled their horses almost entirely by the bridle. The result of this method of equitation, as we may see from the extremely severe nature of the bits they used to employ, was to make their horses heavy in hand. Even when the animal arched his neck in obedience to the bit, he would naturally seek to relieve his mouth by abstaining as much as possible from bringing his hind legs under his body. The horse makes the same "defence" when he is "tied up" by side-reins (see page 93). Baucher (see page 26I), who was the great reformer in school breaking and riding, insisted on the principle of beaucoup de jambes et peu de main. By this he meant that the pressure of the legs (with a touch of the spurs when necessary) should be used in order to bring the horse's hind legs under 
him, and consequently to relieve the forehand of weight. In this way he obtained le rassembler (collection of the horse), which he justly regarded as an indispensable means of breaking. The maintenance of the horse's head in a vertical position, which is a condition of Baucher's rassembler, is a refinement of no practical utility. As I have already remarked, the large number of our saddle horses which are "heavy in front," is the best proof that the majority of Englishmen who get up on horses, "ride the bridle," and neglect the use of the legs as an "aid." At the same time, I must say that every fine horseman in our midst is quite as alive as Baucher was, to the importance of riding more by the legs than by the hands. The breaker should constantly bear in mind the necessity of teaching his saddle pupils to obey the indications of both legs and reins, so that they may be able to be collected when required.

\section{RESPECTIVE ACTIONS OF THE SNAFFLE AND CURB.}

The indications of the curb are complex and indirect, and prompt the horse either to fight against them, or to unduly lower his head and to bring his chin into his chest, in either of which cases his movements are interfered with by the position assumed by the head and neck. The action of the snaffle, especially when it is unjointed (see page I68), is more direct, and its indications are consequently freer from ambiguity. The breaking in of a horse with a curb is apt to spoil him for subsequent work in a snaffle, the use of which can in no way hinder him from being taught that of the curb. Hence the snaffle should be the only bit employed by the breaker for all ordinary requirements, until his pupil is perfect in it. After that, he may teach the animal to go in a curb. When riding under the usual conditions of field or 
road, the snaffle should act on the "bars" and not on the "corners" of the mouth; for the former are more sensitive to pressure than the latter, and by acting on the bars we prompt the horse to bend his neck (to save his mouth), and consequently to yield to the rein. If, however, the pressure falls on the corners of the mouth, the animal will as a rule keep his head and neck stretched out and raised, so as to prevent the bars being touched, in a manner which will more or less deprive the rider or driver of control, and which will hamper the movements of the horse. I may point out that the only practical advantage which the curb has over the snaffle, is that of severity. As high school and circus riders require their horses to execute various lofty airs de manige, they use the snaffle to act on the corners of the mouth, when they wish to make the animal carry his head in an unnaturally high position, so that he may be able to raise his fore legs with exaggerated freedom, as in the Spanish trot or Spanish walk (see page 284).

For further information on snaffles and curbs, I may refer my readers to Riding and Hunting.

\section{DIRECTION OF THE PULL OF THE REINS.}

The movements of the neck are made on the column of bones (vertebra) of the neck, and on the suspensory ligament of the neck, which is a strong elastic ligament that extends from the withers to the top of the head. The centre of motion of the neck will therefore be about four or five inches below the top of the withers; its position varying somewhat according to the nature of the movement. In order that the restraining action of the reins should interfere as little as possible with the carriage of the neck, the direction of the reins should naturally pass through the centre of motion in question. If the reins pass above that 
point, the tendency of their pull will be to raise the head, and consequently to lighten the forehand; if below it, to lower the head and increase the weight in front. For simplicity sake, I am here assuming that a snaffle is used. As the point of application of the mouthpiece (the bars of the mouth) is not in the line of the balancing pole (the neck), my remarks, here, on the action of the reins are made only in general terms; although they are sufficiently exact to bear out the truth of the well-recognised rule that the hands, when riding, should be held a little below the withers.

TURNING, CIRCLING, AND LUNGING THE HORSE.

In order to maintain the proper distribution of weight between the fore and hind limbs, the horse, as I have pointed out on page 63, should turn more or less on his centre, without making a pivot of, and consequently throwing an undue proportion of weight on, either his forehand or his hind-quarters. Although it appears to me impossible to work out the problem mathematically, I venture to state that both theory and practice confirm the supposition that in turning, or in circling, which is merely a form of turning, the track of the hind feet should be the same, or as nearly as possible the same, as that of the fore ones. If the curves be concentric, instead of coincident, the pair of limbs which describe the inner curve (or smaller circle) will naturally bear an undue proportion of weight. We have a practical proof of this in the fact that almost all the strains to tendon and ligament which arise from the ordinary method of lunging with one rein, occur in the fore legs. In this form of circling, the turn being made by acting on the head of the horse by means of the cavasson and leading rein; the head is pulled in towards the centre of the circle and the hind-quarters are allowed to fly out, with the result that the 
fore feet describe a smaller circle than the hind feet, and consequently have an undue amount of weight thrown on them.

The fact of a horse turning his head round to one side causes the position of his centre of gravity to be shifted towards that side, the fore and hind leg of which will consequently bear more weight than their respective fellows under all ordinary conditions. We see this illustrated when the horse is tied head and tail (vide Fig. 77), in which case it is far more difficult for him to lift up either of the legs of the side to which his head is turned, than either of the corresponding limbs of the other side. In turning or circling, this power of altering the position of the centre of gravity is very useful to the horse for preserving his stability by neutralising the effect of the centrifugal force generated by the more or less circular motion. In this way, the head and neck act as the balancing pole of the body. The application of this principle is illustrated by curved portions of railway lines, in which the outer rail is made higher than the inner one, so as to tilt the centre of gravity of the train inwards, as well as to offer a more effectual resistance to the tendency the carriage might have of being carried off the line. The track of circuses and even of running grounds are banked up in a similar manner. The circus rider, when standing on a pad or on the horse's back as the animal canters round the track of the arena, leans inwards, proportionately to the speed, with the object in question, and so does his horse, as we may see if we observe the animal closely. We may therefore conclude, apart from the obvious reason that the horse should look where he is going, that his head and neck should be in the direction in which he is moving, whether he is turning, circling, or travelling in a straight line. In fact, the animal, from the muzzle to the end of the tail, should be bent more or less 
into the form of the curve upon which he is travelling. Although his body from the withers to the root of the tail is capable of but little flexion, the head and the neck have a large amount of lateral "play." The degree to which the horse should bend himself will of course be proportionate to the sharpness of the turn.

From the remarks just made, we may see the necessity, in the turn, of the hind-quarters following the movements of the head and neck. Being impressed with the correctness of this principle, I would venture to condemn those "suppling" lessons by which the horse is taught to bring his head round to one side or the other, while his hindquarters remain fixed. The horse, as I have said before, should learn to obey the side pull of the rein with his hindquarters, as well as with his head and neck.

In most Continental manèges, an attempt is made, when lunging a horse, to counteract the tendency the hindquarters have of flying outwards, by tightening the outward side-rein more than the inward one, or by using only the outward side-rein, so as to turn the head outwards. Although the hind feet can be made by this arrangement to describe the same circle as the fore ones; the head and neck, being bent outwards, are carried wrongly. In the method of circling the horse with the long reins (see Fig. 89), the two necessary conditions are fulfilled; for the head and neck are bent inward by the inward rein, and the hind-quarters are prevented from flying outwards by the outward rein. The same principle is adopted by thr capable rider who preserves the bend of the head and neck with the inward rein, and keeps the hind-quarters in position by means of the pressure of the outward leg, which is drawn back as may be required. One pre-eminent advantage which circling the horse with the long reins has over any method of lunging with leading rein and cavasson, is that 
by it we can not alone exercise the horse; but can also "mouth" him at the same time. Besides, by it we can regulate and control the animal's movements in a manner unattainable in any other way. By this style of riding and by the use of the long reins on foot, the proper distribution of weight can be maintained when turning or circling the horse. I may here explain that when turning or circling a horse to the right (in the direction in which the hands of a watch move), the right rein or right leg is the inward rein or inward leg, and the left rein or left leg, the outward rein or outward leg; and vice versa.

Apart from the turn on the centre, which I have just described and which preserves as far as possible the natural distribution of weight between the fore and hind legs, the turn may be made on the forehand or on the haunches, either as a suppling exercise, or as a movement necessary on certain occasions to which I shall refer later on.

\section{REINING-BACK.}

Combined ability to comprehend and willingness to obey the application of the appropriate aids for reining-back, are useful in all horses, both as an end and as a means. Even on the racecourse, it is well for a jockey to be able at times to rein his horse back at the start, instead of having to turn. round, go back, and come up again, in doing which he might easily lose a good position. Also, among a crowd of horses in the hunting field, when waiting for one's turn to go through a gate or at the only practicable part of a fence, a like command over a horse is to be appreciated. Reining-back is, however, even still more valuable as a means of teaching the horse to obey the aids. There are two forms of the rein-back: one, in which the preponderance of weight is placed on the hind legs; the other, in which it is put on the forehand. We see the former when 
the carter tries to make his draught animal push back a heavy load by raising the animal's head and by forcing him to throw all his weight into the breeching. In the latter, which is alone applicable to saddle work, the horse increases the proportion of weight on his forehand by lowering his

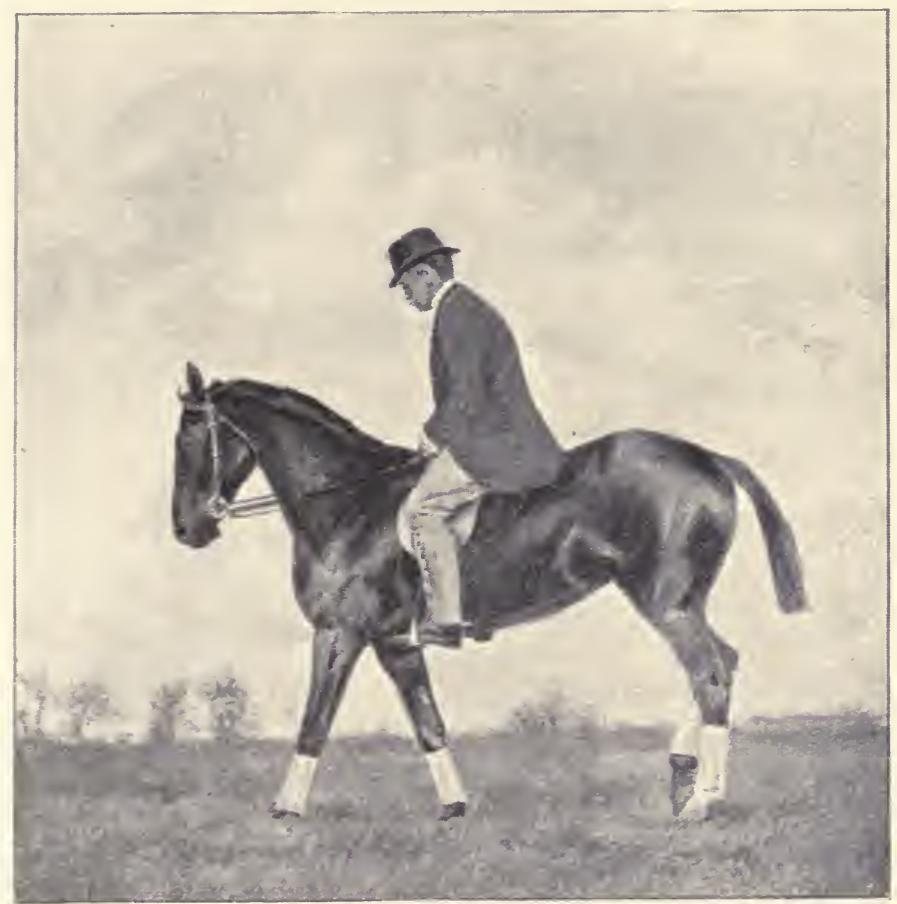

Fig. 7.-Reining-back.

head, and consequently gives freedom and lightness to his hind legs in the backward movement. If it be right for a horse to be light in front when going forward, it is surely correct for him to be light behind when reining-back. Experience tells us that the best way for a horse to rein-back is in diagonal two time (that of the trot), namely, near fore and off hind; and off fore and near hind. The most effective 
method of obtaining this movement is to bend the head and neck away from the side of the least advanced hind leg, so as to fix the other hind leg, for the moment, by placing the proponderance of weight on it. On both reins being then felt, and the hind-quarter of the side opposite to that to which the head is turned, being prevented by some

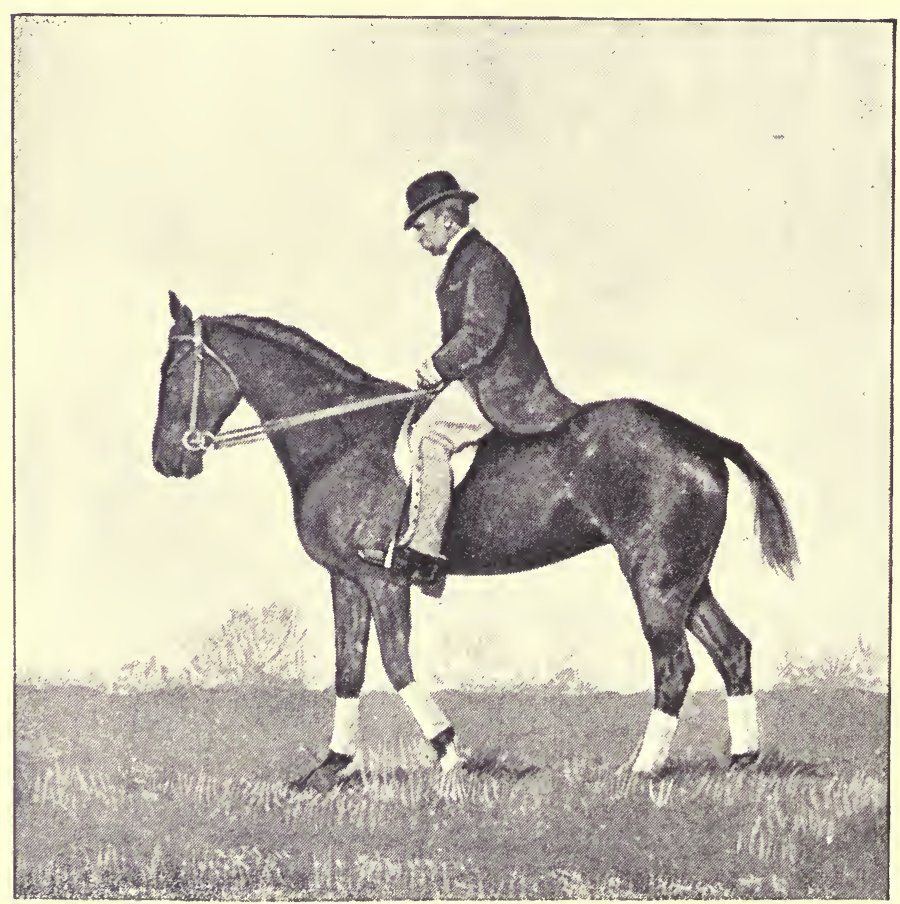

Fig. 8.--Reining-back.

suitable aid from swinging round, the horse will readily lift and draw back the hind leg which bears the least weight, and will follow it by the opposite fore leg. To obtain the next step, the head is turned to the opposite side, and the reversed aids applied. Thus, if we wish to commence the rein-back with the off hind-supposing that both hind legs 
are equally advanced-we turn the head to the left by a stronger feeling on the near rein, and having applied some appropriate aid (such as the leg or whip, if riding ; or rein, if using the long reins) to the off flank or quarter in order to keep the hind-quarters straight, we "feel " both reins, so as to make the horse step back with his off hind and near fore. To obtain the step to the rear with the near hind and off fore, we apply the opposite aids. In Fig. 7, the horse is beginning to take the left diagonal step (near fore and off hind), and is completing it in Fig. 8. For further information on the rein-back, I beg to refer my reader to Points of the Horse, in which I have discussed this pace at some length. The subject of reining-back is dealt with very ably in Barroil's admirable book, L'Art Équestre.

By practising the horse at the rein-back we teach him to obey the pressure of the reins with his head and neck and with his hind-quarters at the same time; in fact, to obey it with both ends of his body, and not with the front end only. This work has also a strong moral effect on the animal in teaching him discipline. It is, as we might naturally infer, specially applicable to the breaking in of a horse which bears too much weight on the reins. We may take for granted that until a horse has learned to reinback with facility and precision, he cannot be considered to have a good mouth.

\section{THE STANDING MARTINGALE.}

The use of this martingale, from a breaking point of view. is to teach the horse, if he be inclined to throw up his head as a "defence" against the action of the bit on the bars of the mouth, to abstain from doing so. The principle by which we gain our end in this respect is by making the animal associate in his mind the idea of pain with the act of throwing up his head. We can put this principle into practice 
by attaching the standing martingale to the rings of the snaffle, at such a length that it will prevent the horse from shifting the mouthpiece off the bars and on to the corners of the mouth. When he finds that every time he "chucks"

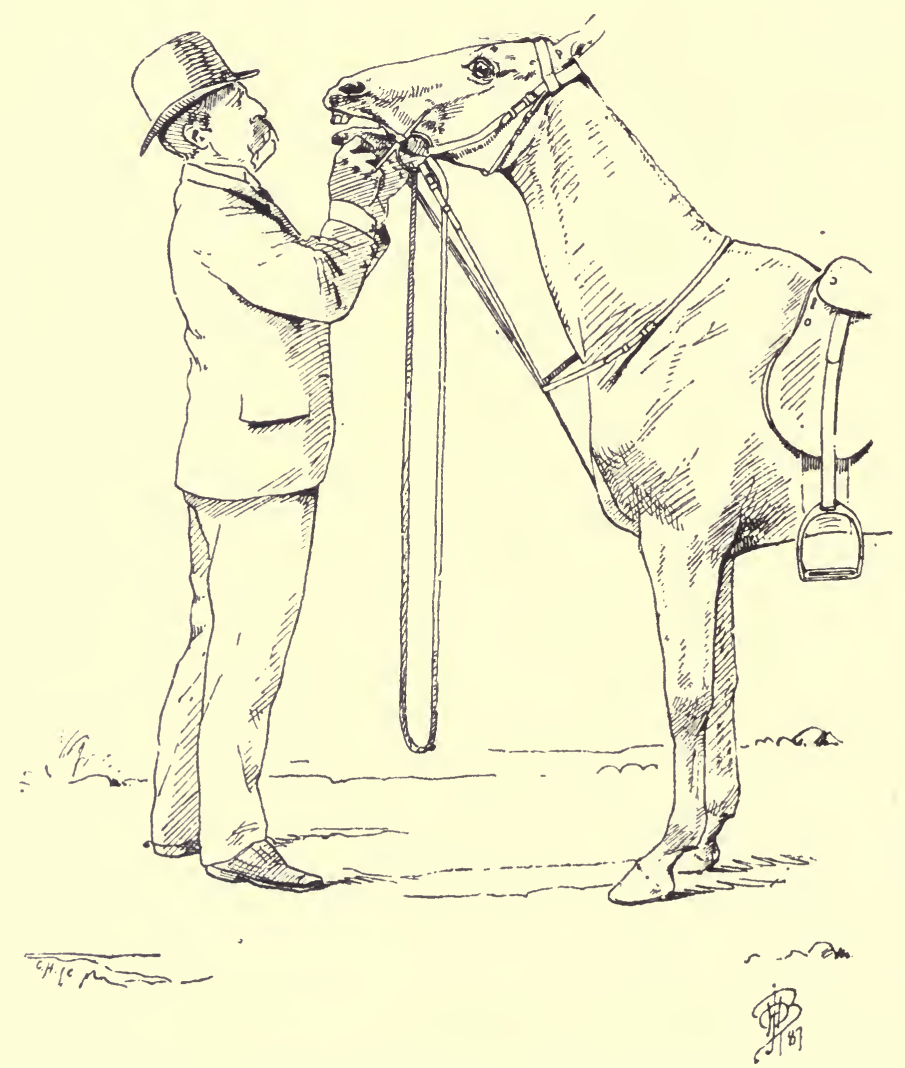

Fig. 9.-Maximum length for a standing martingale.

up his head, he gives the bars of his mouth a severe shock, he will soon cease doing so, even, as a rule, without a martingale. The use of this gear should not, however, be dispensed with before it has produced a more or less permanent effect on the animal's mind. When that has taken place, he 
will often be apparently unable to distinguish whether the martingale be absent or present. In any case, I feel certain from long and careful observation that the intelligence of the horse is not sufficiently developed to enable him to

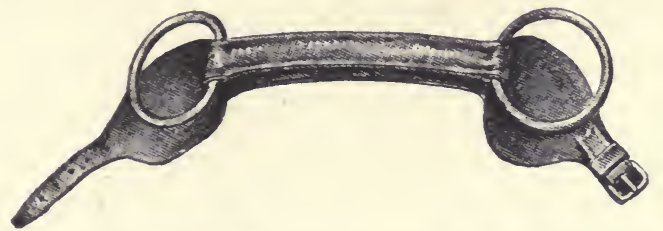

Fig. I0.-Front view of leather-covered, unjointed snaffle.

understand that the presence of the martingale is the cause of the inflicted pain. If he were able to connect cause and effect to such an extent as this, it would be impossible for us to subordinate his will to ours as completely as we are

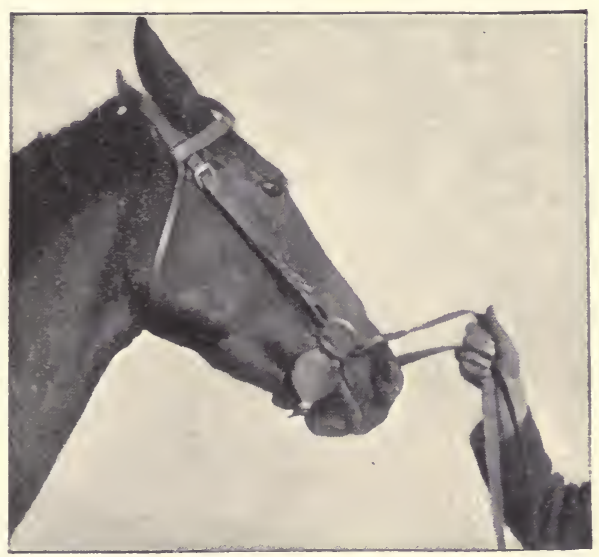

Fig. 11.-Leather-covered, unjointed snaffle, in horse's mouth

able to do. By the employment of this martingale the horse will readily learn the important lesson of bending his head and neck to save his mouth. Finding that it is impossible for him to successfully pull against the standing 
martingale by holding his head high, he will be all the more inclined to "bend" to the rein, even when there is no martingale on. When we wish to give full freedom to the head for all legitimate purposes, short of its being carried so high as to act as a "defence," we may lengthen out this martingale to such an extent that it will only just prevent the horse from being able to shift the mouthpiece of the snaffle off the bars and on to the corners of the mouth (see Fig. 9). If we want to get more power over him, we may shorten it within this limit as may be required. The correct principle of punishment and reward in the education of the horse is admirably illustrated by the use of the standing martingale; for, with it, pain continues as long as the defence; but ceases the moment the animal yields. This useful experience is not afforded by the application of the running martingale; for with it no saving of the mouth is obtained by any yielding of the head and neck to the rein. When the running martingale is on, whatever relief is procured must be the result of the action of the rider's hands, which, however good they may be, cannot give the reward (and consequently cannot aid in the desired association of ideas) with the quickness and precision of the automatically acting standing martingale, the exact length of which is rigidly fixed. Its use undoubtedly diminishes the difficulties of breaking by at least one half. It is easy to improvise a standing martingale with a piece of rope.

If the standing martingale be connected with the noseband, as is often done, it will fail to act in the manner described, owing to the fact that the pressure thus exerted on the nose causes little or no pain; unless, indeed, it be arranged in the way described on page 308. When, however, the too long continued use of a standing martingale attached to the snaffle causes the corners of the mouth to become sore, as may happen with horses which carry their 
heads too high, and which are kept on the turn a good deal-like polo ponies, for instance-we may fix this martingale to the noseband instead of to the mouthpiece. While breaking in the horse, it is always well to employ leather guards, either as a portion of the leather mouthpiece (see

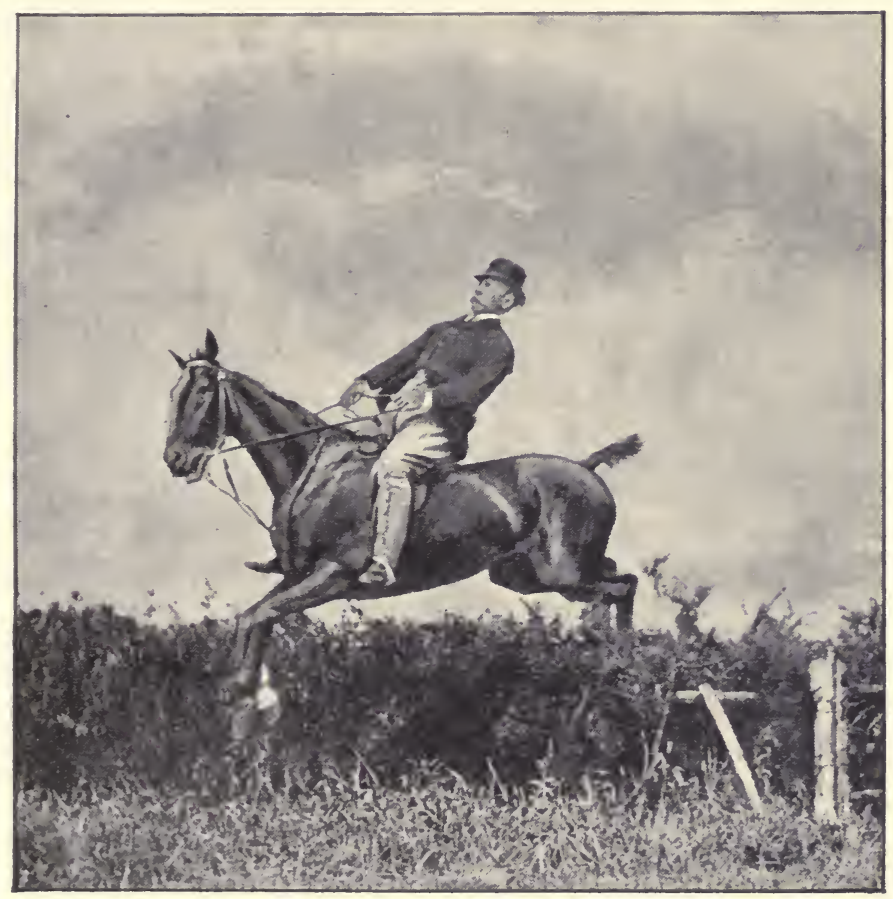

Fig. 12.-Jumping with standing martingale.

Figs. Io and II), or like those used by London cabmen, so as to prevent the corners of the mouth from being hurt.

I give Fig. I2 to show that a moderately tight standing martingale will not interfere with the movements of a horse even when jumping. The horse which I was riding on that occasion was a bad star-gazer and very hard puller. Having had a couple of lessons with the standing martingale, he 
learned to bend his head to the rein, as we may see by the fact of the martingale being loose.

As I have made the foregoing observations entirely from a breaking point of view, I need hardly say that we should teach our pupil to carry himself so well, that on leaving our hands he would not require a martingale of any kind.

BEARING REINS, RUNNING REINS, SIDE REINS, AND NOSEBANDS.

With a horse which keeps his head too low down, a bearing rein which makes him hold his head up to the required height, without interfering with his mouth (see page I73), is often of great help with the long reins. When using them and when driving a horse in harness, I have found no benefit from running reins or side reins, especially when the pull they exert on the bars of the mouth is, as is usually the case, below the centre of motion of the neck (see page 8o). The benefit of a noseband is to prevent a horse "giving" to the pull of the reins only with the lower jaw; instead of also yielding with the joints of the neck and with the joint which connects the head with the neck.

"TYING HORSES UP," "REINING," DUMB JOCKEYS, AND THE PILLARS.

Horses are frequently " mouthed" (" reined" or " tied up ") by having their heads more or less drawn in by reins which are attached to a dumb jockey or roller, and by being kept thus confined for a certain period of time in the stable, or while they are being led about at exercise. I consider this system objectionable; because only the head and neck are acted upon, and no provision is made, as there ought to be, for bending the other end of the body (see 
page 63). Horses which are tied up in this manner will seek to relieve the muscles of the head and neck by abstaining as much as possible from bringing the hind legs under the body. There is also to be considered the error of bending the horse's head and neck at the halt (see page 73). Consequently, the result-as we may, for instance, see with fashionable carriage horses, which of all animals get the most of this kind of mouthing-is excessive bending of the head and neck, and dragging of the hind legs. This absence of collection "behind " might be somewhat remedied during the stationary process of tyingup, if the breaker would stand behind the horse and would keep the animal's hind-quarters under him by means of the whip, according to the principle of the " pillars," which are two upright posts, between which the horse is placed, and to which he is attached by pillar reins. The pillars have fallen almost entirely into disuse, on account of their tendency to make the horse too light in front, thereby causing him to be disinclined to go up to his bridle, and to be ready to rear on slight provocation. One great objection to the use of dumb jockeys, the pillars, and all similar contrivances, is that, even supposing they had a good effect, it would be impossible for the breaker to tell its amount without trying the horse in saddle or harness. Consequently, with any of them he would be working more or less in the dark. With the "long reins," on the contrary, he is in constant touch with the horse's mouth, and can learn at any moment the extent of the progress his pupil is making, so that he is safeguarded against the blunder of doing too much. Again, none of these contrivances are of any use for correcting the extremely common fault of one side of the mouth being harder or softer than the other ; the reason being that their bending is applied only in a straight line, namely, from front 
to rear. So inadequate are they to the purpose of giving a horse a good mouth, as compared to the "Jong reins," that I mention them only to warn my readers against their employment.

Elastic reins, which are sometimes used with a dumb jockey, are wrong in principle and useless in practice, for they do not allow the complete freedom from pressure which the horse should experience as a reward for obedience when he bends his neck and yields to the reins; unless, indeed, they are so loose as to fail to perform their intended work. 


\section{CHAPTER IV.}

\section{METHODS OF HORSE-CONTROL.}

The breaking enclosure--Gentling the horse-Holding and leading a comparatively quiet horse-Making a rope halter-Haltering a loose horse-Teaching a loose horse to come up and to follow-Lifting up a fore leg-Holding up a fore leg-Tying up a fore leg-Blindfolding a horse-The halter-twitch -The rope-twitch-The noose-twitch-The headstall-twitch-The bridletwitch-The Indian war bridle-The Comanche bridle-The cavessonThe strait-jacket-Lifting up a hind leg-Improvised hobble-The wooden gag-Making a horse lie down and keeping him on the ground-Major Wood's method of throwing horses-Throwing a horse with the strait-jacket -The head and tail method-Rareyfying a horse-Sample's horse-taming machine-South African method of breaking.

I PROPOSE in this chapter to describe a number of methods and appliances which the breaker will find useful in making the horse docile. In it I shall say nothing about the subject of mouthing, which I shall reserve for subsequent chapters.

THE BREAKING ENCLOSURE.

For breaking in horses it is a great advantage to have an enclosure of about 20 yards square, with walls around it at least 7 feet high, and if possible roofed in, so that the breaker may be independent of the weather. I find that for convenience and control it should not exceed 25 yards square, except for breaking to harness, when it might be a little larger (see page 253). The minimum size for only saddle work may be put at I2 yards each side. A square 
arena is to be preferred to a circular one, or to a rectangular one which has two of its sides longer than the other two. The ground inside should be soft; so that the legs and feet of animals worked in it may not get jarred, and that horses which are made to lie down on it may not run any chance of hurting themselves.

I may here impress on my readers the danger there is to the breaker of having anyone standing right behind him when he is handling vicious horses; for, in such a case, if the animal makes an offensive movement, the breaker will probably knock up against the other man, and will thus fail to get out of harm's way.

GENTLING THE HORSE.

The term "gentling the horse" signifies the act of handling him in a soothing, though firm manner, while he is under such restraint that he will be unable to resist our friendly advances. For instance, after having made the horse lie down (see page I44), and while preventing him from getting up, we may gentle him by running our hands over him, patting him, and massaging his muscles, especially those which he keeps in a contracted condition. While standing at his back (when he is on the ground), so as to be out of danger, we may bend forward and gentle his legs, and draw them towards us with our hands or by a hobble and rope, with the object of forcing him to readily bend the joints of his limbs.

When a horse "fights" us, he will more or less stiffen his muscles (keep them in a state of contraction) against any movement demanded from him by us. Hence, the more we induce him to relax them, the nearer shall we be to our object of making him "give in." Gentling is therefore a valuable means for making horses docile, and for giving them confidence. 
HOLDING AND LEADING A COMPARATIVELY QUIET HORSE.

The best way to hold a fairly docile horse while standing at his near side, is to draw the snaffle reins over his head, hold them in the centre in the full of the left hand, and catch both reins near the rings of the snaffle with the right hand, having the little finger between them (see Figs. I3 and I4). While holding the reins in this way, we shall

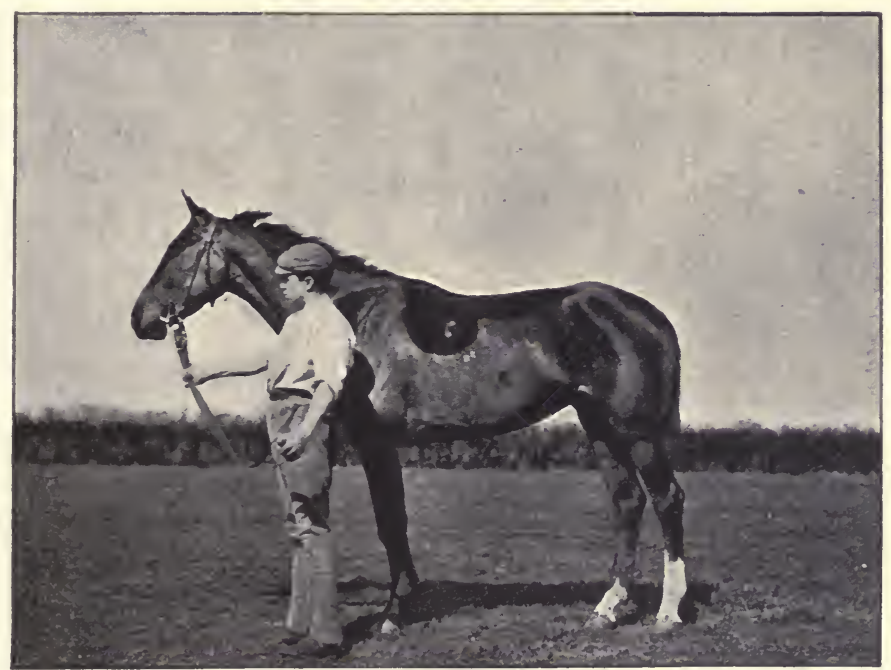

Fig. 13.-Holding horse:

have good command over the horse wlien leading him. If we wish to hold him for examination or for gear to be put on him, we may place ourselves in front of him, catch the off rein with the left hand and the near rein with the right hand, close to the rings of the snaffle ; and hold the horse's head up (see Fig. I5). If a somewhat difficult horse has to be handled behind, say, about his near hind leg, we may, while standing alongside his near shoulder and while 
METHODS OF HORSE-CONTROL.

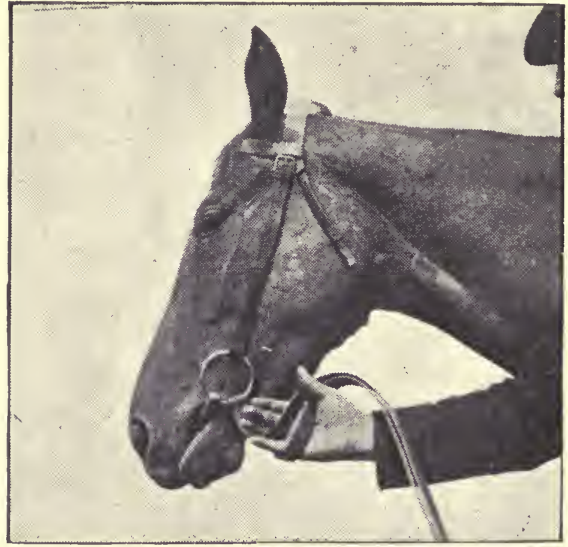

Fig. 14.-Holding horse.

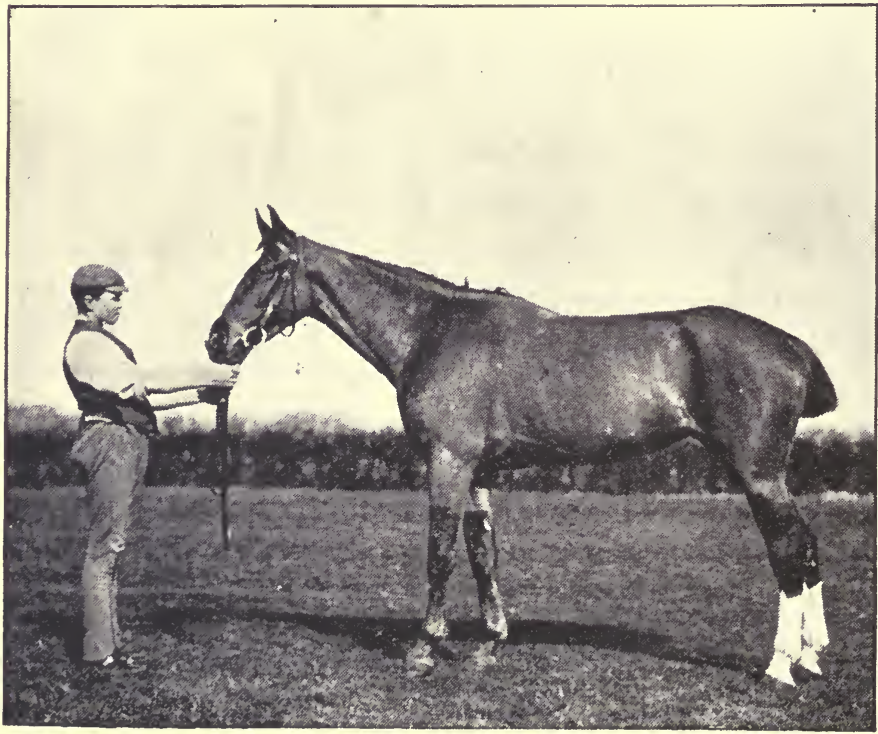

Fig. 1 5.-Holding horse. 
holding both reins in the left hand, press our right fist hard against the base of the neck, over the course of the neck vertebra (see Fig. I6). The fact of keeping the head and neck bent in this way, will prevent the animal, if so inclined, from turning round and kicking anyone who may approach his near hind quarter. The reversed precautions will be

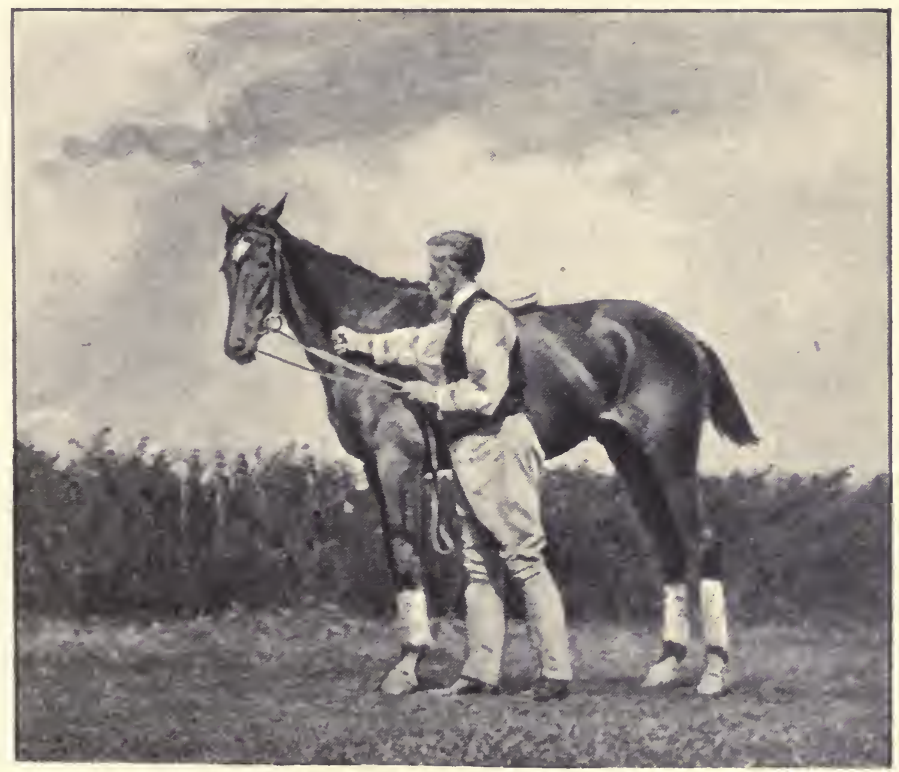

Fig. 16.-Holding horse.

observed when working on the off side. If a double bridle be on the horse, the snaffle reins only should be used.

\section{MAKING A ROPE HALTER.}

The simplest way to do this is to take a rope about half an inch in diameter, and about 9 yards long; make it double for about $3 \mathrm{ft} .6$ in., and put a knot on the doubled part, so as to form a large loop (see Fig. I7), in which to make a small loop (see Fig. I8), for the leading rein to pass 
through. The second knot should divide the large loop, so that the head-piece may be about twice as long as the nose-band. The halter will now be ready to be put on (see Fig. I9). The nose-band may be made sufficiently long,

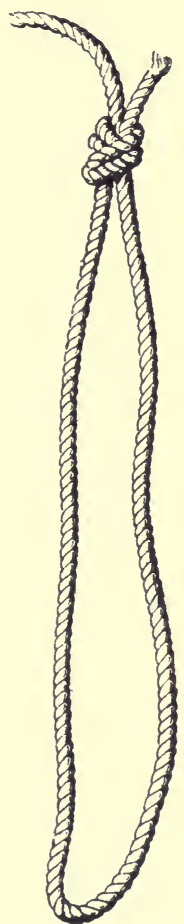

Fig. 17.-First loop in making a rope halter.

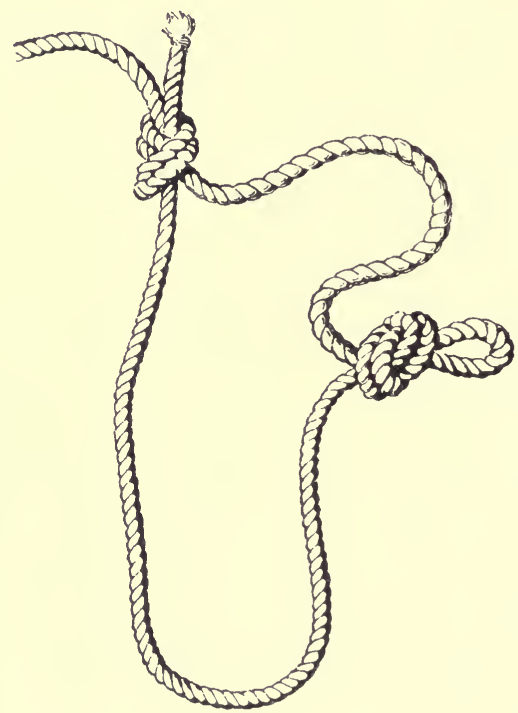

.

Fig. 18.--Rope halter completed.

and the loop through which the loose end passes, tight enough, to prevent the nose-band and leading rein (the free end of the rope) forming a running noose, which might hurt the horse. Or, if required, a knot may be made with that part of the rope which serves as a leading rein, at the ring through which it passes; so that the nose-band of 
the halter may not squeeze the horse's jaws together (see Fig. 20).

The rope employed should be soft, and not too thick; so as to allow the knots to be made with facility.

The reader will observe that this halter which I have devised is only an improvised adaptation, which need not take half a minute to make, of the ordinary halter. I have no

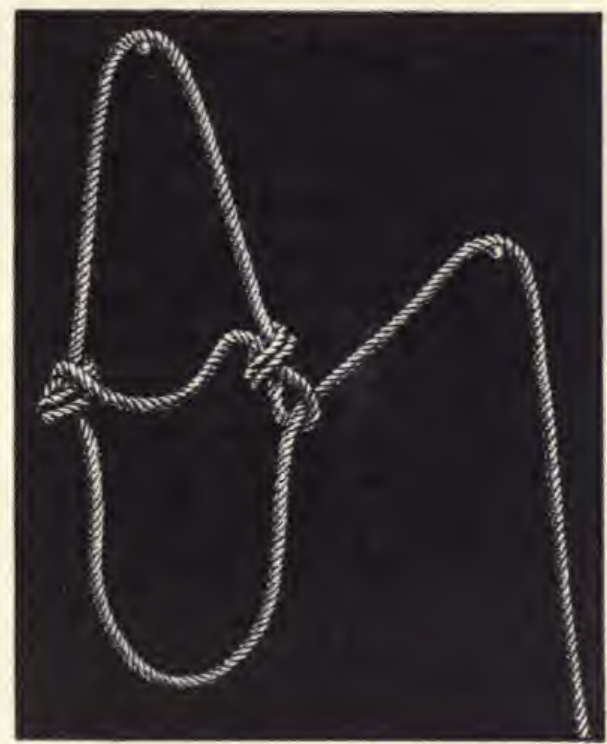

Fig. 19. - Kope halter, reacy to put on

doubt that others, prompted by necessity, like myself, have hit on this rough-and-ready method; although I have never seen anyone else make a halter in quite the same manner as I have described.

HALTERING A LOOSE HORSE.

Let us suppose that the animal is in some suitable enclosure, such as a yard, loose box, or small paddock; for it is almost needless to say, that if he were at liberty in the 
open, and averse from being captured, no man unaided could possibly capture him. The first thing to do is to make the rope halter-as already described-if an ordinary halter be not at hand, and then to get the horse to stand quietly in some convenient corner. We may make him move, or stop, as may be required, by gently working a long pole held in the hands across the body, alternately, behind and in front of him; and, having got

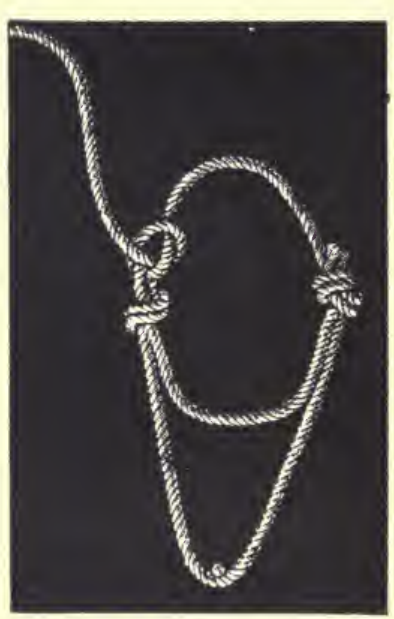

Fig. 20.- Rope halter with knot, to prevent it pinching the horse's jaws. him into the proper position, we may induce him to stand steady, as I have found by experience, by touching him on the neck, and then rubbing it with the end of the pole. I have hardly ever known this plan to fail in its object. Horses, almost always, like having their crest scratched. As soon as the animal will stand still, while his neck is being "gentled" with the stick, the halter may be put on the end of the pole by three turns (see Fig. $2 \mathrm{I}$ ), and the free end of the rope may be twisted once or twice round the pole to prevent it hanging down too low. The operator will now take the pole, with the halter rigged on to it, and will endeavour to bring the crown-piece of the halter behind the ears, without frightening the animal, while holding the end of the pole a little above its head (see Fig. 22). He can repeat the precautions I have described for making the horse stand still, as he may think necessary. As soon as the crownpiece of the halter comes behind the ears, he should swing the pole smartly down in front of the animal's nose, and then 
under the lower jaw; thus bringing the halter into its proper place (see Fig. 23). Nothing now remains except to withdraw the pole, on doing which, the operation will be complete (see Fig. 24). Care should be taken not to bring the pole under the lower jaw before the nose-band is in front of the ears; for, if it remains behind them when the end of the stick is brought down, the horse will be lassoed, not haltered. The precautions necessary to be taken in

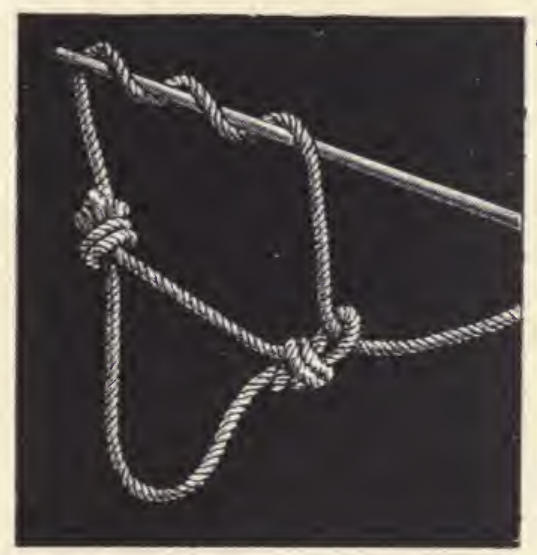

Fig. 21.-Rope halter, put on pole to halter horse.

haltering the horse will depend on the amount of his vice, or timidity. A horse can be thus caught best when he is standing in the corner of a wall which is too high for him to look over. In a circular enclosure, the animal will be able, by turning round, to defeat the intentions of his would-be captor much more easily than he could in a rectangular one. In a roped-in arena, the horse can get his head away from the halter easier than he could do when close to a wall. There is no fear of a horse, however vicious he may be, attacking the operator, if the man keeps the pole across the animal's face, ready, if need be, to give him 
a tap or two on the muzzle. The larger the enclosure, the less inclined will a horse be to "savage" anyone approaching him. In extreme cases, a blow on the forehead might be necessary. I may mention that the brain is covered at the forehead by only a thin plate of bone. Mr. O. S. Pratt, the American "horse-tamer," gives in his book a

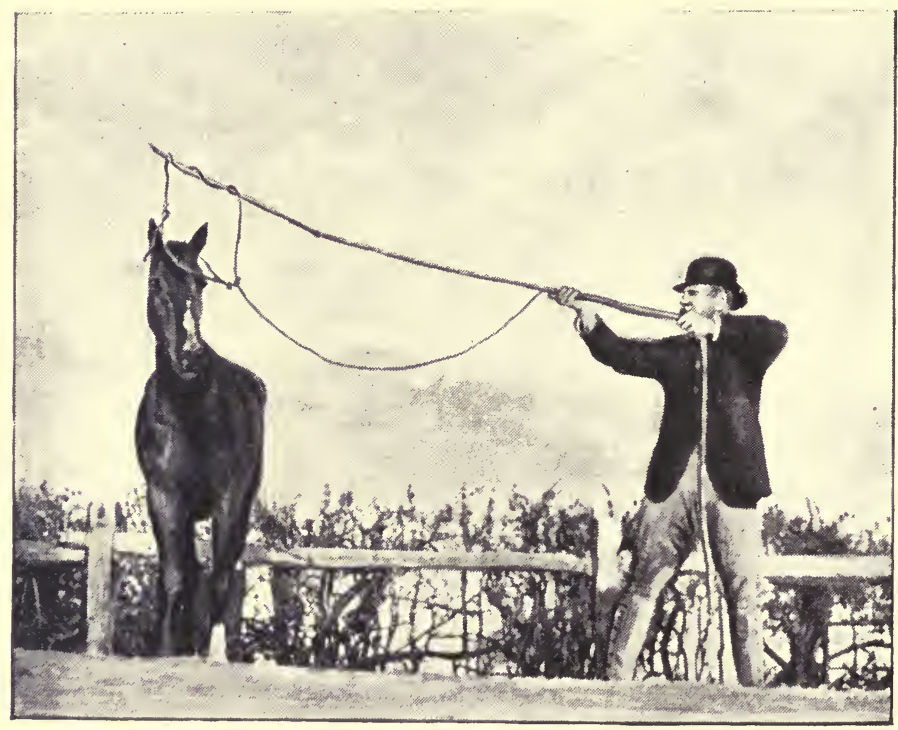

Fig. 22.-Haltering loose horse.

method for haltering a loose horse by putting the crownpiece of the halter on the end of a pole (see Fig. 25). In applying this, the horse is very apt to shy away from the halter, which has to be put on from the front. I have found from experience that the manner of haltering which I have described, and which was shewn to me by Mr. G. A. Banham, F.R.C.V.S., is much better than Pratt's plan. 
TEACHING A LOOSE HORSE TO COME UP TO AND TO FOLLOW US.

If a horse is difficult to catch when loose, we may make him come up to us, by putting him in a suitable enclosure, and then cutting him with the lunging whip-which may

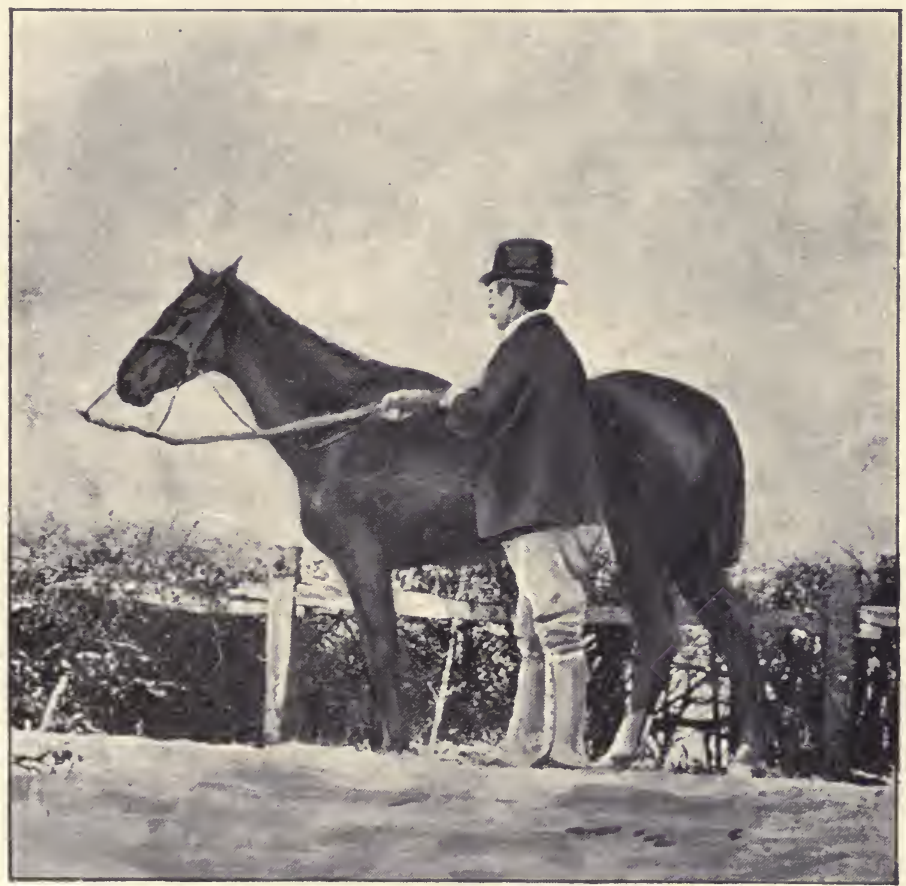

Fig. 23.-Haltering loose horse.

resemble the long whip used in circuses for regulating the movements of horses, or that employed by carters-below the hocks whenever he presents his hind-quarters to us. Having got him into a corner, we should prevent him from escaping out of it, by showing him the point of the whip. As soon as he understands that he exposes himself to 
punishment by turning round, he will abstain from doing so, and can be readily induced to stand still by the point of the whip preventing him from getting away; and, by the fear of punishment, from turning round. By a few dexterous flourishes of the whip we shall have no difficulty in making him come up to us, so as to avoid punishment. He should then be rewarded by having his crest scratched by the end of the whip, and, if he will take it, by being pre-

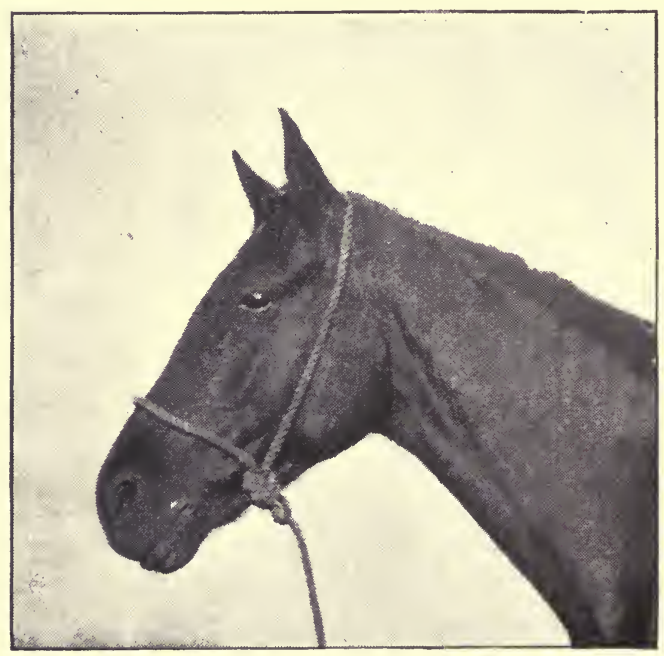

Fig. 24.-- Rope halter on horse.

sented with a carrot or other dainty. By working in this manner, while we continue to walk backwards, we can easily teach him to follow us. After a time, by merely raising the whip, he will run up to us, so as to avoid being hit with it. The foregoing method is the one which is practised in circuses.

Note.-Care must be taken that this is not practised in an enclosure, such as a loose-box where there are any projections from the wall, as for instance a ring or manger, 
for the horse may strike his head against the ring or bang his knees against the manger when the whip is used.' As there are these dangers I would put on knee-caps and try to arrange all safely, but would not discard this lesson, as I consider it one of the most useful for inspiring respect. It also saves trouble; because afterwards, when you enter the loose-box with the harness, etc., you can call the horse

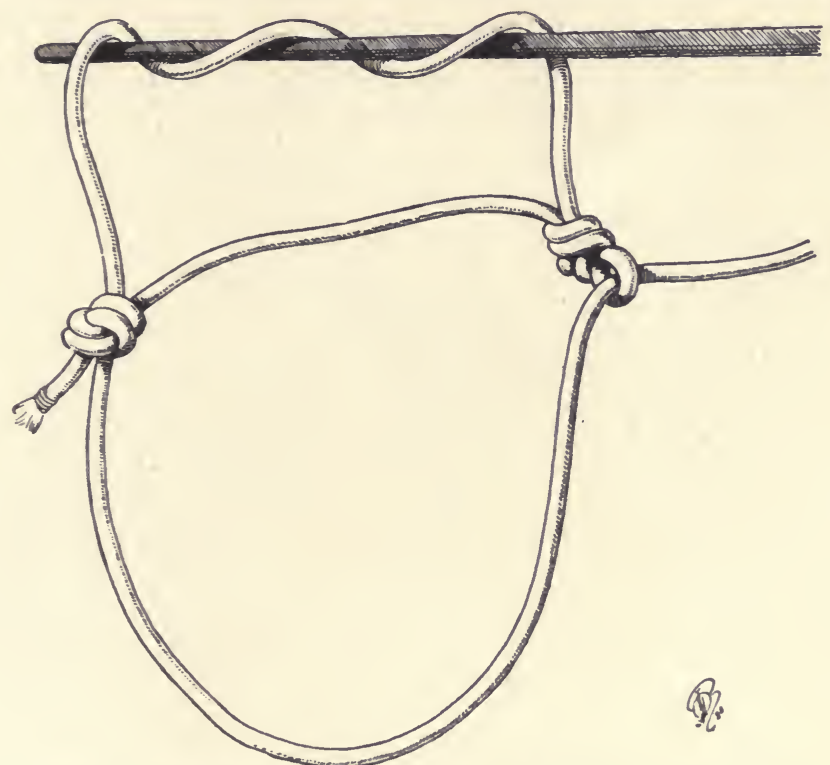

Fig. 25.-Pratt's method of putting halter on pole to halter horse.

up to you to stand quietly while you put the things on to him.

This treatment should appeal to a horse very strongly, for when a strange horse is turned into a field amongst others, one or two of the leading spirits will always come up to him and try conclusions in a kicking match, in much the same way as the new boy has to find his own level with his fists when first sent to school, and in both these cases we know the winner is afterwards treated with the utmost respect. 


\section{LIFTING UP A FORE LEG.}

Having haltered the horse, we may, in order to gain further control over him, take up a fore leg in one of the following ways :-

I. If we are afraid that the horse on our approaching him will "strike out" or kick, we may, as Colonel Rawlings, R.H.A., showed me, form a noose about two feet and a half in diameter, with a rope ; and having laid it on the ground, give the free end to an assistant to hold. We may then

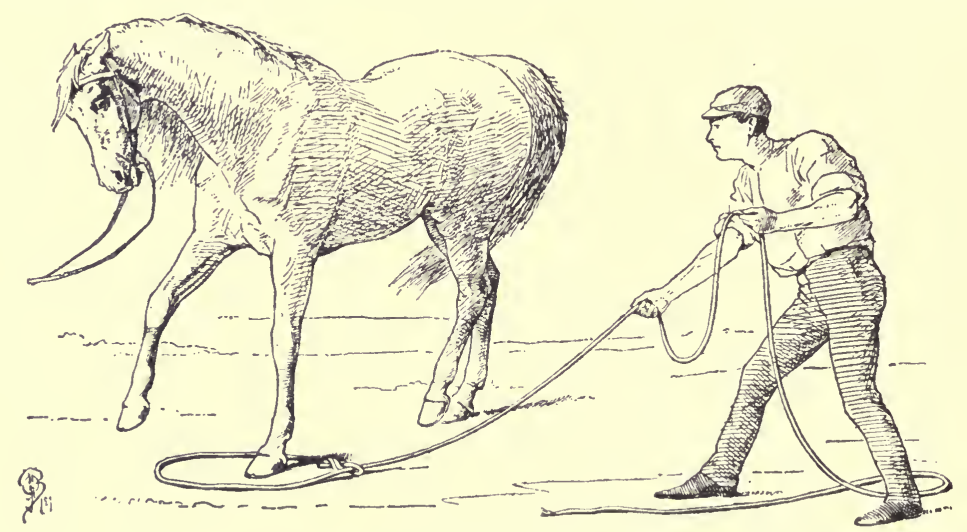

Fig. 2.--Noosing horse's fore leg.

make the horse move about until he places one fore foot within the noose (see Fig. 26), when the assistant should pull the rope, and thus lasso the pastern. Or a rope with a loop at one end of it may be worked round the near fore leg (supposing we are standing on the near side) by means of a stick, and brought back to the hand; the other end of the rope may be passed through the loop, and the pastern noosed. The end of the rope may now be thrown over the animal's back to the other side, and the leg pulled up (see Fig. 27) and secured by passing the rope round the base of the neck (see Fig. 28); or the leg may 
be pulled back by the rope, and lifted up by another assistant. If the horse "shows fight," it may be necessary to blindfold him at this stage of the proceedings. The long pole may also be called into requisition to "gentle" the horse, and thus render him comparatively quiet. The operator can always quickly accomplish his object, in the manner described, if he will only exercise a little patience.

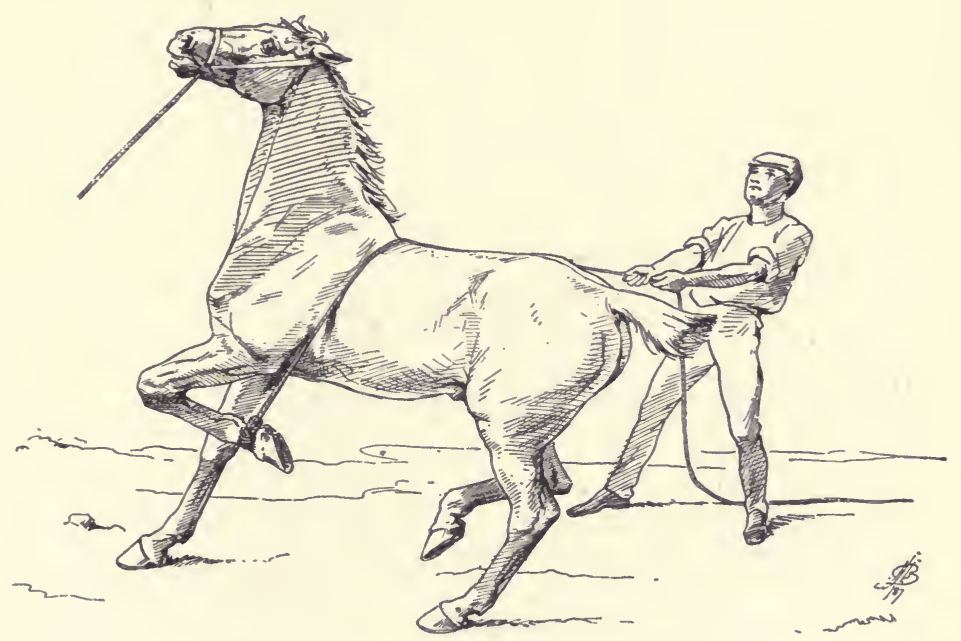

Fig. 27. - Pulling up horse's fore leg with rope.

This method of noosing the leg is similar in principle to that employed in securing the limbs of wild elephants, in India, when they have been driven into a stockade.

2. The best way of pulling up a fore leg with the hand is, as I have found out, to grasp, say, the near fore at the back of the leg and just above the knee, with the left hand ; pinch it with the fingers to stimulate the flexor muscles of the knee to contract; turn the elbow in, and press it against the upper part of the fore arm, so as to throw the weight from the near on to the off fore, and thus render the 
picking-up of the near fore a very easy matter (see Fig. 29). If required, an upward pull is given with the left arm, and the foot is caught with the right hand as the horse lifts it up. I may add that the muscles against which the man's elbow presses, assist in raising the foot from the ground. By this plan the breaker can stand at the side of the leg which has to be raised, and a little away from it, thus keep-

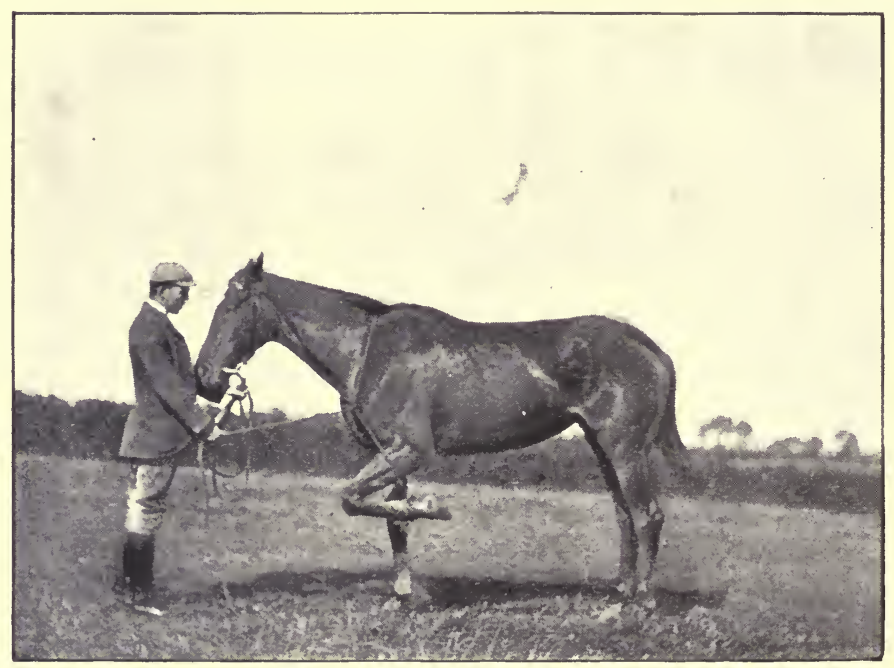

Fig. 28. - Tying up horse's fore leg with rope.

ing out of danger as much as possible. If he tries to lift up the fore leg of a bad cow-kicker by catching hold of the pastern, he will run a great risk of getting hit on the head or body, on account of having to stoop down while standing close to, and a little behind, the fore leg.

3. The usual way carters lift up the fore leg of a heavy draught animal is by catching the hair of the fetlock, and then drawing up the leg. The slight irritation caused by the pull at the roots of the hair will make the horse readily hend the knee. 
HOLDING UP A FORE LEG.

If the fore leg be held up by the hand passing under the fetlock or pastern (see Fig. 30), as is frequently done, the horse, by bearing a portion of his weight on the man's hand,

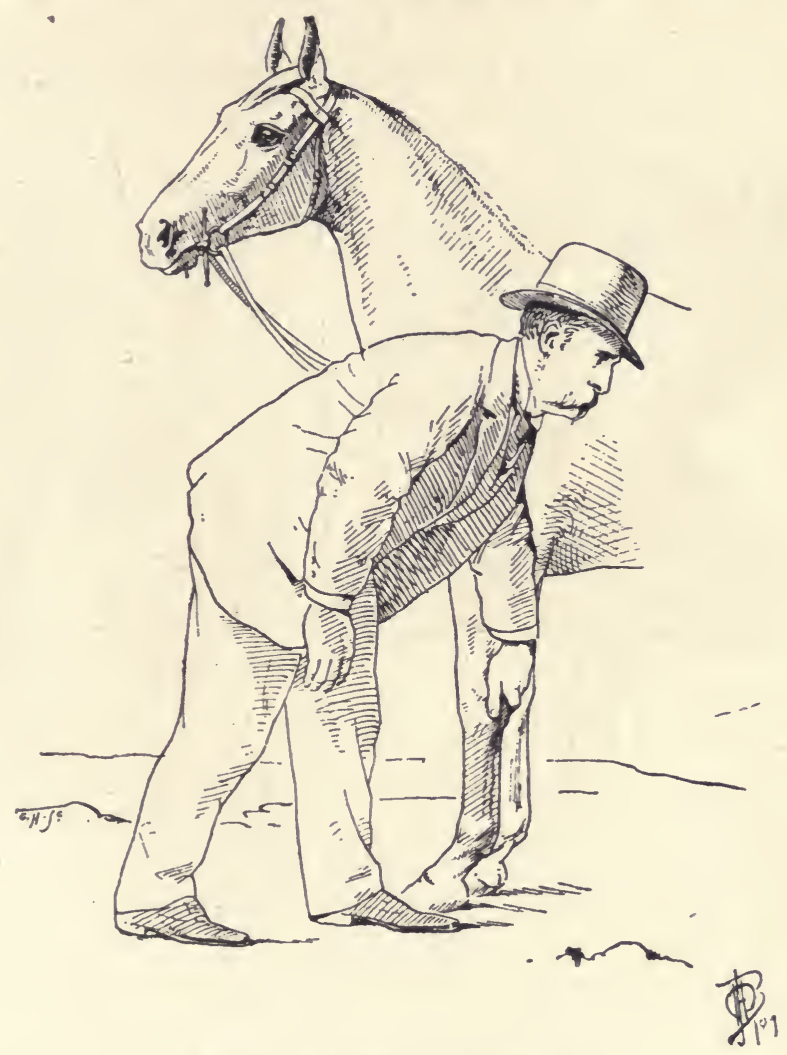

Fig. 29.-Lifting up a fore leg.

can easily kick with either hind leg. The foot of the unshod horse should, on the contrary, be held by the spread-out fingers grasping the front part of the hoof (see Fig. 3I). The shod foot may be held up by the front part of the hoof, under which the fingers pass, while the thumb 
presses down on the sole (see Fig. 32). In either of these cases, the animal will avoid placing weight on the man's hand ; for by doing so, the joints of the foot would become bent in a painful manner.

TYING UP A FORE LEG.

Having "picked up" the foot, we may secure it in either of the two following ways :-

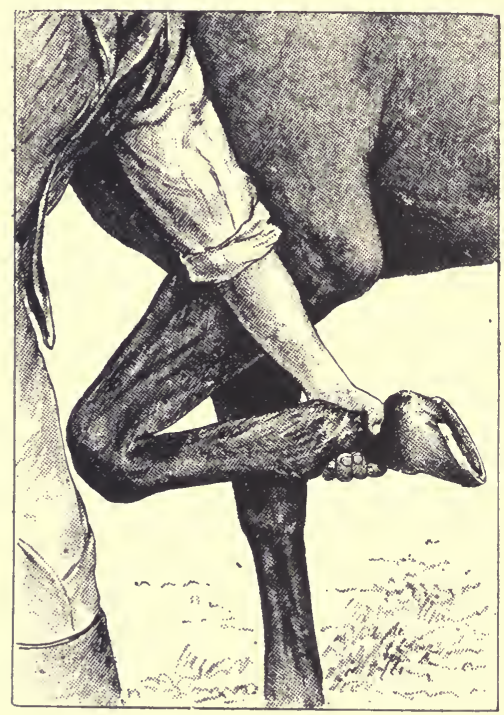

Fig. 30.-Wrong way of holding up horse's fore leg.

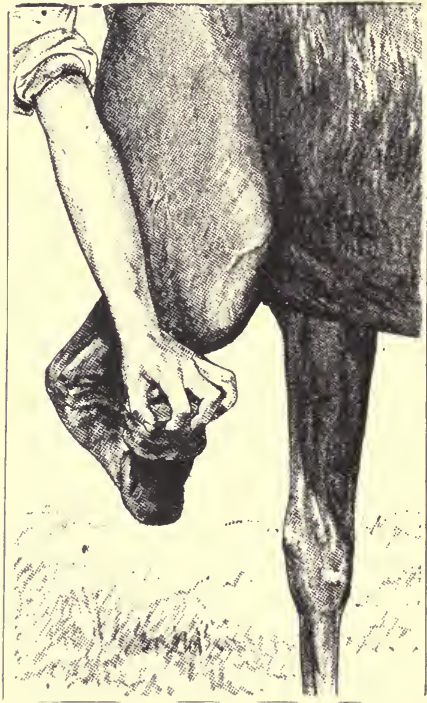

Fig. 31.-Proper way to hold up unshod horse's fore leg.

I. By Rarey's leg-strap, which is about $3 \mathrm{ft}$. long, and is furnished at one end with a buckle, below which a leather "keeper" is placed on both sides (see Fig. 33). To apply it, the free end is passed round the pastern, from the outside, through the keeper at the back of the buckle, thus forming a loop. Another turn is taken round the fore arm, and a second loop is made by passing the end through the buckle. The strap can now be tightened up as may be required, and 
the end run through the second keeper. Figs. 34 and 35 show how this can be done equally well with a stirrup leather, with which two or three turns have been taken round the

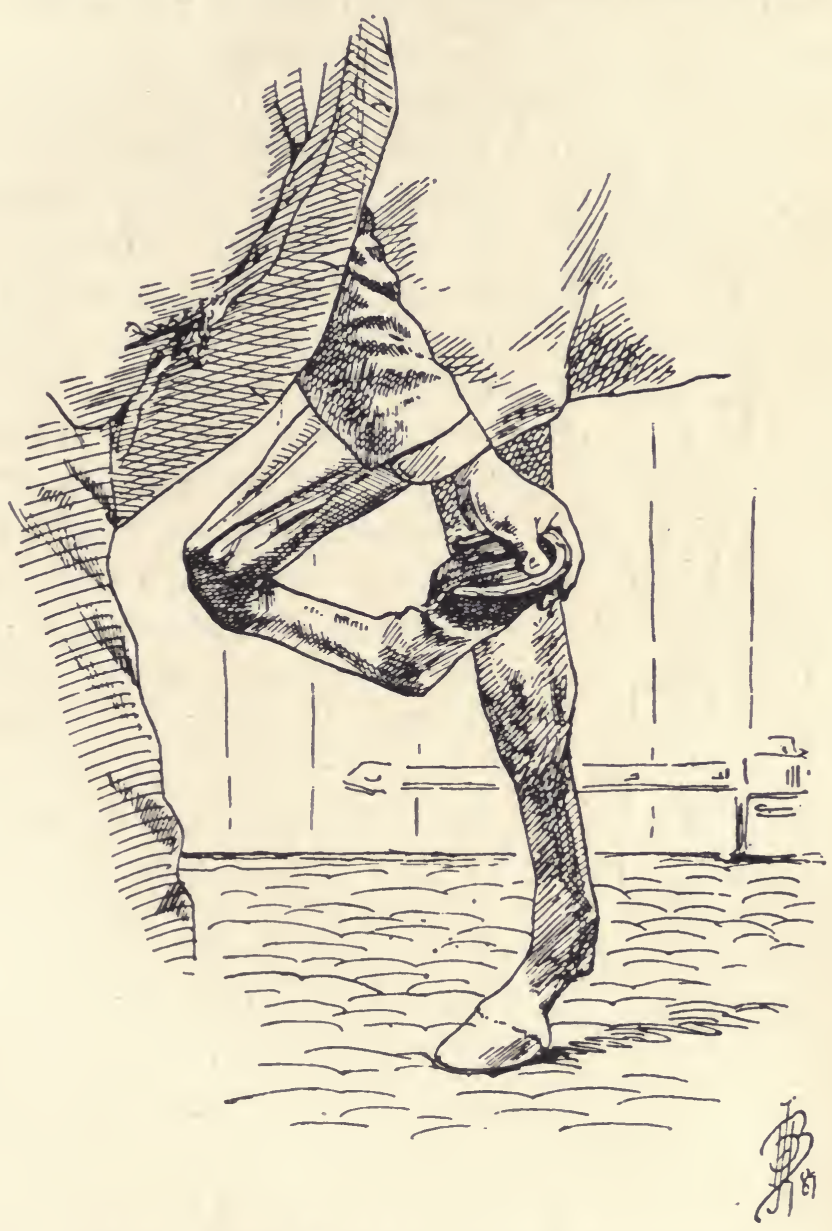

Fig. 32.-Proper way to hold up fore leg of shod horse.",

pastern, so as to bring the punched holes sufficiently near the buckle. The objections to the employment of this method of tying up the leg, whether with a Rarey's strap 
or with a stirrup leather, are: (a) That it is apt to irritate the animal by the compression needed to keep the strap in its place; $(b)$ That, when the leg is thus fixed, the horse, in the event of his "coming down," is liable to hurt his knee ; "capped knee" being the usual result of the injury, on account of the extensor tendon of the knee being at that

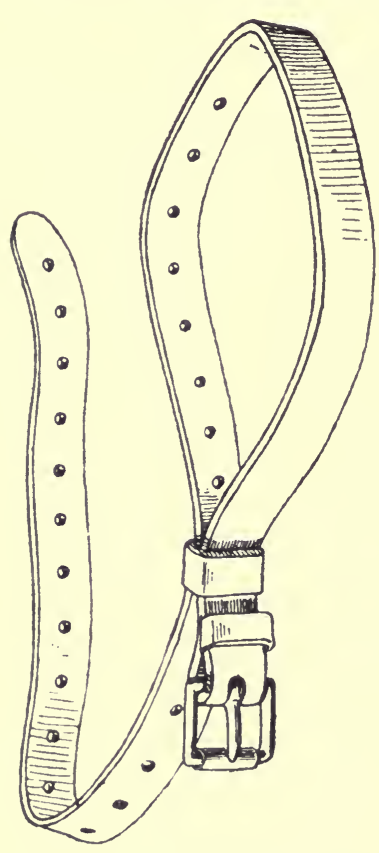

Fig. 33.- Rarey's leg-strap. moment tightly stretched over the part: I have had this accident occur on several occasions, when making horses lie down, even when they had knee-caps on, and when the ground was soft; (c) The heel of the shoe, if the horse be shod, is apt to bruise and cut the elbow; (d) The compression exercised by the strap on the fore arm numbs the leg, and tends to make the animal fall awkwardly, if he is made to lie down; (e) Unless the strap is kept very tight, it is apt to slip down the fore arm, and thus exercise an injurious strain on the fetlock joint.

2. By far the best way for tying up a fore leg is the one described by Mr. Saunders in 'Our Horses,' by which the leg is simply suspended, at any length required, from the surcingle. Mr. Saunders advises the use of a small loop to connect the surcingle and strap together (see Fig. 36), with the object, I presume, of keeping the limb in a plane parallel to the general direction of the horse's body. This is certainly an advantage when making a horse lie down; although I have found, for ordinary purposes of control, that the employment of the small loop may be dispensed 
with, and the leg-strap passed through the surcingle or girth. This method of suspending the leg is very useful when gentling the fore limb, and when shoeing a "difficult " animal ; as the foot can be retained at any convenient height from the ground without irritating the horse, and, consequently, without inciting him to "fight."

I have learned, on more than one occasion, by painful experience, that it is possible for a horse to effectually cow-kick with the hind leg of the side on which a fore leg is tied-up.

A stirrup leather, with two or three holes punched at convenient distances, will, as I have said on page II3, make a capital leg-strap (see Fig. 34). It has the advantage of having, at the back of the buckle, no leather keeper, which is always liable to give way, by reason of the strain exerted on it.

For suspending a fore leg, we need punch no extra

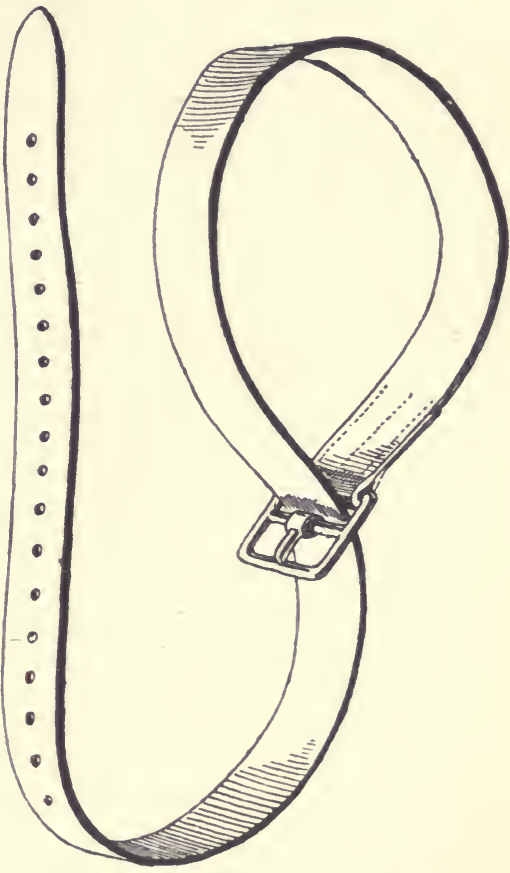

Fig. 34.-A stirrup leather utilised for tying up a fore leg. holes in the stirrup leather, if we take, as already described, a few turns with it round the pastern, before passing its end through the lower part of the buckle. An ordinary stirrup leather would, therefore, require a few seconds longer to apply, than if more holes had been punched, which it is prudent to do, in order to save time, if we have got to tie up the leg of a difficult or dangerous horse. 
Note.-If we use a stirrup leather for fastening up a fore leg, it is perhaps best to buckle it so tightly that the foot remains near the elbow; then the horse, on trying to free it, cannot strike the foot against and injure the other knee.

\section{BLINDFOLDING A HORSE.}

After the animal has been secured in the manner described, or after he has been simply haltered, a further step in the process of rendering him helpless may be taken by throwing a rug or other convenient cloth over his head, and then applying the rope-twitch (see page I20). If he be dangerous to approach, the rug may be placed on the end of a long pole, and then brought over his head, or a blindfolding halter may be put on, now, or in the first instance. This appliance is, I believe, of French origin. It consists of an ordinary headstall, with a cloth filling up the space between the cheek-pieces, brow-band, and nose-band, so as to cover the horse's eyes.

Blindfolding is an efficient means of control with the majority of horses; although it excites some to offer more vigorous resistance than they would otherwise do. I have never found a horse which would, when blindfolded, attempt to kick or strike out on the chance of hitting his man, unless he was touched about the limbs or body; nor bite, whether touched or not, under similar circumstances. I therefore think that the breaker runs no risk whatsoever in going up to the animal's head when it has thus been temporarily deprived of sight, no matter how vicious the horse may be.

\section{THE HALTER-TWITCH.}

With an ordinary halter, or with the improvised halter which I have shown in Fig. I9, the breaker may apply a modification of the rope-twitch (see page r20), by making 


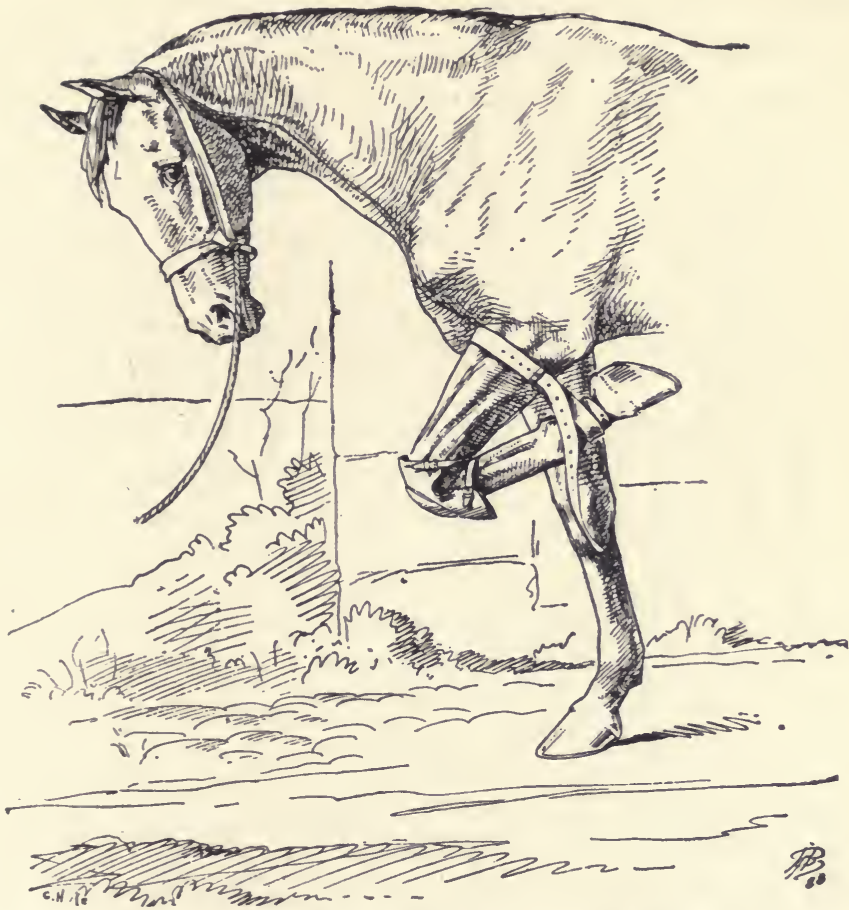

Fig. 35.-Tying up fore leg with stirrup-leather.

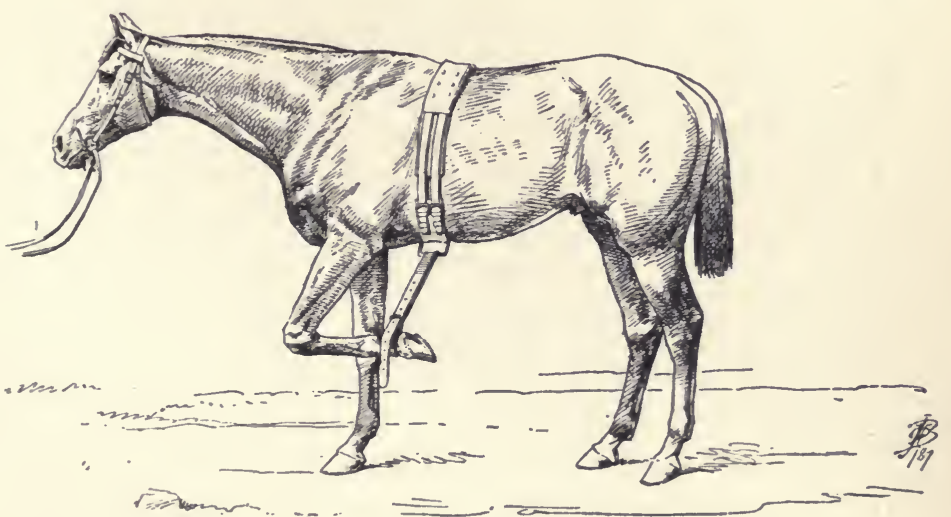

Fig. 36. - Suspending horse's fore leg to surcingle 
a half-hitch with the free part of the rope of the halter, passing the loop over the ears (see Fig. 37), bringing the lower part of the loop under the animal's upper lip, and then pulling it tight (see. Figs. 38 and 39). He may jerk

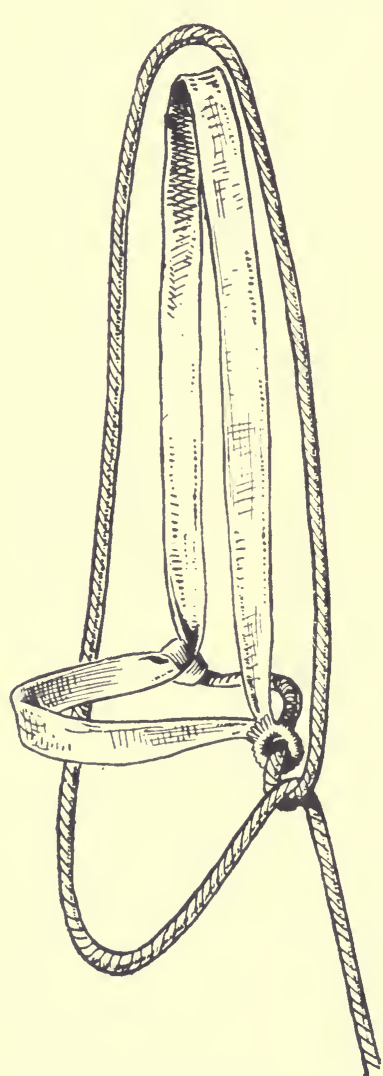

Fig. 37.-Halter-twitch. the rope (leading rein) three or four times, accompanying the action on each occasion with the word "steady!" The part of the rope which passes under the upper lip should be kept slack, except when the jerk is given, and that any other suitable word may be substituted for that of "steady!" No horse, when thus secured, will attempt any aggressive movement towards the man who holds the leading rein. The rope may be jerked and the word "steady!" used as may be required. The pain inflicted by the application of this twitch is a necessary evil which may well be disregarded; for its amount is trifling in comparison with the extent of control obtained by its means. If employed carefully, no mark need be left on the mucous membrane. The proper use of this twitch is thoroughly rational; for it keeps the horse quiet by its deterrent effect, and not by retaining him in a continued state of suffering, as is done by the ordinary twitch. The word "steady!" or any convenient substitute for it, should never be omitted; for after the animal has learned, as he will do in a minute or two, to connect it with the idea 
of pain, the twitch may be removed, and the word alone used, in order to keep him in subjection. In this experiment, it is evident that the horse fears the word, and not the twitch ; for, no matter how often the rope is put on, he will not resent its application more than he did on the first occa-

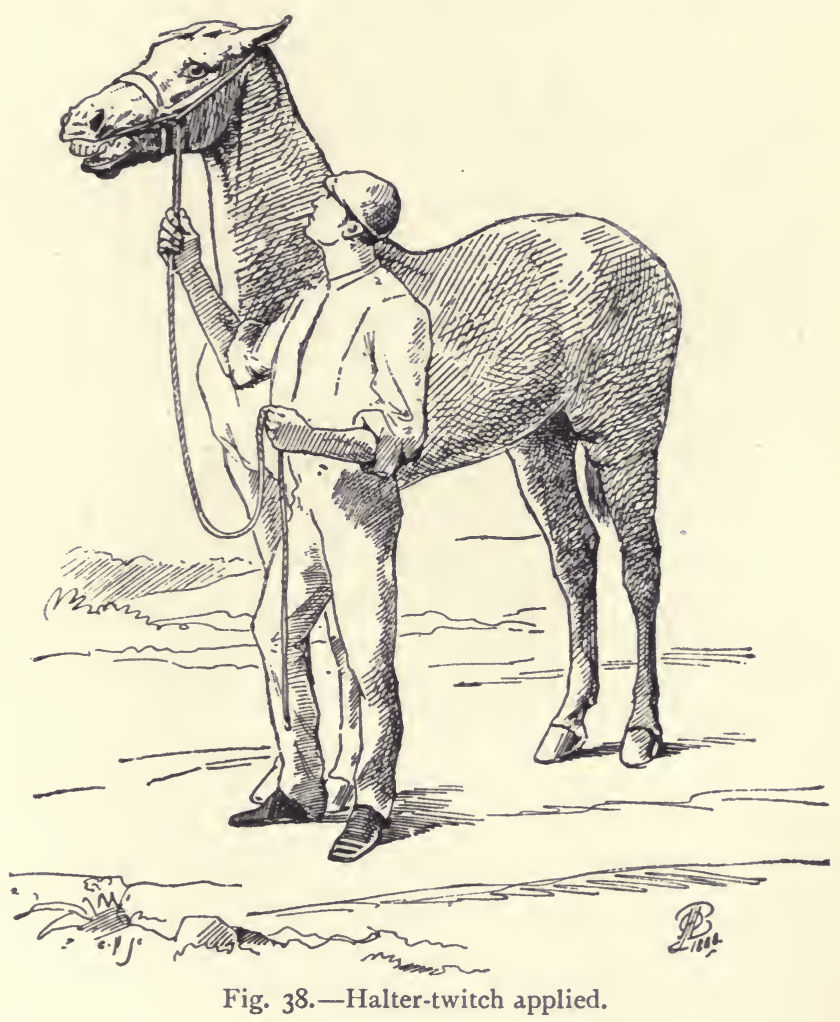

sion. The oftener, on the contrary, the ordinary twitch is employed, the shyer will the animal become of having his muzzle touched. The chief advantages of the halter-twitch, or of the rope-twitch (which is the more effective appliance of the two), over the ordinary twitch are: that it can be easier procured and applied; it does not inflict so mụch 
pain, which, with it, is momentary, and not continuous, as with the other; it is not so liable to slip off; it can be retained in position for any reasonable length of time, to be used as required; it has a good effect on the horse's temper, and not a bad one, like the ordinary twitch ; by its application we can dispense with its use in favour of a simple word of command; and it does not make the horse shy of having his muzzle or mouth touched. The fact of numbers of horses being rendered difficult to bridle by the

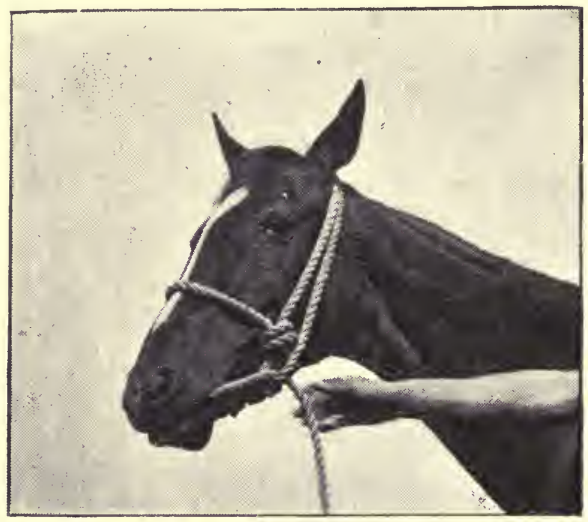

Fig. 39.-Halter-twitch applied.

employment of the ordinary twitch will naturally occur to the reader. The general substitution of the rope-twitch (see following paragraph) for the ordinary one is highly desirable. I may point out that if, when the ordinary twitch has been twisted up tightly, its stick be struck or jerked, on the animal moving, it will doubtless have a deterrent effect, as well as that produced by the needless infliction of continued pain.

THE ROPE-TWITCH.

Everything I have said in the preceding paragraph in fagvour of the halter-twitch, applies still more strongly to 
the rope-twitch, described in Mr. O. S. Pratt's book, "The Horse's Friend," which was published at Buffalo in 1876 . Mr. C. G. Frasier, who was Pratt's assistant for some years in America, tells me that this twitch was not invented by Pratt, long before whose time it was in use. He thinks that it was probably the idea of the "horse-tamer," Fanchion, who practised his art many years ago in the States. Pratt calls it "the double-hitch Bonaparte bridle." It is made as follows: take a rope and make a simple knot with it at one end, at a distance of about eighteen inches from which make another knot loosely, and pass the first knot through the second, so as to. form a loop which will not draw tightly (see Fig. 40). Make a halter by taking a turn of the rope through the fixed loop (see Fig. 4I). Place this halter over the horse's head, and the loop in his mouth. Make a half hitch with the free part of the rope,

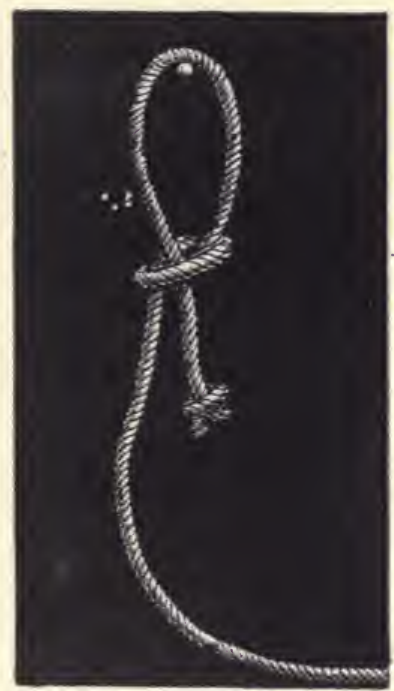

Fig. 40.-Noose which will not "run." pass it over the horse's head and under his upper lip, and draw it moderately tight (see Figs. 42 and 43). By making the fixed loop long, one can obtain more power than with the halter-twitch.

If there be much difficulty in applying the rope-twitch, the best plan, as I have found, is to try the effect of the noose-twitch (see following paragraph). Or the horse may be tied head and tail (see page I55), and it can then be put on without trouble; the animal being, of course, released immediately after this is done, 


\section{THE NOOSE-TWITCH}

(see page I65) is applied by means of a rope, at one end of which a loop that will not run (see Fig. 40) is made. The other end of the rope is thrown over the upper part of the horse's neck and passed through the loop; a stick with a crooked handle being utilised if necessary. While keeping

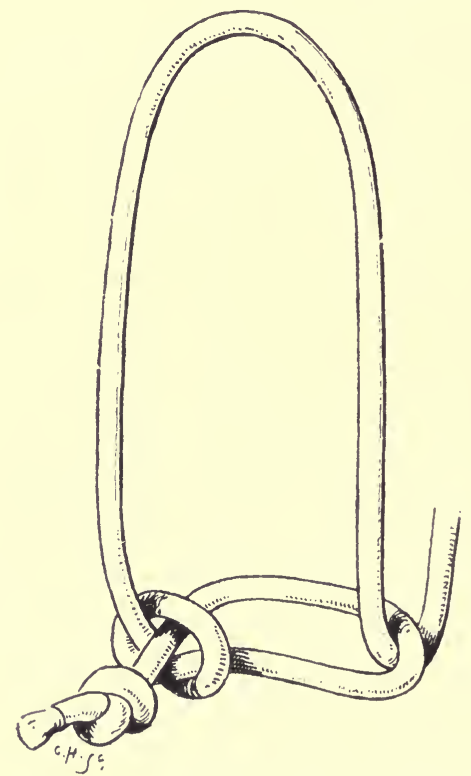

Fig. 41.-Pratt's twitch, first portion.

the fixed loop high up on the animal's cheek, the noose is manipulated so as to come under the upper lip, when it should be drawn tightly (see Fig. 44). It may be used in the same manner as the rope-twitch or the halter-twitch.

THE HEADSTALL-TWITCH.

Fig. 45 will explain this ready and effective method of applying the twitch. The rope is passed through the upper ring of the cheek-piece of the head-stall, and is tied on to 
the lower ring. The turn over the ears and under the upper lip is then taken, with the portion of rope which, after being drawn out, is included between the two rings.

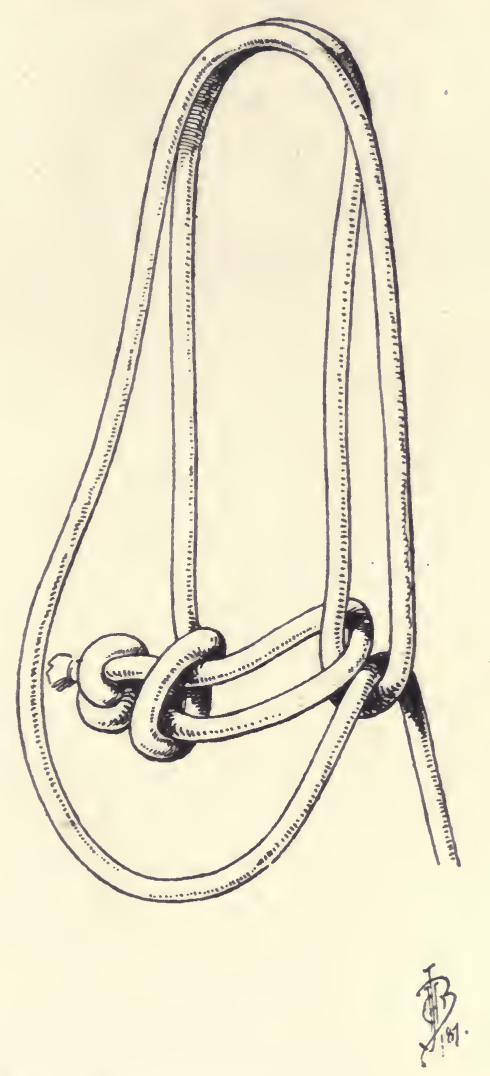

Fig. 42.-Pratt's twitch completed.

THE BRIDLE-TWITCH.

This is a useful and ready means for making the horse stand quietly after he has been bridled, and is applied by passing one of the snaffle-reins under the upper lip, and 


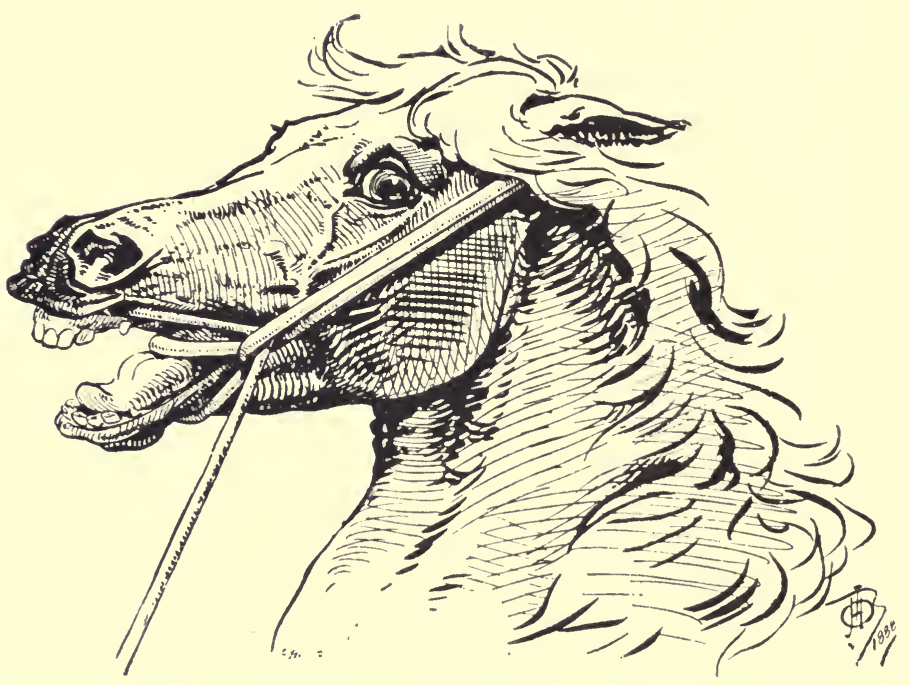

Fig. 43.-Pratt's twitch on horse's head.

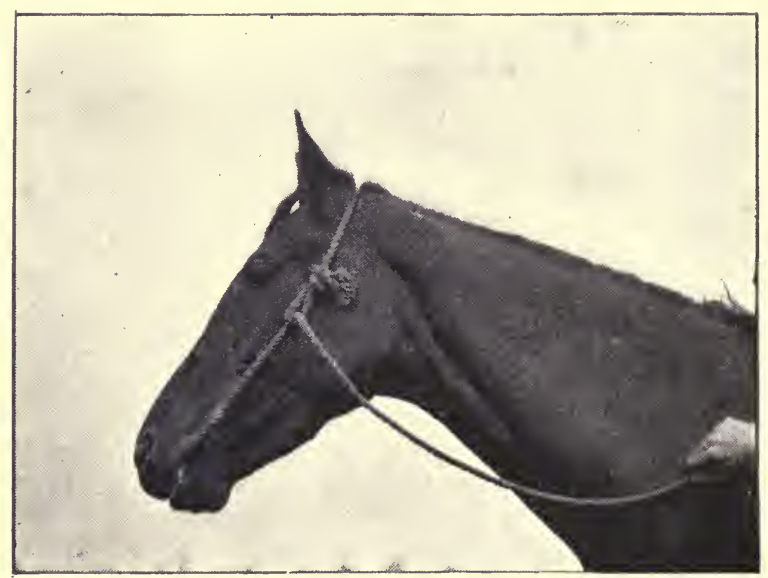

Fig. 44.-Noose-twitch. 
drawing it tightly to the opposite side (see Figs. 46 and 47). I was shown this twitch by Mr. Esa, of the firm of Shaikh Ibrahim and Co., Poona, India.

\section{THE INDIAN WAR BRIDLE}

is a kind of twitch which appears to have been invented by the North American Indians many years ago. To apply it, make a loop which will not run (see Fig. 40) at the end

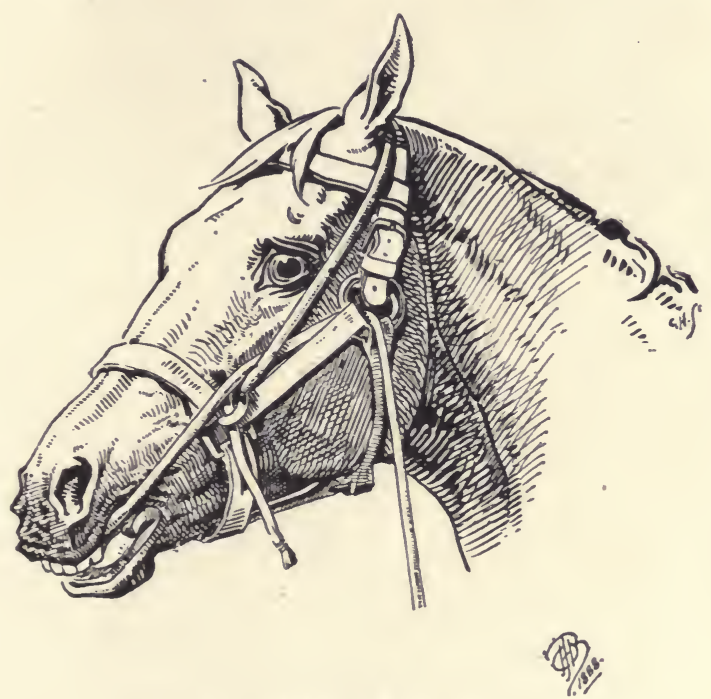

Fig. 45.-Headstall-twitch on horse.

of a rope ; place this loop in the horse's mouth ; pass the other end of the rope over the animal's neck from the off side (supposing that the operator is on the near side) and through the loop; tighten the rope, so as to make the horse draw his head in, and fix it by a running knot. It will then form a very severe means of restriction (see Figs. 48 and 49 ), by reason of the painful pressure which the rope will exert on the bars of the mouth. It can be loosened in a moment by pulling on the free end of the rope. I have 
given up the use of the Indian war bridle; because its effect, like that of the ordinary twitch (see pages II9 to I2I), is due to the continued infliction of pain.

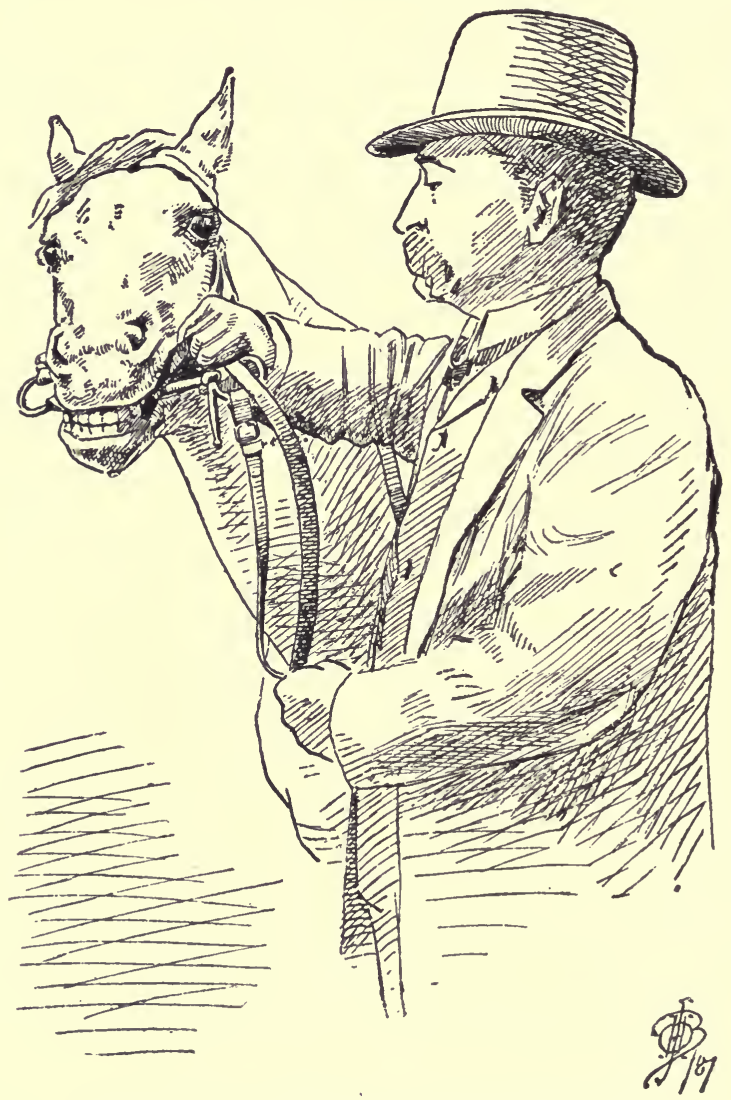

Fig. 46.-Bridle-twitch, front and near-side view.

THE COMANCHE BRIDLE

is the name given in America to a kind of gag which is made as follows: Tie one end of a rope round the horse's neck, close to his head, in such a manner that the noose thus formed will not "run" (see Figs. 40 and 50). Pass the 
other end through the horse's mouth from the off side, and through the loop on the near side (see Figs. 5 I and 52). By pulling the horse by the free end of the rope to one side and then to the other, we can quickly teach him to lead or follow.

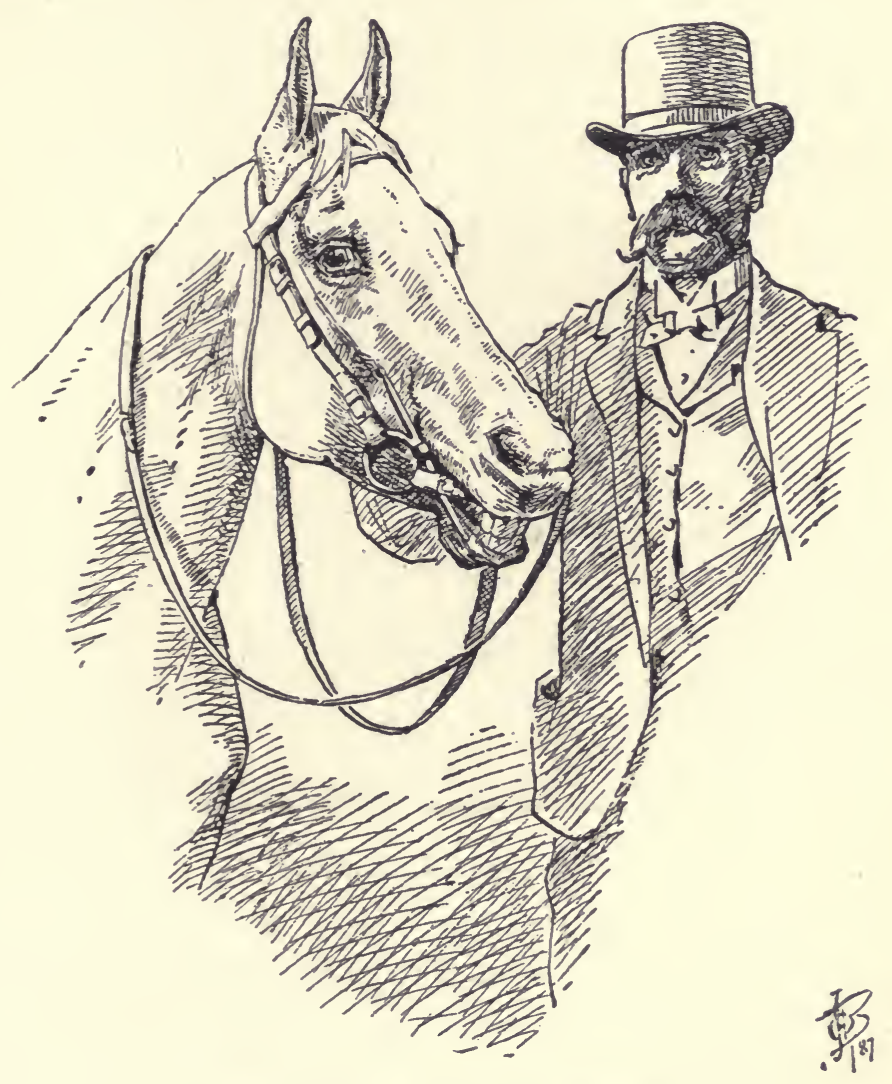

Fig. 47--Bridle-twitch, off-side view.

The principle upon which it acts appears to be that the animal obtains relief from painful pressure by the rope on the corners of his mouth the moment he approaches the man who is pulling at the end of the rope, and consequently 
accepts the pull (or word accompanying it) as a signal to follow. j

\section{THE CAVESSON,}

which consists of a strong leather headstall with a heavy leather-covered noseband, is largely used in Continental riding-schools as a means for making horses steady to handle, mount, lead, etc. Its effect is produced by the

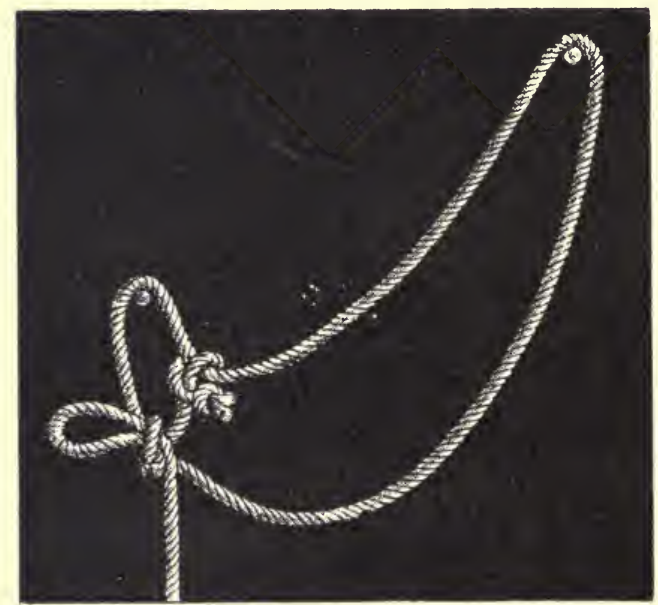

Fig. 48.-Indian war bridle.

breaker jerking the leading rein which is attached to it, so as to inflict blows of varying intensity on the nose as a punishment for disobedience. As its application tends to render the animal difficult to handle about the face, and as its results, with the single exception of teaching a circus horse to circle (see page 342), can be better obtained with the rope-twitch; I would not advise its employment in the breaking in of horses, except in the one case just mentioned. 


\section{STRेAIT-JACKET.}

THE STRAIT-JACKET.

For English readers, I venture to apply this term to the hippo lasso of MM. Raabe and Lunel. It consists of a

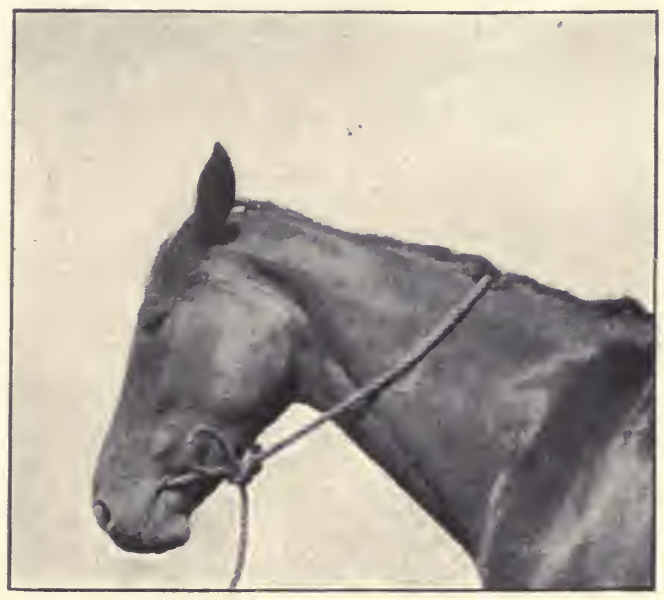

Fig. 49.-Indian war bridle.

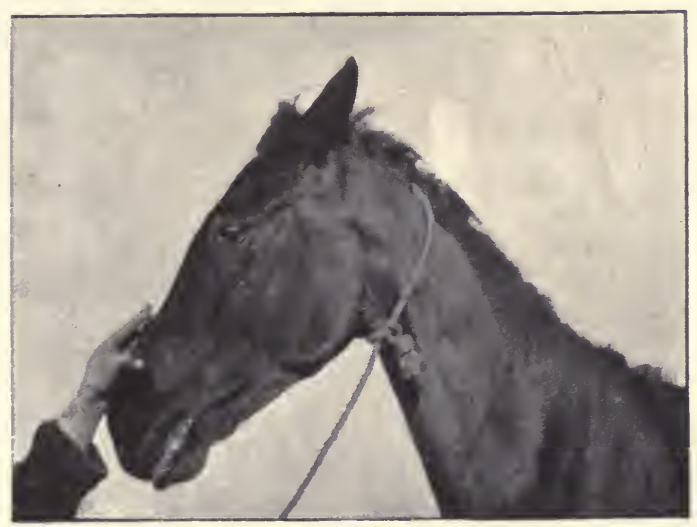

Fig. 50.-First part of Comanche bridle.

breeching and breast-band, supported by straps passing over the back, and connected by traces, which proceed from 
the breeching, through Ds, with rollers on them, at the end of the breast-band, back again through similar Ds on the breeching, and then forward, to become finally attached to buckles on the sides of the breast-band (see Fig.53). A strap and buckle, laid along the top of the back, connect the two back-straps together. A piece of felt may be used with the supporting strap of the breast-band, as a guard to pre-

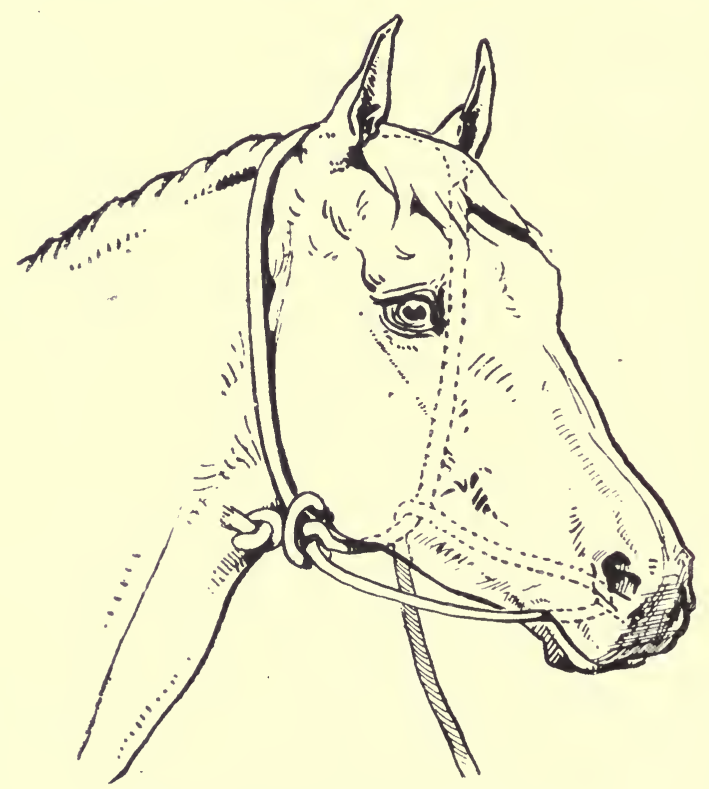

Fig. 51.-Comanche bridle, off side.

vent the strap hurting the back. The breeching should be lined with felt; the back-straps should be made of strong stirrup leather, and the traces should be particularly strong close to the breeching. The breeching and breast-band should be provided, at their respective centres, with a D, to which ropes may be attached in order to keep the animal steady before and behind.

This gear may be applied in the following way: If the 
horse is quiet, the breast-band and breeching may be put on separately, with the back-straps supporting them, and may be connected together by the strap on the top of the back, and by the traces on each side. The breast-band should rest high up against the fore arms, and the breeching behind and a little below the level of the stifles (see Fig. 54).

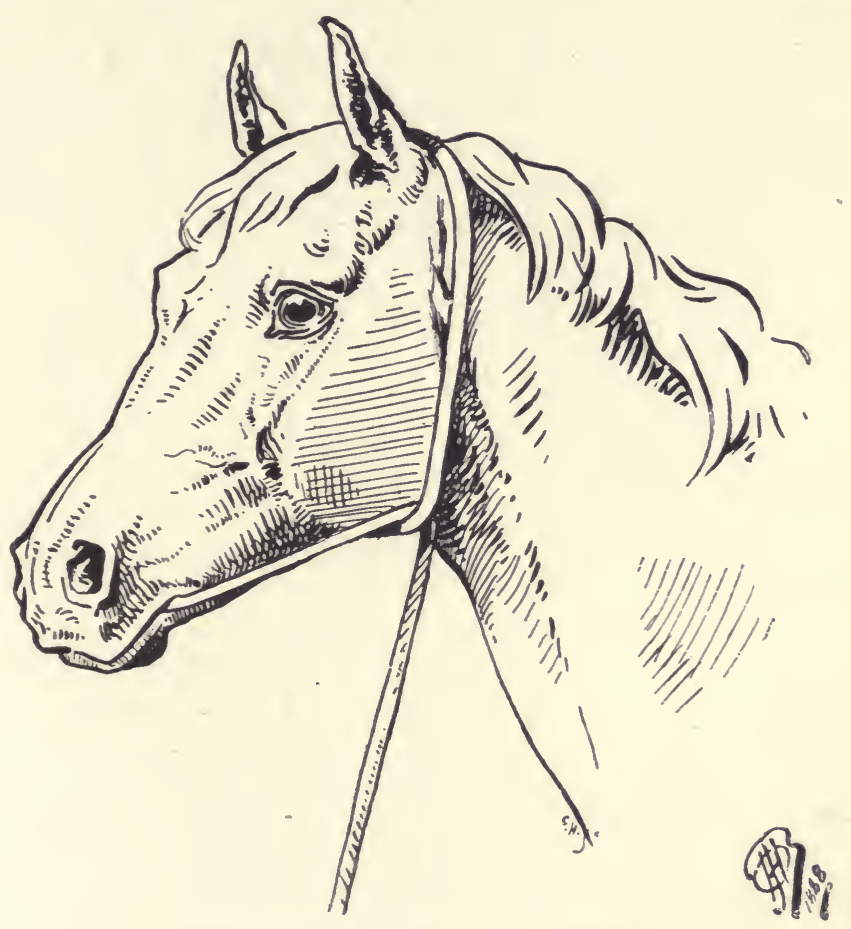

Fig. 52.-Comanche bridle, near side.

If the animal be dangerous to handle only behind, the breast-band may be put on and the breeching attached to it in the manner just described; but without putting it over the quarters. A rope can now be fixed to the $\mathrm{D}$ in the centre of the breeching, which, by the aid of the rope, can be pulled over the croup into its proper position by an 
assistant from behind. Before doing this, the traces should be let out, to be pulled tightly the moment the breeching slips over the tail. In this and other cases of difficulty, ropes may be attached to the ends of the traces, so that the assistants who hold them need run no risk of getting kicked.

When the horse strikes out as well as kicks, the different parts of the strait-jacket may be connected together, with the exception of, say, the near trace, the end of which may
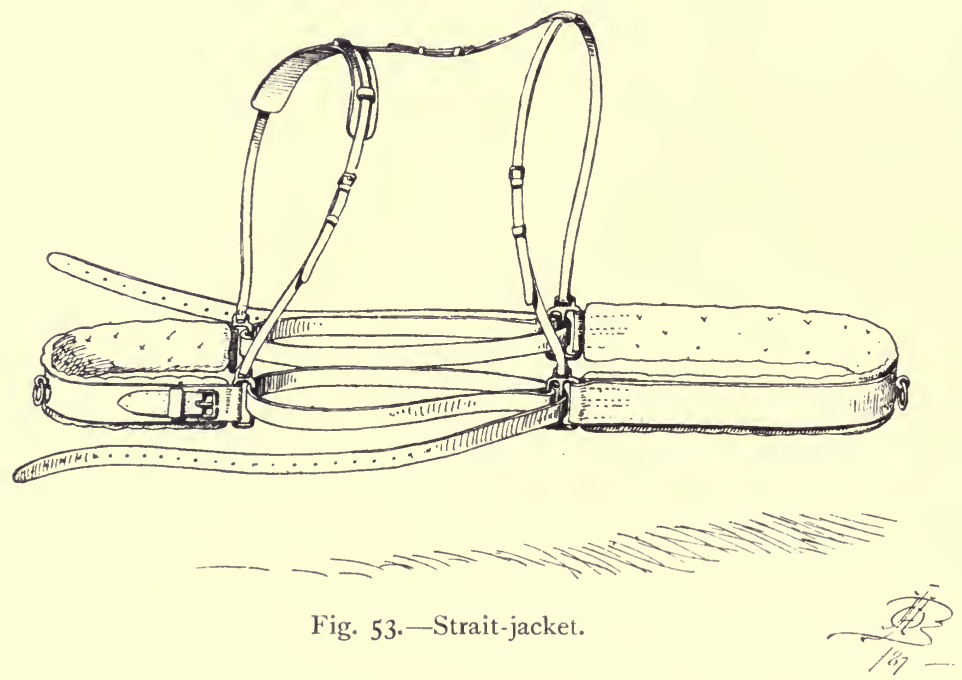

be held by an assistant while another helper holds a rope attached to a D which is on the near side of the breastband. The loop formed by the breast-band and its backstrap is now passed over the horse's neck, the end of the near trace passed through the near side $\mathrm{D}$ of the breastband, and the remaining fixings accomplished. If the animal be not very violent, the gear may be connected together, the loop made by the breast-band and its backstrap passed over the head and neck, and the breeching pulled over the croup by a rope. 
If the precaution of putting on the rope-twitch be taken, no difficulty need be experienced in subsequently applying the strait-jacket.

\section{LIFTING UP A HIND LEG.}

The usual " confidential " method for lifting up a horse's hind leg, the near one for instance, is, while standing by the side of the near quarter, to run the left hand down the limb, take hold of the canon bone with the fingers pointing to the rear (see Fig. 55), and pick the leg up. Or we may run the

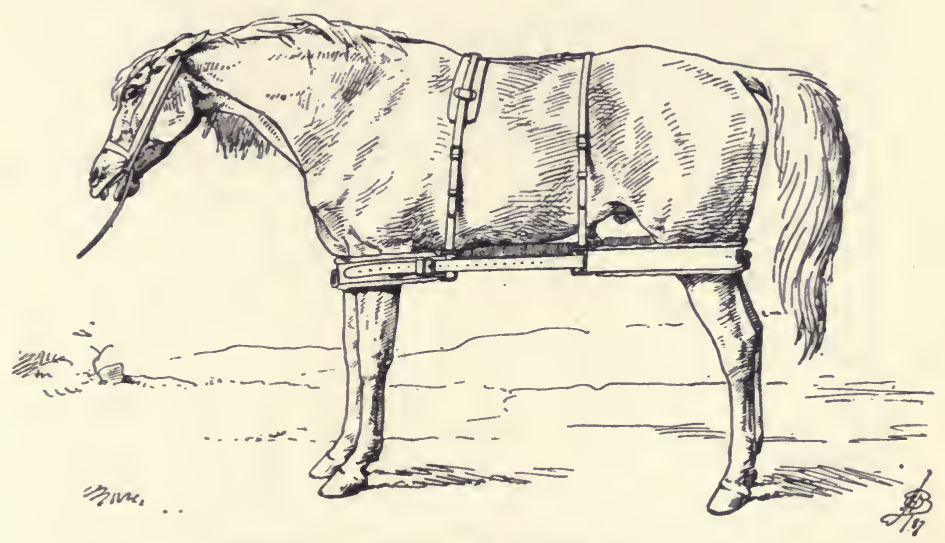

Fig. 54.-Horse with strait-jacket on.

right hand down the leg, place the flat of the hand on the back tendons (see Fig. 56), and lift up the leg by drawing it forward. If we have any doubt as to the steadiness of the animal, we may, while standing clear of the forward action of the hind leg in the event of the horse cow-kicking, and while pressing the left fore arm against the quarter, so as to avoid the chance of being struck, run our left hand down the leg and catch the tendo Achillis (the hamstring), our grip on which will more or less prevent the animal from bending his hock and "lashing out" behind, if he is so inclined. We may then catch the pastern, back-handed, 
with the right hand (see Fig. 57); lift the leg; and place it resting on our left thigh (see Fig. 58). If we have an assistant, we may get him to hold up the near fore leg, as well as to hold the horse. As soon as we get our left hand on the hamstring, and our right hand on the pastern, we should tell him to let go the near fore, and we can then try to lift up the hind leg as before described.

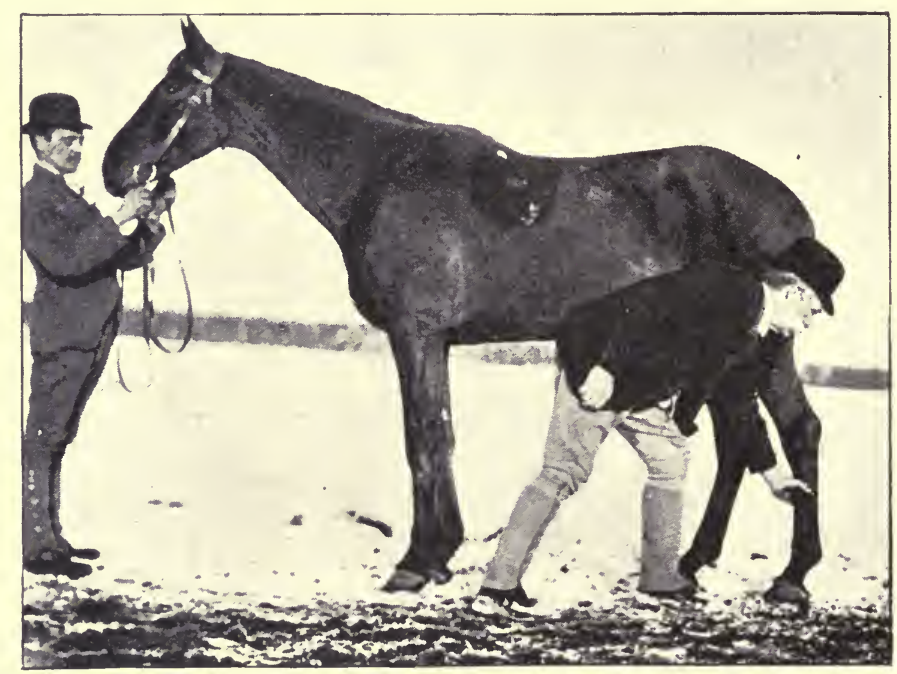

Fig. 55.--Lifting up horse's hind leg.

If we have no one to hold up the near fore, we may " pick it up " with the left hand; grasp the toe of the hoof with the right hand, while facing to the horse's rear (see Fig. 59) ; take a step forward with the right foot; catch the hamstring with the left hand (see Fig. 60); let go the near fore; at the same moment, seize the pastern, back-handed, with the right hand (see Fig. 57) ; and place the horse's leg on the left thigh (see Figs. 6I and 58). This method, which I believe I have been the first to devise, ensures almost compiete immunity 
from danger. As long as we have hold of the fore hoof with the hand, we can get forward out of danger if the horse tries to kick. The grasp of the left hand deprives the hind leg of the greater part of its action, and the hind pastern is caught so quickly after, even if not before, the near fore reaches the ground, that the animal has not time to make an offensive movement. By catching the pastern in the way described,

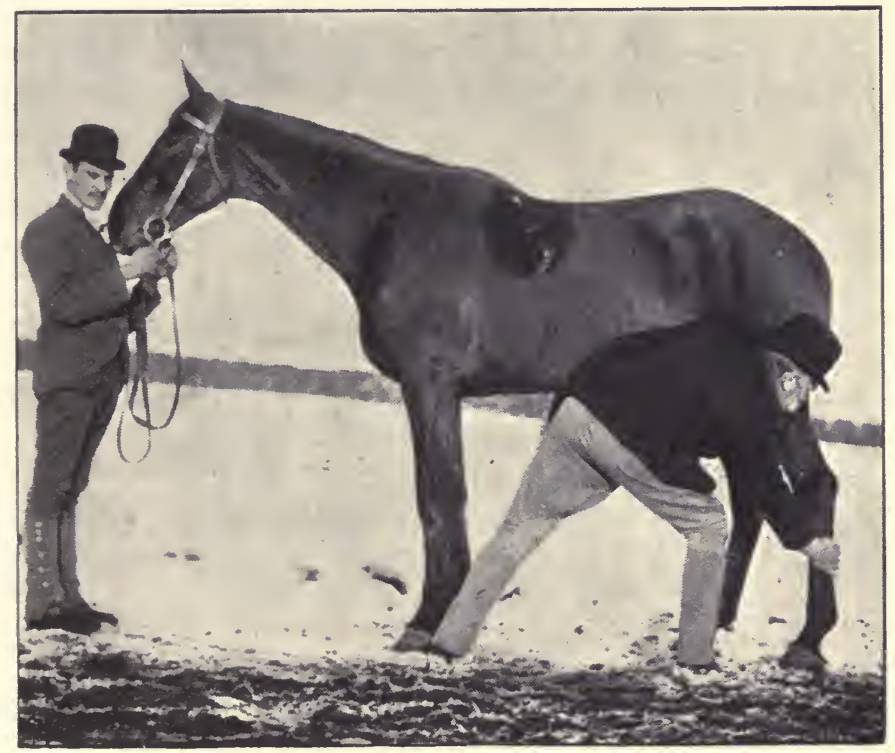

Fig. 56. - Lifting up horse's hind leg.

we aid in preventing the animal from cow-kicking, to do which, he must bend his hock; for the muscle which flexts the foot, extends the hock. Were we to catch the canon bone instead of the pastern, we should, besides losing this advantage, have less ability to act on the lever formed by the bones below the hock, by reason of our shifting the point of application of the "power" closer to the fulcrum (the head of the tibia). The irritation caused by the grasp 
of the hand on the hamstring-which is composed of two tendons-stimulates their muscles to contract, and thus to keep the hock extended. In this operation, we should follow the principles, already laid down, of removing the cause of any pain or irritation inflicted by us on the horse, the moment he yields to our wishes. If the horse overpowers the grip of our hands on his hind leg and kicks out

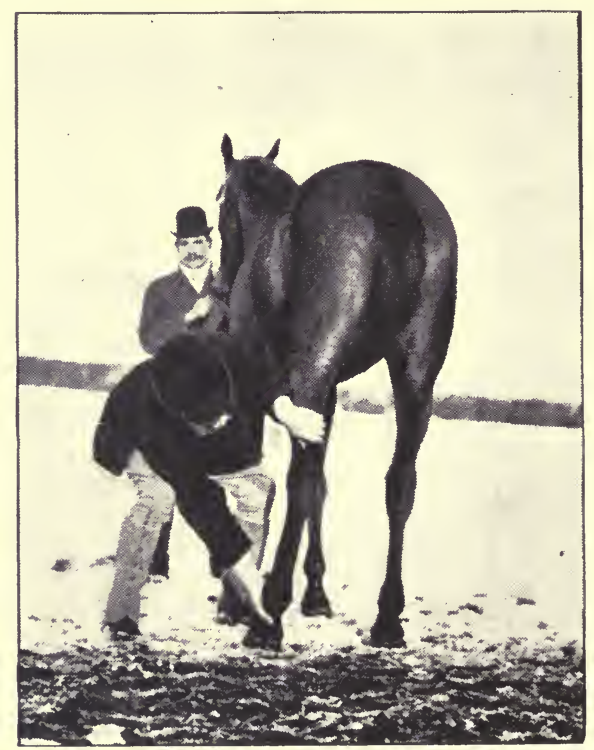

Fig. 57.- Lifting up horse's hind leg.

behind, he can do us no harm ; for we are then in front of his hind leg. If he will not submit, we may apply the ropetwitch (see page I2I) ; and by its aid and a little "gentling," proceed as before described. Instead of lifting up the hind leg with the hand, we may, while the fore leg of that side is tied up, place on the hind pastern a hobble with a $\mathrm{D}$ attached to it (see Fig. 62), and after the fore leg has been let down, lift up the hind leg with a rope or stirrup leather (see Fig. 63).

If the horse be too bad a kicker to allow a hind leg to be 
lifted up by the comparatively gentle means just detailed ; we may, while the horse is being held by an assistant, tie up one fore leg; put on the pastern of the hind leg of the same side - say, the near hind-a hobble; fix a rope to its $\mathrm{D}$; and give the rope to a second assistant. We may then gentle the leg, while the assistant keeps it off the ground (see Fig. 64), or lets it down, according as we see fit. When held in this way, the animal is powerless to hurt us or the

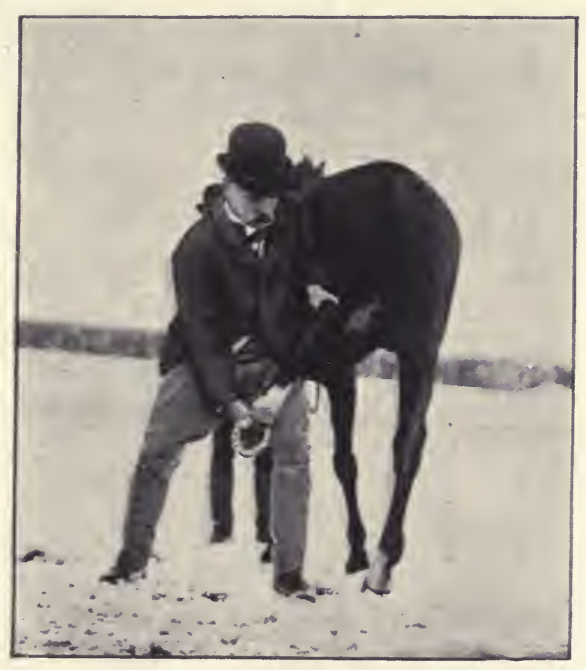

Fig. 58. - Holding up horse's hind leg.

assistant who is behind him. If the horse is very troublesome, we may get the assistant who is at his head to correct him with the rope-twitch, until he "gives in " and allows his leg to be lifted up. Or we may give the leg-rope to the assistant and manipulate the rope-twitch ourselves. If we have not got a hobble, we may fix one end of the rope round the hind pastern by a noose which will not run (see Fig. 40), in which case it is well, by the application of a bandage, or piece of cloth, to protect the pastern from 


\section{I38. METHODS OF HORSE-CONTROL.}

getting chafed. Or we may employ the following method, which was shown to me by General Gatacre:-Having

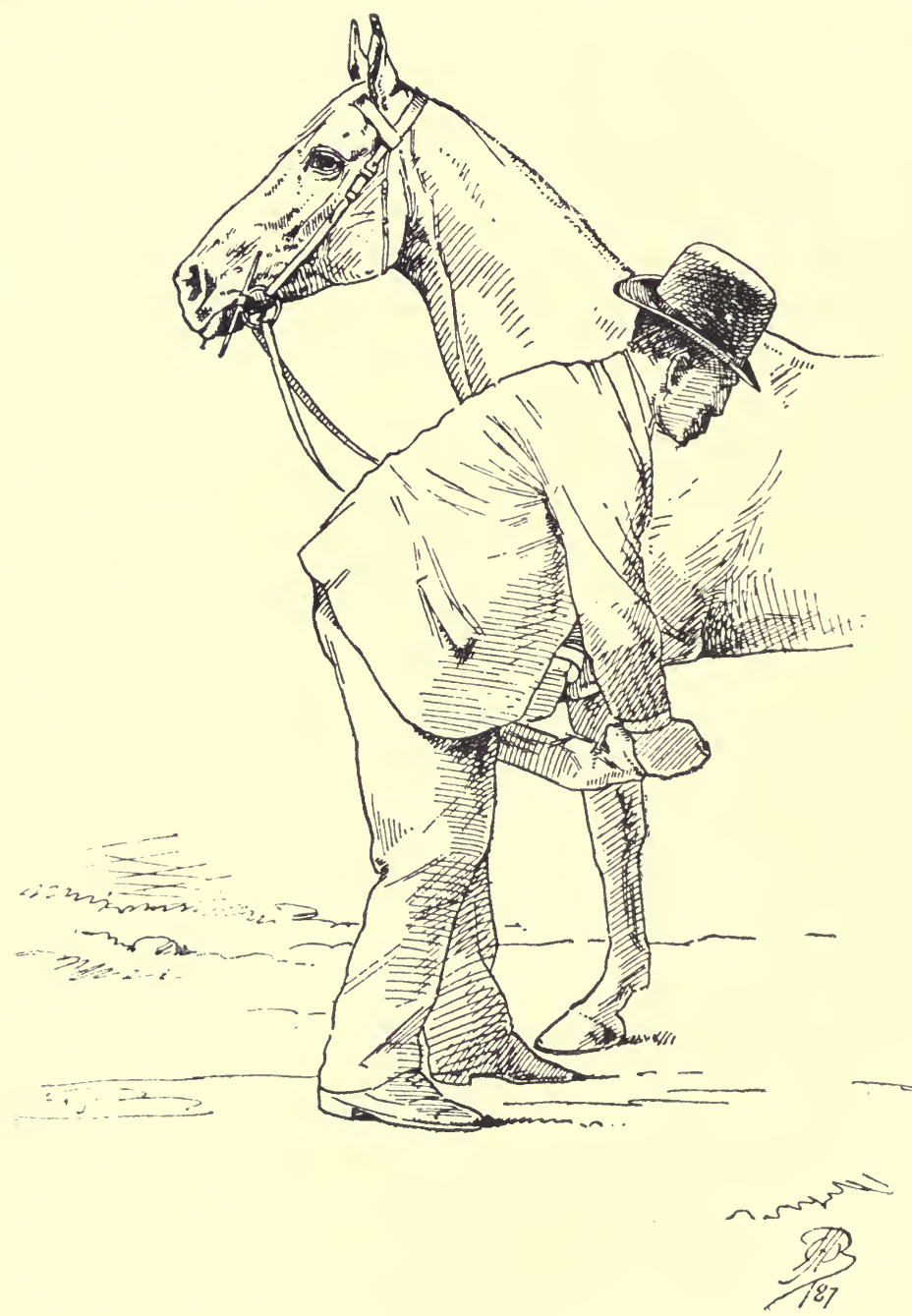

Fig. 59.-First step in lifting up a hind leg without assistance.

taken a strong cord about $20 \mathrm{ft}$. long, we may tie with itto the end of the tail-a "double sheet bend" (see Fig. 65) 
in the middle of the cord, and pass one end through the D to the near side, the other end through it to the off side, and

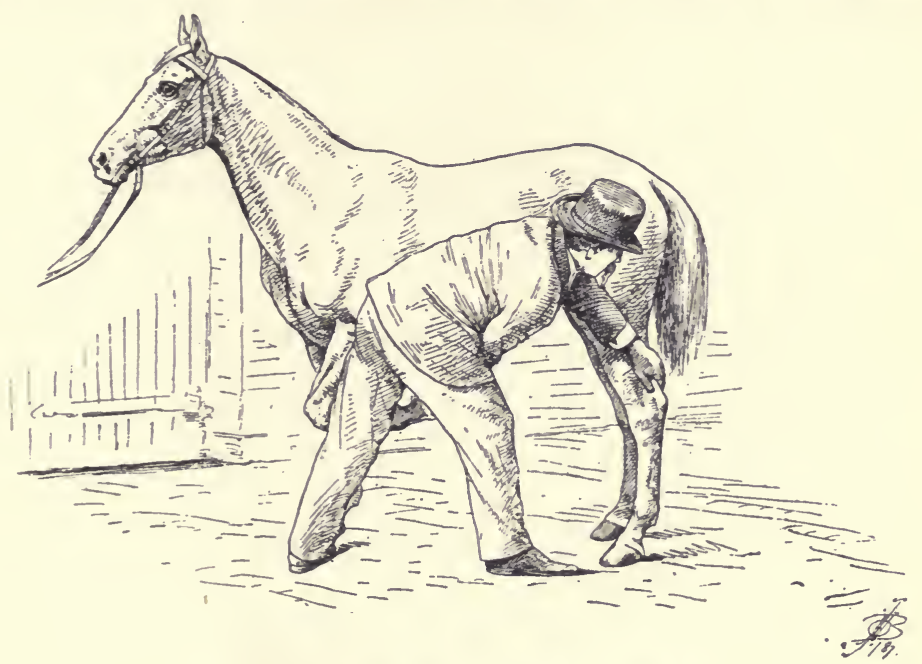

Fig. 60.- Second step in lifting up hind leg.

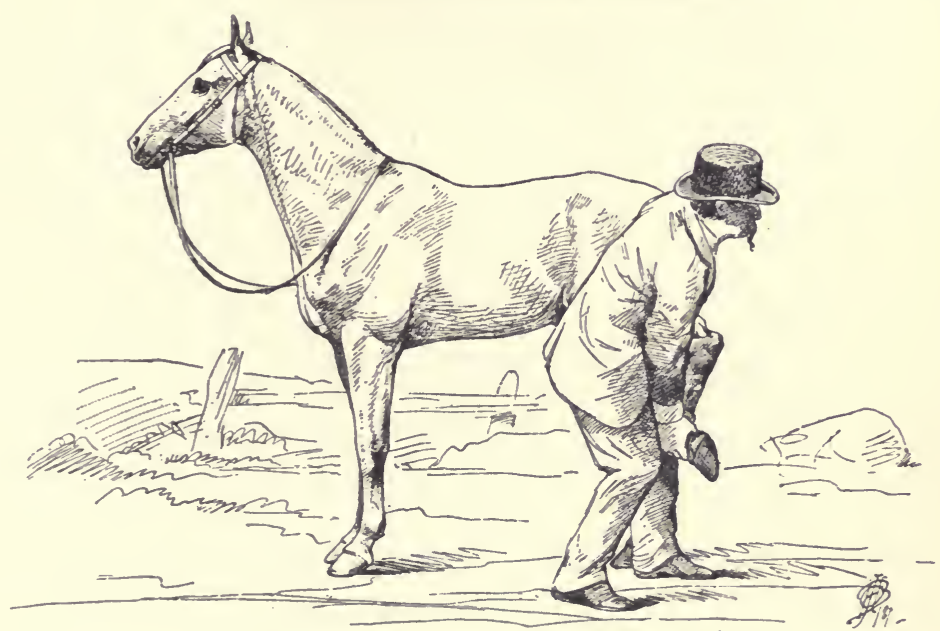

Fig. 6r.-Third step in lifting up hind leg.

give the respective ends to an assistant on each side to hold (see Fig. 66). If the fore leg has been tied up, it should now 
be let down. The assistants should stand at right angles to the horse, and can lift the leg by pulling equally on their respective cords. In this manner, the leg will be brought straight up under the body, so as not to throw the animal

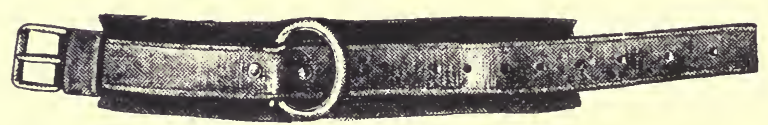

Fig. 62.-Hobble.

off his balance. The fact of thus keeping the joints of the leg flexed will obviate any chance of his straining himself while struggling, which he might do by the old method of using only one cord (see Fig. 67), which would necessitate

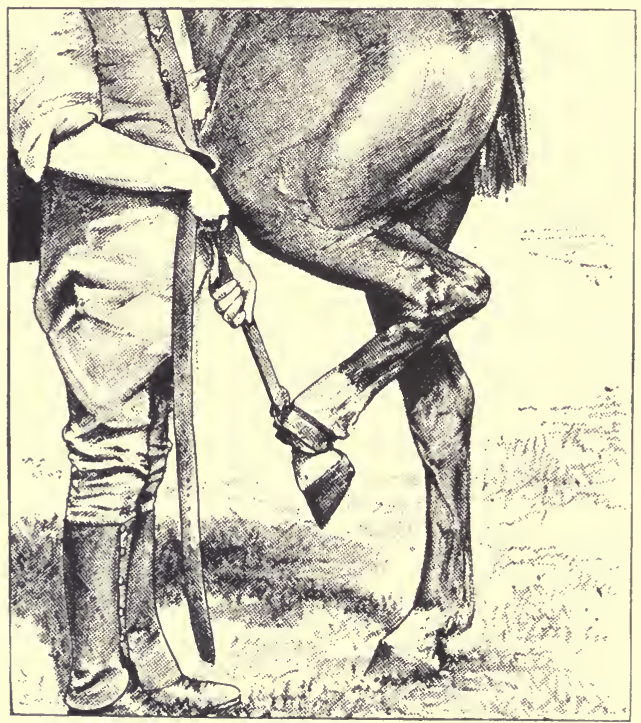

Fig. 63.-Holding up horse's hind leg.

the leg being pulled back, and would consequently disturb the animal's equilibrium. By the other and better plan, the foot may be lifted up and put down again without causing him any inconvenience. It is a most valuable means for 
"gentling" the hind limb ; for its action is irresistible, and it causes no irritation. If the horse's tail is too short to make a knot in its hair, we may pass a loop made in the middle of a doubled cord over the dock, and further secure it by a half hitch (see Figs. 68 and 69).

It sometimes happens that a horse which is difficult to handle behind, will, when we try to lift up one of his hind legs in any of the ways I have mentioned, bear all his weight

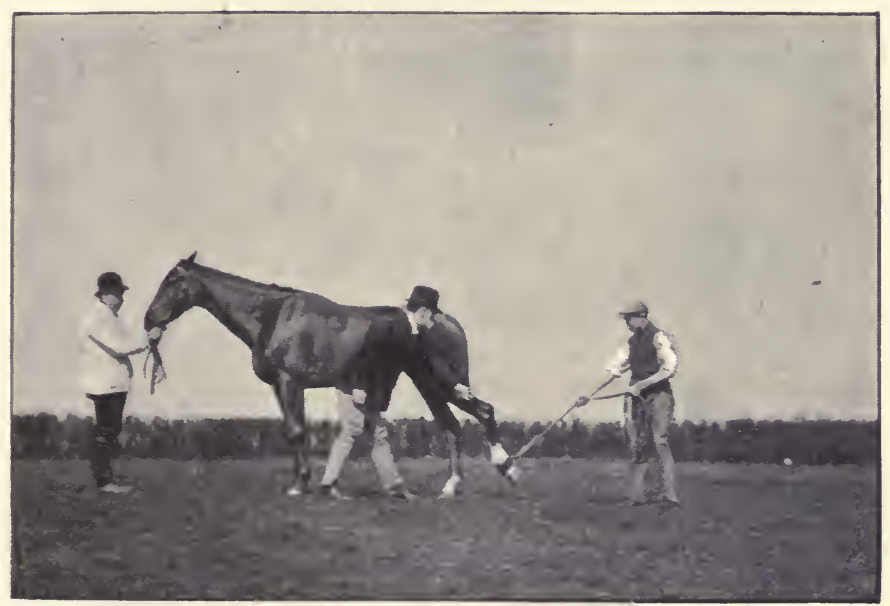

Fig. 64.-Gentling horse's hind leg.

on that limb, or even throw himself down. In such cases, and when he has been very violent, I have succeeded in making him " give in," by keeping him on the ground with his head

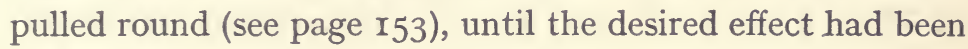
produced.

Note.-Another simple way of taking up a hind leg, is to get a rope about $9 \mathrm{ft}$. long and have a slip hobble at one end which is padded, so as not to draw too tightly or injure the skin when the animal struggles to get its leg free. Next get 
a strong harness collar, preferably one large enough to pass quite easily over the horse's head. Put it on, and if it is dangerous to touch the horse's hind leg, open out the loop,

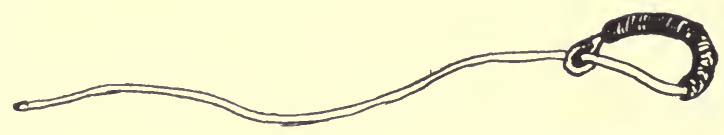

\section{Rlth.}

Fig. 64A.-Padded slip hobble.

and arrange it on the ground so that the hind foot will step into it, after which pick up the rope and pull it so that the loop will tighten round the pastern. Now pass the rope

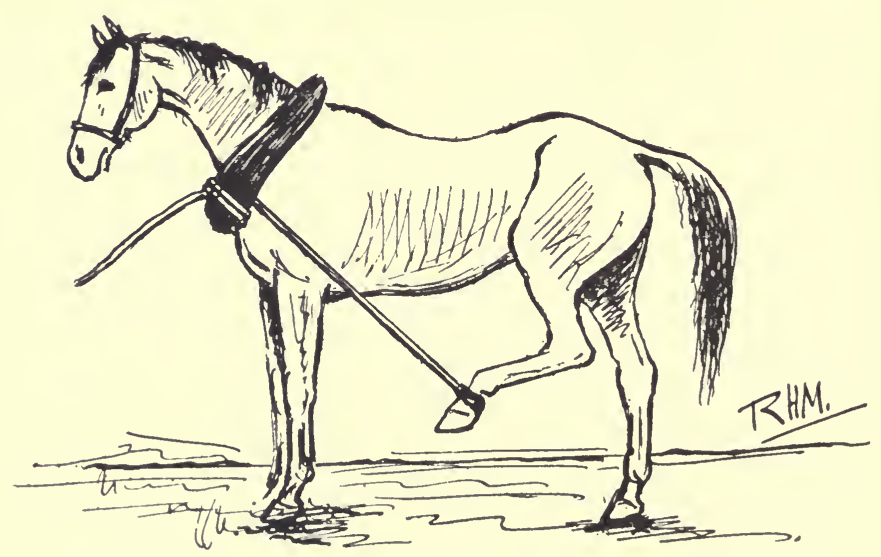

Fig. 64B.-Leg fastened with slip hobble.

twice round the collar, and it will be quite easy to draw the captured leg forward off the ground, and retain it as we wish even if the horse struggles its hardest to get the leg free.

IMPROVISED HOBBLE.

I have devised the following substitute for a hobble by which to lift up a hind leg: Place a stirrup iron, foot part 
pointing to the rear, at the back of the hind pastern, take a few turns with the stirrup-leather round the pastern and iron, and buckle up (see Fig. 70).

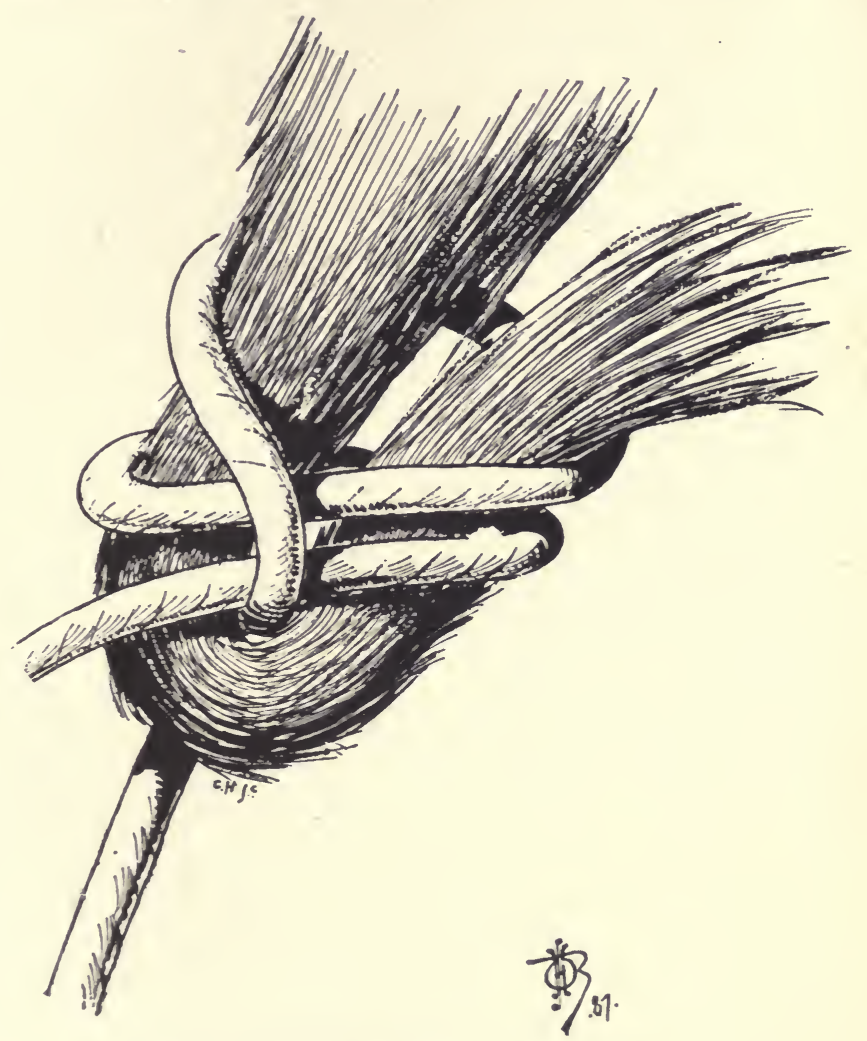

Fig. 65.-Double sheet bend on horse's tail.

\section{THE WOODEN GAG.}

This is useful for preventing the animal from biting, and also for breaking him of this objectionable habit. It may be made out of a block of hard wood, five inches long and two inches square, with the corners planed off, so as to form an octagon in section (see Fig. 7I). It may have a semicircular groove (which is not shown in this illustration), 
about a third of an inch broad, running down the centre of each face of the octagonal, in order to make it more "punishing." A hole is bored down the centre for a chain which is attached to the head-stall. I use leather guards on each side to prevent the animal from getting the gag out of his mouth. This is a modification of Rarey's wooden mouthing bit, which was a round block of wood.

General Peat suggested to me the advisability of having the gag made with sharp edges, and not round; so as to

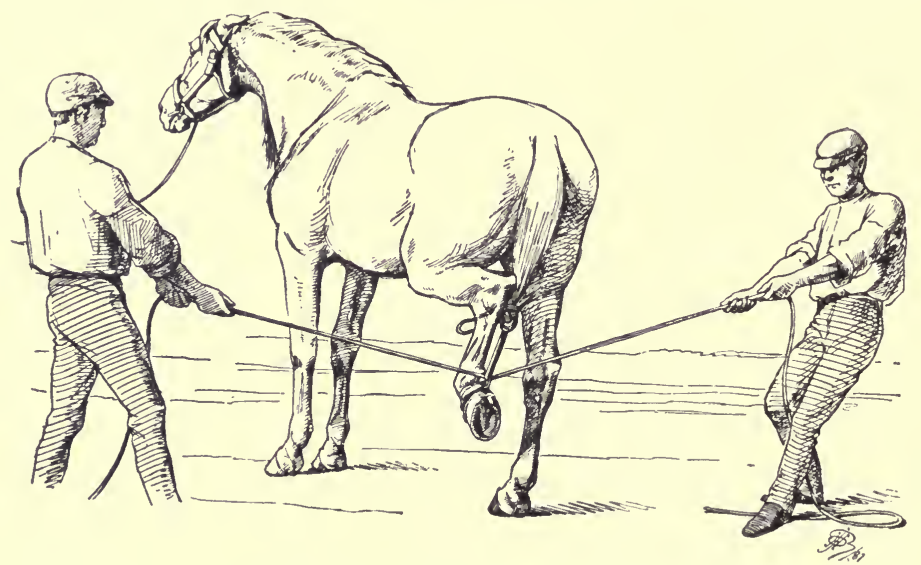

Fig. 66. - Pulling up horse's hind leg.

teach the horse, by the pain inflicted on his gums, not to bite.

MAKING A HORSE LIE DOWN AND KEEPING HIM ON THE GROUND.

F. For making a horse lie down, the following method, which "Professor" Sample informs me was invented by the American "horse-tamer" Hamilton, is the best I have seen, and may be described as follows: Place on the horse a surcingle which has two or three iron rings on its pad, and attach a crupper to the rearmost ring. Put on the horse's 
head a strong head-stall, and fix to its near (for instance) side $\mathrm{D}$ an iron ring. Tie a strong cord or rope by one end to the front (if there be two rings) or middle (if there be three) ring on the pad; pass the other end through the ring on the side of the head-stall, and back through the front ring of the pad. Put knee-caps on, and suspend to the sur-

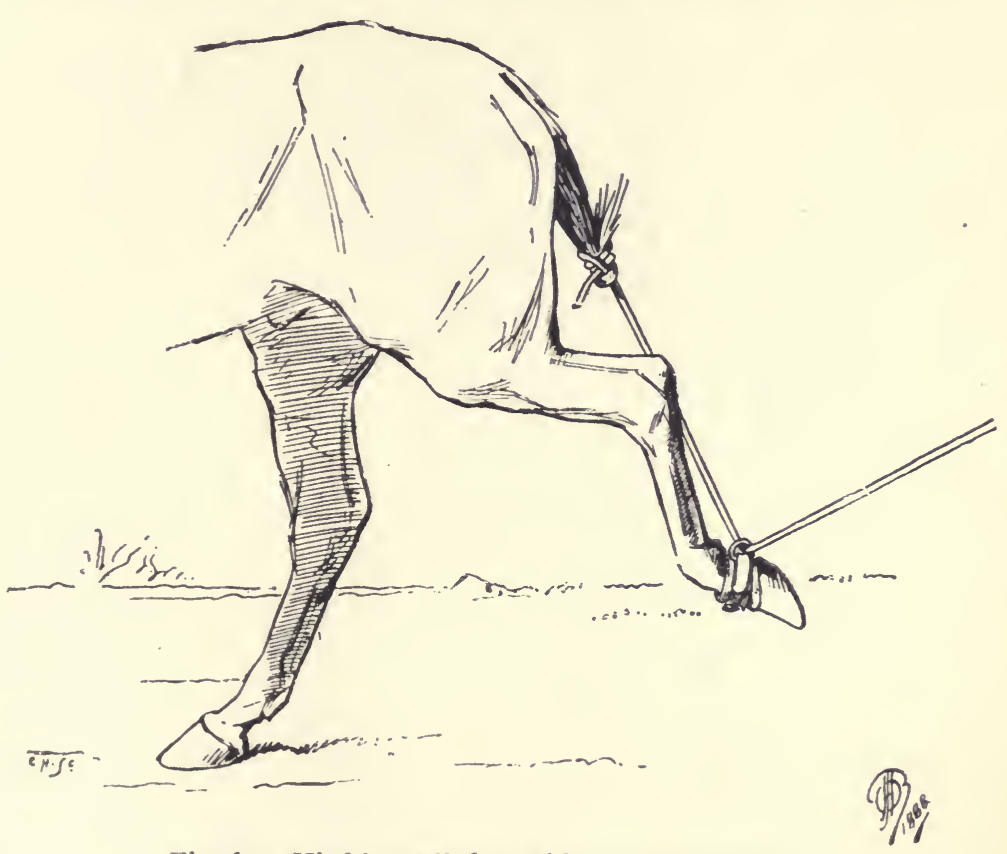

Fig. 67.- Hind leg pulled up with one rope on tail.

cingle the fore leg of the side away from which the head will be turned (see Fig. 72). The buckle of the leg strap should be on the inside, so that when the horse lies on his off side there may be no difficulty in undoing the strap in order to let him get up. I have found that it is a good plan to tie a rope to the horse's tail for an assistant to hold, so that he may be able to pull the animal over on to the proper side if he appears likely to fall the wrong way. Then, all 
being ready, take the free end of the cord, draw the head round to the near side, with the cord across the base of the neck, and keep up the tension until the horse rolls over to the off side (see Fig. 73), either by " giving in " or by being

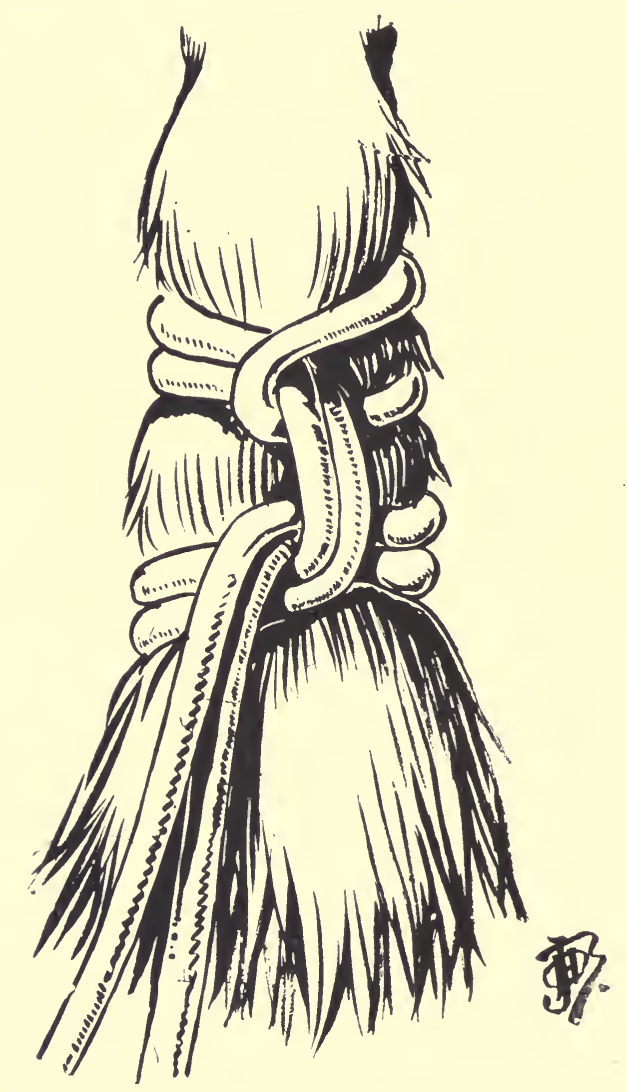

Fig. 68.-Method of fastening a rope to a short tail.

forced to do so. We may find it convenient in some cases, instead of having the rope across the animal's chest, to bring it over the back as in Fig. 74. As a rule, the operator will find it best to stand on the off side and a little to the front of the horse's shoulders. No attempt should be made to 
throw the animal forcibly down; for the effect we should aim at is that to be produced by his "giving in " to power
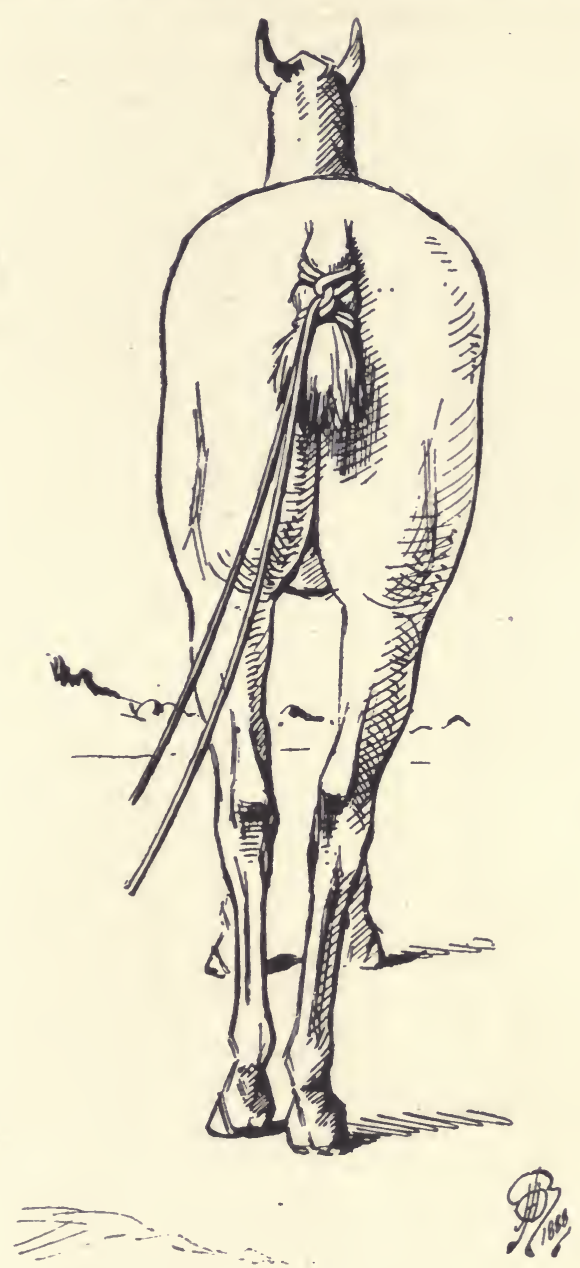

Fig. 69.-Rope attached to short tail.

which he finds irresistible. Hence the more he "fights" and pits the strength of his muscles against the action of our mechanical appliances, the better will be the result of 
our victory. If the horse appears likely to fall on his near side, the assistant who holds the tail rope should pull him over on to his off side; for, if he were to fall on the near side, he would be in

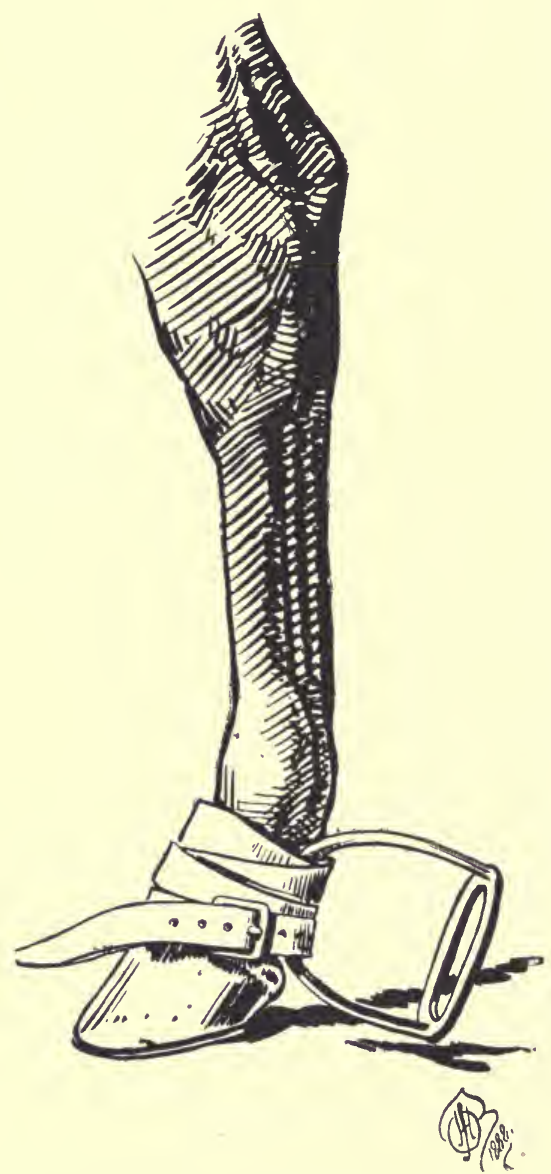

Fig. 70.-Hobble improvised with stirrupleather and iron. the awkward position of having his neck doubled under him. Although this position looks dangerous to the horse which gets into it, I have never seen, in many scores of cases, any injury result from it. The horse may now be kept, say ten minutes, on the ground with his head pulled round to his side (see Fig. 75), and "gentled." When "gentling " the horse on the ground, the breaker should remain at his back (as I have already mentioned), so as to keep out of reach of his heels.

Having carefully attached a rope-noose to the off hind pastern, the breaker may pull that hind limb towards himself and gentle it.

The "gentling" is performed by passing the hand over the various parts of the body, gently rubbing, kneading or bending them as may be required to make the 
horse relax his muscles, when the touch of the hand causes him to contract them from fright or from resentment. The object of the gentling is to show the horse that he need fear nothing from the touch of man, and that he must subnit to it. To carry out the latter part of this condition we may, if the horse shows fight while we are gentling him, pull his head sharply round to his side by the cord (see Fig. 75) so as to punish him; and when he gives in, we may, as a reward, relax the tension.

鄅

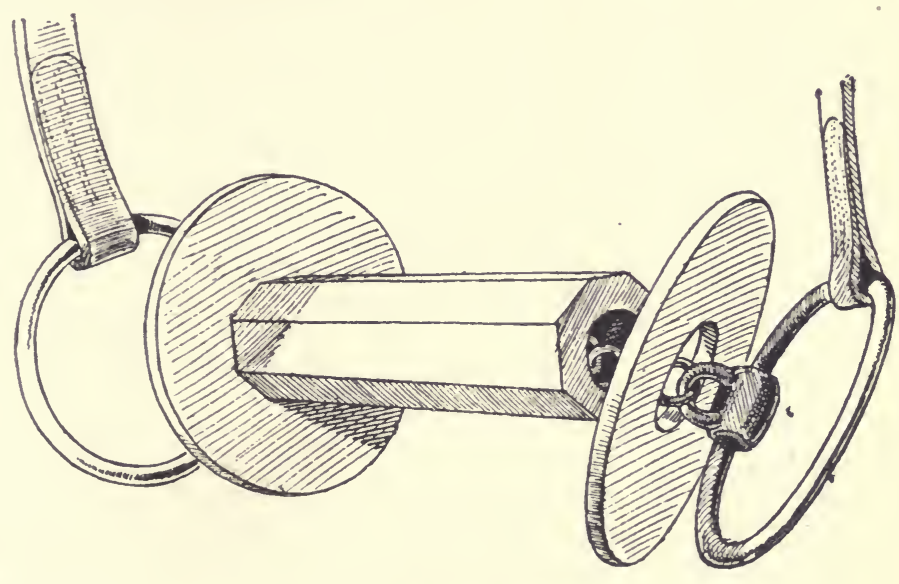

Fig. 71.-Wooden gag.

It is quite immaterial to which side the horse's head is drawn, provided that in either case the opposite leg be tied up.

If the animal goes down without a struggle, and sulks on the ground, he should be forced to "show fight" by keeping him in the constrained position depicted in Fig. 75, until he has got rid, by ineffectual struggling, of most of his "temper." When a horse begins to groan, and to considerably moderate the violence of his struggles, we may feel confident that "the sulk" has been taken out of him 
more or less, and that he is fit to be allowed to get on to his feet again. If an error happens to be made with respect to the amount of the effect produced, it should be on the side of leniency rather than on that of severity ; for the operation can be always repeated and more time given on the next occasion, without running any risk of unduly cowing the animal. Whatever punishment we employ should

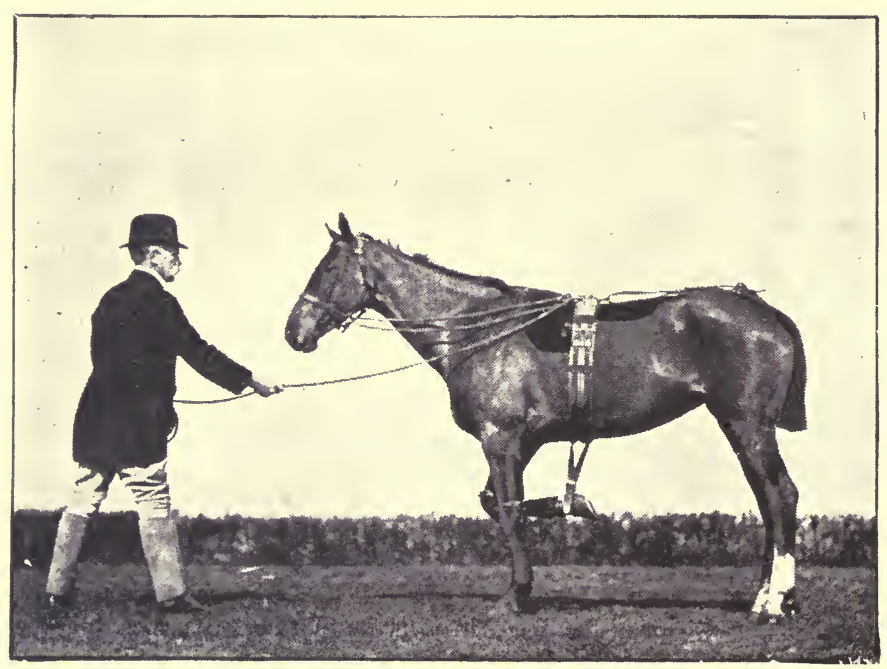

Fig. 72.--Horse ready to be made lie down.

never be pushed beyond the point necessary to gain our required object, which, in this case, is the attainment of authority over the horse.

My own practice with animals that are simply impatient of control, is to produce the desired effect by making them lie down several times; and, with stubborn ones, by keeping them down with their heads pulled round. The latter method might alone be employed, if the ground be hard or slippery, or if the back tendons or suspensory ligaments of 
the horse's fore legs appear unfit to bear severe tension. In such cases both the strait-jacket and throwing gear might be put on the horse, which might be made to lie down with the former and have his head pulled round by the latter ; after doing which the strait-jacket could be taken off, so as to give the animal entire liberty to kick as much as he pleases. We might use body clothing on the horse to save the point of his hip which is on the ground, from getting chafed.

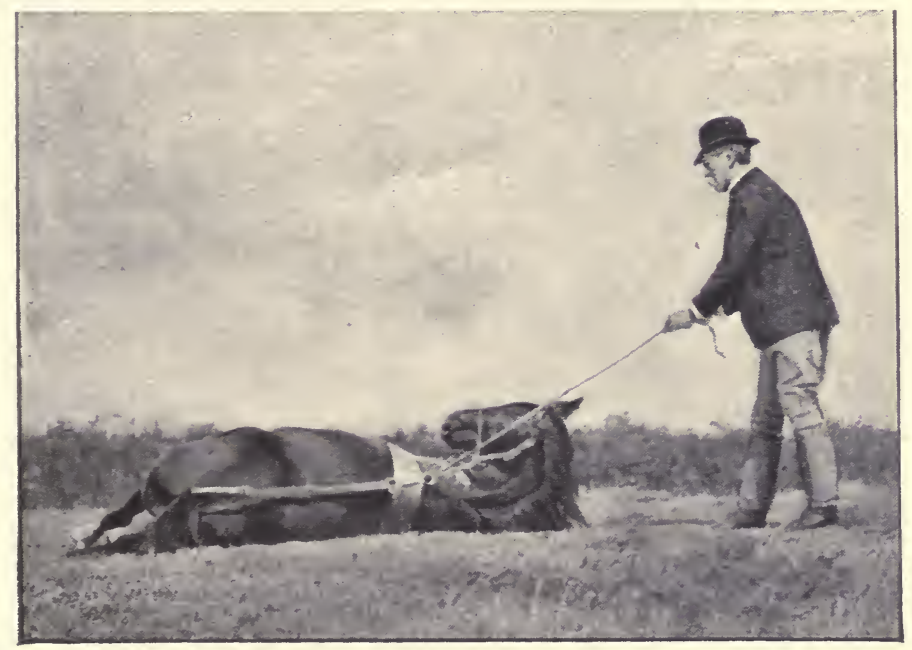

Fig. 73.-Horse on ground.

I wish to impress on my readers the great value, for overcoming stubbornness, of the foregoing method of keeping a horse on the ground.

The throwing gear is exactly similar in its action to that described in Pratt's book, although differing from it in its construction. Pratt used to employ a rope which was looped round the neck and passed through the mouth, for pulling round the head. He also had a single rope to form both surcingle and crupper. The chief objection to Pratt's 
method, as far as I can see, was that the ropes passing through the mouth and under the tail were apt to hurt those parts.

The employment of the tail-rope (see Fig. 74) is an improvement which I have devised, and which I have found very useful; although it is by no means indispensable, especially if the operator be expert. As the surcingle has to be girthed up tightly, I like to use a felt saddle-

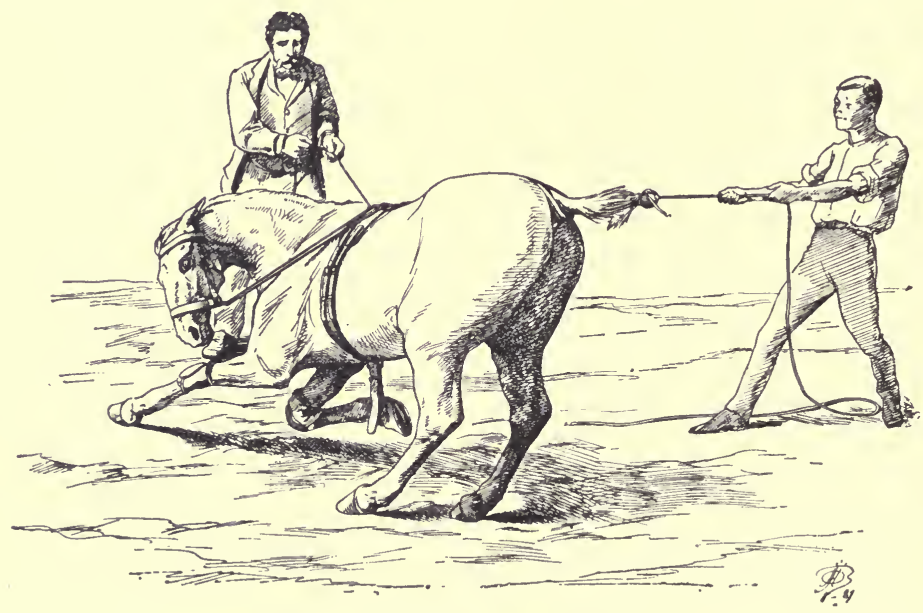

Fig. 74.-Making horse lie down.

cloth or numdah under it, to prevent it slipping forward, in which case it might squeeze the withers, or the crupper might rub the root of the tail.

In order to make a horse "give in" to the required degree, after he submits to lie down readily with one leg tied up, I like to continue the process with both fore legs free until he goes down without any trouble.

When horses are properly thrown they suffer no pain from the process. I remember treating a horse for actinomycosis, which necessitated my throwing him, when dressing 
the affected part. After a few times the animal, on seeing me, would lie down of his own accord.

The attempt to obtain control over the horse, as a rule,

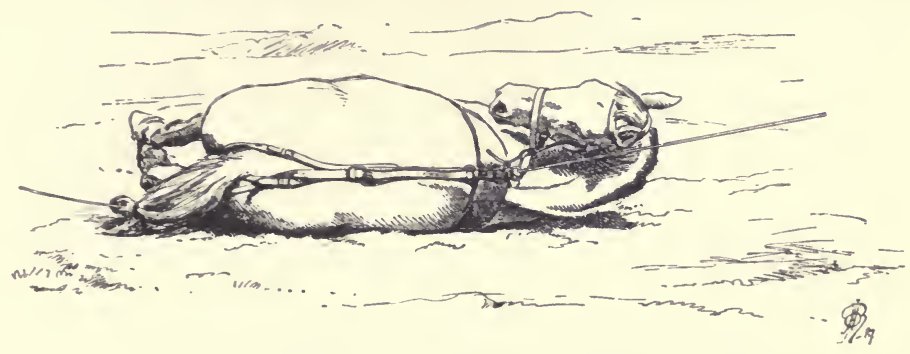

Fig. 75.-Horse on ground with head pulled round.

had best be completed in one lesson, which can be repeated as may be required.

Out of the many hundreds of horses which I have made lie down, I have had only one accident from this cause. The exception was a China pony which went down very

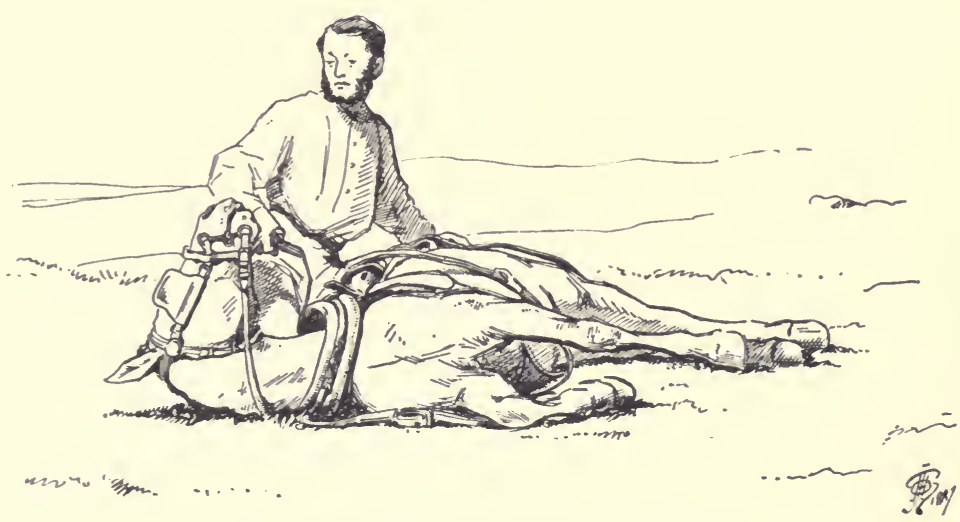

Fig. 76.-Holding horse down on ground.

gently on soft and sandy ground. When I tried to make him get up, I found that he had broken his back.

We may utilise the knowledge that a horse cannot get 
up off the ground when his head is pulled round, in keeping him down-for instance, when he has fallen in harness-by holding his head in an upward and backward direction, while keeping his neck bent by aid of the pressure of the knee (see Fig. 76). We should employ this plan only when the animal attempts to get up; for the position which it entails, is very irksome to him.

\section{MAJOR WOODS' METHOD OF THROWING HORSES.}

I have seen Major Woods, late of the R.M.L.I., throw several horses very cleverly without any special gear, in the following manner, which I believe he invented. Having placed himself on the left side of the horse, which was provided with a head-stall and leading rein, he took up the animal's near fore foot and held it in his left hand, while he drew the horse's head round to the right side by the leading rein, which he kept in his right hand. By forcibly keeping the animal in this constrained position, he obliged him to come down on the near knee, and finally to roll over on the ground. Major Woods claims that throwing the horse in this manner convinces the animal of the ascendency of man more than if special tackle were used. It goes without saying that to apply this method successfully on violent horses, a man must be, like Major Woods, an athlete, and gifted with presence of mind and pluck. Even if we doubt the superiority of its moral effect on a horse, as compared to the plan on the same principle, but with the aid of special gear, we must acknowledge that to carry it out on a really difficult horse is a very clever feat.

THROWING A HORSE WITH THE STRAIT-JACKET.

' To do this, one assistant should stand at his head, another should hold a rope attached to his tail, so that he may not throw himself forward on to his head, while an 
assistant at each of the traces should pull them tight, and then bring him down. As soon as he is on the ground, he should be gentled and handled all over for a few minutes. The process may be repeated or prolonged as may be required. If, say, the off trace be tightened up and buckled, the aid of the assistant, who would otherwise have held this trace, may be dispensed with. This method of throwing the horse is the gentlest in its action of any I have seen. If the appliances and help be at hand, and time be no object, I would recommend that it should be always

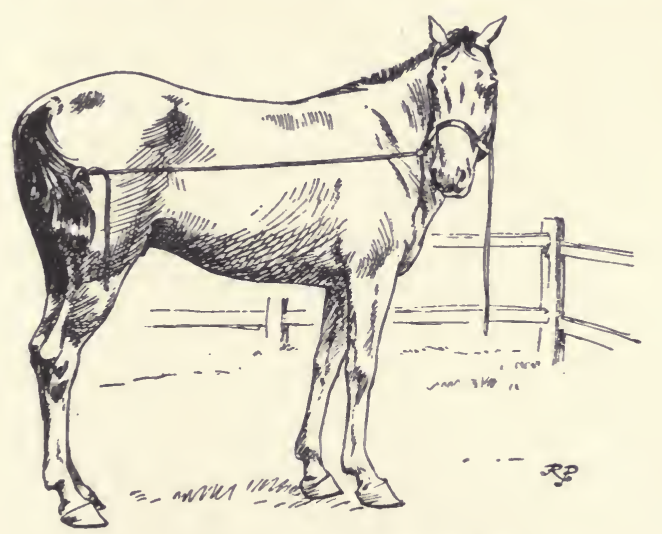

Fig. 77.- Horse tied head and tail.

used as a preliminary to that of making a horse lie down by pulling his head round (see page I44), so as to take some of the "fight" out of him, and to prevent him, as much as possible, from " knocking himself about."

\section{THE HEAD AND TAIL METHOD.}

The earliest mention of this method which I can find, is in Mr. R. Jennings's "Horse Training Made Easy," published in I866. In this book it is referred to as if at that time it was a well-known plan for subduing horses. Whoever was its inventor, Sample merits the credit of having introduced 
it into Australasia and England. I am inclined to think that he utilised it in a more competent manner than did any of his predecessors, The principle of its application, as expounded by Sample, is to place the horse in such a position that the only movement of which he will be capable, while in it, will be a more or less circular one ; and then to induce the animal by every possible means, short of striking or otherwise hurting him, to go round and round, so that he will at last find that this involuntary form of waltzing is more irksome to him than having to bear unaccustomed though innocuous, sights, sounds, and touches. The feeling of having, under strong provocation, to submit to irresistible control, often helps in this case to form the habit of obedience. The carrying out of this method, which had best be practised in a suitable enclosure or in the corner of a field, is as follows :- Having put a headstall on the horse, tie one end of a rope or cord by a double sheet bend (see Fig. 65) to his tail, draw the head about a third of the way round, and tie the free end of the rope to the headstall, so that the head may be kept in this position. The longer the tail, the thicker may be the rope; and the rope or cord should be so fixed to the head-stall that it can be readily loosened or tightened. I have found that it is a great improvement to attach a short rope or strap (a stirrup leather will do) to the side of the headstall away from which the horse's head is turned (see Fig. 77), so that the operator may catch it and thus stop the revolving horse, when he sees that the animal is getting giddy and in danger of falling. To begin with, the length of the cord which connects the head and tail should be so regulated, that it will be just sufficient to make the animal turn round without being able to go forward. In order to obtain increased control, the cord should be gradually tightened from time to time, according as the pupil becomes 
accustomed to the movement; but on no account to such an extent as would cause him to be in danger of falling down; for our object here is to avoid giving him just reason for alarm. Besides, a fall, when the animal is in this position, is not without danger to neck or back.

When the horse has been fixed up in this manner, we may begin operations by gently cracking a whip while standing a few yards away from him, and may continue to do so, if he expresses impatience or alarm by going round and round, until he pays no attention to the noise made by the whip, although we may crack it all over him. We should gradually shorten the cord which connects his head to his tail, and, at the same time, should continue to approach nearer to him, and to increase the noise of the cracking of the whip. Out of hundreds of "nervous" horses which have passed through my hands, I have never seen a single one which, by this head and tail plan, would not, within an hour at the outside, allow the whip to be cracked all over him without evincing the slightest fear, even when the connecting cord had been removed from the headstall and tail. While using the whip in the manner described, we should carefully refrain from hitting the animal with it. After the pupil has lost all fear of the whip, we may proceed in a similar manner to make him bear without flinching being touched with a long pole of convenient thickness and weight. We should begin by placing the pole on the least sensitive part of his body (his "crest," on which the mane grows), and should work up by degrees to the more ticklish ones, such as under the belly, down the legs, in front, behind, and between them. In this way, we should go over the whole of the animal's body with the pole. When he submits to be touched all over, we may try the effect of noise on him, as, for instance, that produced by beating an empty paraffin oil tin, and we may finally 
endeavour to frighten him by flourishing in front of, and all over him, a white banner or other cloth fixed to the end of the pole. In doing all this, our object should be to make him go round as much as possible, by startling him, though without hurting him in the slightest; for the more trying will have been his experience, the less likely will he subsequently be to become startled at anything unusual happening. When he has thoroughly given in, the cord may be taken off his head and tail.

The foregoing method of rendering horses quiet, or of impressing on their minds the idea that they cannot resist the power of man, is applicable only to excitable horses which, under the various kinds of provocation I have described, will go round and round until all the "nonsense" has been taken out of them for the time being. It is not suitable to sulky horses, whose defence against punishment would be to jib. It is useful for curing biters and kickers of their respective vices; supposing that these animals are not also afflicted with stubbornness, in which case a course of making them lie down (see page I44) and keeping them on the ground (see page r49), would be more appropriate. While using the head and tail method, I have never had a horse hurt himself, even when he has fallen on the side to which his head is turned, as will sometimes happen.

After having given the head and tail plan a trial of several years in hundreds of cases in various parts of the world, I now rarely employ it, except as a means for saving labour. Its chief weak point is that it teaches nothing except quietness, which can, as a rule, be better obtained by the use, for instance, of the long reins and rope-twitch. We can also inculcate by the former, obedience to the "aids"; and, by the latter, obedience to the voice, which can also be taught to a considerable extent 
by the long reins. If the horse.is quiet enough to carry a man on his back, riding him round and turning him in small circles will certainly improve his manners more than letting him, with his head tied to his tail go round and round until he sees fit to stand still; to say nothing of the instruction he gets at the same time in control by hand and leg. I have known several instances of aggressively vicious horses, which had apparently "given in" during a head and tail lesson, become in a few hours far worse in their temper, seemingly from resentment at having been rendered temporarily helpless, and from knowledge that, with their freedom, they had regained their power of inflicting injury on those whom they, rightly or wrongly, regarded as their tormentors.

\section{RAREYFYING A HORSE.}

The method by which Rarey used to tame vicious horses was to tie up one fore leg (as in Fig. 35), and then pull up the other by means of a strap attached to the pastern and passing through the surcingle, which had previously been put on. The operator stands on the side of the tied-up leg, and draws the horse's head by the rein to the opposite side as soon as the horse comes down on his knees. Having got into that position, the animal is supposed to struggle to get up, until at last, confessing the superior power of the man, he "gives in" and rolls over on his side. $\mathrm{He}$ is then "gentled" (see page I48), and, finally, on the straps being removed, he is allowed to get up and to commence life as a supposed reformed character. As the operator has to stand close to the animal while it plunges and fights for its liberty, this process of taming has been adopted by very few. Its non-success as a breaking method was further increased by the fact that it was efficacious only with those vicious horses which would "fight to the bitter 
end." These animals, I can assure my readers, form only a small proportion of the horses whose vices make them fit subjects for taming. I have met with many horses which were very dangerous to approach, but which were so sulky that the mere act of tying-up a fore leg was sufficient to make them lie down without their attempting the semblance of a "fight." Others would similarly adopt the recumbent position if they obtained the additional incentive of having their head drawn round to the side of the fore leg which alone supported the weight of the forehand. To make any such method perfect, it is necessary to provide it with means, as described on page I49, for forcing the horse to " fight," when, from sulkiness, he refuses to do so. His refusal to fight, in such cases, is a "defence" which we have got to combat.

Mr. Norton Smith adopted, from " Professor" Gleeson I believe, a modification of Rarey's system, by attaching a long strap or cord to each fore pastern, passing these lines through the surcingle (or through rings on the surcingle), and then carrying them back behind the horse, so that the operator, while keeping out of harm's way, could pull up one or both fore legs of the animal, as he deemed fit. When I saw Mr. Smith performing, he made the horse lie down by pulling both legs off the ground at the same time. Although such a method might do for a show, and especially with a horse that had been taught to "go down" in this way, it is unworthy of serious consideration from a breaking point of view, on account of the danger there is, by it, of the animal injuring himself by coming down violently on his knees or on his head. A breaker cannot be expected to be provided with ground softer than an ordinary grass field.

Sample tells me that Denton Offett taught Rarey the system which now goes by Rarey's name. I see from a leading article in the Evening Standard of 3oth June, I893, 
that "This horse-taming business is very, very old. Mortals who have been privileged to view the glorious collection of Greco-Scythic art in St. Petersburg will see it there in practice--exactly the same twenty-five hundred years ago, as that with which Mr. Rarey made such a prodigious sensation in the days when most of us were young. There, on a silver vase in relief, is a Scythian warrior lassoing a horse; there he is strapping its fore leg up; there, again, he has it on its knees; and, finally, in the last group, it stands, saddled, bridled, 'tamed.' Probably there is not one of these latest methods which could not be traced in ancient times. And still somehow we go on breaking horses in the accustomed way, and vice is as common as ever."

\section{SAMPLE'S HORSE-TAMING MACHINE.}

As a development of the head and tail system-of which he was a great admirer-Sample brought out and patented in I89I a machine by which he proposed to tame horses. It consisted of a box, which was supposed to hold the horse, and which he rotated either by hand or steam at a speed sufficient to render the enclosed animal so giddy that; on being taken out, it would be perfectly quiet to handle for the time being, no matter how wild it had previously been. The exhibition of this machine in London was a failure; partly because its inventor did not provide himself with a supply of wild horses, with which to demonstrate its power. I feel certain that it would be a valuable means for saving labour in rendering quiet freshly-caught horses which have been brought up under uncivilized conditions.

\section{SOUTH AFRICAN METHOD OF BREAKING.}

The usual way adopted by the Boers of the Cape Colony, Transvaal, Orange Free State, and Natal for breaking in 
their horses, is to put a strong head-stall on the young one and another on a steady break-horse, which has a saddle on him, and, having placed the two animals side by side, to tie them securely together by their head-stalls. Fixed in this way, the pupil is unable to run away, rear or buck. The breaker mounts the old horse, whose "company" gives the young one confidence, and in a short time makes his pupil accompany him wherever he likes. After a few days, another man mounts and rides the young horse, which, during these lessons, continues to be attached to the other animal, and thus soon makes his mount quiet to ride. This method is safe and expeditious ; but has the drawback of being liable to make the pupil disinclined to act independently of his fellows. It affords no instruction in mouthing or in the formation of the different paces. The success which I had during my South African tour showed that those Boers whom I had the pleasure of meeting, liked the system of breaking which I taught them better than their own. 
CHAPTER V.

\section{BREAKING ON FOOT.}

Catching a horse and making him quiet to handle--Mouthing a horse with the long reins on foot-Teaching a horse to turn on his forehand-Teaching a horse to lead.

IN this chapter I shall describe the breaking of the horse preliminary to his being either ridden or driven, whatever may be the purpose for which he is intended. I assume that he has not been handled, and that he is in sufficiently good condition to stand the fatigue of breaking. I shall provide, as far as I can, for difficult cases, which, I need hardly point out, often occur even in England; to say nothing of countries in which colts and fillies are brought up under wild conditions. Those of my readers who are fortunate enough to have only quiet horses to break in, can skip the description of precautions and methods which others less favourably placed will find useful, if not indispensable for the attainment of success.

It will be observed that by the system I adopt, the manners of the horse are, as far as possible, made concurrently with his "mouth." In fact, a few days' driving with the long reins (see page I68) would make the wildest or most vicious horse (supposing that the vice did not proceed from disease, as in the case of a mare suffering from nymphomania) quiet to handle, as well as obedient to the bridle. 
CATCHING A HORSE AND MAKING HIM QUIET TO HANDLE.

If the horse is in the open, and is difficult to approach and handle, the first thing we have got to do is to drive him into some suitable enclosure, such as a straw yard, empty barn, or loose box. We may then make a rope halter (see page 99) and put it on with a long stick (see page IOI). I have used this plan successfully in England with colts driven into a farm-yard to be docked or castrated; in South African kraals, with wild horses which had never before been approached by man; in India, with broken-loose man-eaters whose attendants dared not go near them ; and under many other circumstances of more or less difficulty, if not danger. Lassoing a horse in order to catch him, is not a good plan; because it is liable to injure him by causing him to fall violently on the ground, and does not give the operator the command of his head, which is obtained by the other method. If the horse is wild, and the enclosure is small enough to keep him within easy reach, I like to make him stand still in a corner, by means of the lunging whip (see page 105), and then gentle him about the legs (in front and behind), head, neck, back and belly by passing the end of the whip or long stick over these parts. If he makes any attempt to turn round, to kick or to get away, I flick him with the whip below the hocks until he turns his head towards me and stands still. I then make him come up to me, and I put the halter on him. At this stage of the proceedings, we may for safety sake noose a fore leg (see page Io6), say, the near, and give the rope to an assistant to hold, while we take charge of the halter rope. In most cases we can now go up to the horse, and apply the rope-twitch by means of the rope halter which is already on the horse's head (see Fig. 39). If this cannot be done without risk, we may, 
by means of a stick or pole, pass a blanket or similar article over the horse's head, so as to blindfold him. We may then put on the twitch over the cloth, and after we have adjusted it, we may remove the cloth from underneath it. With the twitch on, the man who holds it is safe from being bitten by the horse, or from being struck by a fore leg. If the attempt to blindfold the animal makes him, as it sometimes will do, outrageously violent, and if he also furiously resists any approach being made to his head; we may obtain control by applying the noose-twitch (see Fig. 44). The great difficulty I had experienced in going up to some of the wild horses I had to break in South Africa, prompted me to invent this twitch. In getting it or the rope-twitch on the horse, we may expedite matters and save ourselves from being bitten, by putting a stick into the horse's mouth. He will seldom offer resistance to this being done. In fact he will generally like to get the stick between his teeth. Its presence in his mouth will greatly help to distract his attention from his breaker, and will consequently make him less troublesome than he might otherwise be to handle. Although the noose-twitch is not so effective as Pratt's rope-twitch (see page I20), the fact remains that its power is ample for control in this case. With either the noose-twitch or rope-twitch applied, and with a rope attached to a fore pastern, we may consider that the most vicious horse in the world is entirely at our disposal. At this period or even before it, I have known horses throw themselves down from combined rage and obstinacy at finding that they were mastered. If the horse adopts this defence, tying his head to his tail and keeping him in that position (see Fig. 78) until he has "given in," will, I have found, be the readiest and most effective means of taking the "nonsense" out of him. If he does not try to defeat us in the 
manner just mentioned, we may proceed to tie up one fore leg, and put on the long-reins driving gear (see page I68); and may circle, turn, and rein him back, for about half an hour. Or we may employ the head and tail plan (see page I55). When the horse has been thus fixed up, we can easily tell the state of his temper; for if he be nervous or excitable, he will go round and round at the slightest provocation. If, on the contrary, he be sulky, he will "take as little as he can out of himself"; but when released will be as bad, or nearly as bad, as before. The more he "fights," the more good will the lesson do him, and the sooner will he give in. Our object, therefore, should be to make him "fight"; not by punishment, but according to principles I have already discussed. For sulky horses, and for them alone, would I advocate the taming means of making them lie down and keeping them on the ground with their heads pulled round. No matter how violent or how aggressively vicious a horse may be, he can be made, for the time being, perfectly quiet to handle in a couple of hours, or, if need be, in one hour, by the methods I have just mentioned. A few repetitions-say, half a dozen at the outside-will even in the worst cases confirm the habit of obedience; always supposing that the animal remains in the hands of fairly capable people. It is almost needless to point out that by injudicious management, even placid-tempered horses may be made difficult to handle; to say nothing of temporarily reformed characters, out of the minds of which the good effects of a previous victory of discipline over vicious habits are rapidly fading.

After the horse has been gentled all over and rendered as quiet as practicable by the foregoing measures, any unsteadiness, nervousness, or renewal of resistance may be readily conquered by the employment of the rope- 
twitch (see page I20), which is particularly useful for making horses stand absolutely steady by word of command.

Horses brought up under ordinary civilised conditions will not, as a rule, require any of the strong means of subjection already described. Having haltered one of them, noosed a fore leg, and applied the halter-twitch (see page II6), we can generally put on the gear described in the following section, and make him quiet by mouthing him on foot with the long reins. so that he may acquire

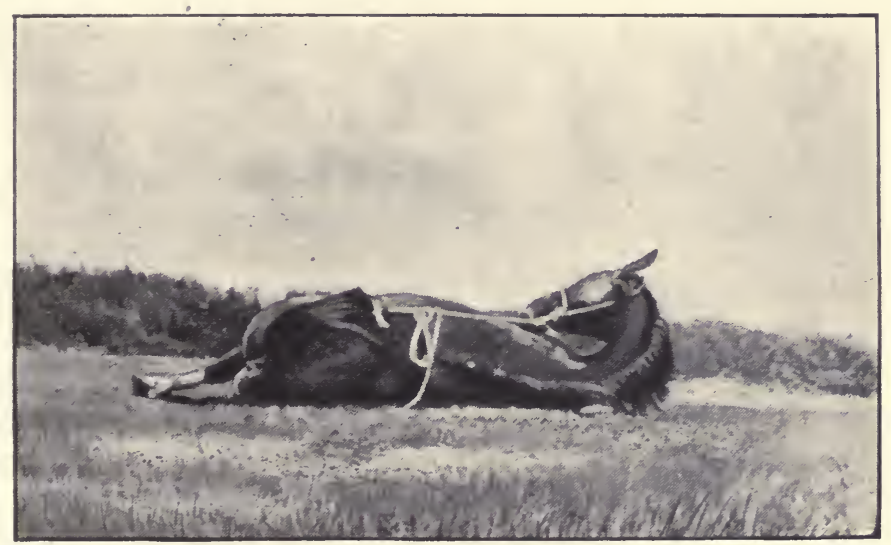

Fig. 78. - Horse tied down on ground.

both "mouth" and "manners" at the same time. To make him "stand" being girthed up, we may have to tie up a fore leg (see page II2); or may hold him with one hand on the rein or on the twitch, and the other hand pressed hard against the lower part of his neck so as to bring his head round, and at the same time to prevent him striking us with the fore leg of that side. While held in this manner (see Fig. I6), it will be difficult for him to kick the man who is girthing-up either the driving-pad or the saddle. 
MOUTHING A HORSE WITH THE LONG REINS ON FOOT.

Taking a fairly quiet, though unbroken horse, or a wild one which has been reduced to obedience according to the directions given in the preceding paragraphs, we may proceed to mouth him with the long reins in the following manner.

The gear which I use for driving horses on foot, consists of a snaffle bridle; a standing martingale; long reins; a driving-pad, which may, or may not, have a crupper attached to it for preventing it from shifting forward; and a bearing-rein, if the animal is inclined to carry his head too low down.

I have found it an excellent plan, when giving young unbroken horses their first lessons in long-rein driving, to teach them to obey the indications of the reins before placing a bit in their mouths. In order to effect this, I attach the long reins to the D's of a strong headstall, and can thus turn the animal in any direction I like without the least injury to his mouth. I would strongly recommend the adoption of this plan in all cases, when giving a horse his first mouthing lesson; because, however gentle the handling of the reins may be, it is almost impossible to avoid the action of the bit causing some slight injury to the sensitive mouth of an unbroken colt. When the horse has learnt to obey the indications of the reins on the headstall, the subsequent chances of injury to his mouth by the pressure of the bit are considerably lessened. When a young horse finds that his instructor is not teaching him a literally painful lesson, he will display his confidence by readily obeying understood orders.

The snaffle which I prefer to all others, for riding as well as breaking, is a flat, slightly curved, unjointed one, covered with leather, and having a strap to buckle behind 
the lower jaw (see Figs. Io and II). My objections to the ordinary snaffle are: (I) it pinches the sides of the lower jaw, by reason of the joint in its centre ; and (2) by being round, its pressure is confined to a very small surface of the gum, the extent of which surface is at least quadrupled by the employment of a flat snaffle not less than an inch broad. The greater the surface over which the pressure is distributed, the less liable will such pressure be to irritate

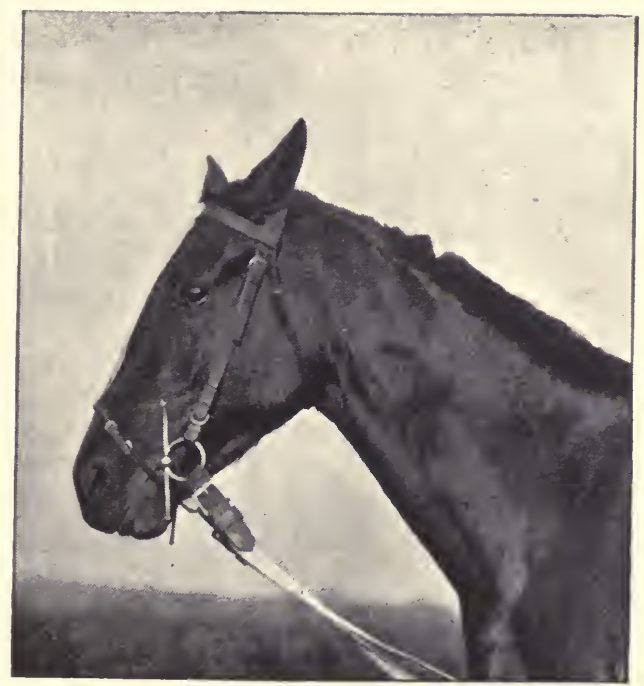

Fig. 79. - Side view ot bearing-rein.

the horse, or to render insensitive the part upon which it is applied. The snaffle I use has a flat, steel core, to give it the required stiffness. The addition, at the back of the lower jaw, of a strap which is a continuation, on both sides, of the leather that covers the mouthpiece, prevents the bit from being liable to be drawn through the mouth, and enables the driver (whether on foot or in a trap) or rider, to pull the horse's head round by acting on the lower jaw. The bearing-rein (see Figs. 79, 80 and 
8I) has a nose-band which comes under the lower jaw, in the chin-groove, below the mouthpiece of the snaffle, and is connected to the bearing-rein by a strap running down the centre of the face. The bearing-rein can be fixed to the driving-pad or saddle. This form of bearingrein keeps the head up by acting on the chin-groove, the bony surface of which is smooth and rounded. As it in no way interferes with the mouth, it is much superior to the ordinary kind, which raises the head by pressing on the corners of the mouth. As a substitute for a bearingrein, we may employ an ordinary pair of riding reins put over the driving-pad.

Note.-It is important that the horse does not hold the bit with a rigid jaw, or put his tongue out over it, for if he continues to pull on one of the gentlest of snaffles, he will harden his mouth. Therefore, if the abovementioned snaffle does not suit a particular pupil, change it at once, and try one of the common thick breaking snaffles. Some colts which pull on a straight, unjointed snaffle, will play lightly with a jointed one, and vice versâ.

The standing martingale is attached to the rings of the snaffle and to the girth of the driving-pad, and is lengthened out as much as is compatible with its preventing the animal from getting the snaffle off the bars of the lower jaw, and on to the corners of the mouth (see page 87, and Fig. 9). I like the reins to be about twenty-two feet long, and made of one and a half inch "circular" (or "pipe ") webbing. I have them buckled on the rings of the snaffle, and separate from each other; so that, if the horse tries to bolt away when being driven on foot, he can be pulled round and held fast, by letting go one rein and holding the other tight. With an ordinary snaffle, we may employ leather guards similar to those used by London cabmen, in order 
to give increased effect to the side pull of the rein, and to prevent the corners of the mouth from becoming chafed. Each guard is made of a circular piece of stiff cowhide, about four and a half inches in diameter, and having, from the centre to the circumference, an opening, which can be laced up. Or it may consist of two pieces of leather sewn together, and will then be a fixture.

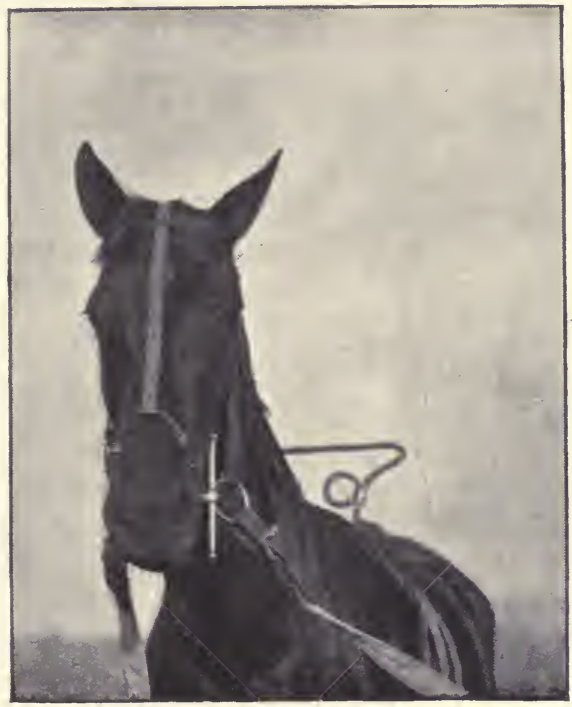

Fig. 8o.--Front view of bearing rein.

Note.-When using the long reins, the driver's movements are so very noticeable each time he reaches forward to turn the horse, that many colts will watch and turn as they see him step forward, instead of waiting for the signal from the rein. Therefore, we might, in these cases, as a prevention, drive our pupils in blinkers.

Just at first when the horse is likely to show fight, we might make the standing martingale shorter, as by so doing, we can drive him more easily where we wish. 
The driving-pad, which is an invention of mine, consists of an iron plate to which a piece of rod-iron of suitable size and shape is securely riveted (see Figs. 82 and 83). The plate is about twenty-six inches long, one-eighth of an inch thick, five inches broad at its widest part, and is made to fit the back. The rod is about two-thirds of an inch in diameter, and is curved in a special manner, so as to prevent the "outward" rein from going over the withers

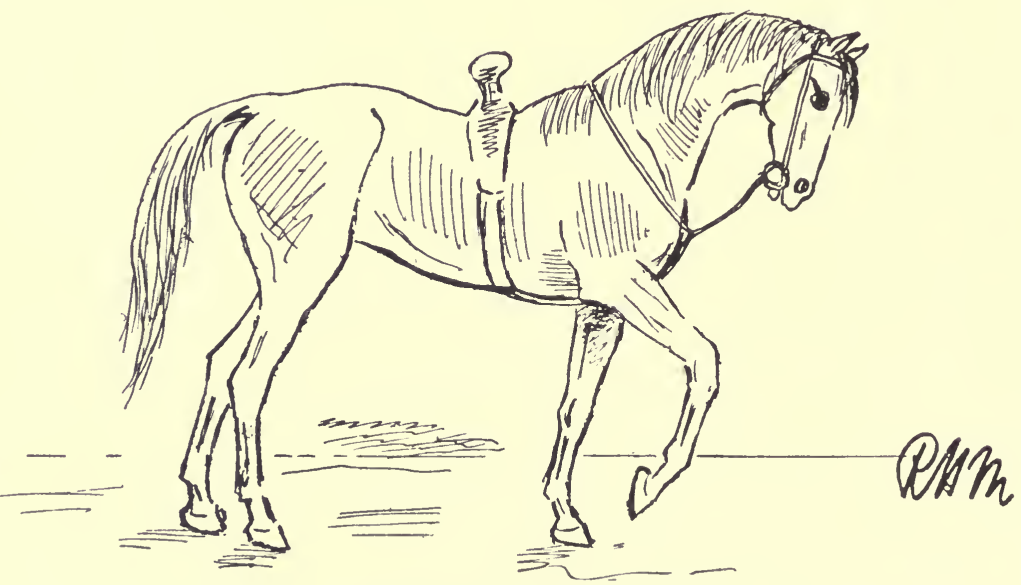

Fig. 8oA.- Standing martingale shortened.

and also to keep it, when required, on about a level with the withers. Above, and on each side of the top of the arch of the iron plate, is attached an iron ring, through which to pass the outward rein, in the event of the breaker wishing to obviate any possibility of this rein slipping over the pad, as might happen in the case of a particularly wild horse that was driven on foot for the first time. If this precaution be adopted, the breaker, when he desires to change the direction of the circle on which he is driving 
the horse, will have to take the rein out of the ring in which it is, and place the other rein in the other ring. Thus, when circling to the right, the left rein will pass through the left ring, and vice versâ. In no case will the inner rein be passed through either of the rings; for unless it is kept well away from the pad, the operator will be unable to obtain full control over the horse. The ends of the iron plate fit into the pockets of a suitably stuffed panel,

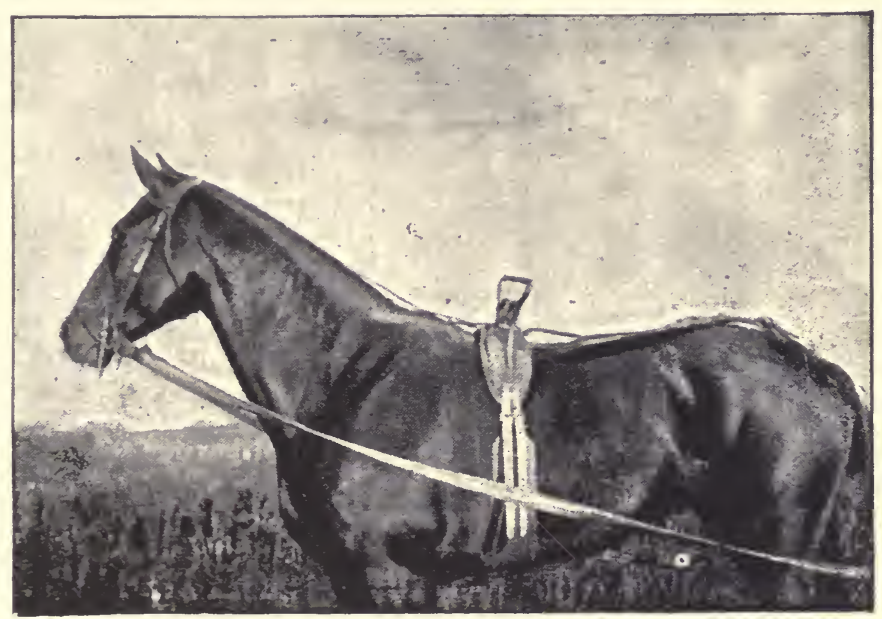

Fig. 81.-Horse with bearing-rein.

and the girth-straps, on each side, are riveted to the iron plate. Before I invented this pad, I used to employ crosstrees (see Fig. 84); on each side of which was placed a leather strap for the rein to run over. The iron pad is less cumbersome than the crosstrees, serves its purpose better, and is practically indestructible. I generally dispense with a crupper, unless the horse has thick low withers, and is particularly wild. As will be seen in Fig. 85, I used to have rein-bearers (about three and a 
half feet long, and made to lengthen or shorten as might be required) hanging from the crupper. They are useful for preventing the reins getting entangled in the horse's legs. The fact of my having discarded them as an article of breaking gear, is no doubt due more to laziness on my part, than to the possession of such skill that would make me independent of their aid.

If circular webbing cannot be obtained for the reins, ordinary driving reins or ropes of suitable length will do.

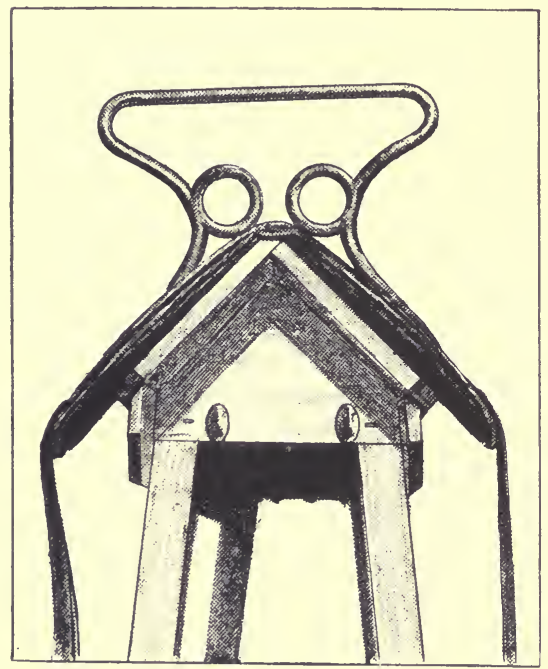

Fig. 82.-Front view of driving-pad.

A standing martingale can be improvised from a running martingale, or with a piece of cord.

When a driving-pad or an efficient substitute for it cannot be obtained, we may use instead of it an ordinary saddle, the stirrups of which, with their leathers well lengthened out, will serve as rein-bearers (see F1g. 86). Although the cantle of the saddle (see Fig. 87) may at times succeed in preventing the outward rein from going over the back; the breaker cannot-as he is able to do with my pad-when using a saddle for a substitute, circle the horse, as is often necessary, with the outward rein on a level with the withers.

Note.-When the stirrups are used as rein-bearers, we should let them out so as not to interfere with the direct pull on the bit with the inside rein, as without a direct 
pull on the inside rein it is impossible for us to prevent the horse from running back and becoming wound up in the reins on those occasions when he is a trifle rebellious; for, as we pull the rein we

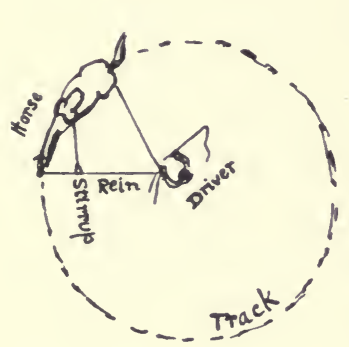

Fig. 82A.

Horse circling. force him back instead of round.

At first, our object in driving the horse with the long reins should be to get him to circle round us in well-balanced style. Hence, he should be bent from muzzle to tail in the direction he is going; the inward rein leading him off, and preserving the inward bend of his head and neck, while the outward rein passes round his hind-quarters (see Figs. 88 and 89) and thus makes the track of his hind feet the same as that of his fore ones, instead of - as would usually occur if this support were removed from the untrained horse -its forming a concentric circle outside that described by the fore feet. To obtain this effect, we should stand to the side, and a little to the rear, of our pupil (see Fig. 90), and should regulate the comparative tension of the reins so as to make the fore feet and the hind feet describe the same circle. We shall find that

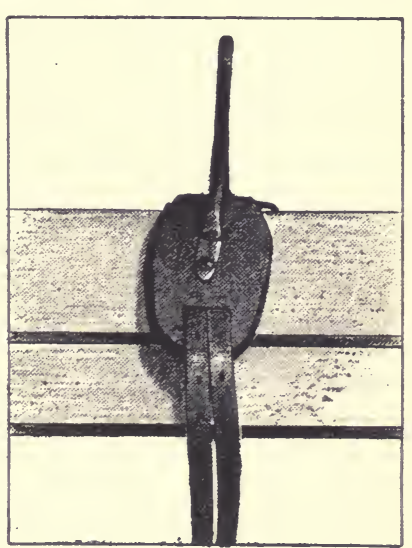

Fig. 83 .

Side view of driving-pad. the lighter the horse is in front (as in the case of a stargazer), the more must the pull on the inward rein exceed that on the outward rein; and vice versâ. Any tendency to star-gaze or to keep the head too low should be cor- 
rected, respectively, by the standing martingale or bearingrein. If the animal be excitable, it is well to commence

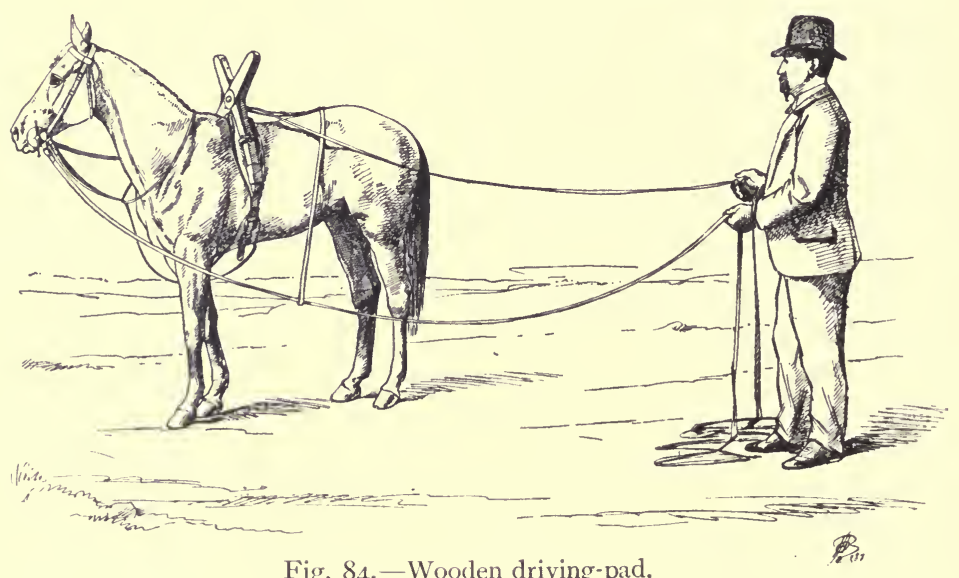

Fig. 84.-Wooden driving-pad.

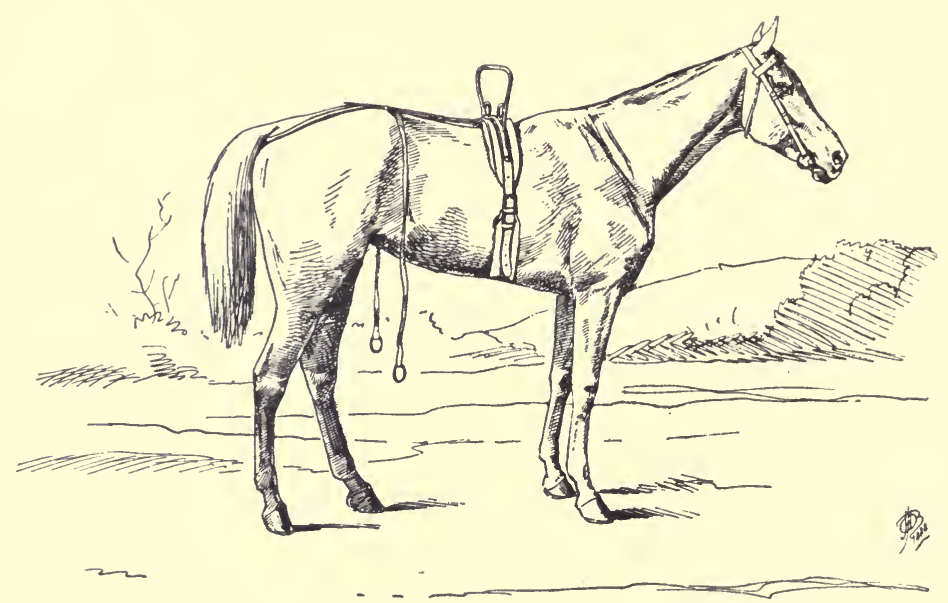

Fig. 85.-Driving-pad, crupper, and rein-bearers on horse.

with the outward rein on the pad, as in Fig. 9I. Then by turning him, bringing the reins down, touching him 
on the quarters with them, and reining him back, we may gradually make him bear their contact without his becoming nervous or fretful. Twenty minutes will be ample to enable us to effect this, even with the worst horse; provided that the animal is not a mare "in season." We may start the horse by "showing" the lunging whip, and we may at the same time "click" to him; so that by continuing the clicking and by diminishing the threatening with the whip, we may soon teach him to move off on

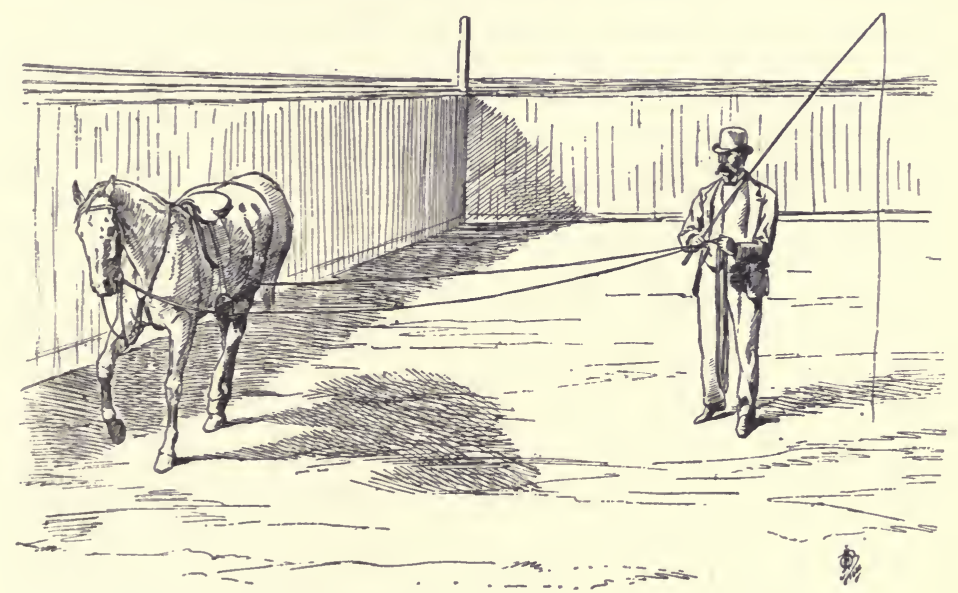

Fig. 86.-Driving horse on foot with reins through stirrup-irons.

hearing the sound of the click alone, or we may teach him to do so by raising our right hand. Having got him to circle quietly for a few times, say, to the left, we may turn him to the right-about with the right rein, which, in this case, will pull his head round to the right, and his hindquarters round to the left; making him, in fact, turn on his centre. He should then be circled to the right and turned to the left-about on the same principle. Every now and then we may halt him by feeling both reins, and when doing so, may accustom him to the word "whoa!" or any 
other convenient substitute, so as to teach him in a very few lessons to stop the moment he hears this signal without needing any hint from the reins. By acting on similar principles, we may teach the horse, when riding, or driving him, to halt in this way. While driving the animal on foot, we should adjust the length of the standing martingale or bearing-rein as may be required. The more he

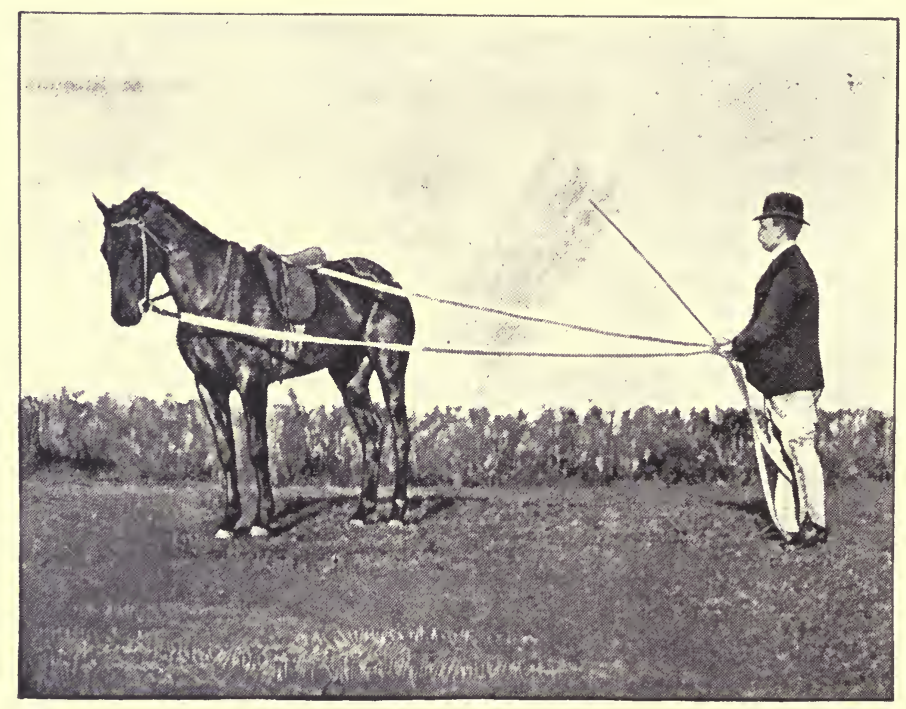

Fig. 87.- - Rein under cantle of saddle.

is inclined to "play up," the shorter, as a rule, should this martingale be, so as to afford increased control. Its use will be needed at first in the large majority of cases, and is of great service in preventing the rein from getting over the back, as well as in giving the breaker command over refractory subjects. In only a few instances, the employment of a bearing-rein, for keeping the head up, will be found necessary ; and much more often with "spoiled" horses than with young ones. The severity of either of 
these forms of restraint should be lessened according as the horse learns to obey the rein, and may be dispensed with when their use is no longer required. Before turning the horse, say, to the left, I change the reins into my right hand with the right rein crossed under the left rein. I then take a long step to the front with the left foot, slide my left hand forward on the left rein, and, having got the proper length, pull the left rein (see Fig. 92), while letting

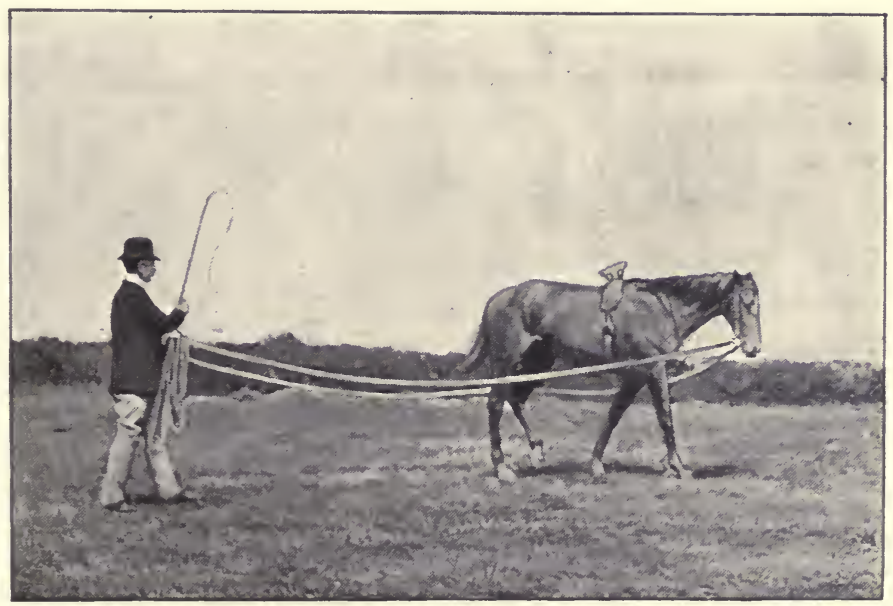

Fig. 88. - Circling horse on foot to the right.

the right one slip through the right hand, until the horse is made to turn to the left. As soon as he is in the new direction, I pass the right rein into my left hand and crossed under the left rein. We should continue the turns until the horse answers the rein as readily with his hindquarters as with his head; that is, until he learns to turn on his centre.

In turning the horse at the walk or trot, it is necessary in order that the movement may be executed with precision, that the head of the horse should be turned towards the 
new direction by the rein, at the moment, or immediately before, the fore foot of the opposite side comes down on the ground, so that, when turning, he may not cross his fore legs. When making the turn, we should be careful to prevent, by means of the outward rein, the hind-quarters from swinging so far round, that the hind feet will be carried outside the track of the fore feet. Preparatory to turning the horse at the trot and canter, we should check

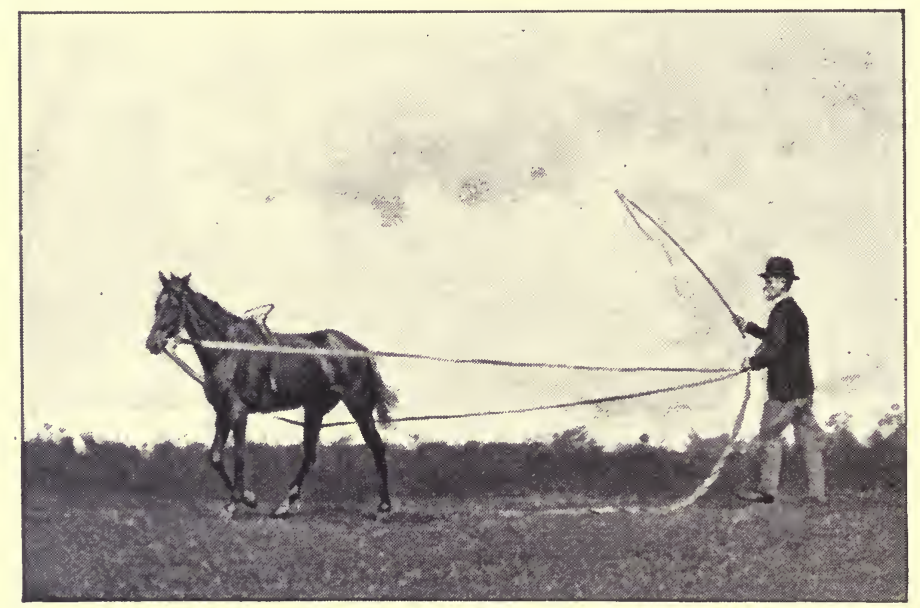

Fig. 89. - Circling horse on foot to the left.

the speed, as may be required, by feeling the reins, so that he mav come round collectedly.

After the horse has learned to do the circles and turns in good form with the outward rein round his quarter, he should be made to execute them with it on the driving-pad (see Fig. 92); so as to accustom him to its action in the position it would occupy in saddle or harness. The breaker should, as before, place himself to the side and a little behind his pupil (see Fig. 90). If he refuses to turn his hind-quarters round, when the rein is on the pad, a light 
touch or two with the whip below the hocks, so as to prevent him fixing his hind legs on the ground as a "defence," will soon teach him to come round quickly. If he be found to be "harder" on one side of the mouth than on the other he should be turned more sharply to

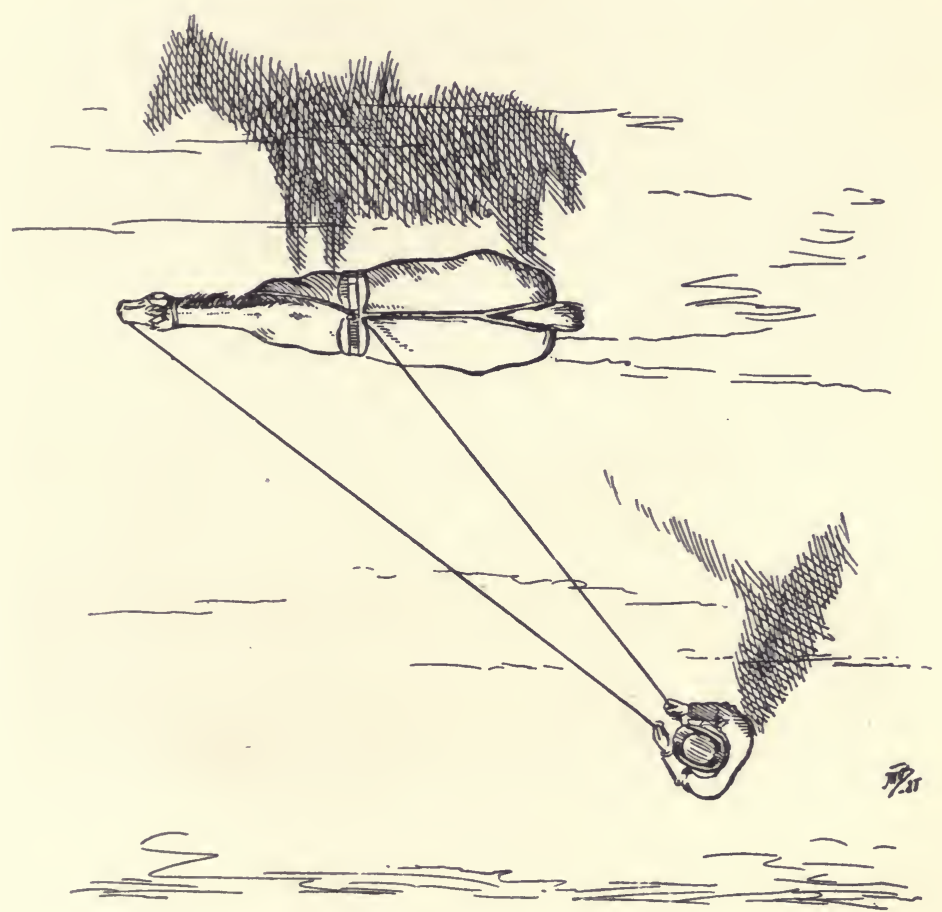

Fig. 90.-Position from which to circle horse (to left, for instance).

the former than to the latter, until he turns equally well to both sides. I advise hitting the horse, when using the lunging whip, below the hocks; for he is less liable to show the marks of the lash on that part of his legs, than above the hocks, where the bones are covered with muscle. Besides, I am inclined to think that a cut below the hocks 
is more likely to prompt a horse to go on, and is less apt to make him kick, than one above them.

Note.-If the horse seems harder at one side of his mouth than at the other, we should make sure that the mouth is not in a painful state, before we try to remedy it by sharp pressure. During a dispute the horse may have got his mouth or tongue hurt, and this would naturally

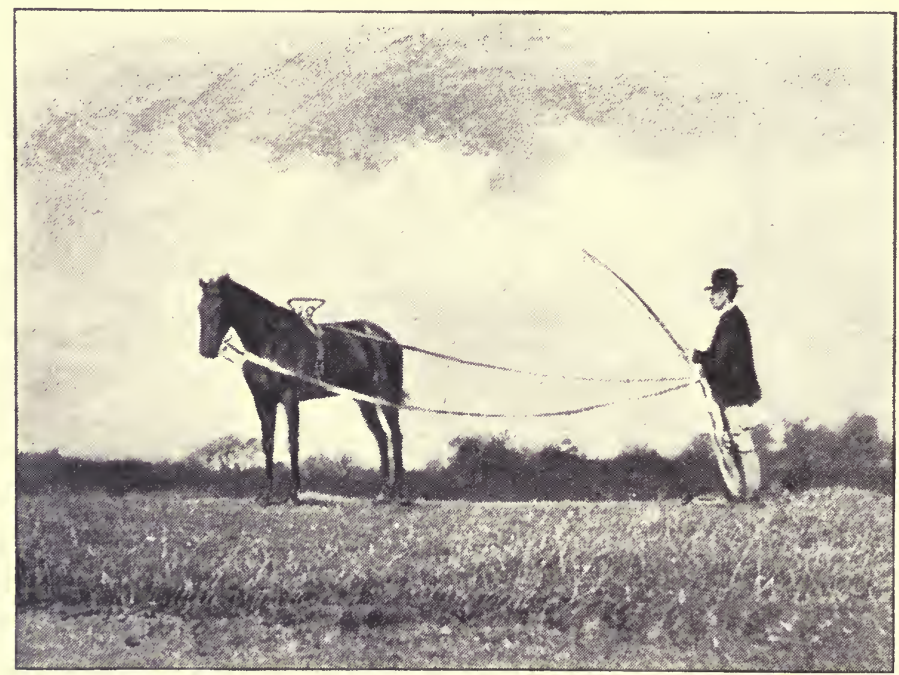

Fig. 9I.-Outward rein on driving-pad.

cause him to hold the bit towards one side and carry his head in what seems to us an awkward way while he is trying to save the injured parts from pressure. In this case we should give his mouth a rest till it recovers.

The circling with the long reins on foot, should be performed on the same principle as that adopted by a capable rider, the pressure of whose drawn-back outward foot is replaced by that of the outward rein. Practice in driving 
on foot is an admirable means for improving one's "hands;" whether for riding or driving.

I should give my first lesson, as I have already mentioned, with the long reins buckled on to the D's of the headstall, and should make the horse thoroughly obedient to the indications of the reins, before putting a bit into his mouth. This lesson should not exceed twenty minutes in length, during which time the horse should have learned to move

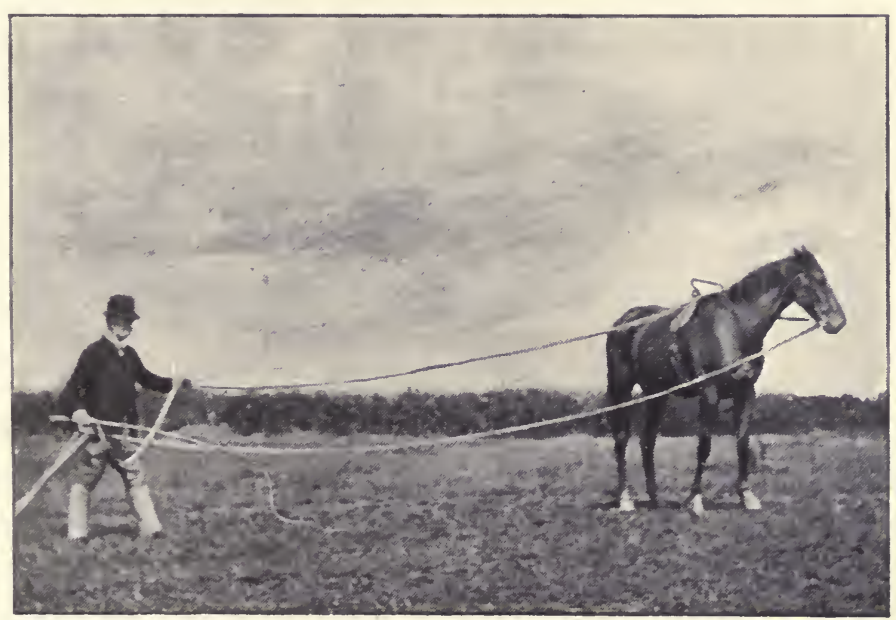

Fig. 92. - Turning horse with rein on driving-pad.

off at the walk on being shown the whip or "clicked" to ; to readily turn to the right, left, right-about or leftabout, on receiving the proper indication of the rein, and to halt. This will be enough under ordinary circumstances; although, on an emergency, this modest limit of instruction may be greatly exceeded. After the horse has thoroughly learned to obey the driver's orders conveyed to him by the reins on the headstall, he may be driven in a snaffle without danger of injury to his mouth. 
The breaker should be thoroughly proficient in the art of long-rein driving and should have obtained the necessary practice on steady, broken horses, before attempting the instruction of a young one. He should also bear in mind the absolute necessity of, outwardly at any rate, keeping a serene, unruffled temper with horses, under even the most trying provocation, and especially in breaking young horses. On more than one occasion I have had a stubborn argument of over six hours' duration with obstinate jibbers ; for I knew that if I had punished them with the whip, my labour would have been entirely in vain. Therefore, as I have already mentioned, success in horse-breaking can only be obtained by an unlimited amount of patience on the part of the instructor.

If the horse be inclined at any time to make too large a circle, we can cause him to describe a smaller one by drawing on the inward rein and slackening off the outward one, the proper amount of feeling on which we should gradually restore according as we gain control over the animal. Sometimes the horse, to avoid the action of the reins, decreases on his own account the size of the circle on which we are driving him. To nullify this defence, we should feel the outward rein the stronger of the two and should drive the horse away from us, so as to get more behind him than previously, and should then gradually lead him off by the inward rein into the desired circle. If he shows "fight," which he will very seldom do with the long reins, we may have to rein him back (see page I86), turn him from one side to the other, or threaten him with the lunging whip.

The whole of the long-rein work should, as far as possible, be done in the circle; for that is, from my experience, the only way by which the driver on foot can preserve a light feeling on the reins. If he drives the horse straight on in 
front of him, he can hardly prevent himself, for the greater part of the time, from keeping too heavy a pull on the animal's mouth. The objectionable practice of driving youngsters on foot for miles along a road, as may be seen in full operation at Newmarket and other training resorts, is a fruitful cause of the dead mouths and habit of boring possessed by the majority of racehorses. The animal, to relieve the bars of his mouth from the constant and painful pressure of the mouthpiece, naturally gets his chin into his chest, in order to transfer a portion of the pull of the reins to the crown of his head. Instead of acting in this fashion, the breaker, if he wants to give his pupil a walk on foot, might, after having mouthed and exercised him in the manner I have described, take him out with the crupper leading-rein (see page 195), the use of which contrivance would obviate any risk of spoiling his mouth.

During the second lesson, which may be given on the afternoon of the day on which the first one was imparted, we may repeat the previous instruction, and then teach the animal to rein back. This is done by bending his head, say, to the left by the left rein, while preventing his hindquarters, by the pressure of the right rein, from turning round. When we obtain this bend, which will naturally put more weight on the legs of the near side than on those of the off side, we should feel both reins, so as to make him take a step to the rear. He will of course do this, other things being equal, more readily with the more advanced hind leg, than with its fellow, supposing that he is not standing "level." Hence his head in the first instance should be turned to the side of the least advanced hind leg. When we obtain this step, we should turn the horse's head to-say, in this case-the right by the right rein in order to obtain the next step; and so on. While working in this way we should try to get the near 
fore to move simultaneously with the off hind, and the off fore with the near hind, so that the rhythmical pace of the rein-back will be a diagonal one of two time (namely, a trot: see Points of the Horse, and not a walk); for the horse is found to rein-back in an easier and more collected manner at the former than at the latter pace. If he is inclined to get his head up, it is best to stand directly behind him. If he lowers it as a defence, we may rein him back with one rein on the driving-pad (see Fig. 9I), or, what is probably the better plan, we may use a bearingrein to keep his head in proper position. Although we should in no way make the work unduly irksome to the horse, we should not be contented unless we get him, in this second lesson, supposing, of course, that he is not a particularly stupid pupil, to rein-back in well-balanced style, twenty or five-and-twenty yards, three or four times. Such a demand will, I feel certain, be considered outrageously severe by those who are unacquainted with the possibilities of the long-rein system; but it is, as I have proved many hundreds of times, with a competent long-rein driver, a thoroughly legitimate one. If the horse, as a defence against the rein-back, fixes his hind quarters, we may render them mobile by cracking the whip or by touching him lightly below the hocks with the lash. We may also take some of the weight off the hind-quarter by shortening the standing martingale. If we cannot effect our purpose by these means, we may place an assistant in front of the horse to threaten him on one side of his hind-quarters and then on the other, while we are occupied with the long reins. Or he may, while standing in front of the horse, take hold of the reins, one in each hand, close to the rings of the snaffle, and aid our efforts in regulating the height of the horse's head and in pressing him back. The presence of the assistant in front of the 
animal will naturally tend to make him rein-back easier. Although I have never found it absolutely necessary, we might at this stage teach the horse the turn on the forehand (see page 193), so as to give mobility to the hind legs. In solving the question of adjustment of weight in the rein-back, we should fully utilise our power of placing the horse's head in whatever position we like (whether by lowered rein, rein on pad, standing martingale, bearingrein, or by the help of an assistant), and that of mobilising the hind-quarters by means of the whip. In executing the rein-back, the horse should be light behind and should lift up his hind feet well, so that his movement to the rear may be executed with safety and freedom. Consequently his head, which is the weight at the end of the balancing pole of his body, should be kept considerably lower (see Fig. 7) than if the movement was to the front. We should here particularly avoid the run-back, in which the horse is liable to fall down on account of the preponderance of the weight being on the hind-quarters. In this case the centre of gravity of the horse's body is brought to an undue extent to the rear, and the ability of the hind legs to form new bases of support is diminished in proportion to the weight imposed on them.

After we have obtained the correct rein-back, we should practise the horse-with the outward rein round his quarter or on the pad, as may be required-at walking in a collected manner, using the whip as a stimulant, the outward rein as a substitute for the drawn back outward leg of the rider, and both reins as a restraint and as a guide. The outward rein, if shaken against his hind-quarters, may serve as a slight though useful incitement for making the horse collect himself. Reining him back from time to time, as may be required, will often be found serviceable ị thịs "setting-up drill," 
When the horse is able, say, after two or three lessons, to go through in a competent manner at a walk the longrein work which I have described, he may be made to do it at a trot and canter. At both these paces, the size of the circle should be gradually diminished in order to teach the horse to collect himself.

Although the horse will, after a time, learn to strike off from the walk or trot into the canter with the leg appropriate to the circle on which he is being worked, it is well to teach him to do so on receiving a suitable signal, which can be utilised when riding the horse in a straight direction. Thus, when circling the horse to the right, for instance, at the walk or trot, with the outward rein round the quarters, I would, in order to give the animal the signal to strike off into the canter with the off fore leg leading, feel the left rein the stronger of the two, so as to turn the horse's head a little outside and his hind-quarters a little inside the circle, and then make him strike off correctly by feeling the right rein, and by "showing" him the whip, or clicking to him. The lead with the near fore, while going on the left circle, would naturally be obtained in the reversed manner.

A dozen lessons, two a day, will under ordinary circumstances be ample for teaching the horse the work with the long reins up to this point. The discipline gone through during that time, combined with the "gentling" action of the reins on the hind-quarters, will in the large majority of cases have taken all, or nearly all, of the nervousness, impatience of control, or aggressiveness out of vicious, wild or otherwise "difficult" animals.

By circling, turning, and reining back a horse with the long reins, we can readily form a good idea of his manners, mouth and temper.

When putting on the long-rein driving gear, we should 
be careful to place on, first of all, the bridle and long reins; then the driving pad with one girth tightly buckled up; the standing martingale through which the second girth passes; the bearing-rein, if required; and finally the crupper. When removing these articles, the reversed order of procedure should be observed. These precautions are necessary in order that excitable or vicious horses may not be prompted to kick or " play up," after the girths of the driving-pad have been undone, but before the connection of the pad with the martingale and crupper has been severed. While on the subject of adjusting gear, I should point out that if we want to put a bridle on a horse which has a headstall on, and which we cannot depend upon standing still with the headstall off, we can place the bridle over the headstall, and then take off the headstall without shifting the bridle in any way, by undoing. the buckle of the headstall and by taking off the browband and the strap which goes through the buckle. If we then draw the noseband forward (see Fig. 93), we can easily detach the headstall by passing the noseband into the mouth, over the snaffle, and finally out of the mouth. On more than one occasion, I have had difficult horses break away from me at the critical moment, between the removal of the headstall and the putting on of the bridle, which has to be passed through, unless the foregoing precaution be adopted.

Nore.-If the headstall is removed from the head and instead buckled round the horse's neck, it will be found sufficient to hold him safely while the bridle is put on, and will be out of the way of the bridle.

American "horse-tamers," none of whom I have as yet found to be horsemen with any knowledge, scientific or otherwise, of the art of riding, use the long reins without a 
standing martingale or driving-pad, and" pass them through rings on a specially constructed surcingle, or through the shaft rings of an ordinary single harness pad, or through the irons of a riding saddle. Men who try to mouth horses in this manner are apt to frequently fail in teaching their pupils to bend their necks to the rein, and at the same time to go up to the bridle; for the majority of animals thus

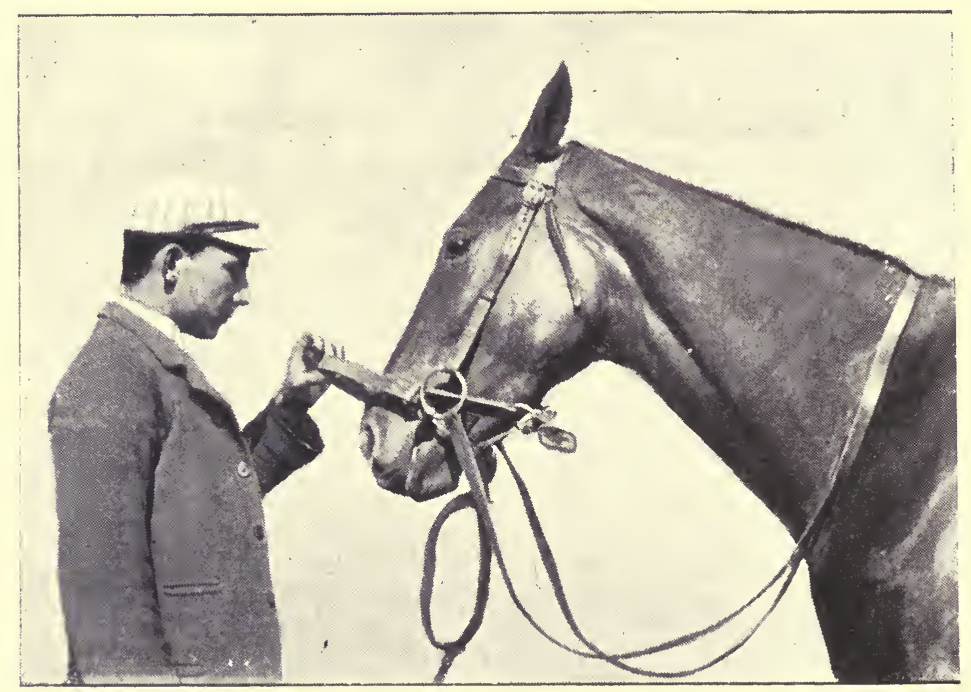

Fig. 93.--Removing headstall without displacing bridle.

treated would resist the action of the mouthpiece by chucking up the head in the attempt to get the mouthpiece off the bars and on to the corners of the mouth. Besides, the horse omits to learn the valuable lesson which the use of the standing martingale inculcates, namely, that of bending his head and neck to save his mouth. When both reins pass through rings on the surcingle, or through the shaft rings of a harness pad, the driver on foot is prevented, by the fact of the inward rein going back to the surcingle 
instead of coming straight from the ring of the snaffle to his hand, from standing in the centre of the circle on which he drives the horse, and is consequently obliged to more or less follow the animal, and by doing so (see page I85) is apt to bear unduly on the reins, and make the horse's mouth "dead." The absence of a driving pad deprives the breaker of the great advantage of being able to raise or lower the outward rein at will. In breaking for harness,

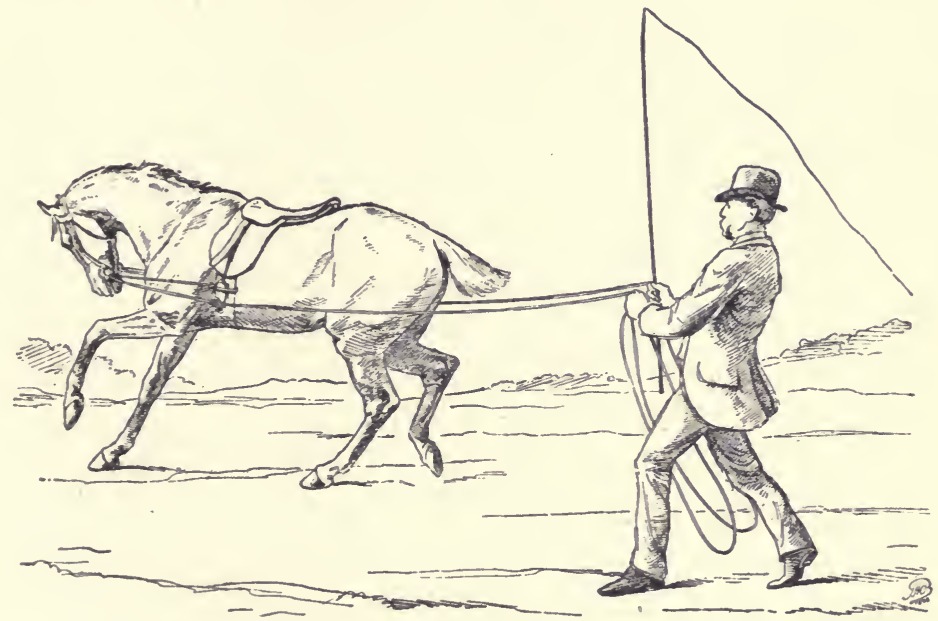

Fig. 94.-Driving horse with running reins through stirrup-irons.

and especially for fast trotting on level ground, the necessity for teaching horses to bend the neck, to get the hindquarters under them, to moderate the speed in response to a pull on the reins, is not nearly so imperative as in educating the hunter, chaser, and charger, which should always have a "spare leg" for any emergency. The method of long-rein mouthing is as applicable to "spoiled" horses as it is to entirely unhandled animals. To my thinking, one great beauty of it-apart from its immense advantage of never giving the pupil the chance of getting the upper 
hand, which he might easily do if the breaker were in the saddle-is that the breaker can at any moment tell how his pupil is progressing by the feeling of the reins, and can accordingly, with well-grounded confidence, use his own judgment in regulating the amount or the nature of the instruction. I am aware that $\mathrm{I}$ am repeating myself in dinning this fact into the ears of my imaginary pupils. The man who, on the contrary, tries to mouth a horse by "tieing him up" by means of side reins, dumb jockeys, or pillar reins, must necessarily work, as I have already said, more or less in the dark and by rule of thumb; for he cannot gauge the progress which his pupil is making, except by trying the animal in saddle or harness. Besides, he commits the two grave faults of working only one end of the body (see page 63), and of endeavouring to "supple" the head and neck of a stationary animal (see page 72). With the long reins we avoid both these errors, and remain in constant touch with our pupil.

Colonel Wardrop showed me a method he practises of driving horses over jumps with long ropes which pass through the stirrup-irons and rings of the snaffle, and are fixed on tightly to the girths and stirrup-irons on their respective sides (see Fig. 94). This excellent authority on the art of training horses to safely "negotiate" the difficult country met with in Ireland, tells me that he has found this method of great use for teaching horses to collect themselves when coming up to the big banks and ditches which are to be seen in the counties of Kildare, Tipperary and Cork. After the horse has been thoroughly taught the long-rein work according to the system I have described, Colonel Wardrop's plan might be useful for giving him a few practical lessons over the obstacles in question.

All I know respecting the antiquity of long-rein driving on foot is that Fallon, an Irish breaker, who was an old 
man at the time, taught, more than sixty years ago, this method of mouthing to the late Mr. John Hubert Moore, the famous trainer of steeplechase horses.

TEACHING A HORSE TO TURN ON HIS FOREHAND.

Having taught the horse by means of the long reins to understand and obey the aids for turning on his centre, we

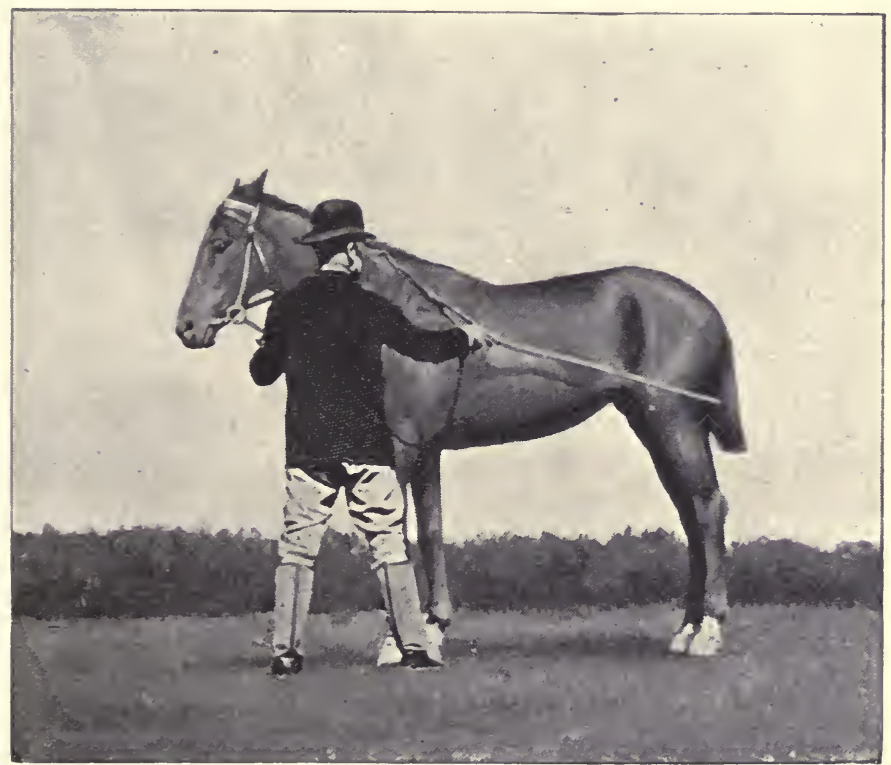

Fig. 95.-Making horse, on foot, turn on his forehand to left with whip.

may proceed to make him equally proficient in those for the turn on the forehand, which is a particularly useful means for teaching him to go up to his brdile, by transferring weight from his hind-quarters to his forehand, and for giving increased mobility to the hind-quarters-of the rearer for instance. The turn on the forehand is the normal way in which a horse changes his direction when at liberty in an open space. 
The turn on the forehand is made on the off fore as a pivot (moving or fixed), when the hind-quarters move from right to left (in the direction taken by the hands of a watch). This I shall call the turn on the forchand to the right; and the movements of the hind-quarters from left to right, with the near fore as a pivot, the turn on the forehand to the left. Respecting the "school" acceptation of these terms, see page $27 \mathrm{I}$.

To teach the horse on foot the turn on the forchand to the left, we may, while facing him and standing close to his near shoulder, take hold of the near rein of the snaffle, not far from the mouthpiece, in the left hand, and the off rein, passed over the lower part of the neck, in the right hand, which also grasps a cutting whip or cane (see Fig. 95). Our object here, as I have already indicated, is to cause the horse to circle his hind-quarters from left to right (in a direction opposite to that in which the hands of a watch move) round the near fore foot, which at first should describe a small circle (that is, it should be a moving pivot); but may, when the animal's education is further advanced, perform the more difficult task of turning round on its own axis without quitting the ground. At first the horse's head should be turned to the left, so as to render the near fore leg more or less stationary, by increasing the amount of weight on it; but later on, it should be kept in the same line as the body, or it may be even slightly turned to the right; for if it be held in either of these directions, the balance of the animal's body will be better preserved than if his head were turned to the left. By lightly touching the near quarter with the whip we should endeavour to make the horse move his hind legs to the right. To prompt him to describe, as he ought to do, a circle round his near fore with his off fore, we may, as often as may be required, touch with the 
whip the back part of the fore arm of the off fore. We should strive to obtain precise movements without any approach to hurry, and by justly meted-out punishment and reward should make our wishes clearly intelligible to our pupil. After a few lessons, the horse may be made to turn on his forehand while holding the head and neck straight, in which position, as I have just said, his equilibrium will be better preserved than if the head were turned to the left. The left rein will, if required, prevent the horse from reining back, and will also keep his head at the desired height. The off rein will stop him from going round too quickly; and both reins will aid in checking any forward advance on his part.

In teaching the turn on the forchand to the right, we should place ourselves near the off shoulder of the horse, and should use the reins and whip in the reversed manner to which we did for obtaining the turn on the forehand to the left. As the action of the whip in this case is preparatory to that of the drawn-back foot of the rider; we should gradually advance its point of contact with the skin until we gain our object by touching the horse with the whip on that portion of his side which the heel or spur would reach.

Teaching the horse to turn on the forehand in obedience to the proper aids, is, I think, essential to the education of all saddle horses; for it is the best preparatory means for making them readily obey the leg.

\section{TEACHING A HORSE TO LEAD.}

After giving the horse his lessons with the long reins, and making him turn on his forehand, there will be little or no difficulty in getting him to lead, which he may be taught to do by using the crupper leading-rein (see Fig. 96) and the words "Come here!" or any convenient substitute, when 
pulling the rope, so as to make the horse connect in his mind the idea of having to come up to us with the verbal command. The crupper leading-rein can be readily made by taking a long rope, doubling it, making a loop in the middle by knotting it, and passing the loop under the horse's tail, and the ends of the rope through the halter, or rings of the snaffle. To prevent this slipping over the tail when it gets slack, we may put a knot in it, in front of the rings of the snaffle, or of that part of the headstall

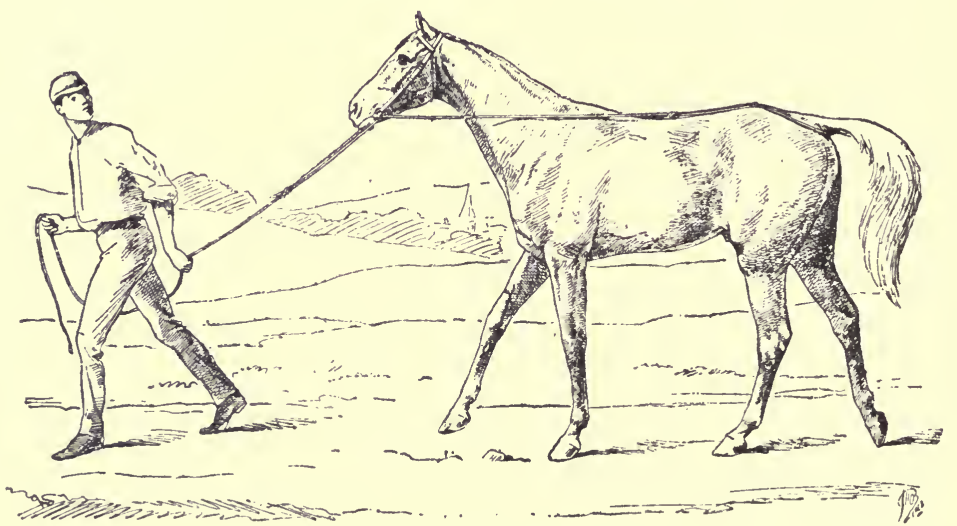

Fig. 96. - A crupper leading-rein.

(see Fig. 97) through which it has been passed. Or we may employ the Comanche bridle (see page r26), which I think is the best means for teaching a difficult horse to lead. I have also found the use of the rope halter (see Fig. 24) very effective; for the pain which the pressure of the rope round his jaws will cause him when he hangs back, will be instantly relieved the moment he goes forward. For making a horse merely come up to one, I like Baucher's method, which is as follows: Hold the reins in the left hand, as in Fig. 98, or the crupper leading-rein, and continue to lightly touch the 
horse on the breast with the end of a cutting whip or switch, until he "comes up," when he should be immediately rewarded by the cessation of the punishment, by being patted on the neck, and by being spoken to in a caressing manner. As a rule, the horse will at first try to avoid the blows by running back, or by swerving to one side or to the other; but failing to escape from

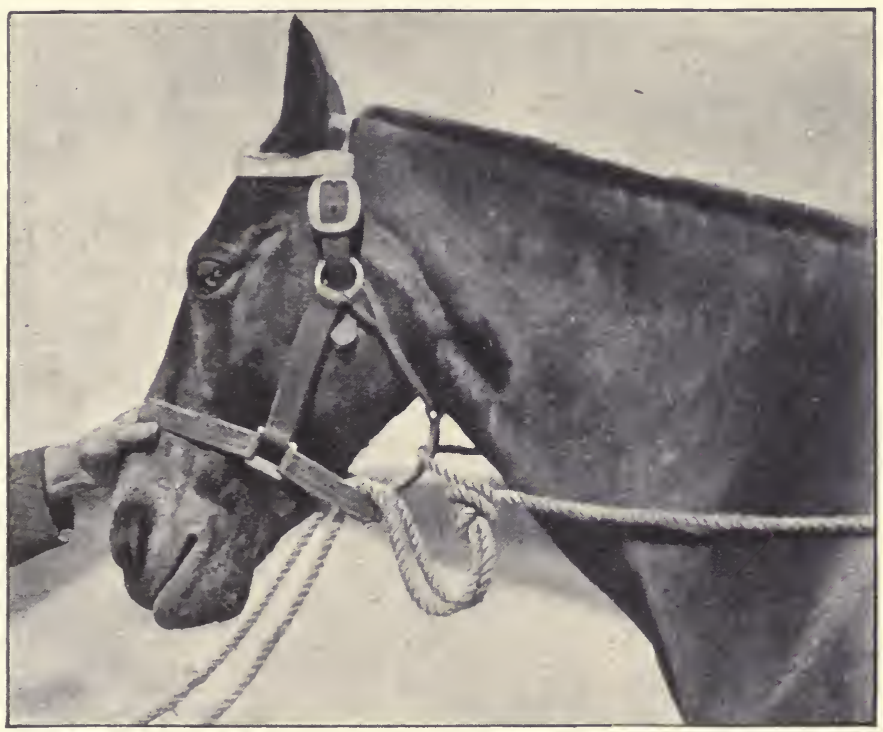

Fig. 97.-Knnot in crupper leading-rein.

the inflicted pain, he will almost invariably go forward. This desired effect is obtained usually in not longer than ten minutes. Three or four lessons will generally be sufficient to make the horse come up to one the moment the whip is pointed towards his breast.

Learning to obey this signal, and that of standing still as a statue on hearing the word "steady," are two very desirable accomplishments in the horse. 
We are all aware that the tendency of a horse when being led by an ordinary leading-rein or by the bridle reins is to "hang" on them, and if jerked by them, to resist the pull given. The use of the crupper leading-rein, on the contrary, prompts the animal to move collectedly on account of the pressure of the rope under his tail stimulating him to bring his hind-quarters under him. I do not know who invented this form of leading-rein, which was employed by Fanchion, Magner, Pratt, Rockwell, and other American "horse-tamers." It is also an admirable means of making - and consequently teaching-a horse to follow a cart or trap behind which he is tied, and also for getting a nervous horse into a railway box. When pulled by the head the natural tendency of a horse, as I have just said, is to resist; but when drawn forward by a rope or other similar material passed under his tail, he is strongly prompted to go on. If a horse which is attached by his head to a carriage in motion happens to make a stumble, the rein or leading rope on becoming tight will have the effect of increasing the weight on the forehand, with the probable result of pulling the animal down on to his knees. If, on the contrary, the horse be attached to the back of the vehicle by the crupper leading-rein, the pressure of the rope will fall on the hindquarters without any interference with the head.

When a man on foot leads a horse, he should, supposing that he is on the near side of the animal, bring the reins over the horse's head, hold both reins at a convenient distance from the mouthpiece in his right hand with the little finger between them, and should have his left hand between the reins at their centre (see Figs. I3 and I4). When the reins are held in this manner by the right hand, the right rein can be tightened by the action of the little finger on it; and a far firmer hold can be obtained, es- 
pecially if the little finger be turned towards the body by the rotation of the wrist (see Fig. 14), than if the reins were separated by the first finger, as directed in Cavalry Drill.

Horses should be taught to lead on the off as well as on the near side. As it is customary to lead a horse only on the near side, and as the man who leads him along a road should in all cases keep himself between his horse

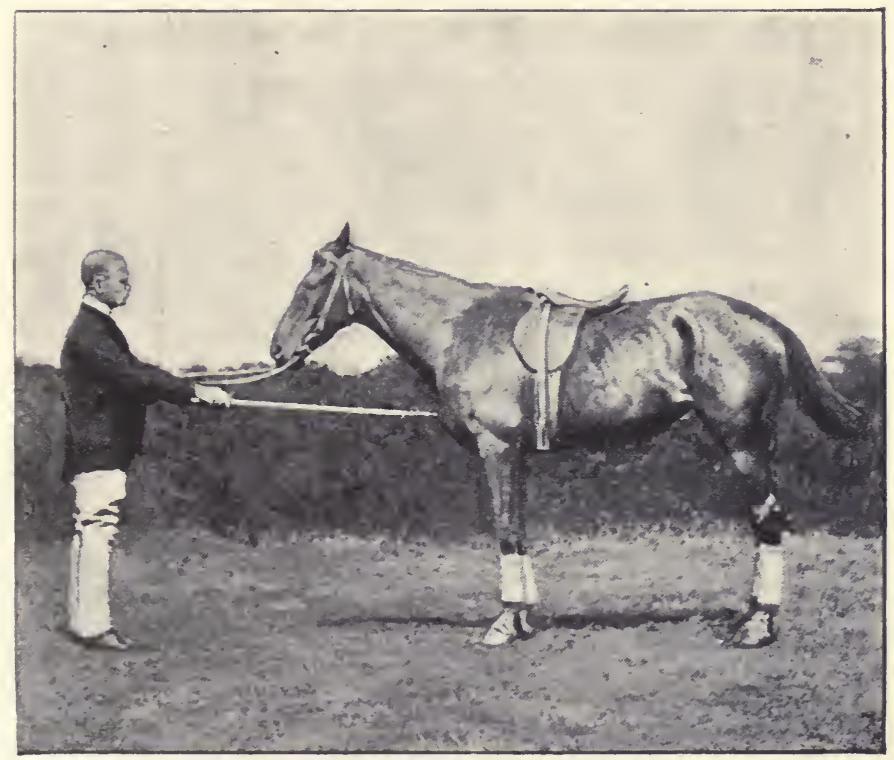

Fig. 98. - Teaching horse to "come up" by tapping him on chest with whip.

and any passers-by, so as to be able to prevent the animal swinging his hindquarters round into danger; led horses are supposed to keep to the right side of the road. With a horse which leads equally well on both sides, the better plan, when leading him along a road, would be for the man to remain on the off side of the animal, and keep him on the left side of the road. 
For leading young horses, a circular mouthpiece is sometimes employed. With it the pressure on the bars is evenly distributed on both sides of the mouth. Or we may use a leading-rein with a pair of spring hooks at one end.

When a mounted man leads a horse which has on a snaffle or double bridle, and which he wants to lead on his off side by the snaffle, he should pass the off snaffle rein through the near side ring of the snaffle (see Fig. 99).

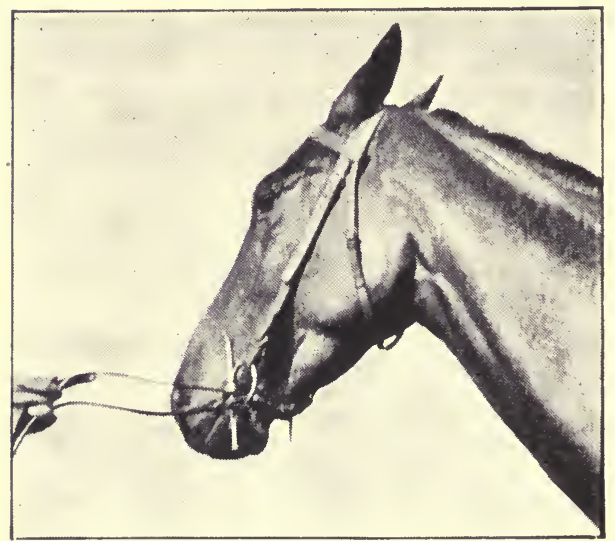

Fig. 99.-Off rein passed through near ring of snaffle for leading horse. 
CHAPTER VI.

\section{ORDINARY MOUNTED BREAKING.}

General remarks-Mounting ${ }^{-}$a horse for the first time-Turning a horse on the forehand at the halt when mounted-Reining back-The walk-The trot - Turning a horse during movement-Teaching a horse to carry his rider in a collected and well-balanced manner-The canter-The halt-Whip and spurs-Time required for ordinary breaking to saddle.

\section{GENERAL REMARKS.}

THE work described in the preceding chapter is applicable to all kinds of horses. In the present one, the whole of the course laid down is suitable to hunters, hacks, chasers, and race-horses. The amount of collection practised should be proportionate to the purpose for which the animal is intended; the maximum, with respect to the horses just mentioned, being observed with the hack; the minimum, with the race-horse. The lady's hack and hunter, besides the work herein detailed, should have a certain amount of special training, to which I shall allude further on. The trooper and high school horse, before being taught any of the airs de manege, may get all the instruction given in this chapter with the exception of the changes of leg at a canter in the figure of eight, to which subject I shall more particularly allude in Chapter IX. I shall reserve the consideration of the breaking of harness horses for Chapter VIII. 
MOUNTING A HORSE FOR THE FIRST TIME.

Having put the horse through the preceding course of discipline, we may test his readiness to bear a rider byafter having saddled him-placing across the saddle a halffilled sack of corn or earth, while using the rope-twitch to correct him in the event of his evincing any resistance or alarm, pretended or real. Having attached the sack firmly to the saddle, we may keep circling, turning, and reining back the horse with the long reins (see page I75), until he becomes quite steady. We may now remove the sack and apply the rope-twitch without shifting the bridle. While the breaker holds the rope-twitch in one hand and the long reins in the other, an assistant may prepare to mount; any unsteadiness being corrected by the rope-twitch. Although I have never known of a case of a horse, however violent he may have been, breaking away when held only by the rope-twitch; still the long reins will be useful as a further precaution in the event of the animal trying to get away. With this object, it is well to pass the right long rein through the left ring of the mouthpiece of the snaffle, as in Fig. 99. The assistant should quietly mount and dismount several times, the horse being rewarded or punished according to his conduct. When he has become accustomed to these operations, the man should mount, and the breaker having given the rope-twitch to another assistant, should arrange the long reins so that he may be ready to drive the horse on foot. He should take a short and firm hold of the reins, so as to get good command over the animal, and should order the rope-twitch to be removed. The mounted assistant, to steady himself, may catch hold of the neck strap of the standing martingale (see Fig. Ioo), which in all such cases should form a part of the breaking 
MOUNTING HORSE FOR FIRS'T TIME. 203

gear. The breaker may now proceed to circle and turn the horse. If the animal attempts to "play up" he should be reined back, turned sharply from side to side, and held well in. As soon as the pupil takes the presence of a man on his back as a matter of course, while he is being circled and turned at a trot, as well as at a walk, the

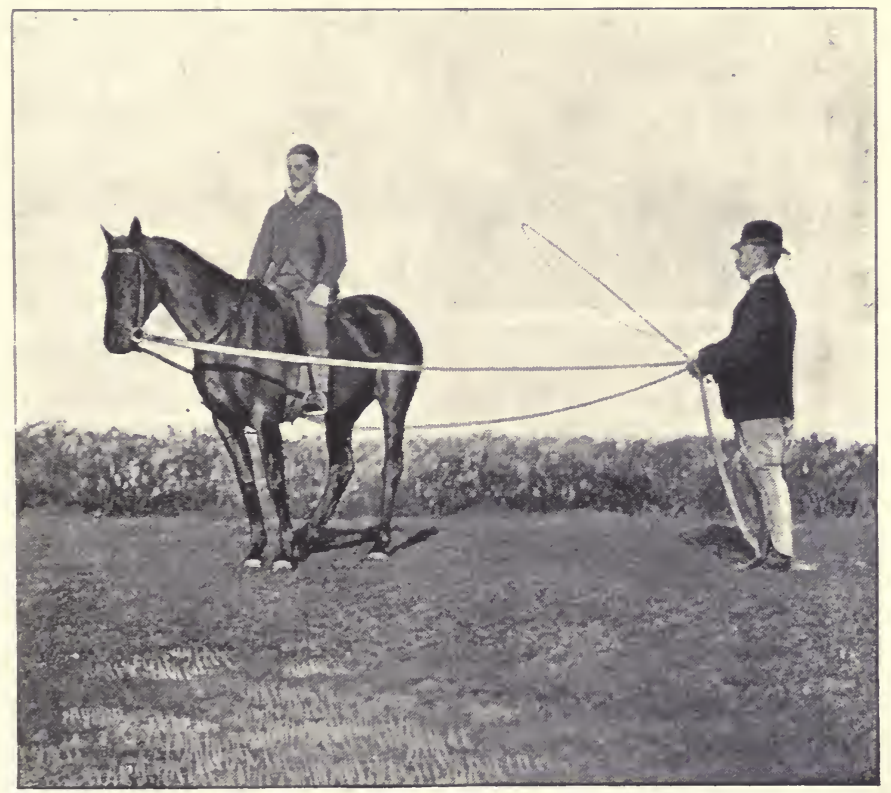

Fig. 100.-Horse mounted for first time.

mounted assistant may be given a pair of ordinary reins to hold and to guide the horse, while the breaker manipulates the long reins, which may be removed after a few minutes, and the entire guidance of the animal confided to the rider. By degrees the rider should accustom the horse to the feel of his drawn-back and unarmed heels, and may stimulate the animal to go on by "clicking" to him. He should be careful while circling, turning, reining back, walking and 
trotting the horse, to use the reins in as nearly as possible the same way as the breaker did on foot.

In the following description of mounting the horse for the first time, I have mentioned some precautions which, like the use of the heavy sack and rope-twitch, would be necessary only in exceptional cases. If we err, we should certainly do so on the side of prudence; for one of the worst possible lessons which the horse can learn is that of finding out that he can throw his rider.

In cases of difficulty, or when great expedition is demanded, we may adopt the following method, which I believe I have been the first to think out and put into practice. Having made the horse go round and round according to the head and tail method (see page I55), and having by it taken any remaining " nonsense" out of him, put over the headstall-which I take for granted has a short strap or rope attached to its off-side D, see page ${ }_{5} 6$ -a snaffle bridle, and knot the reins to the animal's neck, so that they will not hang down. Place the saddle on the horse's back, pass the outer girth of the surcingle over the cord which connects the head with the tail, and girth up. The requisite extent to which the head should be turned round by the action of the cord, will be attained when the animal is tied up just short of what would cause him to fall down, if he were allowed to go round on his own account. Having taken in the left hand the leading rein which is fixed to the off $\mathrm{D}$ of the headstall, we should walk the horse round and round several times, and should test his amenability to discipline by stopping him with the leading rein (see Fig. IOI), and then pulling him round again. If he resists us, we may feel convinced that he is not under proper control, in which case we should, before proceeding further, render him thoroughly docile according to directions already given. We should satisfy ourselves (see 
page 325) that the horse will not resent his sides being touched with the heels of the rider later on. When we think that the animal is fully under control, we should get an assistant, while standing on, say, the near side, to catch hold of the mane about half way up the crest with his left hand, the stirrup-iron with his right hand, and go through the various stages of mounting, beginning with putting his left foot in the stirrup (see Fig. I02), catching the pommel or cantle of the saddle, as he sees fit, with the right hand,

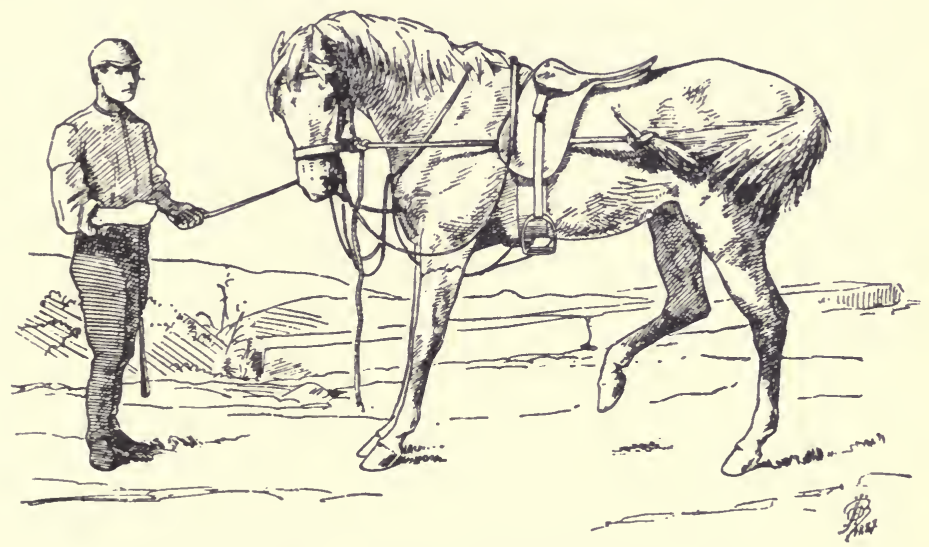

Fig. Ior.-Horse ready to be mounted for first time.

and hopping round on the right foot, while we keep the horse revolving by means of the leading rein. The Australian rough-riders, who are marvellously expert at getting up on difficult horses, place the right hand on the pommel of the saddle, and not on the cantle, as is usually the practice in England and Ireland, and consequently put the left hand high up on the neck, and thereby keep their hands well separated, so as to preserve their balance when mounting. When the horse has shown his perfect tolerance of the assistant keeping his foot in the stirrup and the hands respectively on the saddle and mane, 
while he hops round on one foot, the assistant may raise himself up, so as to stand by means of the left foot in the left stirrup, with his weight to a certain extent on his hands. The next step will be to bring his right leg over, and take up the right stirrup with his right foot. While all this is being done, the breaker, who has hold of the leading rein, should keep the horse circling round, so that the animal may not get the chance of resisting. When fixed up in this manner, the horse's "defence," if rebelliously

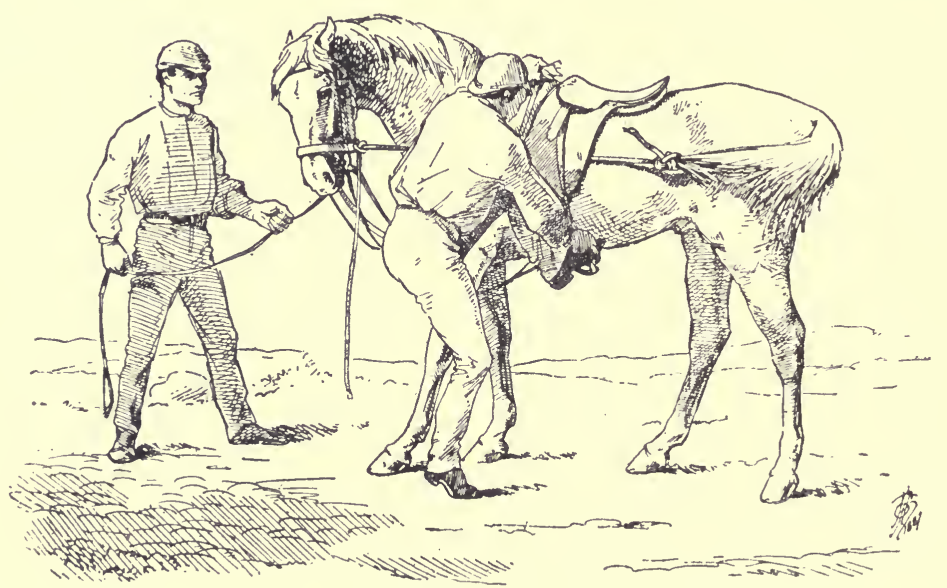

Fig. 102.--Mounting horse for first time.

inclined, will be to throw himself down to the off side, either forwards, sideways, or backwards. Such an accident should not happen once in five hundred times, if the preliminary work has been properly carried out, and if the horse has been rightly fixed up. The assistant, however, should be ready to jump off to the near side in case such an untoward event takes place. If the horse happens to come down in the manner described, the cord connecting his head and tail should be loosened out, the animal made to get up, and the gear re-adjusted, or further discipline 
employed, as circumstances may demand, before recommencing the mounting lesson. A very efficient method of reducing to obedience horses which deliberately throw thernselves down when secured in the way in question, is to keep them on the ground, tied head and tail (see page I67), until they have given up all idea of resistance.

When the horse has got accustomed to the presence and weight of a man in the saddle, the rider may touch him with his heels, lightly at first, and gradually with more pressure, but without hurting him, so as to teach him to bear the contact without resentment or fear. We may then slacken off the cord a little, make the horse go round and round again, and so on, until it will be safe to let him altogether loose. Before doing this, we should, as before, test his quietness by stopping him with the leading rein, and then pulling him round again. When we have loosened out the cord to about half its full extent, we may give the leading rein to the rider, to hold in his right hand, so that he can stop the horse from turning round, if necessary. By holding the near side of the headstall in the left hand and by lightly touching the animal on the near quarter with the whip, we can make him go round, as may be needed. After the cord has been removed, the long reins may be put on, and the breaking proceeded with as described on page 203 et seq. Three-quarters of an hour will be ample, in the large majority of cases, for completing the process of mounting. A second lesson of the same kind, which will take far less time than the first one, may be given on the same day. As a rule, no further discipline in mounting will be required, beyond the occasional use of the ropetwitch to correct unsteadiness.

In all my experience with scores of horses which had for years successfully resisted every effort to mount them, I have never failed to accomplish this object within an 
hour by the method just described; nor has any horse, after I have removed the cord, shown the slightest return to unruliness during the subsequent portion of the lesson. The use of the rope-twitch is specially valuable for rendering a horse steady to mount. The head and tail plan, by producing a powerful moral effect, makes the horse not alone easy to mount, but also quiet to ride. We should not forget to confirm, by repetition, the habit of obedience.

Mr. Litchwark, who is a New Zealand horse breaker, invented the following admirable method of making a horse stand still when mounted for the first time. Put a hobble with a ring on the off hind pastern, put a loop round the animal's neck with one end of a rope, pass the other end of the rope through the ring on the hobble, draw the horse's off hind leg forward by the rope, and when that hind foot is nearly off the ground, tie the loose end of the rope to the loop. The animal will then be unable to buck, plunge, rear or run away, and can be easily mounted on the near side. After finding that the process of mounting is accompanied by friendly pats on the neck, caressing words and no pain, he will, as a rule, soon "give in." The great secret of obtaining perfect control over a horse is to avoid giving him any chance of "playing up."

The practice of all the "horse-tamers" whom I have seen, or heard of, using the head and tail method, is, when they suppose the animal to be sufficiently quiet from the effects of this process, to get an assistant to vault on to the horse's back from the side opposite to that to which the head is pulled round by the cord that connects it with the tail. If the cord be unconfined by girth or surcingle, the rider, whether he has or has not a saddle under him, will be placed in the uncomfortable dilemma of being obliged to ride without any grip by having one leg pulled outwards by the cord, or of having the leg imprisoned between the 
cord and the animal's side. In either case the man will be in a most dangerous position on an animal which is revolving round and round with but little control over its own movements. Without the headstall being furnished with a short strap or rope, which is also an improvement of mine, the breaker will require to be unusually active and skilful, when the animal is revolving rapidly round, to run in and catch the horse by the headstall, so as to stop or diminish the rotatory movement. When the leading rein is on the headstall,

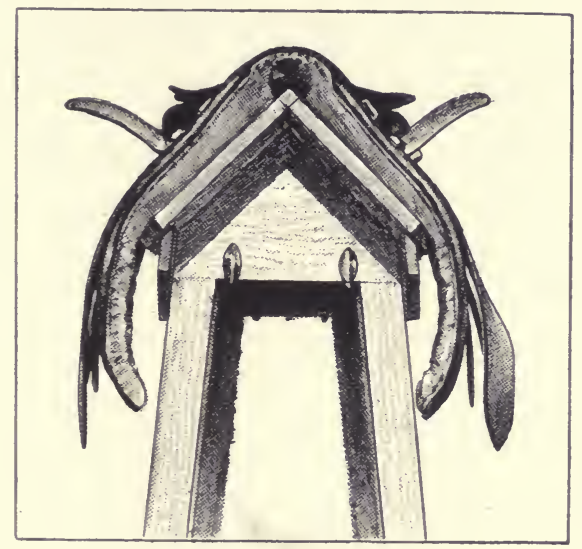

Fig. 103.--Buckjumping saddle.

the breaker can with perfect safety catch it while the horse is spinning round; for it will at that time swing clear of the fore legs and in a convenient position to be laid hold of.

In the foregoing paragraphs of this chapter, I have described methods of mounting on the assumption that the breaker has had one or two assistants. If he be singlehanded, he may, in the case of a violent or otherwise difficult horse, make him quiet by a pretty stiff turn at the head and tail (see page I55), lying down, or tying-on-theground plan (see page I50), and mount before the good effect of the discipline has passed off. In this way an 
expert breaker could within an hour and a half make any horse quiet to mount for the time being ; only a few repetitions being usually needed to make the effect permanent. With ordinary horses, the resources of the breaker need not exceed those to be obtained from the long reins and rope-twitch. The precaution of using a saddle in which one can obtain a firm grip, should not be neglected.

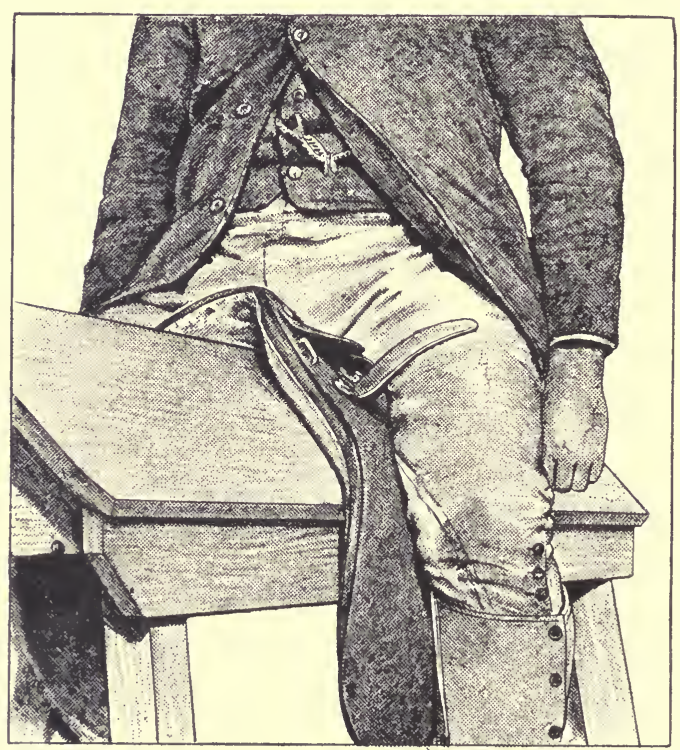

Fig. I04.--Buckjumping saddle.

Having mentioned the subject of a saddle for breaking purposes, I may state that I have designed one out of which it is almost impossible to fall. It is provided on each side with "leaping heads," which give a grip with both legs similar to that afforded to the left leg in a side saddle. The seat in it is far more secure than in any Australian buckjumping saddle I have ever ridden in. With it, I ride with the stirrups rather long, so that I might have no 
difficulty in getting out of the saddle in the event of the horse falling with me. In Figs. I03 and ro4, I have taken off the leather covering of the leaping heads (or horns), so as to show their action more clearly.

After the horse has been mounted, the rider, in order to

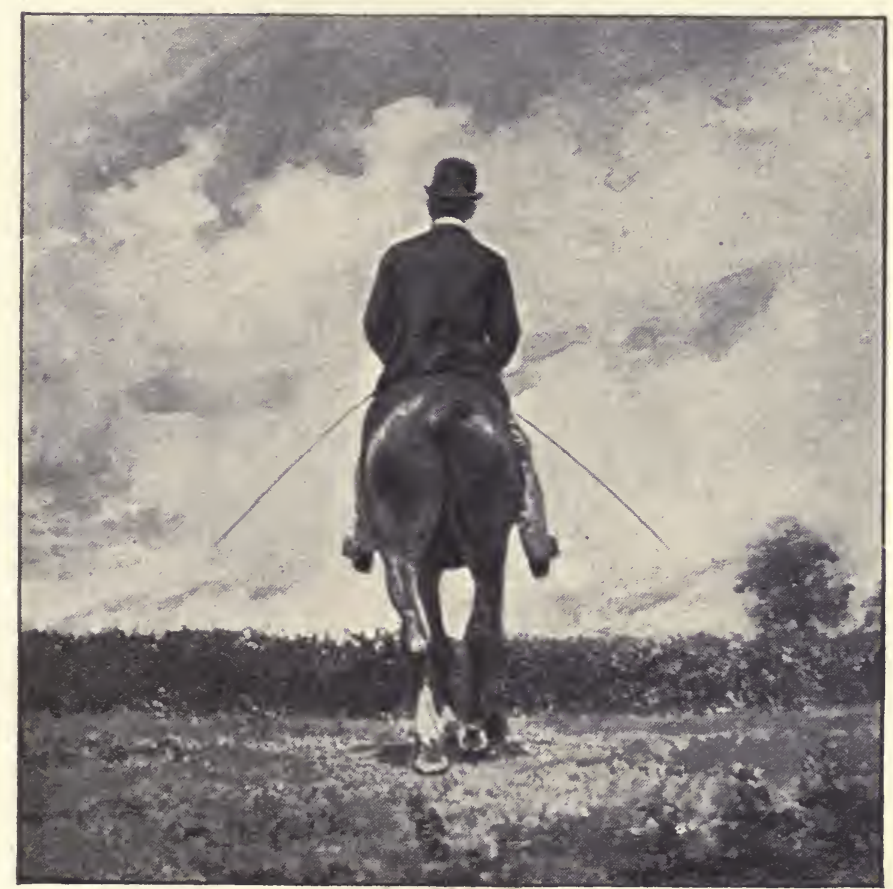

Fig. 105.-A rein and whip in each hand.

confirm the habit of obedience, may walk and trot the animal on the circle round which he had been previously worked, using only the reins and clicking with his tongue as aids. If the horse be sluggish, the breaker or man on foot may stimulate him to go on by "showing " the lunging whip, or by lightly touching him with it below the hocks. If the breaker be single-handed and has to ride the horse, 
he may take a rein and cutting whip or cane in each hand (see Fig. I05), and in the event of his mount being lazy, he may make him go on by lightly touching him with the points of both whips on the sides or hind legs. At this stage of the breaking, I think it is well to defer all further instruction in the aids, until the turn on the forehand has been taught; for it is the quickest and most precise means by which to teach the horse the indications given by the rider's legs, which instruction should now be our chief object, so that our pupil may answer the leg as readily as he has already learned to do the rein. If we continue to ride him without special instruction in leg work, we can hardly fail to get him into the vile habit of depending almost entirely on the reins for guidance. I may here point out that precision in turning can be obtained only by acting on both ends of his body, namely, on his hind-quarters, as well as on his mouth.

TURNING A HORSE ON THE FOREHAND AT THE HALT WHEN MOUNTED.

Having, on foot, taught the horse to make this turn, we shall have little difficulty in doing so when mounted; and may commence by taking a rein and whip in each hand (see Figs. I05 and I06). If we wish to make the turn on the forehand to the right (see page I93), we should depress the right hand and keep it well away from the shoulder, so as to give the indication of pulling the head round as clearly as possible. As the flexibility of the neck increases according to its distance from the withers, the left hand, which holds the left rein, should be carried somewhat to the right and raised, so as to aid in preserving the bend of the neck. We should lean a little forward in the saddle in order to lighten the hind-quarters, and a little to 
the right so as to help in fixing the off-fore. We should begin, as on foot, by lightly touching the off quarter with the whip (see Fig. I07), to make the horse circle his hind legs from right to left round his off fore foot, and should

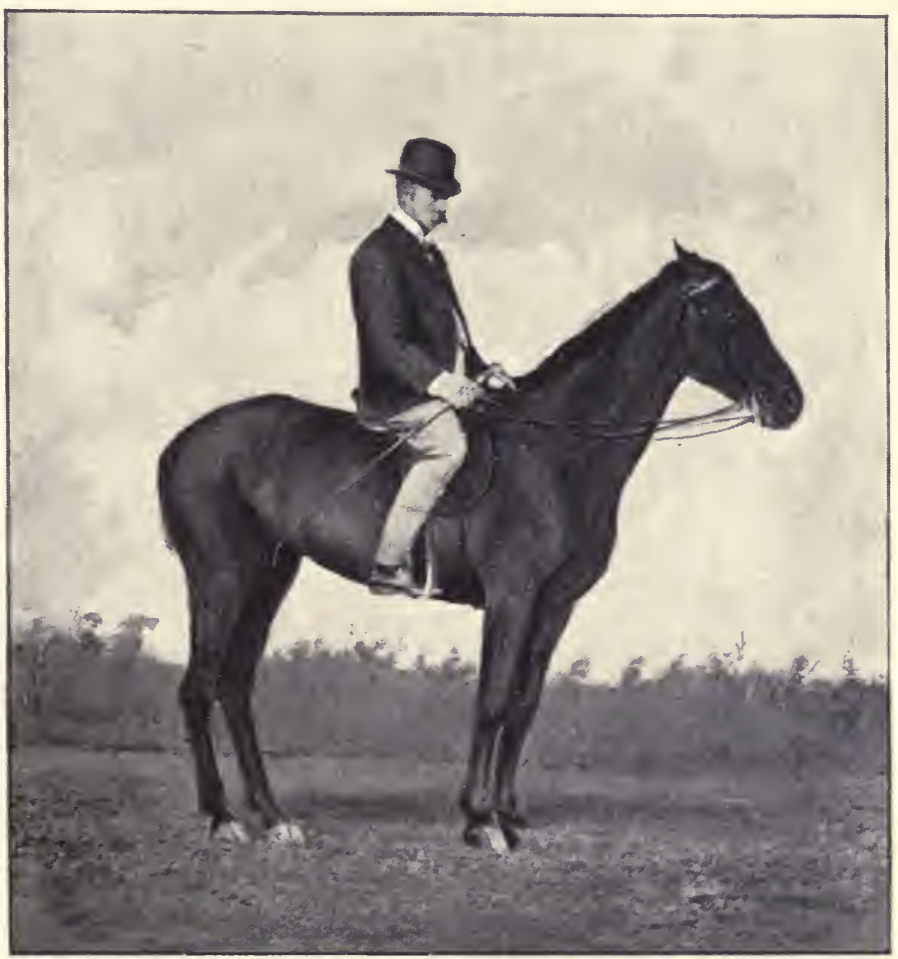

Fig. 106.-Rein and whip in hand.

gradually advance the point of contact of the whip with the skin until it will reach the spot that would be pressed upon by the drawn-back heel of the right foot. As soon as the horse obeys the touch of the whip on the quarter, we should, while using the whip, gently apply the drawn-back right foot to the side, and continue to do so, until the whip is 
brought up by degrees to the foot; supposing of course that the horse yields perfectly to the touch of the whip when in that position. Then, by gradually increasing the effect of the heel, and diminishing that of the whip, we may after a time dispense altogether with the latter in

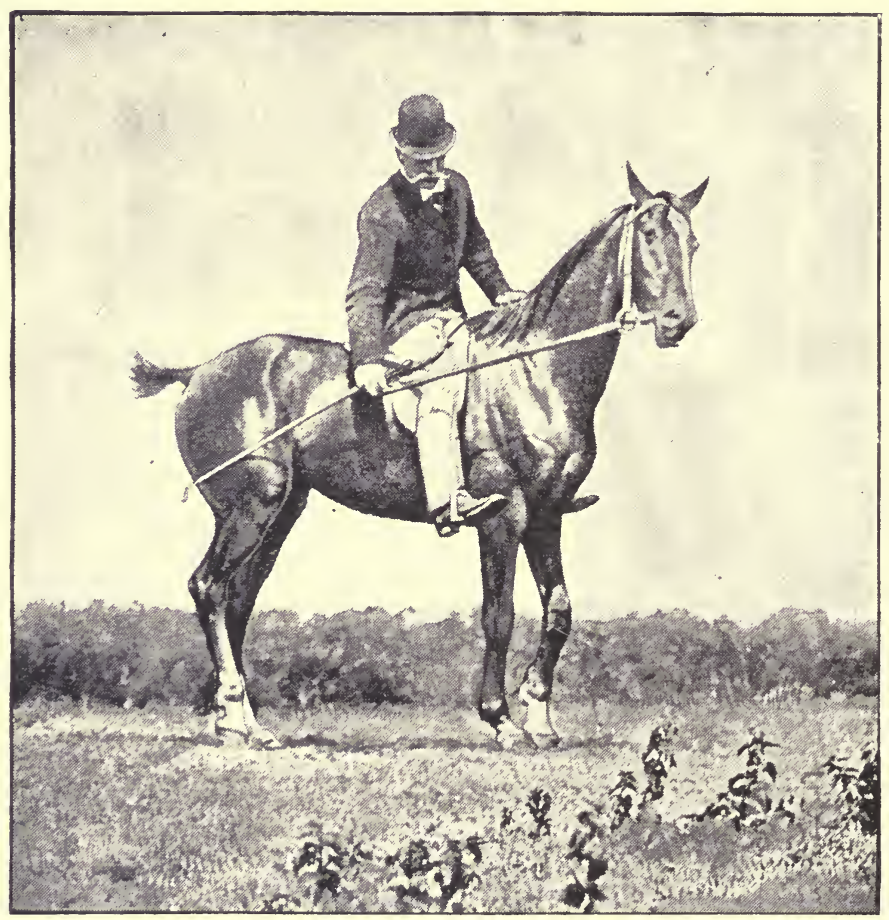

Fig. 107. - Teaching the horse to turn to the right on his forehand by the whip.

favour of the former. The remarks previously made as to precision without hurry, and the way in which punishment and reward should be respectively meted out, apply equally well here. If the movement of the hind legs be made in a precipitated manner, it may be checked by the application on the near hind-quarter, of the whip which is held in the 
left hand, or by the heel, and by "feeling" the left rein and easing off the right rein. If the horse attempts to go forward, he should be checked by both reins. If he tries to rein back, he may be kept up to his bridle by the application of both whips or of both heels. The turn on the

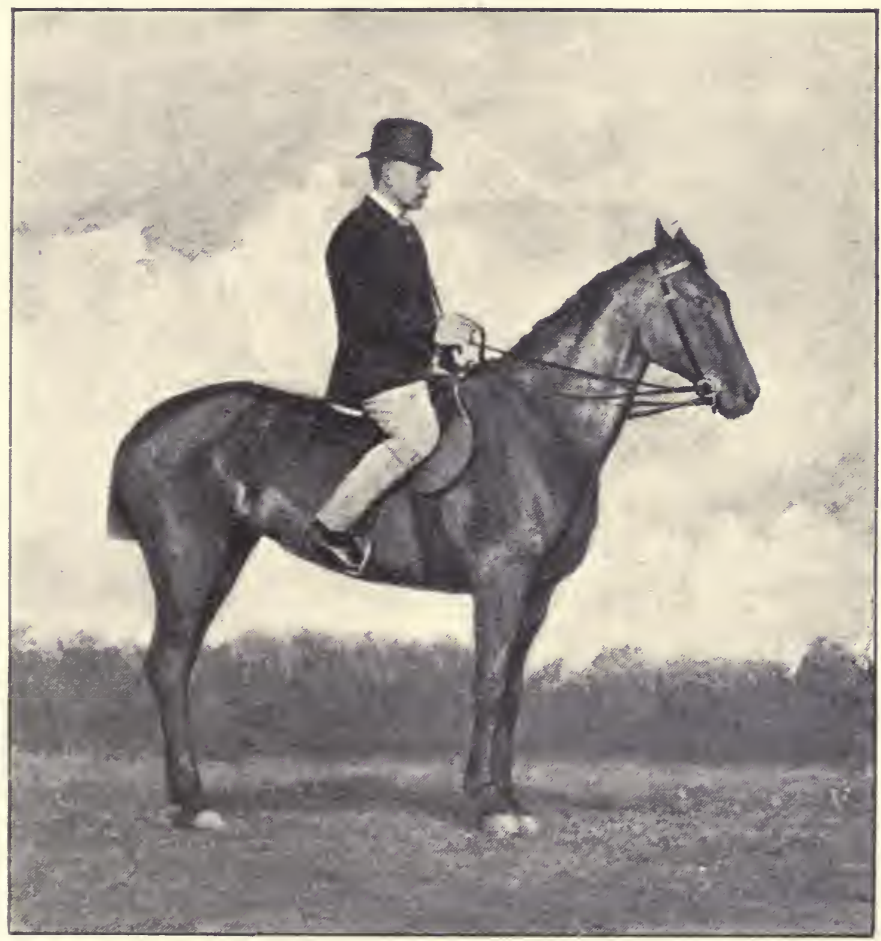

Fig. 108. - Leg drawn back in turning horse.

forehand to the left is taught in the same manner, but with reversed aids. A turn through an angle of $90^{\circ}$, first to one side and then to the other, will be sufficient at first. Ability to turn on the forehand through a complete circle, while keeping the appropriate fore foot fixed on the ground, will demand a high degree of training. 
A quarter of an hour, with frequent intervals of rest, will be long enough for a lesson of this kind.

The position of the leg, in, for instance, turning the horse on his forehand to the right, is shown in Fig. Io8.

\section{REINING BACK.}

To obtain the rein-back from the mounted horse, we should work on the principle which guided us in teaching him on foot (see page I86) to execute this movement at our bidding. To get the right diagonal step (off fore and near hind), supposing that both fore feet are equally advanced, we should feel the right rein so as to turn the horse's head to the right; should apply the drawn-back left foot to the horse's side to prevent his hind-quarters from swinging round to the left and to keep more weight on the off hind than on the near hind; should lean a little forward in the saddle and should lower our hands so as to lighten the hind-quarters; and having produced these effects, we should take a pull at the right rein while keeping the left hand steady, so as to obtain the desired step to the rear. For the left diagonal (near fore and off hind) step, we should use the reversed aids. During the rein-back, the driver should draw his right foot back and apply it the moment the right fore foot comes down; for at that moment, the right hind being more advanced under the horse's body than the left hind leg, it is the proper one with which the horse should take a step to the rear. When the rider applies his drawn-back right foot in this manner, he may touch the left shoulder of the horse with his left foot, so as to give the animal the signal to raise and draw back the left fore leg at the same time as he raises and draws back the right hind leg. The reversed aids are to be applied to obtain the other step. We should here, 
for applying the foot, take our time from the respective supports of the fore feet; because they are easier felt than those of the hind feet. If at the commencement of the rein-back from the halt, one fore foot of the horse be more advanced than the other, we should turn the animal's head towards it, apply the drawn-back leg of the opposite side, and proceed as before directed. If he fails to obey the aids, he should get a repetition of his previous instruction on foot in them.

THE WALK.

The horse uses his head and neck as a balancing pole in no pace so much as in the normal walk, in which, forward progression is obtained as much as possible by displacement of weight with a minimum of propulsion. The horse accordingly brings his head down so as to increase the instability of his equilibrium, and sways it from side to side at each step, which is taken with extremely little fatigue to the limbs, and which covers a comparatively long distance of ground. If, however, the rider by maintaining a tight hold of the reins, keeps the horse's head up and prevents it from exercising its natural function of a balancing pole, the horse will step short and will be inclined to break into a trot, at which pace the head is normally held in a raised and nearly immovable position. Owing to a wrong system of breaking and riding, the majority of our horses are bad walkers. I must here make a distinction between the normal walk and the collected walk, which artificial pace I shall describe later on, as a preliminary exercise to the trot.

We should, as we may see from the foregoing observations, teach the mounted horse to walk with the reins loose enough not to interfere in any way with the movements 
of his head and neck, and should lean the upper part of the body slightly back so as to readjust the distribution of weight between the fore and hind legs.

THE TROT.

In the trot, as I have just said, the horse should carry his head in a raised and nearly immovable position, to attain which we should regulate the height of our hands, and should keep a steady feeling on the reins.

\section{TURNING A HORSE DURING MOVEMENT.}

Having taught the horse to turn on his centre by means of the long reins, on his forehand by the whip and reins on foot, and by the aids when mounted, we may teach him to turn at the walk and trot.

The body of a quadruped being supported at two ends by limbs; it follows that, when a horse turns of his own accord, the point round which the revolution takes place will approach the heavier end according to the difference of weight on the two ends. As the weight on a horse's forehand, which at the halt is only slightly more than that on the hind-quarters, increases as the speed: so will the tendency to turn on the forehand, when a turn is being made, similarly increase. If the weight were equally distributed between both ends of the horse, his balance during a turn would be preserved in the best possible manner, and the track of the hind feet would follow that of the fore feet. In proportion, however, as the weight on the forehand exceeds that on the hind-quarters (or in proportion to the speed); the greater will be the liability of the animal to fall or to have his balance unduly disturbed, when turning, by his hinder end describing a larger arc than the fore part of his body; or, in other words, by the track of the hind feet 
going outside that of the fore feet. To correct this tendency, we should, when about to turn the horse during movement, slacken speed, lean back in the saddle, hold the horse's head up (so as to bring the weight back), apply the outward (the left if the turn is being made to the right, and vice vers $\hat{a}$ ) drawn-back leg to the animal's side, and lean the weight of the body inwards (to the side to which the horse is being turned), so as to oppose the centrifugal force. In order to turn the animal's head and neck in the most effective manner, we should carry the right (if the turn is being made to the right, and vice versâ) hand away from the side of the horse, as well as backwards, and raising the left hand a little higher than the right (so as to bring the left rein against the most flexible part of the neck), should carry it across the body, so as to obtain the desired pressure against the neck. We find from experience that a horse will turn best, other things being equal, when the reins are manipulated in the manner I have pointed out, and when their tension is the same on both sides of the mouthpiece which, under this condition, will have no tendency to be pulled through the mouth, as might occur if one rein were tight and the other slack.

In referring here to the application of the drawn-back outward leg when turning the horse, I take for granted that the turn is made under ordinary conditions. If, however, the animal refuses to bring round his hind-quartersas he does when he "runs out" at a fence, while we are doing our best to "straighten" him-we ought, instead of using the outward (the left, if the turn be to the right) leg, to apply the drawn-back inward leg, or the whip. It is evident that the more the leg is drawn back (see Fig. I08), the more effective will its application be in bringing round the hind-quarters, or in checking their movement in the direction of the applied leg. While sitting 
"square" in the saddle, which is imperative in military equitation, it is impossible to exercise, to any appreciable extent, a stronger pressure against the horse's side with one leg than with the other, owing to the fact that the rider can obtain no fixed point on the side opposite to that on which he may wish to apply pressure. Any slight difference between the lateral pressure of one leg and that of its fellow can be gained only by means of the friction between the rider's seat and the saddle. Even if such "stronger pressure" were practicable, it would fail to be effective, unless perhaps it was far superior to any muscular effort of which the human leg is capable; for its centre of application would be little, if anything, behind the centre of gravity of the weight to be moved. Granting that the mechanical effect even of the drawn-back leg, as in Fig. I08, is not great; we must remember that the horse, by the method I have indicated, has been taught to accept it as a signal for moving his hind-quarters away from it, of for checking their advance towards it. The presence of a spur on the drawn-back foot will increase its effect both as regards intensity of impression and by bringing the point of application still further back. At the same time, the more we eliminate the element of pain from the signals which we habitually employ with the horse, the less likely shall we be to render him unsteady, and consequently unsafe to ride or drive.

It is reasonable to say that in turning the horse at the walk or trot, we should feel the inward rein as the outward fore leg comes down. At the trot, the pace would have to be very slow and collected to allow this to be done with precision. 
TEACHING A HORSE TO CARRY HIS RIDER IN A COLLECTED AND WELL-BALANCED MANNER.

While the breaker is in the saddle he should constantly keep in mind the maxim that one should ride more by the legs than by the hands, so as to teach the horse to go collectedly (see page 72) when required. This collection can be obtained by using the drawn-back heels as a stimulus to the respective hind legs, so that the hind feet may be brought further under the animal's body at each step than they would be were the heels not applied to the horse's sides. Their effect, combined with that of the hands in preventing any increase of speed, will naturally be to lighten the forehand. The manner in which the legs should be applied so as to produce the best effect, is described on page 59. As the extension of the neck will be proportionate to the forward reach of the fore legs, and, consequently, other things being equal, to the speed; the position of the hands should remain fixed while the animal's speed remains uniform. Thus, the horse, on finding that he cannot extend his head and neck beyond the limits allowed him by his rider, will, in response to the application of the heels, bend his head and neck as well as his loins, and will become "collected." As the hands have to regulate the movement, the impulsion must be excited by the legs, whip, or voice, before the reins are "felt." Hence, in no case should these stimulating aids and the regulating and controlling one of the hands be used simultaneously. A worse mistake, in that it renders the meaning of the rider still more ambiguous to the horse, is to feel the reins and then to apply the heels, the only interpretation of which proceeding possible to the horse would be that the rider wished him to halt and rear up. It must be patent to every instructed observer that the vast majority of persons who 
bestride horses in England and Ireland, to say nothing of other countries, "ride the bridle," and altogether neglect the use of the legs as an "aid." Consequently their horses are heavy in front, become prematurely unsound in their fore legs, and are wanting in handiness. The breaker when mounted, should be careful to alternate his lessons of "collection" with well-regulated periods of relaxation so that nervous as well as muscular fatigue may be avoided. I have dwelt in particular upon lightening the forehand and on collecting the horse; as horses are generally more wanting in these respects, than in being too light in front. If, however, the horse does not go up to his bridle, we may try to correct the faulty distribution of weight by the use of the standing martingale for lowering the head; and by employing a general stimulus, such as that of the voice or "company," instead of that of the drawn-back feet, we may hope in a short time to effect our purpose. We should also give frequent lessons in the turn on the forehand (see page 2I2). For further remarks on teaching a horse to go up to his bridle, or to abstain from boring on it, see Chapter XI.

The breaker when riding his pupil should be careful to make him go in the required direction without deviating from it to one side or to the other. A lively horse, when newly broken in, is liable to shy away from and start at all kinds of objects which he may meet in the field or on the road. To teach him that such behaviour will not be permitted, the breaker when in the saddle, and while walking, trotting or cantering along, should take rather a short hold of the reins, so that if the horse makes any attempt to "play up," the breaker may bring him in an instant under control by closing his legs (flat of the foot or heel as may be required) firmly against his sides, and holding his head tight by the reins. If the shy be made, say, to the 
1ught, the animal while looking at the cause of alarm will endeavour to swing his hind-quarters round to the right; consequently the breaker should turn the horse's head and neck round to the right by the right rein aided by the pressure of the left rein on the neck, and the hind-quarters to the left by the drawn-back right foot, or by the whip or cane held (as well as the right rein) in the right hand and applied to the right side of the horse's hind-quarters. The extent of the turn on the centre or on the forehand will naturally be regulated by the amount required to bring the horse's head, neck, and body into their original direction.

\section{THE CANTER}

(see Points of the Horse) is a pace of three time in which the sequence of the steps are: (I) near (or off) hind; (2) near (or off) fore and off (or near) hind; and (3) off (or near) fore. As the horse will naturally lead with the inward fore leg when cantering on a circle, he is said to be going to the left when leading with the near fore (see Fig. I09), and to the right when leading with the off fore. $\mathrm{He}$ is said to be "false" if, when circling to the right, he leads with the left fore leg, and vice versâ. The term "disunited" is applied to the canter when the two legs of the second period of the stride belong to the same side, and not to different ones; as for instance: (I) near hind; (2) off fore and off hind; (3) near fore. If this faulty sequence were adopted when going to the right, the horse would be false and disunited. The reverse of this would, of course, apply to the left circle. When riding a horse at a canter or gallop, we can easily find out with which leg he is leading, from the fact that the leading shoulder is more advanced than the non-leading one, and that our knee which is on the side of the leading leg is carried more to the front than the knee of the opposite side. 
Before beginning work at the canter, I think it well to repeat the long rein practice on foot for teaching the horse to strike off from the walk or trot into the canter with the proper leg leading (see page I88). When he does this readily; we may mount him and take him at the canter to the right and also to the left on the same circle which we used with the long reins. The drawn-back outward leg, aided if necessary by the spur, will replace the outward long rein for preventing the hind-quarters from being carried outwards when circling or turning. As the presence of a rider in the saddle increases the proportion of weight borne by the fore legs, we should lean our body a little back. To preserve the bend of the head and neck in the direction in which the animal is going, we should depress the inward hand and carry it a little inwards; the outward hand (see page $2 \mathrm{I} 2$ ) being somewhat raised, and also carried a little inwards. As an indication, and as a necessary adjustment, we should lean our body a little inwards. An additional indication may be supplied by the touch, on the shoulder, of the inward foot, which may be kept in an advanced position for this purpose. We may teach the horse to lead off, from the walk or trot, into the canter with whichever leg we wish, by acting according to the principles by which we obtained this object with the long reins. If, for instance, we are walking or trotting the horse on the right circle, and wish him consequently to strike off with the off fore, we should turn him a little to the left, so as to bring his right shoulder in front of his left one; lean our body a little to the right; strongly apply the drawn-back left leg; and bring the horse back again into the track of the circle by turning him to the right with the reins, while at the same time raising the hands a little and leaning the body slightly to the rear so as to lighten the forehand. The reversed aids would be used on the left circle for making 
the horse lead off with the near fore. As the animal improves in his acquaintance with these signals, we may diminish the amount of the preliminary outward turn, so that we may obtain the desired lead without altering the direction of his body. We may then gradually increase the

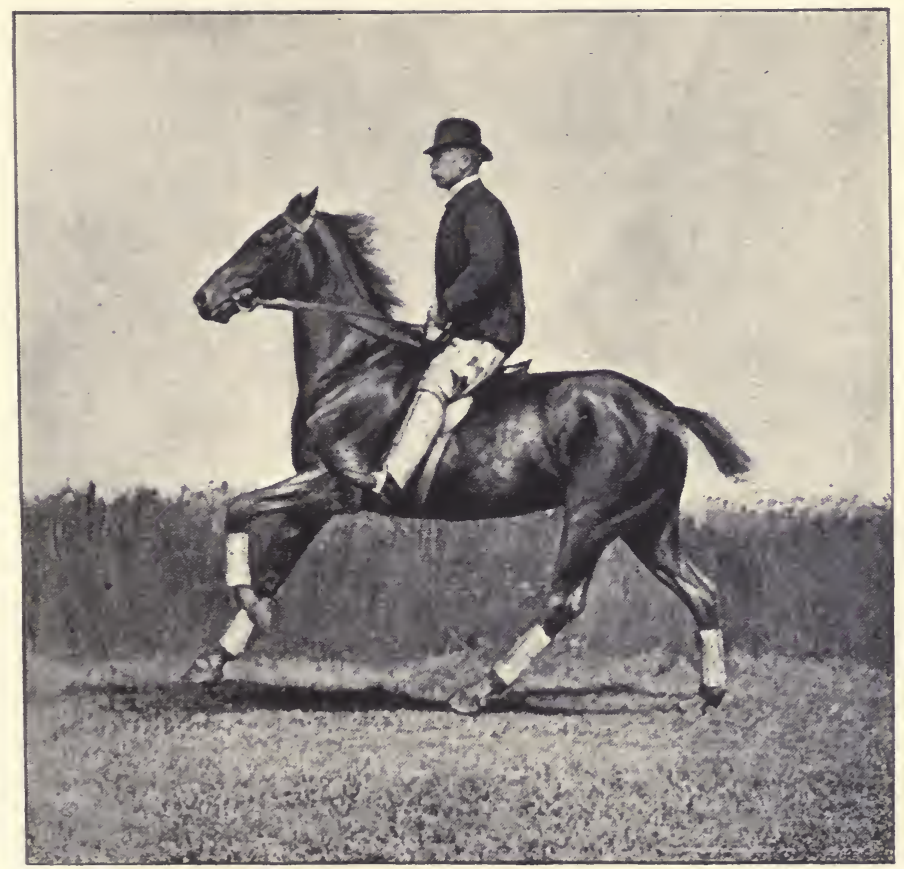

Fig. 109.-Cantering with near fore leading.

size of the circle until we can make the horse lead off with whichever leg we like while he is walking or trotting in a straight line.

When he has learned the foregoing lesson thoroughly, we may take him back to the old circle, and ride him at a walk and then at a trot in a figure 8 , so that he will describe two small circles inside the old circle. We should be careful to change the aids on entering the new circle, 
which would be at their point of contact, so that the horse may not canter falsely during any portion of the figure 8. Under ordinary circumstances, the imperfectly-broken horse would not change until he had gone falsely for about a quarter of the new circle. This want of precision may be disregarded, except in the "school" horse; for to obviate it, the animal would have to be taught to go in such a collected manner, that in acquiring this style his freedom of action might be injuriously affected. Having made the horse fairly proficient at changing the leading leg in the figure 8 , we should try similar turns away from the circle upon which we have been working, so as to prevent him from becoming routin: By keeping him attentive to the change of aids as a signal for a change of lead, we shall soon teach him to change, on feeling the change of aids, when he is cantering on a straight line. Here, again, we need not exact absolute precision as regards the moment at which the change is made. To meet the requirements of ignorant riders, of "bad" ground over which the horse should be allowed to exercise his natural watchfulness against danger, of high speed, and of other disarranging circumstances which are to be met with, especially when going over a "country," I think it well for the horse to be taught to make, when necessary, the required change of lead on his own accord, in the event of his rider failing to give him the signal by a change of aids to do so. I need hardly point out to the experienced horseman that the habit of readily changing the leg at the canter or gallop when a turn is being made to the side opposite to that of the leading fore leg, is valuable in hunters, racehorses, chasers, hacks, troopers, and every other kind of animal, except the high school horse, which is supposed never to take the initiative in any movement. As his work is confined to the manege we need not consider him here. 
One of the clearest signals which we can give to the horse to make him change his leg at the canter, is shifting the weight of our body from the side of the leading fore leg, to that of the non-leading one; for by doing so, we disturb the balance of the horse's body so much, that to regain it, he will be obliged to change his leg.

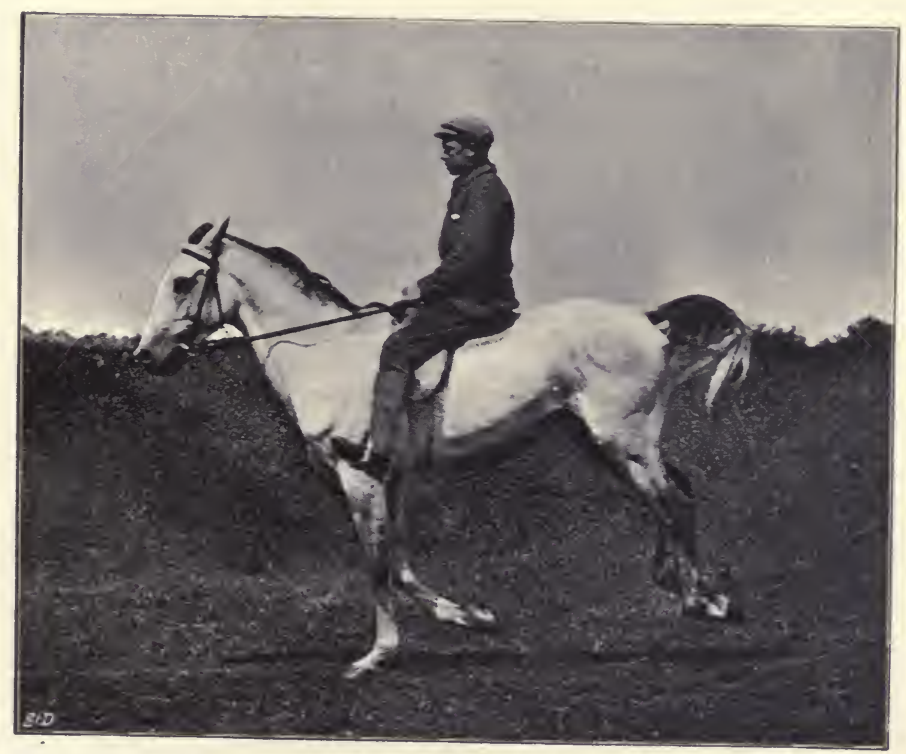

Fig. I 10. - Period of canter or gallop when weight of horse and rider is borne by leading fore leg.

In circling, as well as in turning, the track of the hind feet should be the same as that of the fore feet, and the animal's head, neck, and body should as nearly as possible follow the direction in which the circle or turn is being made.

Some people think that a horse, when cantering, should lead only with the off fore, and that breakers should train their equine pupils to invariably do so. A slight study of 
this pace (see Points of the Horse) will show us that when circling or turning to the left at the canter or gallop, the horse to preserve his balance will have to incline his body inwards, with a corresponding displacement, in that direction, of the centre of gravity. As the weight of the horse and rider has to be borne at one period of each stride by the leading fore leg (see Fig. IIO); it follows that the inward fore leg (in this case the near fore), which is more nearly under the centre of gravity than the off fore, is the proper one with which to lead. Besides, by leading with the off fore whilst circling or turning to the left, the horse will be obliged to more or less cross his fore legs, and will consequently move in an awkward and mechanically disadvantageous manner; to say nothing of the chance of an accident by the near fore striking the off fore, if the turn be made sharply. As the leading fore leg at either the canter or gallop has to do far more work than the non-leading fore leg, the judicious horseman will have his saddle animals broken to lead indifferently with either fore leg, so that one of the two may not become prematurely worn out.

To meet the exigencies of practical work in the field and the requirements of different kinds of riders, I think it is well to provide, as far as possible, against mistakes being made by the horse on receiving imperfect signals. For instance, the horse which has been trained according to the precepts of the "high school," will simply turn his head round to the side on which he feels the pull of the rein. Agreeably to the principles of breaking for everyday use, which I am trying to explain in this chapter, I maintain that the fact of the horse answering the lateral feeling of the rein only with his head and neck serves no useful purpose; but that the habit of his obeying it with his hind-quarters as well as with his head and neck is most 
.valuable. I may here go back to the remarks made on page 63 , and point out that if we wish to "straighten" a horse on his shying to one side or "running out at a fence," our object will be to make him turn on his centre, and not merely to turn his head round without altering the direction of his body. Even supposing that it was always possible to apply the drawn-back leg at the right time so as to make the horse bring his hind-quarters round, it would surely be an advantage for him to do so of his own accord, on feeling the pull of the rein; for the indication thus given by the leg, which can be applied to the side, but not to the hind-quarters, is naturally feeble. Besides, under discomposing circumstances, the rider may not be able to bring his leg back, or may be ignorant. In any case, he will have sufficient firmness of seat, knowledge, or presence of mind to pull the rein of the side, to which he wishes his mount to turn. If, by chance, the rider of a horse which has been broken according to the system I am describing, wants to make the animal turn his head to one side without altering the direction of his body, all he will have to do will be to apply the drawn-back foot of the side opposite to which the bend of the head and neck is being made, so as to arrest the revolution of the hindquarters.

As the shoulder of the leading fore leg, in the canter or gallop, is more advanced than that of the non-leading fore leg, the natural tendency of the horse, when going at either pace, will be to carry his hind legs more or less sideways. Thus, if the off fore is leading, the tracks made by the hind feet will be somewhat to the right of those made by the respective fore feet. An excess of this tendency, which decreases according as the speed increases, and which is usually displayed only when one particular fore leg leads, should be guarded against during the breaking in of the 
horse; for it detracts from the beauty of his action in the paces in question, and interferes with his handiness and speed. The more a horse, at the canter or gallop, carries his head to the side opposite to that of the leading fore leg, the more will he be inclined to bring his hind-quarters round to the other side. Hence, to obviate this objectionable tendency, we should bend the animal's head slightly to the side of the leading fore leg. The best means for correcting this fault, if for instance it is apparent when he leads with the near fore, is frequent practice at turning on the forehand (see page 212) to the left, and passaging (see page 273) to the right; and vice versâ.

I may repeat that, when mounted, we should handle the reins as nearly as possible in the same manner as we did the long reins, while circling the horse on foot.

THE HALT.

If we examine the anatomy of the horse, we shall find that the fore legs, being connected to the body by muscles, are far better able to bear the shock of weight suddenly imposed on them than the hind limbs, which are attached to the body by ligaments. We see that the fore pastern is more oblique than the hind, and that the bones from elbow to fetlock are practically straight when bearing the weight of the body, while the analogous column of bones of the hind extremity, from stifle to fetlock, are more or less bent at the hock under similar conditions. In normal jumping, the weight of horse and rider is received by both of the fore legs before either of the hind limbs come to the ground. The attempt of the rider to interfere with this natural sequence by means of a severe bit will often be followed by sprain of one or both of the hind legs. Horses which are moving at liberty in the open, will, if they 
happen to halt suddenly, purposely receive the weight principally on their forehand; a fact which they will notify by lowering their heads at the moment of stopping. At this instant, the hind legs will be brought under the body to receive their smaller share of the burden. The faster the pace from which a sudden halt is made, the more will the head be brought down. As the weight of the rider adds to the natural preponderance of weight on the forehand, it follows that, to obtain the just distribution of work between the forehand and hind-quarters, in the case of the mounted horse coming to a sudden halt, the animal must put more weight on his hind legs than he would normally do; the rider must carry his weight back; or both horse and man must contribute to the re-adjustment. According to these principles, it appears that in coming to the halt from a fast pace, the rider should grip tightly with his knees to prevent his seat being shifted forward in the saddle; should apply his drawn-back feet to make the animal bring his hind legs under him; should carry the upper part of his body back, so as to prevent the forehand from being unduly charged with weight; should lower his hands; and should take a steady pull of the reins. Accepting this as a typical case, we may vary the application of the aids according to circumstances. Precautions as to infirmity behind or in front should naturally be taken. Although the most sudden halt possible from a high rate of speed may at times be absolutely required, I need hardly say that the more gradual the halt, the less liable will it be to injure the horse. Believing that the horse knows more than his rider about the manner in which the weight on his legs should be adjusted, I am a strong advocate of teaching him to stop by a signal (for instance, the voice) unconnected with the aids, which may or may not be rightly applied. With a horse thus instructed the 
capable rider would content himself with giving the signal, and with looking after the adjustment of his own weight (by sitting tight on the saddle and leaning back), over which the animal could, of course, exercise no control.

\section{WHIP AND SPURS.}

These articles of riding gear may be used as aids or as stimulants. Their function as aids is to make the horse remove from their contact that portion of his body which is touched or threatened by them, or to check its approach if it happens to come in their direction. Thus, in the turn on the forehand, we cause the hind-quarters to revolve in the desired direction by the pressure of the drawn-back heel; and in the turn on the hind-quarters (see page 272), we check that movement by the same means, in which case the pressure has to be patiently borne-not avoided. When we use whip, spurs, or unarmed heels as a general stimulant, we should manifestly apply them, as nearly as possible, at a point midway between the respective actions of the fore and hind legs; that is, close behind the girth.

When teaching the horse to obey the whip, either as an aid or as a stimulant, we should be careful to use it in such a way that he will not become unsteady in the event of his rider carrying anything in his hand.

As the horse's natural impulse on being touched is to remove the offending object by twitching his skin, brushing it off by his tail or mane, kicking it, biting at it, rubbing it against some hard substance, or other similar means, none of which will assist us in breaking; we have got to teach him to interpret, agreeably to our conventional code, and not according to his instinct, the signal we give with whip, spur, or heel. As I have already said, on 
page 38 , the whip and spurs should never be used as a punishment. To avoid making the horse regard the spurs as a means for inflicting pain, we should gradually teach him their use; at first, by pressure of the flat of the foot or heel, by that of the spur without a rowel or with a blunted rowel, and finally by the ordinary spur. We should thus make him so obedient to them, that when riding him we may dispense with their use, the contact of the heel being sufficient to remind him of indications which they had impressed on his memory. Referring to school riding (see Chapter IX.), Baucher justly said that a horse which had been brought to properly bear the application of the spurs is three-parts broken.

TIME REQUIRED FOR ORDINARY BREAKING TO SADDLE.

Supposing, as I have already said, that the horse is in sufficiently good condition to stand the fatigue and strain of breaking, and that the breaker is competent, the time for making the animal quiet to ride and obedient to the aids, under ordinary conditions, need not usually be prolonged, no matter how wild and "green" he may be, beyond the following course :-

One day, in which two lessons may be given, to make the horse sufficiently quiet to be handled, and to be circled with the long reins.

Six days' work (twelve lessons) on foot with the long reins and whip (for teaching the turn on the forehand, etc.), and teaching the horse to carry a rider quietly.

Fourteen days (twenty-eight lessons), for riding the horse at home and outside under various conditions. One-third of the morning lesson (say, half-an-hour) might be devoted to teaching the horse the rein-back, circling, figure 8 , 
changing the leading leg at the canter, etc., on the breaking ground, before taking him out.

At the end of the three weeks which I have allowed for breaking-in the ordinary horse (hunter, hack, racer, or chaser) to saddle, he ought to be thoroughly steady and have a good snaffle mouth.

My readers will observe that I have added to the usual course of English and Irish breaking, reining-back, circling, figure 8 , and changing the leg at the canter or gallop. I would advise, for all saddle horses, instruction in the passage (see page 27.3). By refraining from including it in this chapter, I desire to show that I am not altogether unwilling to make concessions to prejudice.

I reserve the question of jumping for the next chapter. 


\section{CHAPTER VII.}

\section{TEACHING HORSES TO JUMP.}

General instruction-Jumping faults-The hunter-The chaser-The hurdle racer-The show-jumper-Time required to teach a horse to jump.

\section{GENERAL INSTRUCTION.}

Although I strongly advocate the practice of giving a horse his first saddle lessons in a small enclosure, such as a riding-school, I think it is advisable for the hunter or chaser to obtain all his jumping instruction in a field or other open place, work in which would be less liable to get him into a "cramped" style of fencing than in a manège. The tendency of horses to become routiné, to which I shall make further allusion on page 263 , is often well shown in jumping. Hence, I would advise, that practice over a particular line of fences should be restricted, in the case of an intended hunter, to teaching him the necessity of clearing them, and that his subsequent schooling should, as far as possible, be over strange obstacles. I have known some animals become so "tricky" from being frequently ridden over the same jumps, that they would not negotiate a new one, however small, without a refusal or two. The less plucky a horse is, the more inclined will he be to acquire this very grave fault. It is comparatively easy to teach a horse an effective, though "sticky" style of timber jumping; but it is difficult 
to get the generality of young ones to learn the free and "flippant" method which will enable them to go from one field into another without any fear of their dropping their hind legs into a ditch on the far side, or catching their feet against a guard rail, or perchance a wire. To acquire this essentially Leicestershire style, to which I shall chiefly devote my attention, a horse must learn to lift himself well off the ground and spread himself out. I in no way wish to deny that a horse can be taught to adapt his style to the nature of the fence; but such a degree of excellence is difficult to attain, and the attempt to reach it may end by spoiling the animal for both kinds of work. Lest any of my readers may misunderstand my meaning in this connection, I may explain that the one style of jumping to which I refer is that practised in the Shires and on our steeplechase courses; the other, in Galway for getting over big stone walls, and in Australia for clearing very high posts and rails. In the former, the animal always covers a considerable width and can also jump fairly high when required. In the latter, if the horse jumps high, he will cover but little ground. At horse-jumping competitions in England, such as those at Islington, several very high timber jumpers will show ability to clear water of good width; but if asked to jump a four-foot hedge, they would not, unless greatly stimulated, leave much margin on the other side. In both styles, the respective horses should, of course, learn to regulate their pace and measure their distance, according to the nature of the fence.

I might suggest the following obstacles over which to practise the beginner :-

I. A hurdle (commencing at $2 \frac{1}{2}$ feet, and ending at $3 \frac{1}{2}$ feet) bushed with gorse.

2. A hurdle similar to No. I, with, in front of it, a 
drain 2 feet broad at first, and gradually widening out to 4 feet.

3. A $2 \frac{1}{2}$ foot hedge, with on the landing side a drain, say, 3 feet broad, increased up to ro feet.

4. A heavy log "served" with hay-bands to prevent the animal seriously injuring his legs. It may be gradually raised up to 3 feet 9 inches. I like to place another $\log$ a . little in front of it, so as to show the horse where to take off, and to prevent him from getting too close.

Before any jumping is attempted, the horse should be made thoroughly obedient to the aids. Beginning with the long reins, we may circle and turn him on foot, with the outward rein round his quarters, at a smart trot or wellcollected canter. We may put up any suitable small fence, say, a rounded, heavy log of wood served with hay bands, or a hurdle, neither of which need be more than 2 feet high. If our pupil is reluctant in facing the obstacle, we may work him up to it with the reins, keeping him straight by the pressure of the outward rein against his quarter, as he turns from one side to the other, and stimulating him with the voice and sound of the whip. If he persists in refusing, we may put on the crupper leading-rein (see page I96), and after running him about, and pulling him from side to side by it a few times, in order to make him understand its use, we may try to lead him over by it. Or, having handed it to an assistant to go on in front, we may give him another trial with the long reins. In this, as in all other breaking operations with the horse, we should exercise great patience, and should renew our efforts again and again if we do not at first succeed. If the animal "shows fight," I would advise that the whip should be put aside altogether; for, according to my experience, the moment its cut, or even crack, fails to prompt him to go on, it will incite him to offer increased resistance. 
Instead of its effect, we should employ that of the long reins, in circling him, turning him sharply and backing him, until he gives in, or until we are forced to employ stronger means. Mr. John Hubert Moore, the great Irish trainer of steeplechase horses, who taught me this admirable method for curing refusing and other forms of jibbing, considers that its efficacy is chiefly due to the punishment

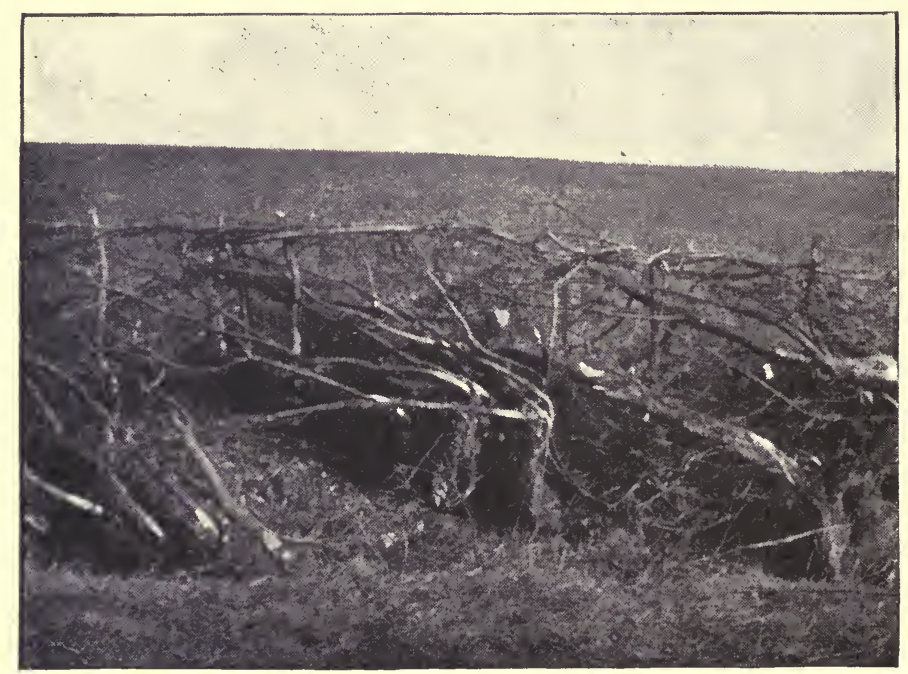

Fig. I I I. - Leicestershire cut and laid hedge

inflicted on the animal's mouth and hocks. It is possible that the animal which has been put through this discipline may imagine that he has no power to resist the command to go forward, after having been forced to turn as the breaker wished. It is not, however, the act of turning a jibber to the right and to the left which will overcome his sulkiness, but its continued repetition; especially if the turns be made sharply. Hence, I am inclined to think that the punishment theory is the right one. The 
horse seems, as with the rope-twitch (see page II6), to fail to connect the idea of pain, in this case, with the man who inflicts it, as he undoubtedly does when whipped or spurred; and, probably on that account, yields the more readily to its influence.

If the animal prove thoroughly stubborn, and time be of consequence, he may be made to lie down, and held with his head pulled round (see page I49), until he appears to "give in." The driving gear should be again put on, and

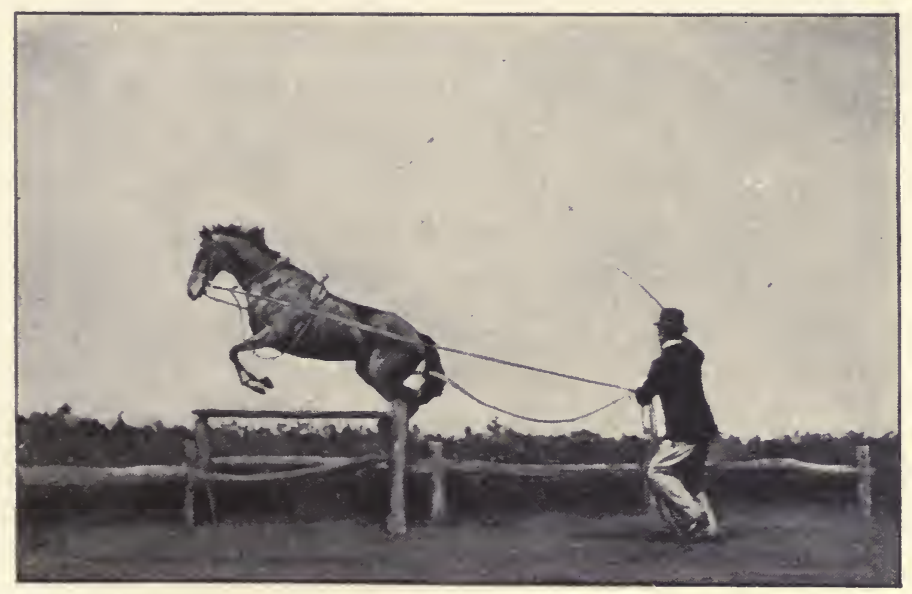

Fig. I 12. - Teaching horse to jump with long reins.

another trial given. This process may have to be repeated. Such strong measures will hardly ever be necessary if we commence with the fence low enough.

When putting the animal through the course of discipline which I have described for overcoming stubbornness by the use of the long reins, I have found that the good effect has been greatly increased by utilising the action of the outward rein on the pad.

The fence may be gradually raised to a height of 3 feet, 
which will be sufficient for the first lesson, and the horse made to jump freely when circling to the right as well as to the left. A second fence may be made on the other side of the track, opposite to the first one. When the horse has learned to jump with the outward rein low down, he should be taught to do so with it resting on the pad; as it will then be, more or less, in the position it will occupy when held by the rider. The horse should be taught to take the fence at the walk, trot, and canter. In getting him to jump width, we may bring him up to it on a large circle, and straightening him as he approaches it at a fast canter, we may let go the reins, which can be caught by an assistant on the other side. The same remark would apply to particular kinds of fences, such as Leicestershire "cut and laid" hedges (see Fig. III), and Irish banks, which one might not be able to construct in one's breaking enclosure. If it were possible to have a gap made in a fence of the kind about which I am writing, one might be able to drive a horse over it on a circle in the usual way without having to let go the reins.

By this method, horses, as a rule, will quickly learn to jump (see Figs. II2 and II3), and not alone to clear the obstacle, but also to negotiate it in the exact style they are required to do when a man is on their back. The more horses are practised in this manner, the more will they appear to like jumping, and will very rarely exhibit, as they are apt to do with a rider, any dislike to the work, from numerous repetitions, backwards and forwards, over the same fence.

The old plan of teaching a horse to jump by leading him over fences with a cavesson and one or two leading-reins should not be employed; for its tendency, by throwing too much weight on the forehand, will be to make him slow at getting away from his fences. Besides this, horses are apt 
to resist any forward pull on either cavesson or head-stall. The action of the crupper leading-rein, on the contrary, while leaving the head entirely free, is to make the horse get his hind legs well under him. One great beauty, to which I have already alluded, of the long-rein system is that by it the horse's movements, as regards pace, speed, and direction, are more under the control of the breaker than by any other method.

A tendency to put too much weight on the forehand

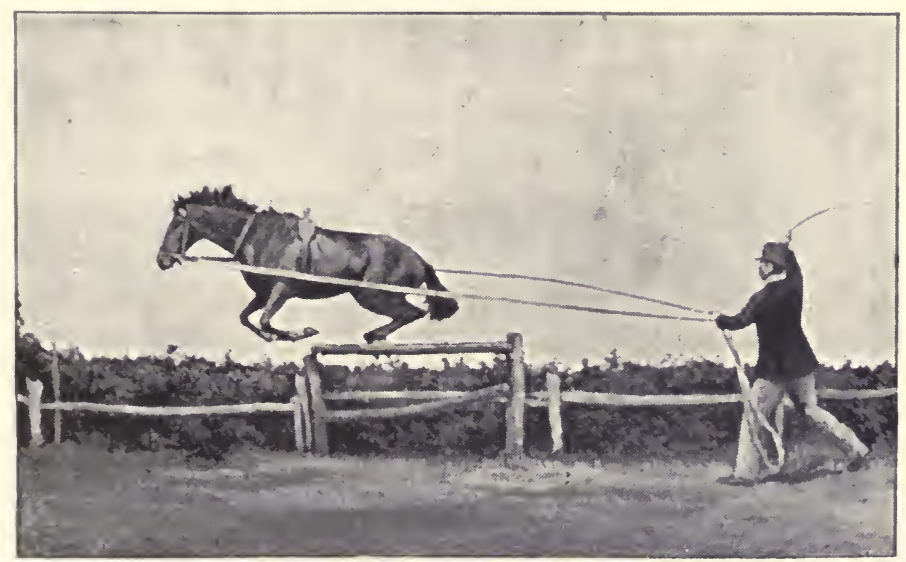

Fig. II3.-Teaching horse to jump with long reins.

when landing, may be corrected by the use of a bearingrein (see page I69), which will be very seldom required for this purpose.

The system of turning horses loose into a circular enclosure (see page 243), fenced in and provided with obstacles, and then making them jump with a long driving whip, is good as far as it goes; but neither it, nor the plan of lunging with a leading rein and cavesson, has any pretensions to teaching obedience to the reins when jumping, without which a safe and clever style is unattainable. 
It is well to make the fences stiff or unpleasant (by the use of gorse, for instance) to hit, so as to teach the pupil not to chance them. Two or three lessons of this sort will be sufficient to make the generality of horses clever enough to carry a rider in good style. The horse should then be saddled, a man or boy put up, without giving him at first any reins to hold, and the horse driven over the fences as before. When the breaker finds that the animal jumps as well with the man in the saddle as he did without him, he may take off the long reins, put on the ordinary ones, and hand them to the rider, who should then take the horse over the fences as before; the breaker using the crack of the whip, as a stimulus, if required. The rider should not be given spurs, unless he is a fine horseman, and unless the horse requires them to make him more lively; but not as a means for overcoming any reluctance he may have to jumping, which should be accomplished in the manner I have laid down.

A horse should not be jumped if he is at all sore on his legs or feet.

One great advantage, among many others, of teaching a horse to jump in the way I have detailed is that, by circling and turning the animal in front of the fences, we can cure him of all impetuosity caused by their proximity, and at the same time make him willing to jump, with thorough light-heartedness, the moment he receives the indication from the rein to go straight and to clear the obstacle. We can easily understand that such training is particularly valuable for the hunter.

After the animal has learned all we can teach him in the breaking field, he should be schooled over a "natural" country; and after he has learned to take his own "line" and jump cleverly in "cold blood," he may be considered qualified to go in "company." 
The snaffle (an unjointed one for preference, see page r68) should be the only bit used with the jumper-whether hunter, chaser, or trooper-when riding him up to a jump ; for the shock which the curb is apt to inflict on the lower jaw when landing, and which is frequently difficult to obviate, tends to make the horse afraid to face the bit; the result being that he becomes unduly liable to injure his hind legs. The fore legs, I may explain, being connected to the body by muscles, and the hind legs by bone; it follows that the former are much better adapted to receive the weight of the horse and rider on landing, than the latter. I have seen many cases in hunters of injury in the hind legs to tendon, ligament, and joint, caused by the injudicious use of a curb. If the horse be too impetuous with a snaffle, he should be again taken in hand by the breaker to be taught obedience to the aids. If the art of breaking were better understood than it is, we would meet with far fewer inquirers after special kinds of bits, with which to hold their horses, than we do ; for they would solve the difficulty by getting their animals properly broken.

If we have the facilities for doing so, we might construct a line of fences in the interval between two concentric circles which have been enclosed so that the horse cannot get out, except at the appointed exit. As a convenient size, I might suggest that the outer circle should be about 35 yards in diameter, and the inner circle 30 yards in diameter. On this circular ride we might put, say, five fences of different kinds, and, by means of the lunging whip, we might drive our pupil at liberty over them, with or without a lead. It is well to have these jumps made particularly stiff, so that the horse will learn that he cannot chance them with impunity. Without going to the trouble of constructing an enclosed line of fences in the 
manner just described, we may practise horses at liberty over obstacles placed round a riding-school or other suitable enclosure.

The two most difficult things in teaching a horse to jump, are to get him, when coming up to a fence, to regulate his speed of his own accord, and to "take off" at the proper distance from his fences, to do which he will have to acquire the ability to put in a short stride, or lengthen his stride, as may be required. This comes naturally to some horses, and in many cases is undoubtedly an hereditary gift. The clever sort appear to have an instinctive dislike to striking their legs against, or_catching

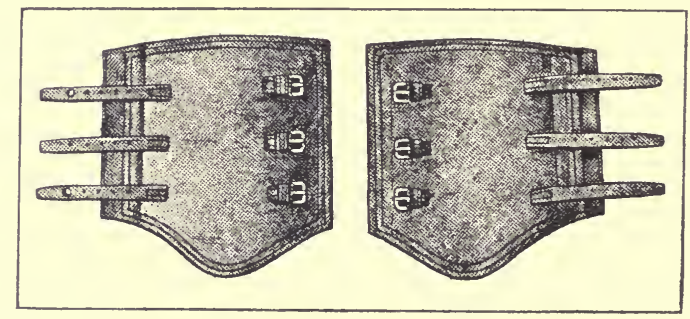

Fig. I 14. - Boots for protecting horse's legs when jumping.

them in, anything. Other horses, on the contrary, despite careful instruction and severe blows and falls, seem incapable of remembering that they should not chance their obstacles, especially when they become excited.

As horses are apt to hit themselves and over-reach when jumping, especially when they are new at the work; I like to protect their legs with boots or bandages. Figs. II4 and II5 show the kind of boots which I use. They are made of strong leather, lined with thick woollen cloth.

\section{JUMPING FAULTS.}

That dangerous fault of chancing fences may be corrected by driving the horse with the long reins over fences which 
are too stiff to take liberties with; but which are not too "big." Or we may practise him at liberty over them in the manner described under the preceding heading.

Jumping too slowly.-Many horses commit this fault without attempting in any way to refuse. It is generally caused by the rider hanging on to the animal's head, or by instruction in jumping by means of the cavesson and leading rein, by which method, the weight is unduly thrown

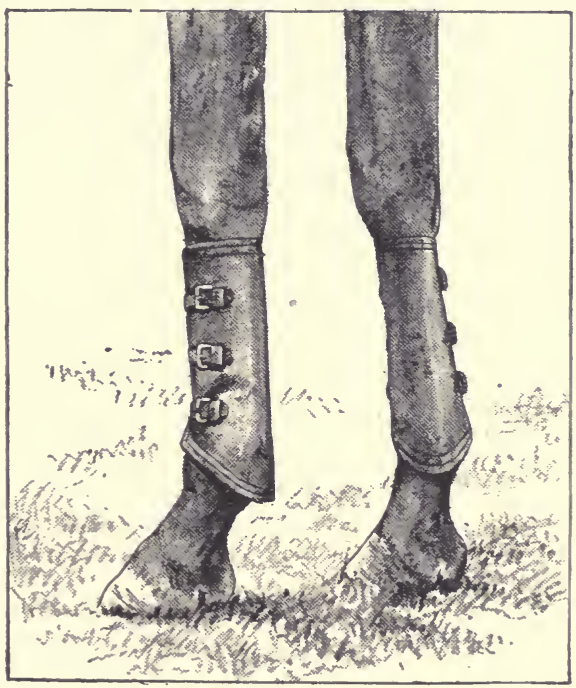

Fig. I 1 5.-Boots for protecting horse's legs when jumping.

on the forehand, and consequently the horse, not having his hind legs well under him when he lands over the fence, is unable to get quickly away from it. Besides this, the animal has to moderate his speed in accordance with that of the man in front of him. By driving him with the long reins on foot we may teach him to go collectedly at any pace we like, and can quickly get him out of the habit of dwelling at his fences. We should, of course, supplement this with judicious schooling, especially in 
company, and should be careful not to interfere with the animal's mouth.

Putting too much weight on the forehand when jumping. - This may be corrected by using a bearing rein (see page r69) when practising the horse over jumps with the long reins, or at liberty (see page 243).

Putting too much weight on the hind legs when landing. -As far as my experience goes, this fault is induced in sound horses only by the use of a severe bit, or by the severe use of an ordinary bit. It may be corrected by mouthing lessons with the long reins, by the use of the standing martingale, and by removal of the cause.

With respect to refusing and running out at fences, see page 317 .

To break a horse of rushing at his fences, we should put him through the course of instruction recommended for pulling (see page 304), and should give him plenty of practice over stiff fences with the long reins, so as to make him regulate his pace without showing any impatience.

\section{THE HUNTER.}

Special attention should be paid to giving the hunter a good mouth and making him temperate, so that he may use his powers to the best advantage, and avoid bringing either himself or his rider to grief. To meet the various conditions in which he may be placed out hunting, especially in a large field and in a difficult country, he ought to be taught to take his fences faultlessly, either fast or slow as his rider wishes, and equally well with or without a lead. He ought to be capable of being quickly stopped or readily turned, even when going at a jump, and to bear such a disappointment without his courage being thereby affected. This valuable attention to his rider's 
signals can be cultivated by practice with the long reins on foot. Above all things it is necessary to teach him that when he gets the signal to go at a jump, he must face it boldly without a thought of pulling up or refusing, no matter how formidable it may appear. A horse broken and schooled in this manner will know, if he be prevented at any time from jumping, that his rider acted from reasonable cause, and not from timidity. The ill effects which the presence of a timid rider has on the temper of a horse is due, I feel certain, not to the supposed discovery by the horse that the man on his back is in a "funk"; but to the animal failing to understand the wishes of his rider. The horse will trust himself to no one whose signals are not clearly intelligible to him. Furthermore, the well-broken horse, if kept facing a fence, while waiting, for instance, his turn at the only practicable spot, will stand without impatience until he receives the wellunderstood signal from hand and leg to go forward; and, even with a short "run," will get into his stride in a moment from the walk or halt, so that he may acquire sufficient speed to clear, if necessary, a ditch or guard rail on the other side. The man who schools a horse should have sufficiently good hands to avoid hurting the animal's mouth, especially when landing over a jump.

The gregarious instinct of the horse, which prompts him to follow his leader instead of taking an independent "line," should be combated by the breaker of the hunter; for unless a horse will go in the direction he is put, he will be neither safe nor reliable. The horse which will jump only when hounds are running, is just the kind of brute to leave one "pounded" in front of some small fence in the event of one becoming separated by chance from the field; to slay one by swerving off to take some seemingly easy, but dangerous, spot ; or to kill one's neighbour by jumping 
on or cannoning against him. We all know that if a horse will leap in "cold blood," he will fence in hot blood; but the converse to this in no way holds good. Therefore, I say, teach the horse which one wishes to make into a hunter, to jump faultlessly by himself, and to take whatever line of country his rider puts him to, before bringing him into the field.

For a country of stone walls, posts and rails, or double banks, a hunter should be taught to check his speed and collect himself far more than he would require to do in a country of hedges and ditches, like Leicestershire for instance.

The preliminary breaking of the hunter will take far less time than experience in the hunting field, without plenty of which he cannot be regarded as a safe conveyance over a country. For this reason, hunters of seven or eight years of age are valued in Leicestershire more highly than those of four or five, other things being equal. Supposing that a horse fresh to the game gets five weeks' cub-hunting, and regular hunting from the first Monday in November, at Kirby Gate, to the second Wednesday in April, with the Belvoir; he will, as a rule, require all that time, with a competent man and an average of three or four days a fortnight, to learn his business. We should initiate the young one very gradually; should leave him a good deal to his own devices; should keep him out a long time, say, to the change to second horses, so as to prevent him from becoming impetuous; and, above all things, we should impress upon him the necessity, when put at a fence, of getting to the other side. In order not to disgust him with the work, ne should always be taken home before he is tired. In the Shires, instruction in making him steady when opening gates and when holding them open, is imperative. 


\section{THE CHASER.}

All the remarks I have made in this chapter respecting the jumper in general and the hunter in particular apply to the steeplechase horse. Although his final test will be racing over fences, we should not attempt to take him fast at them until he can negotiate them faultlessly at a steady canter; for the slower the speed, the easier will it be for him to collect himself and to accurately measure his distance, which are two of the chief tasks for him to learn; the third being to make the necessary effort to clear the obstacle; the fourth, to take his fences at nearly full speed; and the fifth, to get quickly away into his stride again after landing. The third is a question of practice, for the solving of which the rider may at times give a hint with leg, voice, or whip. As jumping too "big" is a fault on the right side, and as experience will generally correct it, I do not think any attempt should be made to remedy such a tendency by the restraining influence of the reins; for the effect of such a proceeding would not improbably be to make the horse slow at "getting away" on landing. The power of jumping while going at a high rate of speed is also a matter of practice, though, of course, some horses acquire it far faster than others. The ability to get quickly away from a fence will in no way be marred by practice in jumping at a slow canter, so long as the moderation in speed is due to the inclination of the horse, and not to the fact that the rider has a tight hold of him by the head. In steeplechasing, and to a lesser extent in hunting, the horse's imitative faculty, if indulged, is liable to cause him to make "mistakes"; one of the most common being that if he is galloping along with another horse, but slightly behind him (say, half a length or so), his instinct will prompt him, on nearing 
a fence, to "take off" at the same moment as his leader does, with the frequent result of a fall. "Running out" or swerving in imitation of the leader may also be often observed. I would therefore advise that the intended chaser should be schooled by himself until he has thoroughly acquired the habit of taking his own line and measuring his own distance when going at speed over a "made country" of orthodox size, before sending him in company. During his first lessons with one or more horses, he ought, according to the argument given, to take the position of leader; and not until he has been found to be fully capable of acting independently, should the other horse or horses be brought alongside of him, or taken in front. I need hardly point out that it is far easier to fix the attention of the horse on his work when he is alone, than when he is under the distracting influences of "company."

THE HURDLE RACER

should be taught to take his fences at racing speed with only just sufficient collection at the three foot six or three foot nine obstacles to make him clear them, even if he "chances" them a little. No matter how clever a horse may be at "timber-topping," it is impossible for him to clear a hurdle in his stride; for the period of suspension of the gallop (see Points of the Horse) is far too brief to allow this to be done. For his particular kind of work, he has, just as much as the hunter or chaser, to be taught to jump, but in a different style; the chief requirements of which are to leap quickly, to avoid jumping too high, and to get away again with the least possible delay. The directions which have been already given in this chapter, will point out how the necessary instruction may be imparted. 


\section{THE SHOW-JUMPER.}

The subject of show-jumping is a difficult one to approach ; for the judging at one place is often conducted under totally different principles to those at another exhibition. Speaking generally, I think I may say that the chief requirement of the show-jumper is to be able and willing to jump a great height without touching the obstacle. As he is not required, like the hunter, to jump high and wide at the same time, he is trained to go up to his obstacles, with the exception of the water-jump, at a very short and greatly collected canter, so that he may take off as near the proper spot as possible, and raise his forehand to the required height before projecting himself upwards and forwards with his hind legs. The angle of elevation of his centre of gravity would consequently be greater and better adapted to his work than that of the free-striding hunter or chaser. As I have analysed, in Points of the Horse, the movements in leaping, I need not go into the subject here. Although attempts are made at Ball's Bridge (Dublin) and elsewhere to make the jumping ring a mimic hunting field, the usual conditions of such contests agree with what I have said. In the training of the show-jumper, we should first of all teach him the short canter by collecting him and making him circle and do the figure 8 at that pace on very small circles. For example, he ought to be able to canter steadily round a circle of eighteen feet in diameter, and to take a stride of not more than five feet in length. My readers will, I trust, understand that I am here writing about his training, and not about his performance in the ring. In teaching him to jump I would supplement the long rein work with a good deal of practice "at liberty," over stiff bars and gates placed on a small circle, say, one of twenty 
yards in diameter, and gradually raised until he could easily clear five and a half feet without touching the timber. I would suggest the use of a walled-in circle; as in it the breaker could more easily control the movements of the loose horse with the lunging whip than if he were in a rectangular enclosure. The whip should be employed to indicate to the animal what he has got to do, or at most to stimulate him; but in no way to punish him. The horse intended for show-jumping should have a good deal of practice at water; for the judges always attach much importance to the way in which the competitors negotiate the "brook."

TIME REQUIRED TO TEACH A HORSE TO JUMP.

An ordinary horse in good condition and of suitable conformation can be taught in one or two lessons of threequarters of an hour's duration, to carry his rider over, say, a three foot six hurdle or hedge, or a six foot ditch, in fair style. But the teaching a horse to measure his distance and to shorten or lengthen his stride, as may be required, on coming up to a fence, is much more difficult; for horses greatly vary in "cleverness." Although a month will be sufficient to make some apt pupils perfect, other animals seem incapable of learning to keep their feet out of harm's way. Long experience has proved to me that if a horse is sound on his feet and legs, we run no risk of spoiling his temper by jumping him over ten or a dozen fences every day, or that number of times over the same obstacles; provided always that we don't pull his mouth about, and that we don't irritate him with whip or spur. A horse requires frequent practice to learn to jump; and, after he has acquired that accomplishment, to keep his muscles in jumping order. 


\section{CHAPTER VIII.}

\section{BREAKING TO HARNESS.}

I Would advise that light harness horses, before being placed between the shafts, should be put through the course of instruction laid down in Chapters V. and VI., with the exception of those parts which refer to cantering and galloping. We might omit, in the case of the heavy cart horse, the training described in Chapter VI. My reason for advocating a certain amount of saddle-work with light harness horses is that it makes them more handy and less inclined to jib, than they would be without it.

The place which I prefer for breaking a horse to harness is a circular enclosure of about thirty yards in diameter, the ground of which is level and hard enough to allow the wheels of the breaking-cart to run smoothly. I would use an "open" (one without blinkers) snaffle bridle.

Before putting the horse in, we may, if in doubt, test his steadiness by the head and tail method (see page I55), gentling him under the belly and about the hind legs with a long pole, and cracking a whip all over him. Having put on the harness, we may circle him for half an hour or more with the long reins on foot (see page I68), and turn and rein him back until he is thoroughly "supple." We may then put him into some suitable, light, two-wheeled trap, and take up our position on the near side on about a 
line with the axle-tree and a little away from the cart, with the off long rein passing under the rail of the splashboard and the near one free (see Fig. II6). As a precaution against possible mishap, we may put on a kicking strap, and may place an assistant holding a separate rein attached to the snaffle on each side of our pupil. We may now start the horse off as before to circle to the left. In the event of being so pressed for time that we could not give the horse a sufficiency of preliminary breaking, we might, if we had the necessary gear, after circling him on foot with the long

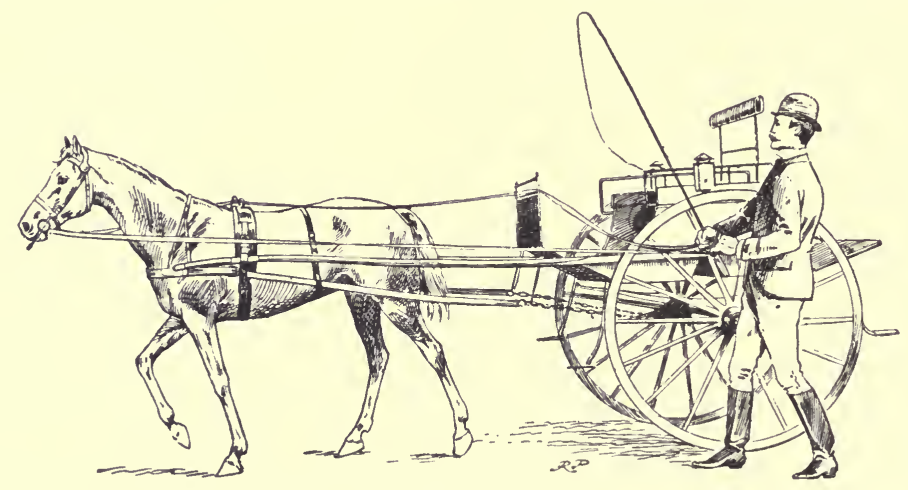

Fig. II6.-Driving horse in harness on foot.

reins, place a strait-jacket (see page I29) over the harness, buckling it up just tight enough to prevent him kicking if so inclined; and after circling and turning him in it for a short time, put him in the trap as before described. After the horse has been circled to the left at the walk and trot and has been found to go steadily, we should change the reins to the off side and circle him at the walk and trot to the right, in a manner similar to that which we did on the near side. We may now, with all proper precautions, put an assistant on the driving seat, and circle the horse to the right and left. After a short time, we may give the 
assistant a pair of ordinary driving reins attached to the snaffle, and passed through the rings of the harness pad. If we have seen fit to employ assistants on foot and a straitjacket, we may dispense with their aid, and get one helper on the box to gradually assume command, while we follow the horse round without interfering with his mouth. As soon as he appears to be reliable, we may take off the long reins and confine the guidance of the animal to the man on the box, or get on to it ourselves. Nothing further remains, before taking the horse on the road, than to teach him to

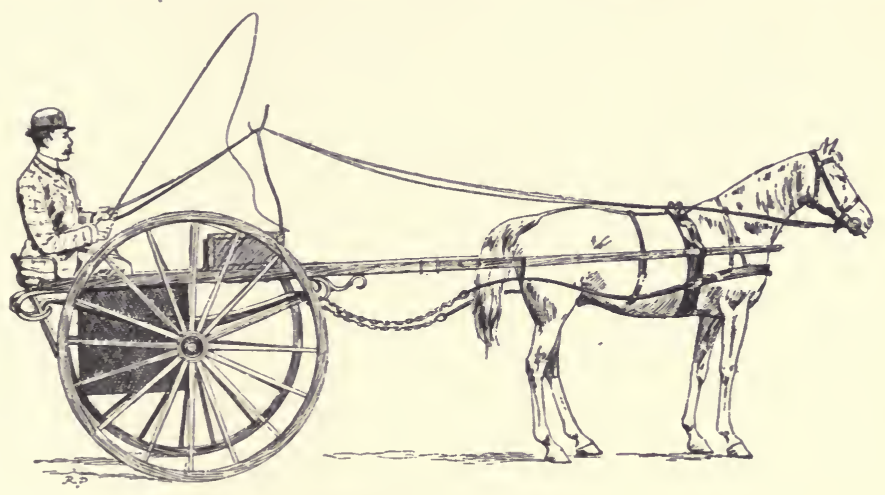

Fig. I $17 .-\mathrm{A}$ jingle.

start off, go steadily from the walk into the trot, or from the trot into the walk, turn, rein-back, and pull-up. I think this method of breaking a horse singly is much to be preferred to putting him first of all into double harness; as it teaches him to work independently of a companion, and the fact of not having another horse near him, secures his attention. Besides, being more under the control of the breaker, he is less inclined to contract the vices of jibbing or of hanging back from the collar, than if he were put in double harness. The breaker, if expert, and with only one assistant, can make any horse which has been well broken to saddle, 
and has not had his temper spoiled by injudicious attempts to put him into harness, steady enough to go out for a quiet drive after giving him, say, a two-hours' lesson on the principles I have just laid down. Having learned the single horse method of breaking, my readers will be fully competent to put a horse into double harness alongside a steady break-horse. There are many horses which go well in double harness, but will not pull by themselves; although almost every animal which will go singly will, as far as I have seen, go in double harness. On this account, and from what I have already said, I would advise that all horses which are intended for harness should get their first lessons singly.

For "rough-and-ready" breaking, a "jingle" (see Fig. II7) is an American contrivance which may be useful. It consists of a two-wheeled cart with such long shafts that the horse, when harnessed, cannot, if inclined to kick, hit any part of the body of the trap. Proving the impossibility of striking the object aimed at, tends to quickly eradicate his pet vice out of the kicker, who, on becoming convinced of the futility of his attacks, will seldom, if ever, renew them when he is put into an ordinary cart, the body of which he might easily kick to pieces if he were aware of his power of evil. This fact does not say much for the intelligence of the horse. My readers will see that the rail on the splash-board, over which the reins pass, is made specially high, so that the horse may not get his hind legs or tail over it. The jingle is balanced so that under ordinary conditions no weight is put on the shafts; but by filling with stones, or any other suitable material, a box which is placed for this purpose in front of the body of the cart, weight may be put on the back of the horse as may be required. The placing of weight on the back is the chief incitement to plunging, bucking, and kicking which horses 
receive while being broken to harness. If the animal has been previously broken to saddle, he will of course not mind weight on his back. A third good point about the jingle is that the door at the back of it is so arranged that, in the event of any mishap or impending danger, the driver can readily slip out behind, and leave the horse and jingle to their fate!

An Irish outside car, owing to the facilities it offers for getting on and off it, is far more convenient and much less dangerous for breaking-in horses to harness than a gig or dog-cart.

When we take out on the road the recently "put-in" horse, we should attempt to form his paces by getting him to go in a thoroughly steady and well-balanced manner. We should pay special attention to preventing him from trotting at a speed faster than that at which he can go with ease and precision; and should keep him collected by holding the reins at a fixed length, and by making him go up to his bit by the voice or whip. Before using either of these stimulants, a slight extra pull of the reins should be taken, so that the horse may increase the tension on the traces gradually, and not with a jerk by suddenly springing forward.

NotE.-If the young horse is hot-headed and inclined to be abnormally flighty, I prefer to accustom it to all manner of noisy movement behind, before attempting to drive it, for if there should be a slight accident, and this has not been done, the horse will probably bolt and break the trap.

To quieten the horse quickly and safely, I put on a Comanche bridle, then the harness, after which I lead it to the breaking enclosure and apply hobbles such as are used commonly at stud farms. They are made up of two ropes, one about $5 \frac{1}{2}$ feet long, the other about 7 feet long. 
Each has a padded slip-loop at one end to encircle the pastern, or leg below the hock. If they are put just below the hocks the horse will not be so likely to step over the ropes from them.

At equal lengths, about a foot from each leg or pastern, the two ropes are twisted together and so brought up together, till they have passed between the fore legs at

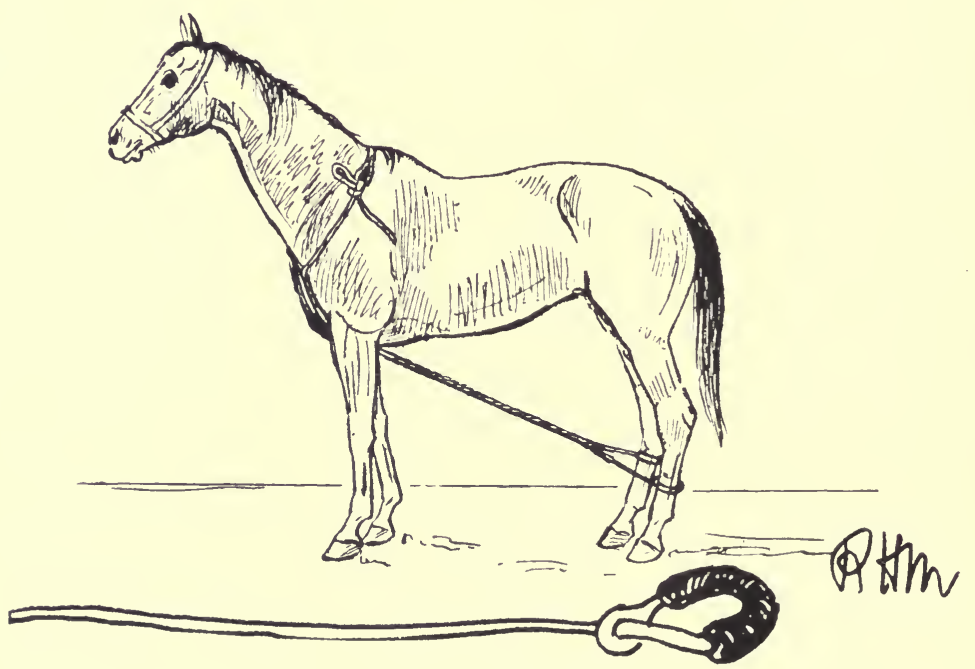

Fig. 117A.--Double hobble in use.

the brisket. Then the shorter rope, which has a loop spliced in its end, is passed over the neck from one side. It should be so long that its looped end just passes over the neck to the other side, where it is met by the longer rope, which is passed through it, drawn tightly and retained by a knot which can easily and quickly be unfastened at any time. In my illustration I have left off the harness, because I thought, with it, there might be greater difficulty in seeing the position of the hobbles.

The man who is at the horse's head holding the "Comanche bridle" should be as gentle and reassuring 
in his manner as possible. An excitable, fidgety man does not improve any horse, and should never be allowed near a young one. He should talk to the horse as though nothing unusual was about to happen, and not keep repeating "Whoa! Steady, boy," etc. Such nervous excitement frightens the horse by warning him that something unusual is about to be done, to which we fear he will object.

When the horse is fast and all ready, the breaking-cart can be wheeled round, the shafts lowered, raised, and backed away again, till at last the horse, finding he is fast, and that nothing is hurting him, loses all fear and stands quietly while the shafts are rattled against his sides and people jump about in the breaking-cart. After this the hobbles can be removed to allow the horse to be led about attached to the cart, and turned gently in every direction while being continually stopped and started again. When the horse refuses to start, a steady pull on the cord of the "Comanche bridle" will soon cause him to jump forward and do as we wish. If the animal seems unusually irritable, the hobbles and leading lessons may be repeated for a few days before he is driven from the cart. 


\section{CHAPTER IX. SCHOOL BREAKING.}

General remarks on school breaking-The school horse-Collecting the horse at the halt-Collecting the horse at the walk and trot-Teaching the horse to strike off correctly into the canter-Changing the leg at the canter-Figure of eight at the canter-Cantering falsely-Turn on the forehand-Turn on the hind quarters--The passage - The passage with head to wall-The passage with tail to wall-Change of hand by the passage-Counterchange of hand by the passage-Circling at the passage--The halt-Change from one pace to another-Shoulder in-Course of school instruction-Additional school movements-Extension of a fore leg--The Spanish walk-The Spanish trot-Turn on the forehand on three legs-The canter on three legs - Changes of leg at the canter-A circus high-school act.

\section{GENERAL REMARKS ON SCHOOL BREAKING.}

THE necessity for cavalry horses, whether acting in masses or singly, being "collected" to an unusual extent, so as to make them as handy as possible, initiated at an early period of military history a special training for war horses, which, while accomplishing its own purpose, was obtained by sacrificing to some extent their general usefulness. As in early times the horseman was a mounted fighting man; the arts of breaking and riding were then cultivated from a purely military point of view. By degrees the system of breaking became elaborated from a means into an end, so that we find many of its most eminent professors absolutely ignorant of riding as a practical art. For instance, Baucher, the great high priest of l'́quitation savante, was never known to ride a horse outside of a manège or circus. As riding 
became more common among civilians, the fact was recognised that the long and arduous training of the manège could not alone be dispensed with in the ordinary riding horse ; but that it was not sufficient in itself to fit him for rough and ready work outdoors, and especially in the hunting field. Riding-school teaching has accordingly fallen into disrepute-in France almost as much as in England. Like in many other changes of opinion, the good points of the old style were lost sight of by those who went to the opposite extreme. While relegating to the circus such wholly useless airs as the Spanish trot and walk, and cantering on three legs, we must not ignore the fact that school work, judiciously applied, is an admirable system of equine dancing, deportment, drill, or gymnastics (whichever way we look at it) for teaching the horse to carry himself in a well-balanced manner, and to obey the aids promptly and with precision. We may regard it under three heads : (I) For forming the horse's mouth, paces, and manners ; (2) For show work, as in a circus ; and (3) for the requirements of military service. In the present chapter I shall treat of the first and second divisions, in which the cavalry element is so far ignored that the rider holds a rein in each hand. Both the "knights of old," who used exceedingly long stirrups, and Eastern horsemen, who had extremely short ones, being unable to apply their legs as an aid, rode their horses chiefly by the bridle, and having consequently made them heavy in hand, were obliged to employ extremely severe bits to collect them. Baucher introduced into school practice the admirable system of keeping the horse light in hand by the use of the leg, or, if need be, of the spur. Without wishing in any way to detract from the credit due to Baucher in this matter, I may mention that the system of riding a horse more by the legs than by the hands appears to have been known in England and Ireland long 
before the great Frenchman was born. Sam Chifney, who was the George Fordham of the latter end of the eighteenth century, certainly knew it by the way in which he speaks in Genius Genuine of riding a horse in a race "as if you had a silken rein as fine as a hair, and that you were afraid of breaking it." Custance in Riding Recollections says : "Fordham sat back in his saddle, and, as it were, drove his horse from him." He also tells that "Wells was a very strong man on a horse, and used to lap his long legs round them at a finish." This style of riding has been traditional among jockeys who never heard either of the "high school" or of Baucher. It was tanght to me in Ireland more than forty years ago when I was a boy, as the old, orthodox method to follow.

One of the first maxims of the high school is that the horse must yield up the initiative entirely to his rider; that is, he should do nothing of his own accord. Hence the rider must remain constantly in close touch with him by hand and leg. If the pressure of the unarmed heel be not sufficient, the spurs will have to be kept close to the horse's sides; if possible, brushing through the hair without touching the skin, unless required. To enable this to be done, the knees have to be kept a little away from the flaps of the saddle, with the result that their strength of grip is considerably diminished. As the maintenance of this delicate touch is impossible under conditions of rough work in the open, and as its strain on the attention and muscles of the horse would be unduly severe, to say nothing of the loss of grip; this method of riding is applicable only to the manege, the circus, the parade ground, and on special occasions, such as those of single combat between cavalrymen, when the maximum amount of control over the horse is required. As I have before said, school work, from a breaking point of view, is a means, but not an end. 
That being the case, we should allow the horse to resume his natural attitude or gait (permitting him to "stand at ease" or "march at ease") after performing any of his school tasks, none of which should be prolonged to such an extent as to tire him. I shall consider, in Chapter X., the relations of school breaking to military riding.

In order that the school horse may be maintained absolutely under the control of his rider, we should avoid giving him set tasks of an unvaried nature; we should not commence, stop, or alter the work at particular places; and we should not allow him to act for himself, without receiving a signal from his rider, so that he may not become routins. As a case in point, we should on no account, when teaching a horse to strike off correctly in the canter, always begin at one spot, whether on a circle or in a straight line; for if we do so, the animal will look out for his arrival at that point, to start off of his own accord, and thus, by taking the initiative, to deprive us of command over him. We here touch on a weak point of school breaking, namely, that a horse whose instruction is confined to the manège, becomes routine to the school, so that he will perform his work properly only in it, and would require, in order to fit him to act outside, a further (though, necessarily, a much shorter) course of teaching, which would have the effect of more or less impairing his cleverness indoors. Hence, high-school horses are, as a rule, exercised only in the manège. I have seen this tendency to become routiné to a certain place well shown by horses which I practised at various school airs on a particular part of my paddock; for although they would do this work with precision and brilliancy on the improvised manège, they would, until I had accustomed them to the change, try to "play up" the moment I took them off the well-remembered track. Therefore, school breaking, however valuable it may be, 
can be regarded only as preparatory to instruction in the open.

Our military riding-schools are twenty yards wide by sixty yards long. For the school training of single horses, the manige need not be larger than twelve yards by twenty-four yards, or even a circle of twelve yards in diameter will do. With single reins, one rein is held in each hand. With a bit and bridoon, apart from the ordinary application of the bridle, the snaffle is used to keep the head sufficiently raised by acting on the corners of the mouth, and the curb to depress it. The use of the curb is not indispensable for obtaining the airs of the high school ; but from its severity it is, as a rule, more effective than that of the snaffle. The collection to be obtained from the latter bit is in every way to be preferred to that by the former, the indications of which are complex and necessarily confusing. For instance, we have with it pressures, respectively, on the bars of the mouth, on the chin-groove (by means of the curb-chain), on the top of the horse's head (through the headstall of the bridle), and in some cases on the roof of the animal's mouth (through the agency of a high port). The indications of the snaffle are simple, and as nearly as possible, direct. If its effects are obtained slower than those of the curb, they are far less liable to arouse the opposition of the horse, who will generally resent punishment that appears to him to be unmerited.

THE SCHOOL HORSE.

The chief physical points which are required in the school horse are: light forehand, well-placed-on head and neck, sloping shoulders, oblique pasterns, strong loins, and powerful hocks. The principal mental ones are : lightheartedness, so as to give brilliancy to his move- 
ments, and entire absence of any tendency to be sulky. Well-bred horses are the best for this work. A horse to shine in the manege should be broken exclusively for that object, so that he may not acquire the habit of taking the initiative. School work greatly tries a horse's temper. Hence, while engaged in it, we should be constantly on our guard not to unduly annoy our pupil. If he "plays up," we should assert our authority ; but with a minimum of force; and, having gained our point, should suitably reward the animal for his compliance, which, as a rule, is best done by ending the lesson, and by giving him some coveted dainty. The acquisition of serious "defences," such as rearing, prancing, and refusing to turn to one particular side, is generally the result of the breaker demanding too much, continuing his demands too long, treating the animal harshly, and especially applying the aids in a confusing manner.

M. James Fillis justly points out, in his Principes de Dressage et d'Équitation, that geldings are more suitable for high-school work than either mares or entires; the former being specially liable to jib and to become irritable on being touched with the spur; the latter, to rear, and to become unduly heavy on the forehand.

COLLECTING THE HORSE AT THE HALT.

To teach a horse to collect himself at the halt, we may, while holding the reins and whip, as in Fig. 95, place ourselves to the left of the near shoulder and make the horse extend himself by tapping him with the whip behind the fore legs. To prompt him to relieve himself out of this constrained position, we may tap him with the whip on the croup, so as to make him bring up his hind legs, which, on account of the remembered relief, he will soon learn to do. on being 
touched with the whip in this manner, without having previously brought his fore legs to the front. To be precise, we should touch the near or off side of the croup to make the horse bring up, respectively, the near or off hind leg. If necessary, we can prevent him by the reins from going forward, or from turning round. Having taught him on foot to collect himself at the halt, we may mount him, and by holding the reins in one hand and by touching him on the croup with the whip held in the other hand, we may make him bring his hind legs under him as before described. Or we may hold in each hand a rein, and a whip to be applied to the side. By using the drawn-back heel, with or without spurs, at the same time as the whip, by increasing the effect of the heel while diminishing that of the whip, and by restraining with the reins any forward movement, we can soon teach the horse to collect himself at the halt by means of the heel and rein. If one hind leg be less advanced than the other, we should give the horse the signal to bring it forward by touching him with the drawn-back foot of the same side, and should place a preponderance of weight on the stirrup of the opposite side. When attempting to collect a horse, we should, as a rule, raise his head, so as to bring the weight back.

COLLECTING THE HORSE AT THE. WALK AND TROT.

Having collected the horse at the halt, we may put him into the walk by increasing the pressure of the drawn-back feet, and slightly yielding the reins. We may obtain collection at either the walk or trot by applying the drawn-back foot at the same moment as the forefort of that side comes down, by placing more weight on the opposite stirrup, and by feeling the opposite rein the stronger, while checking the forward movement with both reins. By this manner 
we arrive at the school-walk (pas d'ćcole). In it the horse raises his knees higher and advances his feet less than in the ordinary walk, between which and the short collected trot it is intermediate. If, while proceeding at the schoolwalk, we increase the action of the legs, and continue the alteration of weight from side to side, without adding to the tension of the reins or only slightly yielding them, the animal will break into the trot; and from the trot into the canter. My readers, on referring to Fig. 3, will see that at the moment when a fore leg is placed on the ground during the trot, the hind leg of that side is off the ground, and being ready to be brought forward, is consequently the proper one to be stimulated to obtain collection. The same remarks apply to the walk, except that the hind leg, say, of the off side, quits the ground at a time when the off fore is bearing a full share of weight and the near fore is being brought forward (see Fig. 6); and vice versâ. The quicker the hind legs are brought forward at the walk, the nearer will that pace assume the character of the trot.

Having thus obtained a short, well-collected trot, we should go on until we get it slow, lofty, in perfect time, and with a slight pause when the knee is raised to its greatest height. This form of cadenced trot is known in French as le passage. By continuing the stimulating effect of the leg and by increasing the restraining action of the hand, we check the forward movement, and get the piaffer, which is a high-actioned trot without gaining ground, or le passage sur place. For the passage and piaffer to be brilliant, there should be a moment of suspension (all four feet off the ground at the same time) between each step. In the passage, there is necessarily more knee action than forward reach. If when attempting the passage or piaffer, the movements of the horse become hurried, he should be halted, "made much of," and collected afresh, so as to 
give him confidence, without which it is impossible to make him understand our wishes. Both the piaffer and passage (which give brilliancy to the trot and walk) can be obtained either by stimulating the horse from the walk to the trot and holding him in, or by drawing him in from the ordinary trot to the slower and more elevated paces. The comparative action of the fore and hind legs can be increased by respectively raising, or lowering the hands, and by bringing the weight of the body backward or forward; and vice versâ. As the piaffer is useful only as a preparatory exercise for the collected short canter, and for change of leg, we should not check the horse if, when at the piaffer, he breaks into this canter. Although the piaffer is, in itself, of no practical utility, the collected short canter is indispensable for cavalry purposes, especially in single combat with sword or lance.

Although to obtain the desired effect quickly, we may in our first few lessons bend the horse's head to one side or the other when proceeding in a straight direction, we should avoid doing so later on ; for elegance of carriage is incompatible with any rocking movement of the body.

TEACHING A HORSE TO STRIKE OFF CORRECTLY INTO THE CANTER (see page 223).

We may begin from the trot, and should in all cases first collect our horse. Just before turning a corner of the school, when trotting for instance to the right, we should touch the horse with the drawn-back left heel at the moment when the near fore comes down; and, as described on page 224, apply the other aids for obtaining the canter with the off fore leading. By starting the horse at a corner when he is oblique to the track upon which he is about to travel, by turning him round, and by leaning to the off side, the 
utmost freedom is given to the near hind leg to be brought forward, so as to commence the change of pace. I have pointed out on page 267 that when a fore leg comes down in the trot, the hind leg of that side is off the ground. Accepting the remarks made on page 267 with reference to the walk, we may apply the aids for making a horse strike off into a canter from the walk, in the same manner as we did for getting him to lead off from the trot. If the horse tries to revert from the canter into the trot, we should keep him up to the canter by applying the outward drawn-back heel or spur. Having attained our object when going to the right, we should seek it in the same way to the left.

The utility of placing the horse obliquely to the direction in which we wish him to canter, depends on the fact that when a horse canters (or gallops), the leading shoulder is somewhat in advance of the non-leading one. Hence, it is easier for him, when placed obliquely to the track, to lead off with the more advanced fore leg, than with the other fore leg.

To teach the horse to strike off into the canter from the halt, say, with the off fore leading, we may place him in a corner of the school obliquely to one of the long sides and on the right rein; we should, by touching him with the drawn-back left heel, make him advance the off hind more under him than the near one; and having thus prepared him, should make him strike off in the way described in the two preceding paragraphs. When he has learned to do this, we should give him similar instruction on the left rein. When we have thus got him to strike off correctly with either fore leg, we should gradually bring him to do so, when placed in a straight line and away from the walls of the manège. This air requires a horse to be thoroughly obedient to the aids, and demands a preparation as well as a stimulus. 
Although, to facilitate instruction, the horse may at first be placed with his head turned away from the direction in which he is to proceed, he should be taught later on to strike off into the canter from the trot, walk, or halt, with his head straight, or even slightly bent to the side of the fore leg with which it is intended for him to lead off. He will then have to rely almost entirely on the respective signals given by the legs and by the displacement of the weight of the rider's body.

CHANGING THE LEG AT THE CANTER.

Having taught the horse, without changing his direction, to strike off steadily and promptly into the canter with either fore leg, as may be required, from the trot, walk, and halt, we may canter him down the centre of the school, say, with the near fore leading, and at the moment when he brings that leg down on the ground, we should apply the drawnback left leg, feel the right rein, place the weight on the right stirrup, and make the horse turn more or less sharply to the right, so as to oblige him to change his leg. We should gradually work him in this way, and with the off as well as the near fore leading, so that he will make the change on receiving the signal from the aids, without deviating from a straight line. By practising him at this and by keeping him well in hand, we may finally get him to change his leg at each stride, at every second stride, or at every third stride as may be desired.

We select the moment the horse brings down the leading fore leg (namely, the third period of the canter, see Fig. I20) as the one at which to give the signal for the change; because the hind leg of the same side as the leading fore is about to quit the ground at that time, and consequently, on being stimulated by the rider's foot, it can be brought forward under the animal's body with the least 
possible delay, so as to make the required change. It may be objected that it is impossible to tell, when in the saddle, the exact periods of the canter; that school riders, long before the horse's movements at the canter had been investigated, were able from practice to give the signal for the change; and that, in attempting to do so, we must be guided solely by the inspiration of the moment. Although the necessary skill can be obtained only by practice, one certainly is greatly helped in one's endeavour by knowing the principles upon which one should work.

\section{FIGURE EIGHT AT THE CANTER.}

We should teach the horse the figure 8 at the canter in the manner described on page 225, except that we should make the horse change his leg immediately on entering the new circle.

\section{CANTERING FALSELY.}

Purposely making a horse canter falsely is the best possible practice for teaching him to obey the aids and for preventing him from becoming routins; for it forces him to subordinate his natural inclinations to the aids. I may point out that up to this we have made the aids conformable to the movements of the animal. When he canters in this manner, say, with the near fore leading when on the right circle, he should have his head turned to the left, and the rider should place more weight on the left stirrup than on the right one. Having taught him to canter falsely on both circles, we may make him do so on the figure 8, in which the changes of the leading leg will also be false.

TURN ON THE FOREHAND.

After having obtained this movement in the manner described on page 212 , we should try to do the complete circle on both turns, with the respective pivot foot being 
fixed on the ground, and the head slightly bent towards the side to which it is being turned. The movement which I have called the turn on the forehand to the right is the pirouette renversée à gauche; and the turn on the forehand to the left, the pirouette renversíe à droite.

\section{TURN ON THE HIND-QUARTERS.}

This movement should be taught to the horse with a great deal of discretion; for it is apt to make him rear as a "defence." We may begin on foot, by holding the reins and whip in the same way as in the turn on the forehand (see page I93). We should, for obtaining the turn, say, to the right, bend the head to the right with the right rein, push the forehand round to the right with the left rein, and check any rotatory movement of the hind-quarters by the application of the whip (see Fig. 95), which may be used to press against the left thigh or lightly tap it. The horse should be relieved and "made much of" (patted on the neck) at each step gained. In the turn on the hind-quarters to the right, the off hind will act as the pivot, which at first should be a moving one ; that is to say, instead of, in this case, the off hind remaining fixed on the ground, it may describe a circle of, perhaps, a couple of feet in diameter. The nearer approach there is made to fixity of pivot, the more inclined will the horse be to rear. If the fixed pivot be demanded, its accomplishment should be delayed to a late period of the breaking; for the horse will then be less liable to "play up "than he would have been when his education was less advanced. In the turn on the hind-quarters to the right, when mounted, we should draw back and apply the left foot, advance the right foot, lean a little back and to the right side, raise the left hand a little higher than the right hand, and turn the horse's head and neck to the right. The opposite 
aids are used for the turn to the left. We should be particularly careful against putting young horses too much on their haunches, so that we may not strain their hocks.

I may mention as an interesting point that if a horse makes a sharp turn when at liberty in an open space, he will do so on his forehand; but when in a cramped position, as in a narrow pathway with walls on each side, he will probably turn on his hind-quarters; for he can shorten the horizontal space occupied by his body much easier by raising his forehand than by raising his hind-quarters. We all know that the ordinary horse can readily turn round when standing on his hind legs; but is unable to do so if he tries to balance himself on his fore legs. On the other hand, as the fore legs bear a larger proportion of weight than the hind ones, it is easier for the horse to turn on the former than on the latter, when his movements are not cramped by want of space. The turn on the hind-quarters through a complete circle is the pirouette ordinaire of the high school.

\section{THE PASSAGE}

(to use the term employed in English military riding-schools) is a side movement in which the track made by the hind legs is apart from and parallel to that of the fore ones. It can best be done when the horse is collected at the walk, trot, or canter. If uncollected, especially at the walk, the animal may fail to raise his outward feet high enough to clear his inward ones. The horse is placed obliquely to the direction in which he is to proceed; his head is turned towards that direction, and his outward feet (the near if he is going to the right, and vice versâ), both fore and hind, cross in front of their respective fellows (see Figs. II8 and II9). Instead of two tracks (fore and hind), the animal really works on four tracks, namely, one for each foot. 
The passage is not alone useful in itself for enabling a side movement to be made, without the necessity for turning the horse round; but when executed at the canter, it is a valuable practice for teaching the horse to lead off and change his leg in a well-balanced manner at that pace.

The English term, passage, must not be confused with

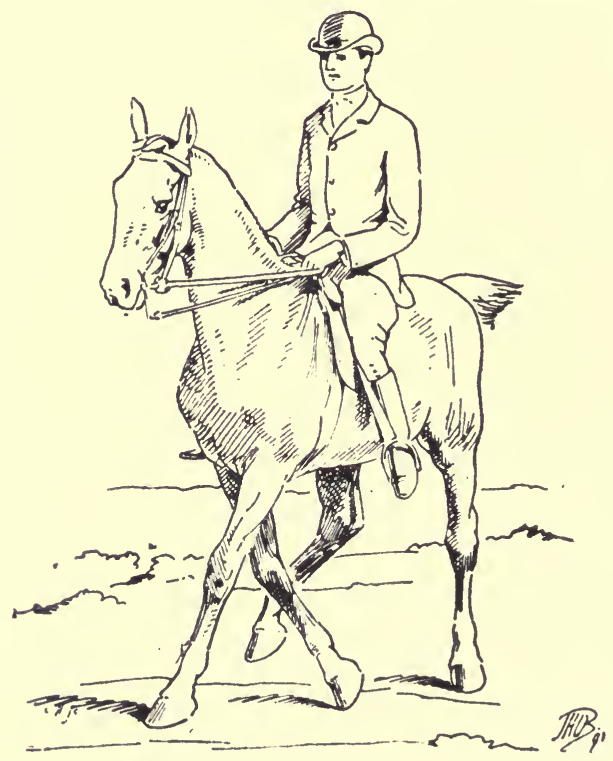

'Fig. Ir 8.-Passage to the right.

the French one, which is written in the same way, and which is a short and lofty trot (see page 267).

\section{THE PASSAGE WITH HEAD TO WALL.}

We may obtain the passage by gradually converting the straightforward advance into a side movement by the aids. Thus, when going round the school to the left at a walk, we may check, to a certain extent, the forward movement by the reins, and place the horse in an oblique direction to the track 
and with his head to the wall by the action of the drawnback right leg. The horse's head and neck should be slightly bent in the direction he is going. The pressure of our right leg, which should be used only at the instant the near fore comes down, gives the horse the signal to carry his off hind in front of and across his near hind. As he

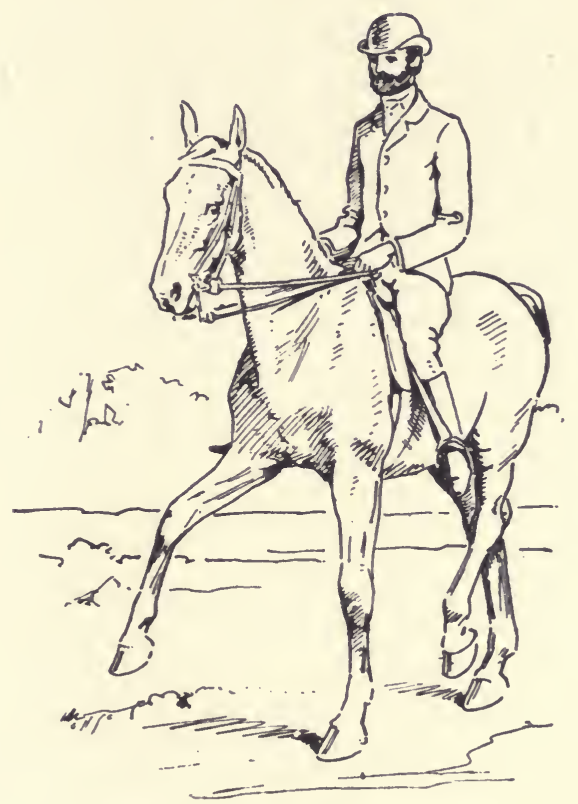

Fig. I 19.-Passage to the right.

will naturally readjust his own balance by lifting up and carrying his near hind to the left when the off hind has been placed on the ground across it; the pressure of our right leg, to be effective, should be reserved as a signal for the off hind, and consequently should not be continuous. We should place our weight on the left stirrup, and should apply the advanced left foot to the horse's shoulder to aid in balancing the animal. If he retreats from the track, we 
should bring him up to it by closing both legs, and should make him strike off into the passage by feeling the left rein and by applying the drawn-back right foot. When the movement has been executed for the required distance, we should apply the drawn-back left leg, and should straighten the horse. We may then try the right pass on the other hand, and with the opposite aids. After the animal has gained some proficiency, we should commence the passage, if going to the left on the track, by turning the horse on the forehand to the right through an angle of $45^{\circ}$; if to the right, the turn should be made to the left. It is necessary that the horse be placed obliquely to the track; for if he is put at right angles to it, it will be impossible for him to cross his outward legs in front of their inward fellows, and at the same time move in a direction parallel to the track. When passaging to the left, the right is the outward side, and vice versâ. In "making" the corners of the ridingschool, a quarter pirouette (turn on the hind-quarters) to left or right (according as the passage is to the left or right) should be executed, so as to bring the horse into the proper position for his new direction.

The passage may be done at the walk, trot, "passage," or canter. When performed at the last-mentioned pace, the outward and drawn-back leg should be applied only at the moment when the non-leading (and outward) fore leg comes down, which it does at the same instant as the inward hind leg. For instance, when attempting the left pass at the canter (with, naturally, the near fore leading), we should apply the drawn-back right foot at the moment when the off fore comes on the ground, so that the off hind, which is in the air at that time, may be readily crossed in front of the near hind. We should begin by placing the horse at only a small angle to the track, and gradually work him on until he can do the passage at an angle of 
$45^{\circ}$, or even less. We must remember always to keep more weight on the inward stirrup than on the outward stirrup.

THE PASSAGE WITH TAIL TO WALL.

After the horse has learned to do the passage with his head towards the wall, the presence of which has the natural effect of regulating the movement to a considerable extent, we may teach him the more difficult evolution of doing the passage with his tail to the wall. Being, say, on the right rein, we may turn the horse on his haunches to the right through an angle of $45^{\circ}$ (one eighth pirouette), and make him pass to the left as before directed, with his hind feet on the track. Having gone the required distance, we may halt him, turn him on his haunches through an angle of $90^{\circ}$ (quarter pirouette), and make him pass to the right. We may change the passage with tail to wall to passage with head to wall, or vice versâ, by turning the horse on his centre.

A school horse should be able to passage down the centre of the manige or in the open, and without the assistance of any wall by which to regulate his direction.

\section{CHANGE OF HAND BY THE PASSAGE.}

We may change the hand to which we are going by making the horse move diagonally across the school at the passage. The direction of the passage should be at an angle of $45^{\circ}$ to the side of the school from which the departure was made; the body of the horse should be kept parallel to the sides of the school, and the horse may resume his straightforward direction on regaining the track after his diagonal march.

\section{COUNTERCHANGE OF HAND BY THE PASSAGE}

is executed in the same manner as the preceding evolution, except that when half the diagonal movement has been 
made, the aids are reversed, and the horse is brought back to the side of the school which he has just left, by a passage, the direction of which will be at right angles to that of the first one. Practice of this air at the walk, trot, and finally at the canter, is a valuable preliminary to instruction in change of leg at the canter.

\section{CIRCLING AT THE PASSAGE.}

This can be done either with the head or with the tail turned towards the centre of the circle, the diameter of which will usually be half the length of either of the short sides of the school, say, ten yards. This circle, when the head is turned towards the centre, is in reality a turn on the forehand (a pirouette renversée) on a movable pivot; when the tail is turned in that direction, it is a turn on the hindquarters (a pirouette) on a movable pivot. Instruction in these circles is essential to the education of the cavalry horse.

THE HALT.

The remarks made on page 230, et seq., respecting the halt, apply equally well to arrest of movement when made under school conditions. The moment for the halt from the canter appears to me to be that at which the non-leading fore leg comes to the ground (see Fig. 4); for then the shock, due to the sudden stoppage, will be fully borne by both hind legs, and by one fore one. The weight-bearing function of the non-leading fore leg will have practically ceased at the moment when the leading fore leg is brought down (see Fig. I20).

CHANGE FROM ONE PACE TO ANOTHER.

To change from the canter to the trot, we may, as the leading fore leg comes down (see Fig. I20), apply strongly the drawn- 
back outward foot; feel both reins; lean a little forward ; and put weight on the stirrups. By the application of the drawn-back foot we prompt the horse to bring the hind leg of that side quickly to the front; by feeling the reins we check the advance of the leading fore leg so as to get the feet of these two legs to come to the ground at the same

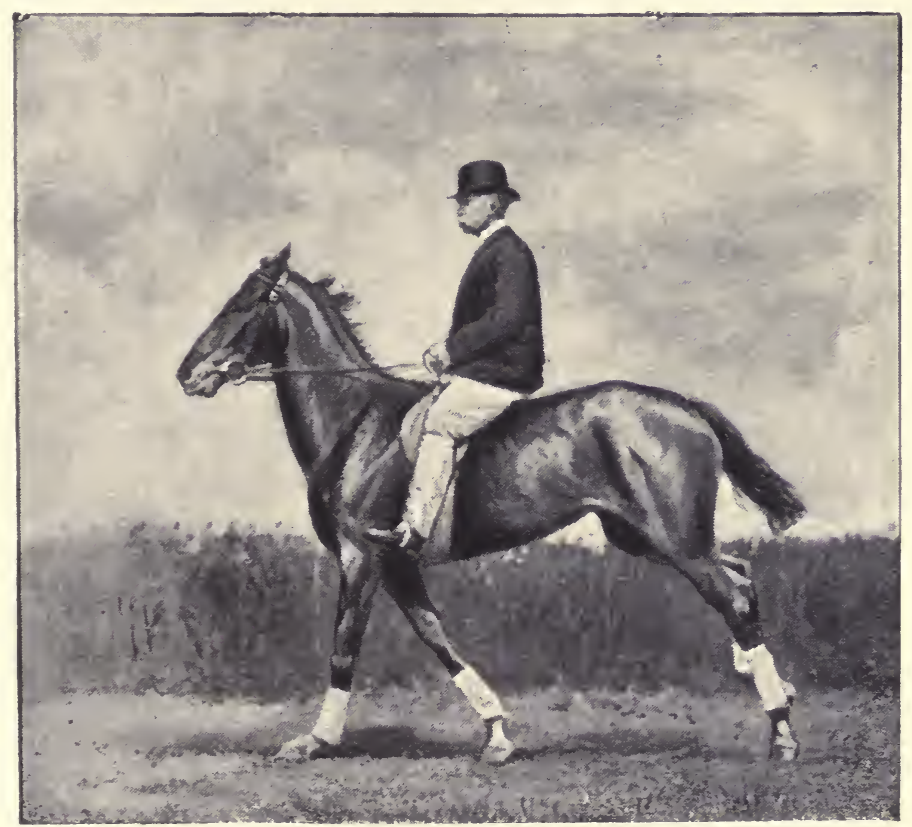

Fig. 120.-Cantering with near fore leading.

moment; and by leaning forward we facilitate the advance of the hind leg; the result being that the canter becomes changed into a trot. The trot is a pace of two time, in which the near fore comes on the ground at the same moment as the off hind; and the off fore, as the near hind. In the canter, the non-leading fore leg and the opposite hind leg move together; consequently all that we have to do to convert it into a trot is to check the action of the 
leading fore leg and hasten that of the opposite hind, so that they, also, will move together.

To change from the canter to the walk, we may, at the moment the non-leading fore leg comes to the ground, apply the aids in the same manner as for the halt (see page 278 ), and then instantly slacken the reins.

\section{SHOULDER IN.}

In the "Bending Lesson" of Cavalry Drill, there is taught a movement to one side, called "shoulder in," which is similar to the passage, except that, when doing it, the horse's head is turned away from the direction in which he is going. It is practised, in our military riding-schools, only with the tail to the wall; and the passage, only with the head to the wall. The imposition of such a restriction on the passage is unreasonable; for it is a movement which is frequently required to be performed by cavalry in the open, where there is no wall to guide the direction of the horse. In the French school, from which the English and Germans have derived their notions of military equitation, the appuyer (passage) épaule en dedans (shoulder in) is synonymous with the passage croupe au mur (croup to the wall), or, as I have called it, passage tail to the wall. The English author, or authors, of the "bending lesson" evidently thought that the term epaule en dedans had reference to the way in which the horse was "bent," and not to the fact that his shoulders, and not his tail were turned towards the inside of the school. My readers will have seen that the passage "head to wall " is preparatory to the more difficult movement of the passage "tail to wall" (epaule en dedans). The fact of the regulation "shoulder in" being executed with the head turned away from the direction in which the animal is proceeding, con- 
demns it as a movement to be employed outside of a ridingschool. If it be thought fit to retain it as a means for teaching the use of the aids, it (like the passage) should be practised head to wall as well as tail to wall. Personally, I abominate it; for it is the defence which the majority of refusers adopt when they "run out" at an obstacle, and when their riders vainly try to pull them straight.

\section{COURSE OF SCHOOL INSTRUCTION.}

The foregoing details of school training might be imparted more or less in the following sequence, supposing, of course, that the horse has gone through the preliminary work treated on in Chapters V. and VI.

I. Collecting the horse at the halt, walk, and trot, without going so far as to obtain the passage or piaffer.

2. Circling and figure 8 at the collected walk and trot.

3. Turn on the forehand.

4. Turn on the haunches.

5. Passaging: change of hand and counter-change of hand at the collected walk and trot.

6. Circling at the passage at the collected walk and trot.

7. Passage and piaffer.

8. Collected canter.

9. Starting in the canter from the trot, walk, and halt.

Io. Circling at the canter.

II. Passage : change of hand and counter-change of hand when cantering.

I2. Figure 8 at the canter.

I3. Change of leg at the canter.

I4. Cantering falsely.

I5. Circling at the passage when cantering.

If the turn on the haunches provokes the horse to rear, we may correct such a tendency by practice at the turn on the forehand (see page 27r). 
Three months would be ample for teaching the horse the course of instruction laid down in Chapters V. and VI. and in the present one.

\section{ADDITIONAL SCHOOL MOVEMENTS.}

As all the airs which I have written about in the preceding pages of this chapter are of use from a breaking point of view; I have thought fit to separate their description from that of the following school exercises, which, though interesting to look at, are of no practical value. As the work of learning them is apt to make restive, from excessive collection, horses which have not had a careful school training, I would advise that they should not be attempted until the pupil has mastered all the movements previously described in this chapter, and is ready to go freely forward in obedience to the pressure of the legs. Those of my readers who wish to obtain further information about these airs should consult Fillis's Principes de Dressage, and Barroil's Art Équestre, in which they will find them lucidly and exhaustively described.

\section{EXTENSION OF A FORE LEG.}

Our object here is to make the horse, when at the halt, extend either of his fore legs, according as we wish, straight out to the front, and hold it motionless, in a more or less horizontal position, for a short time.

Having placed the horse on the track of the riding-school with, say, his off side towards the wall, we may, while standing on the ground and facing him, take hold of the reins by the left hand under the chin, raise the animal's head up, and turn it towards the off side, so as to relieve the near fore of weight, and begin to lightly tap the front of the cannon bone (or fore-arm, as may appear most efficacious) 
of the near fore. in order to induce the horse to raise that leg and extend it to the front. Having gained our object with one fore leg, we should try to obtain it by reverse methods with the other, so that the horse will extend either leg and keep it stretched out to the front on being threatened with the whip. As soon as he will readily accede to our demands while standing close to the school wall, we should take him to the middle of the school, in order to obtain like results there. This will be a task of several days' duration, and will demand a great deal of patience and tact. In it we should "hasten slowly," and should be guided by the principles which I have already laid down for equine instruction. We may facilitate our work by having at first an assistant to lift up and raise the operated-on leg by means of a cord or strap attached to the pastern. The use of this appliance should, of course, be gradually discontinued, according as the horse learns to obey the touch of the whip.

When the horse is perfect in the lesson which we have been giving him on foot, we may mount him, and substitute by degrees the appropriate aids for the action of the whip, with which we at first obtain the extension of the off fore, for instance. We should collect the horse; raise his head, so as to place the muscles of the neck in an advantageous direction for lifting up the limb; turn his head to the left and lean on the left stirrup to transfer weight from the off fore to the near fore; and apply the left drawn-back heel, at first cautiously, so as not to make him revolve round. The turning of the animal's head to the left is only a temporary measure to hasten the extension of the off fore ; and that in the perfect form of this air the head and neck will be held straight, or slightly turned to the right, at which time the pressure of the drawn-back left foot will be indispensable for preserving the true balance 
of the animal's body: The reversed aids are required for the extension of the near fore.

\section{THE SPANISH WALK}

(see Fig. I2I) is a walk in which each fore leg is extended straight out to the front in a direction as nearly as possible parallel to the ground, kept in that position for a brief moment, and placed on the ground without bending the knee, after the body has been brought forward the requisite distance for the step.

Having made the horse perfect in the extension of a fore leg to the front, we may commence instruction in the Spanish walk on foot, by holding the reins in the left hand, as before, close to the chin while facing the horse. Having obtained extension of one fore leg in the manner described, we should bring the animal forward by the reins, assisted, if need be, by "clicking" with the tongue, so that he will take a step forward. While he is doing this we should, by the whip, prevent him from bending the leg at the knee. After rewarding him for his correct performance with one leg, we should proceed to obtain a similar step with the other, and by diminishing the interval of time between the steps, we shall at last arrive at the Spanish walk. While using the whip we should face the horse and walk backwards, and should at each step turn his head to the side of the leg which is at that moment on the ground. When mounted we should apply the same aids as we did for the extension of a fore leg, and having obtained it, should make the animal go forward by the action of the legs, and, if necessary, by "clicking," which we should dispense with as soon as practicable. We must bear in mind that at each step there should be a change of aids. 


\section{THE SPANISH TROT.}

The only difference between the Spanish trot and the Spanish walk is that of pace. At the Spanish trot there should, if possible, be a moment of suspension (all four feet off the ground at the same time) between each step, so as to give brilliance to the air. The transition between the walk and the trot in this case is made by increasing the

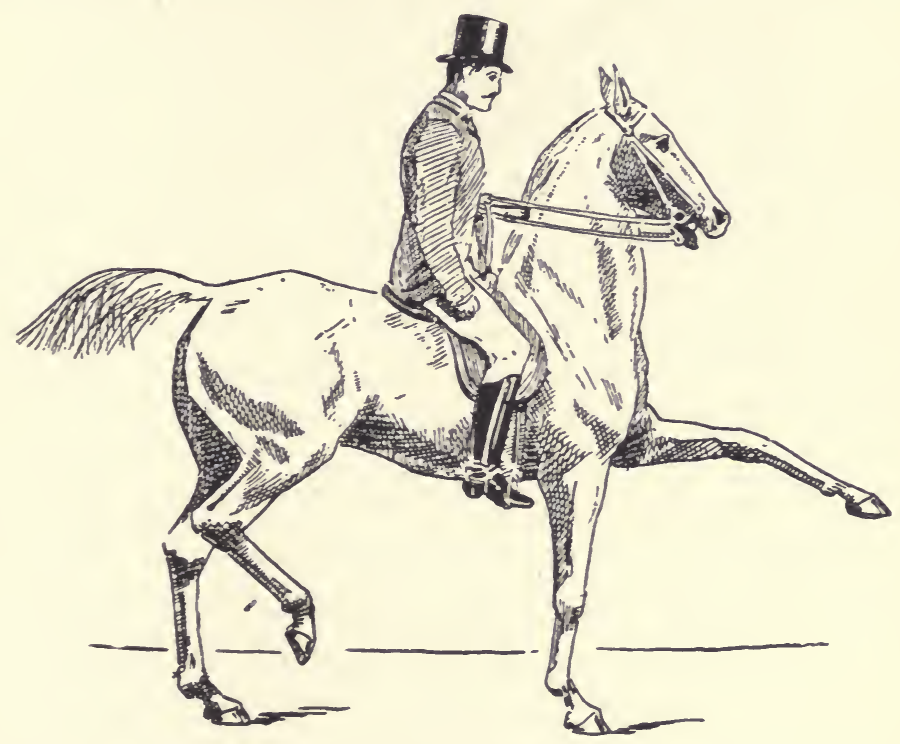

Fig. 121. - The Spanish walk.

effect of the drawn-back left heel when the horse extends his off fore to the front, and that of the right heel when he extends the near fore. "If, as almost always happens, the horse moves one leg in a lazier fashion than the other, I work only with it, which is the best way to act on the memory of the horse, and to make him understand, by my touches of the spur, that he moves this leg too indolently." (Fillis.) This great master of l'équitation savante warns us 
to demand from the horse, at first, only a few steps (not more than four) of the Spanish trot, lest the animal may acquire the habit of doing it in a listless and slovenly manner.

\section{TURN ON THE FOREHAND ON THREE LEGS.}

In this exercise the horse turns his quarters from left to right while holding his right fore leg raised off the ground and extended to the front, and vice vers $\hat{a}$. To begin, we make him turn his hind-quarters, say, from left to right, with his near fore as a centre, through about a quarter of a circle, using the aids as before directed (see page 2I2). We halt him by applying the drawn-back right foot, make him extend his off fore, and when he has brought it down, we make him continue the turn; and so on until he will do the complete turn with the off fore straight out and more or less parallel to the ground. We obtain by the reversed aids the turn of the hind-quarters from right to left with the near fore en jambette (raised and extended).

\section{THE CANTER ON THREE LEGS}

consists of a canter in which the fore leg of the side to which the canter is made, is kept off the ground and extended to the front. The principle, as taught by M. Fillis, of obtaining this air, is while cantering the horse very collectedly, say, to the right, to halt him and make him do the jambette (more or less horizontal extension of a fore leg) with his off fore. Start him again on the same leg, and continue halting him and obtaining the jambette, until we get him to canter for a stride or two without putting the off fore on the ground. We should then caress him to show him that he dirl what we asked him to do ; should begin again, and work with him in the same way until he does the exercsie perfectly. By the reversed aids we may obtain the canter on three legs with the near fore en jambette. 
CHANGES OF LEG AT THE CANTER.

As circus airs, the horse may be taught at each stride (au temps or tac au tac) while advancing, and even without gaining ground. The horse may then be vulgarly said to dance the polka. In these movements, care has to be taken to prevent him swinging his body from side to side.

Among other airs which I may mention are the trot to the rear, passage to the rear, and canter to the rear.

A CIRCUS HIGH-SCHOOL ACT.

As a specimen of high-school work I give the following num:ro, which I saw M. James Fillis execute in the Circus Renz at Hamburg on his famous high-school horse Germinal.

I. Deux pistes au trot (passage at the trot) ; trot allongs, serpentine.

2. Galop (canter): deux pistes (at the passage), voltes ordinaires (circles on the hind-quarters) et renvers'es (on the forehand); galop sur trois jambes, à droite et à gauche.

3. Passage: piaffer ballots.

4. Galop: changements de pied à deux temps (change of the leading leg at every second stride) en changeant de main; changements de pied à un temps; allure modir'é, ralentie sur place et au grand galop.

5. Galop à gauche, sur place et en arrière.

6. Galop à droite, sur place et en arrière sur trois jambes.

7. Trot espagnol ordinaire à un temps.

8. Trot espagnol nouveau à deux temps sur chaque jambe.

9. Trot espagnol nouveau, alternatif à un et deux temps.

The serpentine is a passage at the trot of four steps to the left, four to the right, and so on ; or vice vers $\hat{\imath}$. In fact, it is a successive counter-change of hand of four steps at a time. In the piaffer ballot:, a step forward and a step backward is alternately taken with one fore leg and the opposite hind leg. 


\section{CHAPTER X.}

\section{BREAKING FOR SPECIAL WORK.}

The race horse-The lady's horse-The cavalry horse-The polo pony-The park hack-The fashionable harness horse-The shooting pony-Mules and zebras.

For convenience sake, I have grouped the description of the breaking of certain classes of horses in this chapter without regard to similarity of method.

THE RACE HORSE.

As race horses are generally "tried" as yearlings in November or December, their breaking cannot usually be deferred beyond the age of eighteen months. As their trial will probably not be beyond three furlongs, and as it will be given merely to see if the youngsters are worth persevering with and entering for future events, the breaking need not be more than what will be sufficient to make them handy to ride. In order to imperil the soundness of their legs as little as possible by having no weight on their backs, they should be broken chiefly by means of the long-reins, and by the whip, on foot. Having been handled from the time they were dropped, there will be but little difficulty in rendering them quiet and obedient. Between their trial and the following racing season, which commences at the latter end of March, there will be plenty 
of time to teach the two-year-olds the whole of the instruction contained in Chapters V. and VI. I wish here to draw attention to what I have said on page 226 respecting the desirability of having every animal (except the school horse) taught to readily change, of his own accord, the leading fore leg at the canter or gallop, when a turn is made to the side opposite to it. As a case in point, I may mention that the great difficulty experienced by many race horses in coming round certain sharp turns on particular racecourses, such as Tattenham Corner at Epsom, or when galloping on a more or less circular track, is generally due to the fact that these animals lead with the wrong fore leg (gallop "falsely," see page 223) while making the turn, instead of changing the leg when they come up to it, or starting with the fore leg nearest to the inside of the course, and continuing to lead with it. This tendency makes some horses act well only on a right-handed track; others, only on a left-handed one. The muscular strain entailed by having to gallop falsely militates against the animal's chances of success far more than the momentary diminution of speed which a change of leg would cause. Besides, when galloping falsely, it is impossible for the horse to make a turn sharply.

In order to change the leading leg at the gallop or fast canter, it is necessary for the horse to slacken his speed for a stride or two. The habit of a horse galloping or cantering always with the same fore leg leading is extremely liable to cause that leg to become prematurely worn out; because nearly twice as much work will, on that account, be imposed on that limb as on its fellow. On a comparatively straight course, or on a course the turns of which lend themselves to the purpose, and especially over a long distance, it would be manifestly an advantage for a race horse to do half of the journey with one fore 
leg leading, and the other half with the other fore leg leading, provided that he could gallop equally well in both cases. The fact that very few race horses can do this, proves the necessity for such instruction.

When a horse is about twice as tired on one fore leg as he is on the other, he ought to be able to gallop far better if he could ease the tired limb at the expense of the fresh one. Horses which habitually lead with one particular fore leg at the gallop or canter, generally lose the ability of extending themselves properly when they happen to change the lead to the other fore leg. The cause of this incompetence is, I think, due to the fact that, in the canter or gallop, the centre of gravity of the animal's body is more or less shifted to one side-namely, to that of the leading fore leg. Hence, the horse which has been accustomed to travel with more weight on, say, the right side, when the off fore leg is leading, will naturally try to bear his weight on the right side when the near fore is leading, and will consequently go in an ill-balanced manner. Besides, when such horses happen to change to the unaccustomed fore leg, they sometimes omit to change the leading hind leg, and consequently go disunited. I do not think I need say more on the advisability, when breaking in race horses, of teaching them to gallop equally well on either fore leg, and to change the leading leg when necessary. If such an improvement in the breaking of race horses was substituted, it would be also requisite to give special tuition to the jockeys who were to ride them. As the subject of riding, except as regards its connection with breaking, is not within the province of this book, I have dealt with it fully in Riding and Hunting.

Ability to rein-back, and even to passage, will in many cases be valuable at the start of a race. Considering that five or six short and easy lessons would be generally suf- 
ficient to teach these accomplishments, as far as they are needed for the purpose in view; ignorance can alone be the cause of neglect to impart them. The remarks made in Chapter VI. on collecting the horse apply equally well here.

\section{THE LADY'S HORSE.}

Any horse which has been broken in according to the principles I have laid down, will carry a lady quietly; although some animals will need circling with the long reins, turning to the right on the forehand, and work at the figure 8, to teach them not to "edge away" from the skirt to the right with the hind-quarters. The following points will also need attention:-(r) As the lady, from the peculiarities of her seat, is unable to keep her hands sufficiently low, her horse should on no account carry his head too high. (2) As a lady has not the advantage of a leg on each side of her mount, her horse should "bend" himself readily to the rein, and go collectedly without requiring to be "pulled together." (3) He must be taught to answer the touch of the whip behind the girth on the off side in the same manner as he would do on feeling the pressure of a man's right foot. (4) He should be made as easy to turn to the right as to the left, which is the lady's weak side. (5) He must not have the slightest tendency to rear; as that is a "defence" which is peculiarly dangerous to a lady, and which she is comparatively powerless to resist. (6) He must not pull hard; for an amount of "catching hold" of the bridle which might be prized by many a feeble-kneed man, would be reprehensible in the horse intended for the weaker-armed, but stronger-seated lady. The desired carriage of the head and neck may be obtained by the long-reins, standing martingale, reining back, circling, and figure 8 . 
The lady's park hack may have to be taught to strike off in the canter always with the off fore leading. It is certainly an advantage for a lady's horse, whether hunter or hack, to readily obey the signal to go off into the canter with either fore leg leading, or to "change" the leading leg when required.

The tendency which all horses have at the canter and gallop to carry their hind-quarters outside the track of their respective fore legs, is as a rule increased in the lady's horse by the fact that he leads far more often with the off fore than with the near fore, and that the lady's legs and skirt are on the near side. To correct this fault, he should be practised at passaging (see page 273) to the left, and at turning on his forehand (see page 2I2) to the right.

If it be desired to put a lady on a horse which has never before carried a side-saddle, but which has been broken in for a man in the ordinary rough-and-ready style, it is well to accustom the animal to the habit by putting a sidesaddle on him, attaching a skirt or rug to it, and circling, turning, and reining him back with the long reins until he ceases to pay attention to the loose cloth on his left side. We should also make him, by means of the rope twitch (see page I2o), stand perfectly steady while an assistant wearing a skirt is mounted like a lady on the saddle. I have never found that it required more than half-an-hour's tuition to make a horse which was quiet for a man to ride, equally quiet for a lady. It is well to know that a horse which is mounted for the first time by a lady, is apt to be frightened chiefly by the right leg and the portion of the skirt that covers it, being brought over his shoulder and lower part of his neck.

For a secure seat, a lady requires to ride with the stirrup leather so short (see The Horsewoman) that she cannot use a spur with ease and precision. Hence, if she wishes 
to practise high school riding (see Chapter IX.), she will have to ride with as long a stirrup leather as a man. The whip, which may have a spur attachment on it, performs on the off side the duty of a spur.

THE CAVALRY HORSE.

As the work of the trooper has often to be carried out under rough conditions which demand the cleverness of the hunter more than the precision of the school horse, I would advise that, although his education should comprise the course laid down in Chapter IX., with the exception of the "Additional School Movements" (see page 282), he should also be taught to turn on his centre by the pull of the rein without the pressure of the leg, and to make the necessary changes at the canter, of his own accord, without the signal from the rider's heel (see page 229). Thanks to the admirable memory of the horse, it is easy to teach him both systems. He should also be taught to jump well, and for that reason should be thoroughly broken to the snaffle before using the curb. As the cavalry soldier in action will have his right hand occupied with his sword or lance; perfection in one-handed riding should, above all things, be demanded from his horse, which, being obliged at times to cross a "difficult" country, will be all the better for knowing the direct indications of the two-handed system of riding, as well as the reversed ones of the one-handed style. In this there need be no chance of confusing the horse, which is fully capable of correctly answering direct and reversed indications, as we may any day see in the case of young horses ridden in a halter without a bit and with a single rope as a substitute for the reins. In teaching a horse to obey the indications of the reins held in one hand, we may begin by taking a rein in each hand, and then pro- 
ceed, while making the turns and circles, to gradually diminish the lateral effect of the inward rein on the mouth, and increase the effect of the outward rein on the neck, until the latter can be used to the almost entire exclusion of the former.

We should endeavour to finally obtain the turn by merely laying the outward rein on the neck; for the more we pull on it, the more will we draw the muzzle away from the side to which the horse is being turned; and, consequently, the indication on his mouth will be contrary to that on his neck.

Men who think, when riding with the reins in one hand, and separated, according to the Cavalry Regulations, by the little finger, that they can turn the horse merely by shortening the inward rein, should try to do so when sitting on the box-seat of a one-horse carriage, and holding the reins in one hand. They will then find that, as the reins are prevented by the terret-rings from being brought against the neck, they will be unable to effect the turn in the manner asserted. In turning the horse with the reins in one hand, the hand has to be held higher than when both hands are used; for the effect of the outward rein on the neck in turning increases according to the distance, from the withers, of its point of contact. As the troop horse may have to go over a country, he should go up to his bridle more freely than the school horse. A state of collection should be maintained with cavalry horses only during the time it is necessary for the execution of some particular manœuvre and to keep their place in the ranks.

THE POLO PONY,

like the cavalry horse, should be ridden always with one hand, except during his first lessons. He may be put through the same course of instruction as the trooper (see 
preceding section), except that he need not be taught to jump, and his paces should be confined to the walk, canter, and gallop. He should be practised at starting off into full gallop and halting as quickly as possible. He should be taught to carry his head high, and to avoid going up to his bridle, so that he can be halted and turned in a moment, when required. He ought to have a good deal of work with the long reins and at passaging, so as to prevent him from acquiring the habit of shying off the ball by yielding his head and neck to the rein without altering the direction of his body. He should, of course, be taught to disregard the polo stick being flourished about him, which we can do by using the rope twitch and the word "steady" (see page I20), or the head and tail method (see page I55). I may mention that the subject of breaking in and training polo ponies is fully discussed in Capt. E. D. Miller's recent work, Modern Polo, which I have edited.

\section{THE PARK HACK.}

A course of school training will greatly add to the brilliancy of this animal, in whom we require particularly springy and showy action without any of the exaggerated knee action of the hackney. The body of the park hack should be accurately placed in the line of progression, out of which we should not deviate during movement. The showy walk (which should approach the French passage) and the well-collected and brilliant canter are more his paces than the trot.

\section{THE FASHIONABLE HARNESS HORSE.}

The "extravagantly" high trot is the special pace of this animal. Although it should be as lofty as possible, it must be free from "dishing" (turning either or both of 
the fore feet outwards when off the ground), or from any rocking movement of the body, and the legs must have a certain amount of forward reach, so as not to give the idea of the feet being lifted up and placed down on the same spot. In this artificial gait the action of the hind legs will have to be sacrificed to some extent to that of the fore ones. His school work may be limited to the walk and trot, at which we should collect him sharply, and at the same time press him forward with the legs, while holding the hands high. While riding this horse at a trot the rider should not rise in his stirrups; for if he does so, he cannot fail to more or less disturb the balance of the animal's body. The use of heavy shoes will increase the knee action. In driving him, the principle of collecting him with whip and hand and keeping up his head should be observed.

\section{THE SHOOTING PONY.}

Having thoroughly broken the shooting pony according to the principles already discussed, we may make him steady to the gun by the rope-twitch and the word "steady" (see page I20). A turn at the head and tail method (see page I55) might be used as a preliminary to the education by the rope-twitch. It may be well to teach the animal to lie down (see page I44).

MULES, ZEBRAS AND THE PRJEVALSKY WILD HORSE.

These animals are so stiff in the neck that there is great difficulty in giving them a good mouth. Mules, as a rule, are timid animals which take time to make up their minds to do anything unusual, and are consequently apt to be misunderstood by men who treat them as if they were high-couraged and impulsive horses. Mules, I have found, possess more affection than horses for those who are kind 
and sympathetic to them. Many of them are fine natural jumpers, and show particular care to avoid "chancing" their fences. I don't think that mules are harder to make quiet than horses. Of all asses, the mountain zebra (see Fig. I22) is the most difficult to break; as he is sulky, stupid, and has an almost immovable neck. I have found the Burchell's zebra, which is more nearly akin to the horse than any other ass, comparatively easy to break.

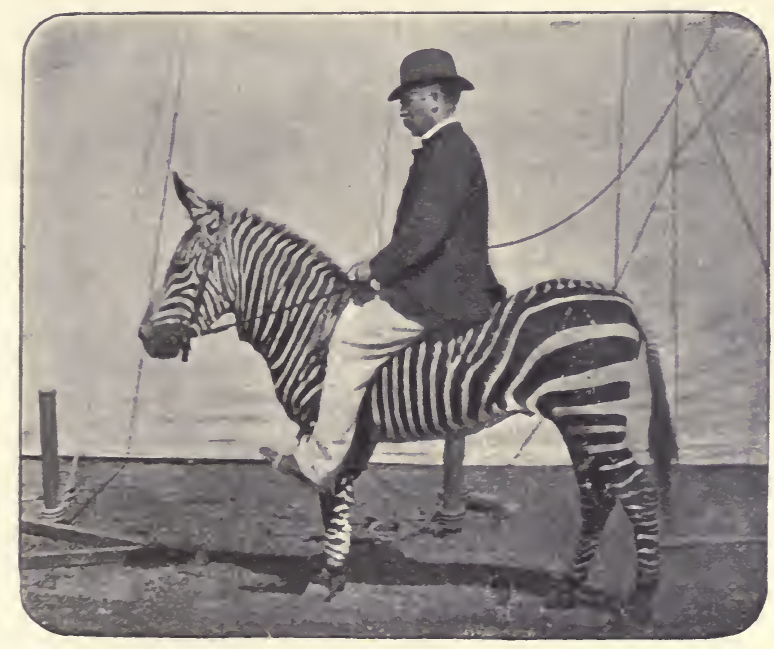

Fig. 122.-The mountain zebra.

I did some interesting breaking in of zèbras at the Zoological Gardens last March. The first animal I took in hand was Jess, a Grévy zebra mare, which was about nine years old. She stands nearly fifteen hands high and is a very powerful animal. The first problem was how to get a head-stall or halter on Jess in her loose box. A peculiarity about zebras is the extreme sensitiveness of their ears, in which respect they are entirely different from the normal horse. In South Africa and on the Rus- 
sian steppes I never had any difficulty in haltering a semiwild horse, which had been driven into a krall or small enclosure, by the aid of a halter on a long pole, as already described. But the slightest touch on the ears drives a zebra almost mad. Consequently, this horse-haltering plan is not successful with zebras, unless they are lassoed in the first instance, and thus brought more or less under control.

Having haltered the zebra, the next step in her breaking was to take her outside into a small enclosure, which was considerably hampered by the presence of trees in the centre. To obtain more control, it was necessary to put the loop of a rope round the fore pastern, so that the striped lady might not give me a playful or vicious pat when I went up to her. With horses there is no trouble in adjusting this loop, by, as I have already described, placing it on the ground and making them step into it, at which moment a pull on the rope promptly lassoes the pastern of the too confiding fore-leg. Every zebra I have handled has viewed this loop with great distrust, and evidently understood the purpose for which it was placed on the ground. Consequently, a breaker has to be very artful in order to circumvent these reasoning Equidæ. In their struggle for existence they have to be much more intelligent than the domestic horse, a fact which we can readily see by their larger brain capacity, which is well shewn by their broad and "bumpy" forehead.

When a fore-leg has been noosed, it is safest to raise it off the ground, which can be easily done by passing the rope over the animal's back, under its breast, and then pulling it. Having thus secured the zebra I tied her " head and tail " in the manner already described, and after a short exhibition of play, she readily submitted to driving by means of the long reins. The "leading rein crupper" 
quickly taught the mare to lead, and the young soldier attendant was soon riding her about the enclosure and on friendly terms with his mount.

In the afternoon of that day I adopted similar tactics with another but younger Grévy zebra mare, and before evening she allowed herself to be ridden quietly.

Next morning, Jess, who had been haltered during the

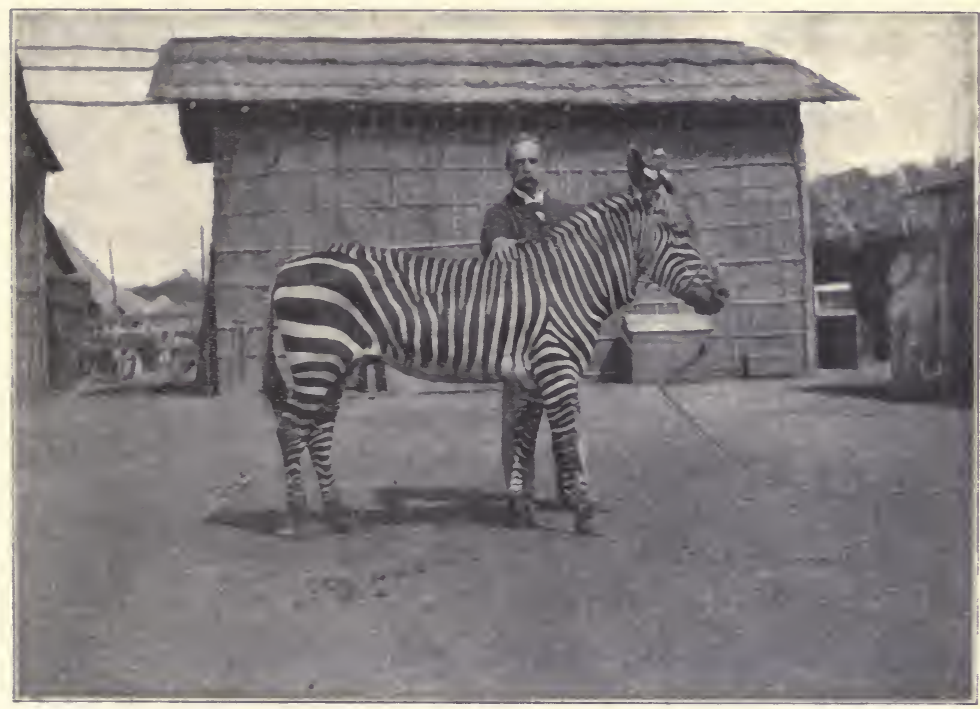

Fig. 122A.-A mountain zebra.

night, so as to save the trouble of catching her, was produced in the enclosure, and seemed so amiable that I trusted her too much, as I saw when the very badly-fitting saddle came too far forward and pinched her withers, with the result that she promptly bucked her rider off. In this respect I made a mistake in not providing myself with my Australian buck-jumping saddle; for our ordinary English saddles are of comparatively little use when a horse or zebra starts bucking. We must bear in mind that 
the greatest difficulty in subduing zebras is their extreme cunning in refusing, under ordinary circumstances, to exhaust themselves by "playing up," which horses do in a way that would make a zebra smile. I found it expedient with this powerful animal to make her lie down until she arose submissive and quiet to be ridden without any trouble. The younger zebra evinced very little desire to assert her authority. Jess, however, was far less trouble to break in than a Mountain zebra stallion which I made quiet for my wife to ride in Calcutta, probably because my Calcutta pupil had only been in captivity a short time.

After the mares were reduced to obedience I was asked to handle a Grévy zebra stallion, which gave me some trouble in his efforts to bite and kick. He finally allowed himself to be mounted, and made no attempt to bite my hand when I placed it in his mouth. I was very sorry to hear that this zebra died about four days after his breaking lesson. As I knew nothing about this unfortunate occurrence, I cannot do better than give the following extract from a letter I received from Mr. Pocock, who is the Superintendent of the Zoological Society's Gardens :"I was very much astonished to hear on Sunday morning that our zebra stallion was down, because he seemed all right on the Thursday and Friday following the breaking, and it was not till Saturday that signs of weakness began to show themselves in the fore-quarters, as was testified by his toppling and dropping momentarily on to his knees. He was not handled at all after the Wednesday when you broke him. To what extent the death was attributable to the breaking, if indeed it was at all connected with it, it is quite impossible to say. The post mortem examination revealed no sign of any internal injury, though the organs were carefully examined. However, the comparative 
brittleness of the ribs showed the animal to be considerably older than was supposed, and his death casts no reflection upon your skill, judgment and gentleness." One of the keepers subsequently informed my wife that the zebra had been ailing for some time. If I had been aware of this fact, I need hardly say that I should not have attempted to break an animal so infirm.

The Prjevalsky wild horse, as we can see by Salensky's Russian book, is supposed by the large majority of Continental naturalists to be untameable, and I was delighted to have the opportunity of disproving this assumption, when staying recently with Professor Cossar Ewart at Penicuik. I met with much the same passive stubborn resistance as I had experienced with mules and zebras, and after an argument of a couple of hours duration, I got no striking reply out of Prjevalsky, except a sharp kick on my left shin. He husbanded his strength all through the interview, and finally concluded in a very logical manner that submission was the best policy. Although he consented to be ridden, he refrained from cantering, and imitated the trot only by a very lazy form of shuffle. The chief distinguishing characteristics of the Prjevalsky horse are absence of forelock; short mane, which in summer is erect like that of the donkey, and partly hangs down in winter; and a tail, which for about four inches down the back of the dock (solid portion of the tail) has short and bristly hairs.

The Russian naturalists G. E. and M. E. GroomGrjeemailo tell us that "The Mongolians have made many attempts to tame these wild horses, but have always been unsuccessful. These animals refuse to obey man, whom they fear, and consequently they cannot be utilised. The Mongolians capture these horses in a very simple manner. At foaling time, each of the Kalmucks goes with two horses 
to the desert, and, having found the herd, follows it up until some of the weak foals fall down on the ground from fatigue, and are then captured and put with the Kalmuck's horses." For information concerning the different varieties of zebras I would refer my readers to Points of the Horse. 


\section{CHAPTER XI. \\ FAULTS OF MOUTH.}

Boring-Pulling and running away-Throwing up the head and star-gazingJibbing-Rearing-Shying-Running out to one side and difficult to turn"Keeping behind the bit," prancing, and "breaking " when wanted to walk or trot-Teaching pacers (amblers) to trot-Carrying the hind-quarters, in the canter or gallop, outside the line of progression, and refusing to lead except with one particular foreleg-" Putting too much weight on the forehand" when mounted-Plunging forward when starting in harness-Pulling away from and hanging against the pole when in double harness.

THE classification of vices and faults adopted in this and the following chapter is necessarily somewhat arbitrary, as their causes are more often complex than simple. The arrangement adopted in both of these chapters has been made solely for the sake of convenience. The fact that all equine vices do not possess generally accepted names has obliged me, in some cases, to sacrifice elegance of expression to clearness of meaning.

\section{BORING.}

When the horse has got into the habit of carrying his head too low, we may get it into the correct position by circling and turning him with the long reins on foot (see page I68), while keeping the outward rein on the driving pad, or while using a bearing-rein (see page I69). We may then mount him, and by the action of the legs and hands make him go collectedly (see page 2r9), so that 
he will be obliged to hold his head at a proper height. To aid him in this, we should keep our hands higher than usual. Practice at the rein-back (see page 2I5) and at the turn on the haunches (see page 272), will probably be of use. When the animal bores on one rein more than the other, we may adopt the same procedure, except that we should devote our attention chiefly to getting him to turn to the side on which his mouth is "hard," until he will do so as easily to it as to the other.

PULLING AND RUNNING AWAY.

I can draw no line of distinction between these two vices, except one of degree; for animals which would be uncontrollable runaways with some men, would be only hard, or even moderate, pullers with other men. Besides, circumstances alter cases : for instance, I have ridden horses which it would be impossible for me to pull up in a race, chase, or sharp burst with the hounds; but which I could easily control when hacking, even in company, or on parade. I shall, therefore, for convenience sake, consider running away as an extreme form of pulling. Before beginning a discussion on this subject, I must candidly state my disbelief in any system of pure breaking by which a violent, masterful puller can be made permanently quiet for an indifferent rider to keep in control at fast paces under exciting circumstances. It is worthy of note that a fine horseman not alone holds an unruly animal in check; but also teaches him habits of discipline by the application of the "aids."

A large number of hunters and other saddle horses unjustly acquire the reputation of being pullers; because, when under excitement, they like to start off in a gallop; but if they were "given their head" for, say, two or three 
hundred yards, they would bend to the rein and settle down under perfect control. The fact of checking them at first upsets their temper and makes them fight. If allowed to " jump into their bridle" and go off gaily at first, they seem to be so well satisfied at having gained their point, that they do not resent being asked to go slower afterwards. The same remarks apply to many harness horses. Patient and capable riding and driving, as the case may be, are the best remedies for such pseudo-pullers.

Horses which are hard pullers may be divided into two classes, namely, those whose defence is to put weight on the fore-hand, and those who try to assert their will by placing it on the hind-quarters. The large majority of runaways practise their pet vice from a spirit of pure opposition to the wishes of their would-be master. Any nervousness which they may exhibit is, in almost all cases, only a cloak for their sin. Eagerness to return to the stable, or excitability when approaching ground on which the animal has been previously exercised, may be mistaken by inexperienced persons for a desire to run away. The least dangerous form of pulling is that which is caused by the horse leaning unduly on his bit, to the action of which he is abnormally insensitive. I have known a horse which used to run away (if I may employ the expression) at a walk. Harness-work, by inducing the animal to increase the weight on his forehand, often gives rise to the passive (if I may employ the word) form of pulling in saddle. As long as this boring on the rider's hands is unaccompanied by a feeling of disobedience, the fault can be easily cured by teaching the horse to understand the meaning of the "aids" (see Chapters V., VI. and IX.). The form of pulling which is most difficult to remedy is that in which the defence is made by lightening the forehand. As a common example, I may cite 
horses which, in their attempts to get away, carry their heads as high as they can, prance and dance about if the rider tries to make them walk, especially when their heads are turned towards home, and rear on slight provocation.

In all those forms of pulling in which "temper" plays a part, the animal should, above all things, be taught that he must obey. Although instruction in the aids will have a general good effect on the animal's mind in rendering him docile, as well as attentive to our signals, our efforts in gaining the mastery will be greatly facilitated by taking the "nonsense" out of the rebel by, for instance, making him lie down and keeping him on the ground (see page 149), or by putting him through the head and tail system (see page 155 ). We may repeat this discipline as often as may be needed, and may employ it conjointly with instruction in the "aids." We should also utilise the good effect of work. It is a significant fact that pullers which are put to long-continued work, such as being kept out hunting for, say, five or six hours, or for a still longer period in a hansom cab or "growler," generally give up after a short time their desire to run away, the futility of which is no doubt impressed on their minds by the thought of the weary hours which are before them. The good effect of hunting in curing pulling may be often seen by the fact that although the animal was in the early part of the day greatly excited by the hounds and field; he gets so much sobered down in the afternoon, that when his head is turned homeward, he walks or trots along in more lively fashion than he had previously adopted a few minutes before, when going from one cover to another. To produce a salutary effect on a puller by hunting, we should take him out as often as possible (at least, three times a week), and should keep him out as long as we can without unduly fatiguing him.

A puller which puts too much weight on the forehand 
should be taught to go in a collected manner (see page 22I), for when collected he will be unable to resist the control of hand and leg. We should circle, turn and rein him. back by means of the long reins (see page I68); and having got him obedient and." supple" to them, we may put him through a large portion of the school work described in Chapter IX., especially that which has reference to collection. Cantering the horse in circles of gradually decreasing size will have a good effect in breaking him of pulling, by teaching him to go collectedly.

A horse whose defence in pulling is to lighten the forehand will carry his head high in the air. After taking the "nonsense" out of him in the manner already described, we should endeavour to correct the defective carriage of the head by circling the animal with the long reins while using a standing martingale on the rings of the snaffle, and while keeping the outward rein round the hind-quarters. Frequently turning him, especially at the canter, will have a good effect in making him lower his head and bend his neck. When circling such a horse with the long reins, we should confine ourselves almost entirely to the use of the inward rein, so as to place as much weight as possible on the forehand. The size of the circle should be gradually diminished. Such horses should not be practised in the rein-back. A course of harness-work, so as to accustom the animal to put an increased amount of weight on his forehand, might be useful with a horse of this kind.

The question of what is the best bit for holding a puller, is a difficult one to answer. Personally, I am entirely in favour of an unjointed leather-covered snaffle (see page I68) used with a standing martingale attached to its rings. In a few instances, I find a curb (with a low port) useful ; but only when it is placed low down in the mouth (just clear 
of the tushes), so that the curb chain will have no tendency to work up out of the chin-groove. I am no believer in the saying, with reference to various kinds of bits, that there is a key to every horse's mouth. Experience tells me that the great cause of pulling lies in the brain, upon which, rather than on the jaw, an impression has to be made in order to correct the vice. Besides, we must remember that in hunting and other forms of 'cross-country riding, it is not enough to be able to control a horse's speed ; but we must also use a bit which he will "face."

\section{THROWING UP THE HEAD AND STAR-GAZING}

are difficult habits to correct. By working the horse in the manner described in the preceding paragraph, and by riding him in a properly adjusted standing martingale (see page 87), I have always succeeded in making the most inveterate practiser of these tricks bend his neck to the rein as long as I used this martingale, against which the animal invariably ceased to bear after a time. But in some instances, even after being for months under the influence of the standing martingale, I found that if I removed this appliance, the animal, on quickly becoming aware of its absence, would resume his old game of throwing up his head on slight provocation. The object, as I have already explained, of the standing martingale is to teach the horse to abstain from carrying his head too high, by learning that if he does so, he will save the bars of his mouth from the painful pressure of the bit.

Mr. Kemp, A.V.D., tells me that horses may be broken of this objectionable habit by using a noseband, inside the front part of which three or four cowrie shells (small marbles would have the same effect) are sewn; the noseband being kept in position by a standing martingale, 
which should be of such a length as to keep the line of the face at an angle of about $45^{\circ}$ to the ground. This plan is on the same principle as that of the standing martingale attached to the rings of the snaffle; for in both, the object is to make the horse relinquish his favourite trick on finding out that its practice inflicts on him pain, from which he can save himself by bending his neck to the rein.

The term "star-gazing" may be applied to the habit of continually keeping, or trying to keep, the head raised to an undue height. That of "chucking up the head" seems appropriate to the habit of throwing up the head only when excited, or at intervals. Both require similar methods of treatment.

\section{JIBBING.}

Although jibbing is far oftener a fault of temper than of mouth, I prefer to discuss it in this chapter than in the following one ; because it can, as a rule, be best corrected by lessons in mouthing.

A jibber is a horse which, without just cause, refuses to proceed in any required direction, although he may be willing to go in some other direction. As a rule, a jibber will turn to one side, but not to the other. Acting on the fact that the horse is an animal possessed of but little intelligence, we shall generally succeed in overcoming the defence of the jibber in saddle, if we force him to circle several times to the right and to the left with the long reins on foot (see page $\mathrm{I68}$ ), or in the turn on the forehand, both on foot (see page I93) and when mounted (see page 212). Failing to fix his hind-quarters, which we can easily move round his forehand by means of the whip or cane, if not by the leg; he will usually go off in the desired direction. The rebel should be turned to one side and then to the other, and reined back pretty sharply, so as to convince 
him that we are able to make him move even against his will. Were he able to reason, he would not accept the fact, which he appears to do, of our being able to make him circle and turn to the right and to the left as a proof that we are able (which we are not) to make him go forward. After the discipline on foot with the long reins or whip, or with both, it is always well, on mounting the animal, to use the whip or stick on his hind-quarters to obtain the turn on the forehand if needed. The application of the whip with this object should be restricted to light flicks (a little above the hock for preference), just sufficient to act as a signal to the horse to move his hind legs away from the whip or cane, which, in such cases, should on no account be used as a punishment. For the present purpose, I would disregard the spur in favour of the whip; for the former cannot be applied so far back as the latter, and is much more liable to irritate the horse to resistance. Instead of at once proceeding to ride the horse after giving him a lesson with the long reins, we may put an assistant in the saddle merely to accustom the horse (as a further mark of our success) to the weight; and continue to drive the animal until he will move freely in any direction. The mounted assistant may then take the reins, and may circle and turn the horse several times before taking him for a regular ride. If the rider be capable, the horse will seldom, if ever, perceive the change made in the management of the reins. If he were intelligent enough to do so, he would, knowing that he had his rider at his mercy, refuse to accord him the obedience which he had been compelled to yield to the driver on foot.

If the horse resolutely sulks, the breaker, to expedite matters, may take the "nonsense" out of him by making him lie down (see page I44), or by keeping him on the ground with his head pulled round (see page I49), until he 
apparently gives in. He may then get another trial at circling and turning. If he still resists, he should be put down again; and so on for three, or even four, times. The change of discipline, from circling and turning, to the distressing one of being made to lie down, and of being kept in a very irksome position on the ground, is most efficacious for the jibber, who seems to quickly recognise the fact that the restraint on the ground is a punishment for his misbehaviour. Having failed, after putting forth all his powers of opposition, to resist this painful form of coercion, he will have but little energy left to stiffen his neck against a demand which is attended by no inconvenience, except that of "giving in." As soon as I find, on taking the jibber first in hand, that he refuses to turn round to one particular side when the rein is on my driving pad (see Fig. 92), I try to pull him over on his side, which will generally be an easy task, and I then tie his head to his tail by means of a rope or cord connecting his tail to the head-stall, which I have previously put on over the bridle. When I have not been able to procure a head-stall, as has often happened to me in foreign countries, I have improvised a halter out of a piece of rope (see page 99), put it on the horse's head while he was lying down, made a knot (see Fig. 20) in the part of the rope which passes under the chin, so as to prevent the rope acting as a running noose round the jaws, and attached the end of the rope to the tail at such a length as to pull the horse's head round to his shoulder. I would then keep him in this unpleasant position (see Fig. 78) until I thought he had given in sufficiently, say, for twenty minutes, during which period he would generally, from time to time, struggle desperately to get up. His repeated failures to do so would naturally impress him with the idea of his powerlessness to resist my wishes. One should be very careful not to carry this 
painful form of discipline to a point which might be dangerous to the animal. I believe I have been the first to employ the method of making a horse lie down, in combination with driving on foot, as a remedy for jibbing. By adopting the means I have described, the breaker, if he be patient and expert, ought to succeed in making any jibber obedient in saddle after a lesson of a couple of hours' duration. Each succeeding lesson would be of decreasing difficulty, until the habit of obedience is established in a short time. All such desired effects can be produced much easier in a secluded enclosure than in the open.

It is not uncommon to meet with, especially in the mounted branches of the Army, horses which will go anywhere in company, but which will refuse to quit their companions, or to act as single riding horses. This peculiarity, the habit of trying to press the rider's leg up against a wall, tree, or other convenient object, and all other forms of jibbing, may be treated in the manner just described.

Jibbing in harness is a far more difficult fault to overcome than jibbing in saddle; for the presence of the cart greatly favours the "defence" of the horse. Before trying to eradicate the vice, we should satisfy ourselves that it is not caused by any ailment, such as sore shoulders, which should be cured before we proceed further. As our first object, when contesting the question of supremacy with the horse, is to gain the best kind of victory we can over our opponent, even if he has no direct bearing on the point at issue ; we should put the horse (of course, without the cart) through exactly the same course of discipline as I have recommended for the jibber in saddle. We may then harness him to a light, empty, two-wheeled trapinside a manige or other suitable enclosure, if possibleand working him on the track on which we had previously handled him, try to circle him with the long reins (see 
page I68), open snaffle bridle, and standing martingale, to the side to which he more readily bends. Having accomplished this, we should endeavour to get him, by taking a wide sweep, to turn to the other rein, and, if we are successful, should circle him freely on it, turning him and changing the direction of the circle so as to produce the best result. If he remains obstinate, we should take him out of the cart, and put him through the previous discipline, as we may deem advisable. As soon as we think he has given in, we may put him again between the shafts, and give him another trial. In attempting to start or turn the animal, we should on no account use the whip, except to raise it as a signal for the horse to go on, or possibly to crack it. Having accustomed him, while using the long reins, to receive the click of the tongue or the sight of the raised whip as a signal to start, he will almost always obey it at this period of the lesson. While the horse is on the circle, a light feeling of the inward rein will also be an indication for him to move on. When the horse circles and turns, with the cart behind him, in perfect obedience to our signals, we may gradually load it with any suitable objects, so as to accustom him to weight on his back. When he takes all this in good part, we may, while keeping him at a walk, get an assistant to quietly mount into the trap, and give him the reins, as soon as the animal shows that he does not mind the presence of a person behind him. The horse may now be taken into the open, and circled and turned by the driver a few times before being taken on the road.

We should be careful not to employ any words or other signals that might remind the animal of previous acts of disobedience which, presumably, had been successful in their object. When breaking a jibber, I like to use an open bridle ; because I find that horses go "kinder" with= 
out blinkers than with them. If it be imperative that our pupil should be driven in an ordinary harness bridle, we may accustom him to it after we have got him to go steadily in an open one.

If a jibber appears afraid of the whip, it is well, in the first instance, to prove to him, by giving him a turn at the head and tail method (see page I55), that we are not going to hurt him, when we crack it or flourish it about in his vicinity.

The jibber in double harness may be cured of his vice in the manner already described. If a pair jib, they should be broken of this vice separately, before being tried together.

\section{REARING}

is of two kinds; one, the less common, the manifestation of impatience to go on by a horse which is too "light in front" ; the other, a form of jibbing. Horses whose vice comes under the first heading are naturally " free goers," and are willing to proceed in any direction, though they resent being kept in the same spot. As a rule, they exhibit this "defence" only under occasions of excitement. They are extremely liable to be converted into jibbers by bad management. Rearing jibbers, as I may call those horses which practise the second form of rearing, are often light-mouthed horses; though I have met many hard pullers among the number. When a horse which is "heavy in hand" rears, we may conclude that he commenced his tricks as a jibber, and finding, probably by accident, that an attempt at rearing discomfited his would-be master, he cultivated the art of standing on his hind legs from that time. I might mention a third form of rearer who deliberately tries to crush his rider by throwing himself backwards on him. He appears to be 
vindictive as well as rebellious. There are, I think, extremely few rearers of this kind; as in all my experience of bad equine characters in various parts of the world, I can remember only one rearer of this description. I am inclined to think that such animals are very seldom met with, and that the majority of horses which have the reputation of throwing themselves back on their riders would do so only under provocation from the man or woman on their back.

In breaking a rearer, if we find that his fault arises from his being " behind the bridle," and probably from being at the same time too impetuous, we may try to put him straight by teaching him the turn on the forehand, both on foot (see page I93) and mounted (see page 212), and by turning with the long reins. It is often beneficial, supposing, of course, that the ground is soft, to provoke the rearer to rear when reining him back with the long reins, the outward one being on the driving pad (see Fig. 9I), and then try to pull him over in order to practically demonstrate to him the unpleasantness of such a reversal, so that he may abstain for the future from placing himself in any such position. As a further means of obtaining good behaviour, I would take, with all rearers, this opportunity of having them on the ground, to tie them head and tail and keep them down, as I have described on page 3II, until any remaining "nonsense" which might have been lurking in their minds had been removed. Since I adopted the method, which I copied from the French icuyers, of teaching rearers the turn on the forehand (pirouette renversée) with the whip, I have as a rule very little difficulty in making even the worst rearers stop their pranks and go in any direction in which I wished to ride them, after giving them a lesson of this kind for, say, a quarter of an hour. After succeeding perfectly in this manner, 
it would not be safe to trust such a horse to the guidance of a rider who did not know how to manage him before giving the pupil several (say, a dozen) similar lessons in order to confirm the habit of obedience. To insure this object, I would advise that a further effect should be made on the mind of the animal by making him lie down (see page I44), and, if necessary, by keeping him on the ground with his head pulled round (see page I49). Although I advise reining-back with the long reins on foot as a means of reforming the rearer, I do not think that, in such cases, it should be practised when mounted; for when the man is in the saddle, he is too much at the mercy of the horse to be justified in provoking the animal (as reining-back often does) to rear. All our trouble, tact, and judgment will be of no use, unless the person who rides the temporarily reformed character refrains from using the "aids" in a manner which would be liable to prompt him to recommence his old tricks. Among the best means for attaining that undesirable object are: striking the horse on the shoulder with the whip and holding the hands high.

The vices of rearing, jibbing, and bolting are sometimes combined in the same animal.

\section{SHYING}

may be caused through "light-heartedness," desire on the part of the horse to show off his power over his rider or driver, fear, defective sight, or the natural timidity which almost all young horses display towards unaccustomed objects. As the commission of this offence is, as a rule, rendered possible only by the fact of the animal not being obedient to the "aids," instruction in them will prove the best general treatment. Leaving out those cases which are due to defective sight, I would advise that the shyer 
should have a few sharp lessons in circling, turning, and reining-back with the long reins, by which means his "nonsense" and nervousness will not alone be taken out of him; but he will also be made amenable to the reins. Besides this, we may teach him the turn on the fore hand on foot (see page I93), and when mounted (see page 2I2). If the horse is very nervous or very unruly, we may give him a course of head and tail work (see page $\mathrm{I}_{55}$ ). Unless the shying is combined with jibbing or determined rearing, the severe discipline of making a horse lie down and keeping him on the ground (see page I49) will- not be required. For shying off the ball at polo, off the peg at tent-pegging, and other forms of this vice, see following paragraph.

\section{RUNNING OUT TO ONE SIDE, AND DIFFICULT TO TURN.}

Here, as in shying (see preceding paragraph), our great means of reformation will be work with the long reins, and practice at the turn on the forehand. After having given our pupil one or more effective lessons in the manege or on the breaking ground, we may test his steadiness as follows. Supposing that he runs out to the left when coming up to a fence or on some particular part of a race-course, we should, when mounted, take a rein in each hand and hold the cutting-whip or ash plant in the right hand (see Fig. I06), ready, the moment he attempts running out to the left, to pull his head round to the right, and to bring at the same moment his hind-quarters round to the left by the application of the whip or stick, so as to place him again in the direction from which he tried to deviate. As the turn can be made far easier on the forehand than on the hindquarters (see page 27I), it follows that the whip, or its substitute, should be applied to the latter in preference to 
the former. This is a point of breaking which is well worthy of attention, especially as it is opposed to the practice of the large majority of riding men. We must remember that, when a horse makes good an attempt to bolt away from the direction in which we wish to retain him, he does so on account of our inability to turn his hind-quarters to that side. Therefore, with a horse which refuses to the left on coming up to a fence, I hold the whip (as well as the rein) in my right hand, and apply it to his hindquarter; instead of, as is the usual custom, applying the whip (whichever hand it may be held in) to the near side of the horse's head, neck, or shoulder. With a horse which refuses to the right, the reversed aids would be required. I have found this method to be as successful in practice as it is sound in theory. After having made the horse obedient to the application of the whip, we should gradually substitute that of the drawn-back heel; so that, finally, we may be able to keep him straight by the rein and leg alone. The practice adopted by some hunting men and hunting ladies of striking their horses down the right shoulder for refusing (almost always to the left) and other faults, appears to be admirably calculated to make them run out to the left on slight provocation.

To break a horse of "whipping round" (turning sharply round) at some sudden or pretended cause of alarm, we should make him, according to methods already described, obedient to the leg. Thus, suppose the animal on seeing some (to him) terrifying object to, say, his right front tries to "whip round" to the left, we should pull his head to the right, and try to bring his hind-quarters round to the left by the pressure of the drawn-back right leg. 
KEEPING " BEHIND THE BIT," PRANCING, AND "BREAKING" WHEN WANTED TO WALK OR TROT.

There are two kinds of horses that will not "go up to their bridle"; the one, which refrains from doing so on account of laziness; the other, on account of temper, or eagerness to go forward. The former may be improved by the stimulus, judiciously applied, of whip or spur, and of "company"; the latter, by teaching them to put an increased amount of weight on their forehand, and by showing them that they must obey. In an impetuous horse, we may correct the failing by practising him in turning on the forehand, and by the use of the standing martingale when working him with the long reins, and also when riding him. When driving him with the long reins on foot, we should gradually decrease the size of the circle, and should bear almost entirely on the inner rein, so as to make him put an increased amount of weight on the forehand. I have found that, as a rule, it is not advisable to give such horses work at the rein-back. Keeping behind the bridle, when practised by an impetuous horse, is almost always a "defence" against the authority of the rider or driver, and is then an extremely difficult vice to cure. The animal affected with it will be liable to rear, "star-gaze," prance about, and "break" when wanted to walk or trot. We should use the various remedial means described in the preceding lines of this paragraph, and when riding the horse should avoid applying the legs to his sides; for doing so would have the effect of lightening his forehand. I would strongly advise that the "nonsense" should be taken out of him by one or more fairly severe lessons in the head and tail system (see page I55), or, better still, by making him lie down 
and holding him on the ground with his head pulled round (see remarks on pulling, page 306).

Horses which do not go up to their bridle sufficiently when jumping are apt to injure their hind legs by putting too much weight on them. Long rein work over fences (see page 240) with a fairly short martingale, and riding over obstacles with a large smooth snaffle and plenty of " rein," will soon break the animal of this vice.

\section{TEACHING PACERS (AMBLERS) TO TROT.}

We may modify the gait in the desired direction by circling the pacer with the long reins on foot in a ring sufficiently small to compel him to trot instead of to amble. I may explain that as the amble is a lateral gait (near and fore hind, and off fore and off hind), the horse which adopts it on a circle will have to step shorter with the inside pair of legs than with the outside, and will consequently be inconvenienced by this mode of travelling, proportionately to the smallness of the circle. As the steps of the trot, on the contrary, are composed of one inside and one outside leg (near fore and off hind, and off fore and near hind), the size of the circle will not affect the regularity of this diagonal gait. Having obtained a well-balanced trot to both reins (right, as well as left) in a small circle, we may gradually increase it, until it is from I5 yards to 20 yards in diameter. We may then put the animal into a light two-wheeled cart, and circle him on foot with the long reins, until he trots as steadily with the cart behind him as he did without it. We may now get into the cart, and trot him on the circle to the right as well as to the left. We may gradually enlarge the circle, do figures of eight, and end by working the horse on a straight line. 
CARRYING THE HIND-QUARTERS, IN THE CANTER OR GALLOP, OUTSIDE THE LINE OF PROGRESSION, AND REFUSING TO LEAD EXCEPT WITH ONE PARTICULAR FORE LEG.

On page 222, I have discussed appropriate means for correcting the tendency which some horses have of keeping the body in a position more or less oblique to the direction in which they are going, when cantering or galloping. When a horse persistently chooses to lead with one particular fore leg, at these paces, we may neutralise this predilection, supposing that the preference does not arise from unsoundness or malformation, by practice at circling (with the long reins and when mounted) to the opposite side. For instance, to the right, if the near fore be the favoured one, in which case we should also work him at turnings on his forehand to the left and at passage to the right, until he is equally handy with both fore legs. If the animal's habit be to lead with the off fore, similar, though reversed, movements should be executed. Making him canter "falsely" (see page 27I) with the less used fore leg will be of service in "suppling him."

PUTTING TOO MUCH WEIGHT ON THE FOREHAND WHEN MOUNTED.

We may correct this fault by practice at reining back with the long reins, and when mounted, by teaching the horse to turn on the hind-quarters (see page 27I), and by collecting him (see page 22I). With horses which put too much weight on the forehand when landing over a jump, we may use a bearing rein (see page I69), when practising them with the long reins at leaping (see page 240). 
PLUNGING FORWARD WHEN STARTING IN HARNESS.

Having put on an open snaffle bridle, give the horse a good lesson with the long reins (see page I68), practising him at circling, turning, reining back, starting and pulling up. Then put him into a light two-wheeled trap and circle him on foot (see Fig. II6) in the same manner as we did before we had put him between the shafts. We may then gradually work him in the way described on pages 253 and 254, until we can start, drive, and pull him up without his showing any impatience.

PULLING AWAY FROM AND HANGING AGAINST THE POLE WHEN IN DOUBLE HARNESS.

Having seen that the gear is all right, we may proceed to drive him on foot, and form his mouth and manners in the manner already described in this chapter. 


\section{CHAPTER XII.}

\section{FAULTS OF TEMPER}

Difficult to catch-Difficult to handle, bridle, saddle, mount, or dismount fromDifficult to ball or drench-Unsteady with the whip, under fire, when drawing swords, when touched with the heel, etc.-Difficult to lead into a doorway, horse-box, etc.-Difficult to shoe-Buckjumping-Biting and savaging-Kicking and striking out in front-Pawing at night-Pawing back the litter-Rubbing the tail-Sleeping standing-Difficult to harness and unharness-Getting the tail over the rein and kicking when in harness - Lying down in harness-Hanging back in the stall.

UNDER this heading, I shall put all the faults due to nervousness, impatience of control and aggressiveness, which I have not noticed in the preceding chapter.

\section{DIFFICULT TO CATCH.}

If a horse is difficult to catch when loose in the open, or in an enclosure, such as a loose box or yard, we may break him of the annoying trick by teaching him to come up and follow us on our giving him a signal to do so (see page 343). We should then reward him with some dainty, such as a piece of carrot, for his compliance-after having punished him for his disobedience.

DIFFICULT TO HANDLE, BRIDLE, SADDLE, MOUNT, OR DISMOUNT FROM.

We may take the "rough edge" off a horse's nervousness or impatience of control, by driving him with the long 
reins, or by giving him a good turn at the head and tail method, the effect of which may be completed by the use of the rope-twitch. By teaching obedience to the word "steady!" (see page II8) we can, with a degree of certainty unattainable by any other means, make the horse stand like a statue, by mere word of command. The rope-twitch can be so readily and easily applied, is so effective in its results, and is so free from evil consequences, that its application is of the utmost value in rendering horses docile. Having made the refractory horse acquainted with the meaning of the word "steady!" we may take hold of the loose end of the rope-twitch and direct an assistant to proceed to handle, saddle, mount, or otherwise try the temper of the animal, whom we should punish by jerking the rope and uttering the word "steady!" the moment he makes the slightest refractory movement. Each time the punishment is inflicted, the objected-to action should be recommenced, and the punishment repeated until obedience is obtained, when a caress and encouraging word should testify our approval. We should continue this instruction until we have made the animal thoroughly obedient. The noose-twitch (see page I22), from the ease with which it can be applied and taken off, is particularly useful for making horses steady for mounting and dismounting. If time is pressing, or if we are unable to accomplish our purpose by less severe methods, we may make the horse lie down and keep him on the ground (see page 149) until he "gives in."

\section{DIFFICULT TO BALL OR DRENCH.}

Aided by the rope-twitch (see preceding paragraph), I have never had any trouble in making refractory horses take a ball or drench. Mr. D. C. Pallin, A.V.D., informs 
me that he has invariably succeeded with horses which were deemed impossible to drench, in making them drink by mounting them, sitting well forward, drawing the head round to the off-side by the headstall with the left hand, and then giving them the draught out of a bottle with the right hand. This gentleman also advises to have a man on the back of a horse which is difficult to ball, while the operator is giving the bolus. The aim of these expedients is to make the horse take the drench or ball at the time, and not to render him permanently docile in either of these respects.

UNSTEADY WITH THE WHIP, UNDER FIRE, WHEN DRAWING SWORDS, WHEN TOUCHED WITH THE HEEL, ETC.

These manifestations of nervousness or of impatience of control may be corrected, either wholly or for the most part, by putting the horse through a course of long-rein work on foot, while subjecting him to the effects of the causes of his impatience. Or we may use the head and tail method, or teach the animal the word "steady!" with the rope-twitch. For making a horse steady while the man on his back draws a sword, especially from a steel scabbard, we should, after having saddled the horse, attach the sword to the saddle by the waist belt, so as to leave it and the sabretache (if used) hanging down the near side of the horse. Then, while using either the rope-twitch or the head and tail method, we may, with the aid of a long stick, move the sword from side to side, and withdraw it more or less out of the scabbard, so as to make it rattle. For accustoming a horse to stand the pressure of the heel, we may, in the same manner, teach him first of all to bear being gently poked in the side with a long stick, the end of which has been covered with some soft substånce. When 
we have got the unmounted animal quiet in this respect, we may put an assistant on his back, and complete his education with the rope-twitch, while the rider flourishes, or cracks, a whip about him, draws a sword, touches him with the heel, etc.

The use of the rope-twitch will be found a ready means for making a horse steady while his rider cracks a hunting whip. An animal which has to carry a huntsman or whip, must bear this being done without "playing up."

DIFFICULT TO LEAD INTO A DOORWAY, HORSE-BOX, ETC.

For overcoming this fault we may employ the means detailed on page I95. Sometimes the horse, as a defence in this case, places himself more or less at right angles to the direction in which we want him to go. We may then get him straight by making him turn on the forehand (see page 193) to the required extent. He will, as a rule, make no further resistance, as soon as he is straight. If he still resists, we may reduce him to order by circling, turning, and reining him back with the long reins (see page 185). In very exceptional cases it might be necessary to take the "nonsense" out of him by making him lie down and keeping him on the ground with his head pulled round (see page I49).

\section{DIFFICULT TO SHOE.}

Horses are frequently made " difficult to shoe," especially behind, by the practice some smiths employ of pulling the leg away from the body, so as to upset the animal's equilibrium. If the horse which is thus treated, gets punished for making a natural attempt to retain his balance, we need not be surprised, after a few such repeti- 
tions, at finding him difficult, if not dangerous, to shoe. The principles upon which we should act in correcting this fault are: (I) to avoid, as much as possible, altering the animal's equilibrium, while lifting a leg off the ground and holding it up; (2) to make the horse- understand that if he disobeys us we shall punish him, and that if he complies with our wishes we shall reward him; and (3), in the event of his displaying determined resistance, to show him that he must obey.

In these cases it is, as a rule, best to put on the ropetwitch in the first instance. To avoid throwing a horse off his balance when lifting up his hind leg, it is well to help the horse to place more weight on the other side, by turning his head towards it, and by gently shoving him over to it. Thus, if we wish to have the off hind lifted up, we may get the animal's head bent round to the near side by an assistant holding the twitch or rein in his left hand, and pressing his fist against the base of the neck on the near side (see Fig. I6); while the man who lifts the off hind, or another assistant, presses against that limb. If the foot which is to be operated upon be a fore one, we may lift it up (see page ro8) and suspend it from the surcingle (see page I 14). If it be a hind one, it is well, first of all, to tie up the fore leg of that side, and then put on the hind pastern a hobble (see Fig. 62), or one improvised out of a stirrupiron and leather (see Fig. 70). We may then get command over the leg by pulling it back (see Fig. 64); and finally raise it by a doubled cord attached to the tail or dock (see Figs. 65,66 , and 68). If we have got a strait-jacket and find it inconvenient to attach a rope or cord to the animal's tail, we may deprive him of his power to kick us, if we put on him the strait-jacket, which should be loose enough for its presence not to interfere with the horse preserving his balance; and may then lift up the hind 
leg by a rope or strap attached to the pastern, preferably by means of a hobble. We should gentle the limb, whether it be a fore or hind one, and should gradually accustom the foot to the hammer; correcting the horse with the twitch, if obliged to do so. For further directions on this subject, see page I33.

\section{BUCKJUMPING.}

I have seen very many cases of this vice among Australasian, South African, and South American horses; but none among European horses, Arabs, Barbs, or East Indian horses. The means which I have found to be most efficacious in eradicating or in preventing it are : giving the horse a good "mouth;" proving to him that, despite all his efforts to do so, he will be unable to buck while a man is on his back; and producing on his mind a strong impression of our power over him. It is evident that the worst possible lesson which a horse that is inclined to buck can receive, is that of throwing his rider; and that the next worse one is that of bucking. We may begin by giving the animal one or more sharp lessons with the long reins (see page r68), circling, turning, and reining him back, until he is thoroughly "supple." We may make him lie down and keep him on the ground with his head pulled round (see page I49), until he apparently gives in. Having allowed him to get up, we may tie his head to his tail, saddle him with one girth over the cord (see page 204), make him revolve round, and gentle him on the ribs with the end of a stick (see page 325) until he stands its touch. The horse may now be mounted in the manner described on page 202. Or we may omit the head and tail work, and have the horse saddled and mounted with the long reins on him, as soon as he gets 
on to his feet after undergoing his discipline on the ground. While holding the long reins with a firm grip, we should pull the horse round from side to side and rein him back, the moment the assistant gets into the saddle, so that the animal may not be able to buck; and having obtained control over him, we should circle and turn him at the walk, trot, and canter, until he goes quietly. The long reins may now be taken off, and the ordinary reins given to the rider, who, previous to this, should not touch the reins, although he may use the breast-plate, neck strap of the standing martingale, or other convenient object, as a help, in case of accident, for retaining his balance. Or we may omit the discipline on the ground, and trust to the effect of the long reins and head and tail method. In mild cases, mouthing with the long reins, and using them in the manner just described, for controlling the horse when the assistant mounts him, will be sufficient for an expert.

\section{BITING AND SAVAGING.}

Apply the wooden gag (see page I43), and, if necessary, tie up one fore leg, or put on the strait-jacket. Then handle the horse, and give him every opportunity to bite, so as to show him that he cannot effect his purpose, and that, when he vainly attempts to do so, he will hurt his mouth by the pressure of the gag on his gums. On this account, its action is most salutary, and differs entirely from the muzzle, which simply protects the object of the animal's resentment, without either checking the practice of the habit, or punishing him for indulging in it. With the gag on, the horse is unable to bring his teeth together. The fore leg may be let down, or the strait-jacket taken off, as soon as the horse is quiet to handle with the gag alone. This appliance may be kept in the horse's mouth 
for an hour or longer, during which time he should be handled with gentleness and freedom; particular care being taken not to irritate the animal, whose confidence and affection we should now endeavour to win. The worst biter ought to be rendered safe to handle, when the gag is out of his mouth, by giving him a week's course of three of these lessons daily, with a subsequent lesson, now and then, if necessary. For safety sake, the breaker should teach the horse the meaning of the word "steady!" (see page II8) with the rope-twitch. Though many bad, treacherous biters have passed through my hands, I have never met one which would attempt to bite, immediately after the gag has been taken out of his mouth, if he had been handled with it on for a quarter of an hour, or even less. It might be advisable, with very vicious horses, to make them lie down, to gentle them on the ground, and, if necessary, to keep them with their heads turned round (see page I49), until they had "given in." It is also well to teach them the word "steady!" with the rope-twitch.

If the horse under treatment is inclined to "savage," that is, to rush at and worry the object of his dislike, we may render him docile by putting him through the discipline described in the preceding paragraph, and by keeping the wooden gag (see page 143) in his mouth during his lessons with the long reins, and also when riding or driving him with an ordinary snaffle. Savaging in company, as at polo or with troops, can generally be cured in a short time by this treatment. In bad cases, we may employ the wooden gag instead of the snaffle for controlling the horse with the reins. We can have no confidence in riding or driving a horse which has been inclined to savage, until we have made him obedient to the aids.

An expert breaker, when driving a vicious horse on foot with the long reins, can, if the animal rushes at him, always 
turn him round by pulling the outward rein. If he backs and kicks, he should punish him by pulling him sharply round, alternately, with each rein.

As the horse instinctively uses the action of biting to remove or drive away irritating objects, he will sometimes bite without any vicious intention, and will often, in such a case, evince his concern, if not regret, at finding that he has inadvertently hurt a human friend.

\section{KICKING AND STRIKING OUT IN FRONT.}

We may reduce the kicker to obedience by making him lie down (see page 144), by keeping him on the ground with his head pulled round (see page I49), or by the head and tail plan (see page I55) until he "gives in"; and then by thoroughly mouthing him on foot (especially at the rein-back) with the long reins, so as to make him more attentive to the indications of the rein than to the practice of his favourite vice. Teaching the horse the meaning of the word "steady!" (see page II8) with the ropetwitch will also be of use. I have found that long-rein work on foot is specially applicable to kickers. It not alone teaches them to obey the aids, but also accustoms them to be touched about their hind-quarters. When the breaker is using the long reins, he can always save himself from being kicked by pulling the horse's head round with the inward rein.

It is advisable to teach a kicker to turn his hindquarters away from us (see page 164) when we approach him, supposing of course that he is free to do so, as he would in a loose box for instance.

One of the most objectionable vices a hunter can have is kicking at other horses or at hounds. The presence of the orthodox danger signal, in the form of a red bow on the 
animal's tail, is no excuse for bringing into a large field of horses a brute which will resent being touched behind; for such accidental contact is often unavoidable when going through gates, or when waiting in a lane or road outside a covert which is being drawn. Making the horse attentive to the aids, by putting him through a strict and long course of instruction, both on foot and when mounted (see Chapters V., VI., and IX.), is certainly the most effective means of getting such a kicker under control; for when he has acquired the habit of not alone obeying the signals given by hand and leg, but also of keeping his attention fixed on looking out for them, as long as the rider is on his back, he will have neither the inclination nor the time to commit assaults on his neighbours, even under a fair amount of provocation. To make doubly sure, the rider of the well broken-in horse which was formerly a kicker in the hunting field, should, in case of doubt, collect him with hands and legs, and should lighten his forehand by raising the animal's head. Here, a touch of the curb and a sharp word of reproof will aid in maintaining discipline. As a rule, immediately before a horse kicks with both hind legs, he transfers a considerable portion of the weight borne by them to his fore legs, and to do this the more easily, he lowers his head. As far as I have seen, horses which kick in the hunting field generally lash out with only one hind leg, and often do so without the slightest provocation or warning either to their rider or to the object of their malice. Also, my experience is that kickers out hunting strike their victims more frequently without being touched, than by being stimulated to do so by contact. If to this indictment we add the fact that when horses which are strangers to each other, get turned out into a field together, they are very apt to kick each other, even though they be usually good-tempered; we cannot help coming 
to the conclusion that kicking in the hunting field proceeds far more often from deliberate vice than from mere ticklishness. When a rider gets kicked, he should console himself by the thought that his broken or contused leg was the result of faulty aim on the part of the aggressor. To supplement the effect of hand and leg, it is well to teach the kicker the meaning of the word "steady!" (see page II8). With hand, leg and voice we shall have three effective means of control always at our disposal to remind the kicker of his duty; supposing that we commit the sin of taking him into the hunting field.

Besides the discipline described in this chapter, we may, with the kicker in harness, use the strait-jacket loosely put on over the harness to prevent him from doing any mischief, while giving him sufficient freedom to walk or trot. I have found that making him lie down by means of the strait-jacket a few times before putting him between the shafts has always a very good effect. If he persists in kicking, there is nothing that will render him so quiet as keeping him on the ground with his head pulled round (see page 149) until he gives in. Mr. Mitchell, A.V.D., who is an excellent breaker, tells me that he has obtained admirable results with bad kickers, by fixing, parallel to their sides, two stout poles, each about 7 feet long, secured in front of the chest and behind the quarters, so that the animal cannot get free from them, and then letting him kick until he is tired. This method, and the employment of a "jingle" (see page 256), by giving the horse nothing to kick at, will have a good effect in teaching him the uselessness of doing so. In most cases, I would use the rope-twitch, to make him connect in his mind the idea of punishment with the practice of his vice.

An excellent method of curing or preventing the practice of kicking in harness is to attach, at each side, a rope or 
rein to the crupper, say, four or five inches from the dock, pass it through a pulley or ring on the shaft, at about right angles with the point of attachment to the crupper; carry it forward, and fix it to the ring of the snaffle, at such a length that if the horse tries to kick he will give his lower jaw a violent blow. While acting as a kicking strap, it will be the means of making the horse associate in his mind the idea of pain with kicking in harness. We might connect it to a gag bearing rein, which, besides punishing the corners of the animal's mouth, would pull his head up, and thus tend to check the elevation of his hind-quarters every time he attempted to kick.

The old expedient of tying a kicker's tail to the splinter bar is often successful in breaking the animal of his vice. In other cases, it serves only to aggravate the objectionable habit. For this object, the tail may be secured by a double sheet bend (see Fig. 65).

I believe it is impossible, even with the most careful instruction, to render safe in harness some bad-tempered, treacherous horses which have had a successful trial or two at kicking a trap when between the shafts. The memory of such an experience appears to be particularly lasting in the equine mind.

For striking out in front, we may tie up one fore leg (see page II2), put the strait-jacket on (see page I29), apply the rope-twitch (see page I2O), or tie the horse's head to his tail (see page 155), and gentle both fore legs. The use of the rope-twitch is generally the quickest method.

The vice of kicking in the stable at persons or horses may be cured or kept in check by a few sharp lessons in making a horse come up to us with the whip (see page 343); for by such instruction we can teach the animal to turn his quarters away from us, the moment we raise our hand in a threatening manner. We may also teach him to obey 
the word "steady!" (see page II8) with the rope-twitch, and while that is on his head, we may bring horses close up behind him, and correct him sharply by jerking the rope. We should on no account forget to use the word "steady!" every time we jerk the rope. As a precaution, we may make the horse "stand over" in his stall, by pulling his head round with a cord attached to the side of the headstall, passed through a ring on the top of the roller, and

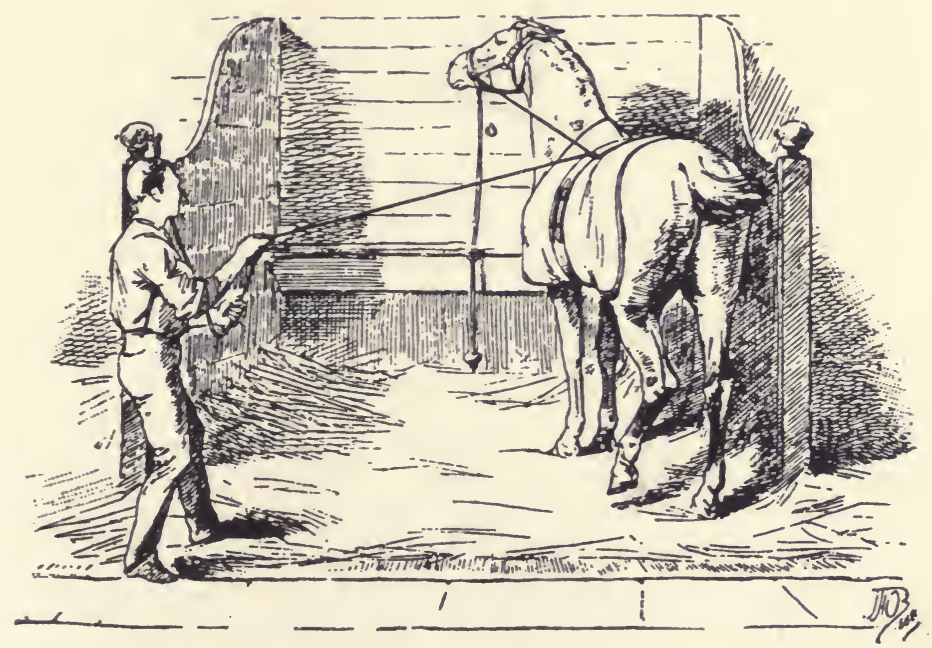

Fig. 123.-Pulling kicker's head round.

carried outside of the stall (see Fig. I23). Whenever we pull this cord in order to make the horse turn his quarters away from us, we should employ some appropriate verbal order, such as "over!"

Although I have had but little experience of breaking horses of the vice of kicking at night in the stable, I might suggest the use of the strait-jacket (see page I29), which should be loose enough to allow the animal to lie down and get up. I have seen it recommended, in such cases, 
to hang some soft object, such as a large bag filled with hay, behind the animal, so that, when he kicked, it would give to the stroke, and would then swing back and hit him, without hurting him; the effect being that the horse would get tired of kicking the inoffensive object, and he would accordingly drop the habit. If this method be adopted, I would suggest that the animal should, before

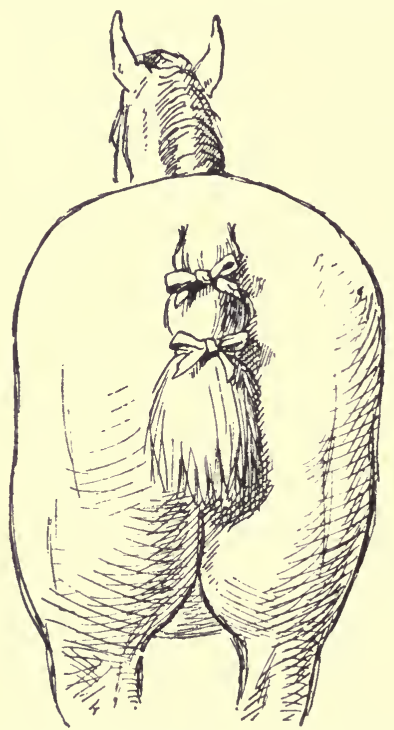

Fig. I24. - Tail tied with tapes to prevent horse rubbing it.

being left for the night, be accustomed to the stuffed bag, or whatever else is used, touching him. Tying up one fore leg, or applying the rope-twitch, will keep him quiet while this is being done. I take for granted that he has been previously made thoroughly docile, with the exception of this particular vice. The strait-jacket, loosely put on, would, I have no doubt, prevent the kicking. If it was properly applied, and gradually let out, say, a hole or two each night, it would, in all probability, break the horse of 
this trick. Connecting together by a rope the near fore with the near hind, and the off fore with the off hind, or connecting together both hind legs, passing a rope from the coupling rope, between the fore legs, round the base of the neck and securing it, would effectively prevent kicking; but such gear would not be safe to be left on at night; as the horse might get "cast" in his stall by his legs becoming entangled in it. The habit of abruptly kicking from time to time with one hind leg, is a symptom of the presence of a particular kind of mange insect (symbiotes) which infests the legs. I have known horses to kick at night from being disturbed by rats, in which case a cat should be kept in the stable.

\section{PAWING AT NIGHT.}

We may prevent the practice of this vice by employing a spancel (coupling strap) to connect the animal's fore legs together, so as to give him freedom to lie down, but not to paw. The use of this strap would, no doubt, in time cure the vice.

\section{PAWING BACK THE LITTER.}

I note that a correspondent, replying to a query in The Field, as to some means of stopping this practice, which causes the horse to sleep more or less on the bare floor, states that connecting the fore legs in the manner I have described in the preceding paragraph, will accomplish the object in view, and, after a few repetitions, will wean the animal from the habit.

\section{RUBBING THE TAIL.}

Although this vice comes more within the province of the veterinary surgeon than within that of the breaker; it may not be out of place if I mention that a bandage 
wrapped round the dock, or Mr. D. C. Pallin's plan of tying round the animal's tail two separate pieces of tape (see Fig. I24), will almost always make him stop the practice of this habit. If the rubbing be due to disease, appropriate remedies should be employed.

\section{SLEEPING STANDING.}

There are many horses that will never, voluntarily, lie down-a habit which seriously detracts from their capacity for work. Such animals might be taught to lie down (see page 144), and made to do so in their stall. Having no experience in this matter, I offer this advice merely as a possibly useful suggestion. In all cases, a good, deep bed of straw will be a strong inducement for a horse to lie down.

\section{DIFFICULT TO HARNESS AND UNHARNESS.}

We may circle the horse on foot, with the long reins (see page I68), and rein him back while he is in the shafts, so as to accustom him to them. We may then tie up one fore leg, apply the rope-twitch, and have the horse harnessed by drawing up the cart, while he is kept standing still. After repeating this once or twice, the leg may be let down, and the harnessing performed as before. After the horse has become quite steady, he may be backed into the shafts. Or we may put the strait-jacket on over the harness, make the horse lie down two or three times with it, and having got him on to his feet again, draw the traces of the strait-jacket so tight that, if he attempts to move, he will fall down. While keeping him standing with the strait-jacket on, we may try to bring the shafts over his back, letting him fall if he begins to struggle. In the great majority of cases, the horse will quickly learn to regard the fact of falling down as an irresistible 
punishment for his unsteadiness; and will accordingly give in, and stand quietly. After he does so, we may gradually slacken out the traces of the strait-jacket, until we can remove this apparatus altogether. For safety sake, in single harness, we should use the kicking strap, or a "jingle," if we can get one. If the animal be very determined in his resistance, we may take the obstinacy out of him by making him lie down, and keeping his head turned round (see page 149).

If the animal is difficult to unharness, we may use the rope-twitch, which will be sufficient in almost all cases. To prevent the horse springing forward, we may make him lie down a few times by means of the strait-jacket, and we may put it on him before taking him out of the shafts; or we may take the "nonsense" out of him by making him lie down (see page 144), or by keeping him on the ground with his head pulled round (see page I49).

GETTING THE TAIL OVER THE REIN AND KICKING WHEN IN HARNESS.

I regret to say that I know no means of permanently breaking a horse of the habit of whisking his tail over the reins at times when it is within reach. We may, however, by driving the animal on foot, and accustoming him to bear the rein under the tail, or by using the ropetwitch (see page I20), teach him not to kick when he finds the rein in that position. I presume that the horse might be taught, by the rope-twitch, not to whisk his tail over the rein on feeling it touch his hind-quarters; although, not having practically tested this expedient, I cannot speak positively as to its merits. I have rendered several animals which were previously addicted to the habit in question, quiet when the rein got under their tails, or touched their quarters, by the means described; or by 
gentling those parts when the animal was tied head and tail (see page I55). I have met some cases in which the kicking was caused by pain, due to pressure on melanotic tumours that were on the under surface of the dock.

\section{LYING DOWN IN HARNESS.}

We should make the animal obey the indications of the reins, by driving him on foot with the long reins; at first by himself, and finally in a trap. If he lies down, a sharp slap on his muzzle will generally make him jump up. The most effective means for curing this vice is making the horse lie down and holding him on the ground with his head pulled round (see page 149) until he gives in.

\section{HANGING BACK IN THE STALL.}

To prevent, if not to cure, the vice of hanging back against the chain or rope which connects the horse's headstall to the manger, we may substitute for the head-stall a rope halter (see Fig. I9), which will hurt the horse (see page 196) if he pulls against it, but will relieve his jaws of painful pressure the moment he comes forward ; or we may attach the horse to the manger by the crupper leading rein (see page I96).

In any case the rope should not be so short as to prevent him from lying down in comfort. I have been told that a good way to cure this trick is to shorten the chain by tying together, with a piece of thin twine, two of its links which are some distance apart, so that when the animal pulls on the chain he will break the twine, and will then cease to pull, because he will then believe that he has broken the chain. For a horse with this habit, a broad band may be placed across the entrance to the stall, so as to allow him to rest against it if he likes. 


\section{CHAPTER XIII. CIRCUS TRICKS.}

General remarks-" Begging "-Bowing and shaking the head-Circling steadily at liberty-Teaching a horse to follow-Handkerchief work-Jumping over another horse, etc-Kicking-Kissing-Kneeling down-LaughingLiberty work-Limping-Lying down-Obeying without reins-Polka, dancing the-Pushing a man out of the ring-Rearing and walking on the hind legs-See-sawing on a plank, etc.-Shaking hands-Waltzing.

\section{GENERAL REMARKS.}

Although circus tricks have little or no connection with horsemanship; many of them are interesting from the fact of their showing how horses can be trained on the principle of association of ideas, which is employed by all successful breakers, however much they may differ from each other as to details.

In teaching these tricks, it is well to accustom the animal to some invariable and suitable signal, whether manual or vocal, for each separate feat, and to reward his obedience by a piece of carrot, lump of sugar, crust of bread, bite of lucerne, bit of sugar-cane, caress, or other appropriate mark of approval. Having taught the horse one signal, we may, for show purposes, gradually substitute for it another signal which will be less evident to the public. Thus, instead of making a horse bow (see next page) by pointing our hand, whip or stick towards his chest, we may obtain the same result by advancing a foot. The beauty of a performance 
like that of Mr. Probasco with his "talking horse," Mahomet, is that the signals are so skilfully arranged and given that they cannot be detected by the spectators. I may mention that a "talking horse" is one which bows to say "yes," shakes his head to signify "no," and paws the ground to indicate numbers. In this way he can answer questions in the affirmative or negative, count, do "sums," and, when his master has the aid of an accomplice, perform "thought-reading" feats. For such work we require a horse which has a natural aptitude for the business.

\section{BEGGING.}

The horse may be taught to "beg," that is to stand with one fore leg bent and off the ground, by tapping the leg with a whip or cane, or by pulling up the foot by means of a strap or cord, while at the same time repeating the word "beg." As soon as the horse's foot is off the ground he should be rewarded with some dainty, the very sight of which, after a short time, will make him "beg"; or he will do so if the whip be pointed towards the part.

\section{BOWING AND SHAKING THE HEAD.}

These tricks are taught by lightly pricking the horse on, respectively, the breast or the crest, so as to make him bite at the offending object, or try to remove it by shaking his head and neck. He will thus soon learn to make his bow (to say "yes"), or to shake his head (to say "no") at the mere advance of the hand in the direction of the indicated part. The pin may be held in the hand or fixed to the end of a stick.

\section{CIRCLING STEADILY AT LIBERTY.}

After having taught the horse to circle with the long reins, we may fix his head in position by side reins so as to obtain 
adequate control, and lead him round the ring with a leading rein attached to a cavesson. When we want to make him halt, we should jerk the leading rein so as to make the noseband of the cavesson strike his nose, and should at the same moment bring the point of the lunging whip in front of his face. By diminishing the painful action of the cavesson and by continuing the threatening use of the whip in front of the animal, we shall soon be able to make him halt, rein back or turn, by the whip alone. Having previously taught him to go on by raising the whip behind him, we may, while lunging him with the leading rein and cavesson, make him go forward, vary his pace, or halt, by merely altering the position of the whip. After a few lessons we may dispense with the cavesson and leading rein, and work him "at liberty."

\section{TEACHING A HORSE TO FOLLOW.}

Besides the whip method (see page I05), we may teach the horse to follow us by the use of the Comanche bridle (see page I26), by making him turn round towards us, first at one side and then on the other, always accompanying the pull of the cord with the words "Come here!" or some similar expression. Mr. C. G. Frasier taught me this method.

\section{HANDKERCHIEF WORK.}

We may teach a horse to pick up a handkerchief by, while standing at his side, pricking him on the ribs with a pin or pinching him so as to make him turn round and snap, and, consequently, to seize with his teeth a handkerchief which is held in a convenient position for him to take it. When he catches hold of the handkerchief, we should gently remove it and should substitute some appropriate dainty, such as the usual carrot, for it. In 
this way the horse will soon learn to recognise the fact that he gets a reward for taking hold of the handkerchief, and can then be readily taught to pick it up or to take it off one of his legs, to which it has been loosely tied. Horses that are naturally ticklish and inclined to snap are the quickest to learn this trick in this manner. Instead of getting the horse to catch hold by irritating him, the same object may be attained by tying up in the handkerchief a piece of carrot or other bonne bouche, and inducing the animal to lift up the handkerchief in his endeavour to get at the contained delicacy.

When a horse has learned to catch hold of a handkerchief, he may be taught to fire off a gun, placed on a stand or on his back, by attaching a handkerchief to its trigger, and by indicating with the whip or hand the object to be seized and pulled.

\section{JUMPING OVER ANOTHER HORSE, ETC.}

Let us suppose that we want to make one horse stand perfectly still and unheld, while another jumps over him. We might then adopt the following procedure. Take an enclosed ring, like that of a circus, and close to its side, and on one of its diameters, construct a trench about 3 feet deep and 2 feet 6 inches wide, with a ramp leading down to it. Within this trench place a clothes-horse or other convenient stand, with rugs over it, and teach the jumper to go round the circle by means of the whip, and jump this obstacle. We may then substitute for the dummy the real horse, which we can teach, by means of the rope-twitch (see page II8), to stand perfectly still. All that now remains is to gradually fill up the trench while continuing the lessons. We may dispense with or retain the side reins. 


\section{KICKING.}

A horse can be taught to kick by touching him on the croup with the whip, and patting him on the neck when he kicks, which he will soon learn to do, if he be that way inclined, on being merely "shown" the whip.

The tricks by which the unridable mule of circuses gets rid of his would-be riders, are, generally, rearing and kicking in quick succession; followed, if necessary, by lying down and rolling. He will do any or all of these antics in obedience to signals given with the whip.

\section{KISSING.}

This is done by accustoming the horse to take some coveted bit of food out of one's mouth. In teaching a horse to do that part of the Dick Turpin "act," in which Black Bess, while lying exhausted on the ground, turns round and kisses her master before dying, the animal is made to lift up her head by pricking her with a pin on the shoulder.

\section{KNEELING DOWN.}

See "Lying down."

\section{LAUGHING.}

This meaningless trick is accomplished in the same way as a horse is taught to shake its head, by pricking him with a pin; except that the irritation is applied to the muzzle. The horse thus learns, on the signal being given, to turn up his upper lip, and show his teeth.

\section{LIBERTY WORK.}

In a circus, horses are said to work "at liberty" when they perform their "turns" loose in the ring and without 
a rider. Side reins are generally employed in order to obtain the desired control. I need hardly say that the various feats look much more effective if side reins are not put on. As a rule, the only indications which such horses obey are those of the whip; although the ringmaster will often make them appear to carry out his verbal orders. For ordinary work at liberty we want to make the horse go round the ring at the walk, trot, canter or to halt at word of command (see page 343); to come up to us (see page 343); to turn round ; to rear (see page 349); to kick (see page 345); to kneel down (see page 345 ); to lie down (see below); to pick up a handkerchief, or to remove a handkerchief from any leg on which it has been tied (see page 343); to limp on any required leg (see next paragraph); to fire off a gun (see page 344); and other kindred acts, all of which are done in obedience to the whip, and possibly in memory of the carrot which on previous occasions has been given as a reward.

\section{LIMPING.}

A horse can be taught to go lame on any particular leg when at liberty by making him keep it off the ground by tapping it with a whip, and continuing to do so when he is in movement. After a time, the animal will obey the signal of merely pointing the whip in the direction of the limb which the operator wishes the horse to favour.

\section{LYING DOWN.}

Make the horse lie down in the manner described on page i44. When he does so, without offering any resistance, let down the strapped-up leg, and repeat the lesson, until perfect obedience is obtained. We may then take off the throwing gear, and make him lie down 
by drawing his head round to, say, the near side, with the rein, while standing alongside the off shoulder. The horse will now easily learn to lie down, on receiving a signal to do so, as for instance by bringing his head round. It is well to conduct these lessons on a soft piece of ground with plenty of litter on it, so as to afford the animal an inducement to lie down. Colonel Salkeld, of the 2nd Bengal Cavalry, has suggested to me the advisability of giving this instruction to army horses, when ordered, after parade, at a time when they are more or less tired.

Having taught the horse to lie down in the foregoing way, we shall have little difficulty in making him do so by touching his fore legs with a whip. With this signal we may teach him to kneel down on either fore leg, or on both fore legs, and, while in the latter position, to place his face on the ground. We may also teach him to sit up on his haunches like a dog.

In circuses, horses are generally taught to lie down and to kneel down by means of the whip. To do this we may first of all teach the animal, as in "begging" (see page $342)$, to hold up either fore leg on its being touched with a whip, then strap up one leg, and make him hold up the other, and thus come down on his knees. Or we may pull his fore legs from under him (à la Norton Smith, see page I60), one after another, while giving him the signal with the whip.

\section{OBEYING WITHOUT REINS.}

Mr. Rockwell, the American horse-tamer, instructed three horses so well, that he was able to drive them together in a trap, and make them moderate their speed, turn, stop, and go on, in perfect obedience, by signals without reins. "Professor" Sample used to drive 
tandem with a leader that did his work without either reins or traces! The following would be appropriate signals for performing Rockwell's feat :- "Clicking" with the tongue, for "go on" ; "steady," for "moderate speed"; holding up whip, or saying "whoa!" for "stop" ; holding whip to the left, for "turn to the left" ; holding whip to the right, for "turn to the right." Sample's tandem leader did his "act" without instruction.

The right-about-turn and left-about-turn might be indicated by bringing the whip round to the right rear, or to the left rear, as the case might be. The signals should be taught the horse by employing them, on all occasions, when using the equivalent indications of the rein, which, to be additionally impressive, should be given sharper than usual.

It is comparatively easy to teach, when mounted, a suitable horse to obey without reins a number of indications, the effect of which is good in proportion to the difficulty experienced by the observer in seeing their application. Here, alteration of the position of the rider's weight comes largely into play. The effect of the voice may be restricted to obtaining the halt. The horse should be light-mouthed, and of a generous and observant disposition. We may commence in a riding-school or other suitable enclosure.

POLKA, DANCING THE.

A circus horse at liberty is said to dance the polka when he changes the leg at every stride (see page 287) at the canter. This movement, which is particularly difficult to teach, may be obtained by the use of the long whip in getting the required changes of leg. 
PUSHING A MAN OUT OF THE RING.

The familiar circus trick of a horse putting his forehead against the back of the clown or ringmaster and pushing him out of the ring, can be taught the animal by making him, by means of the whip, follow us (see page 343), while our back is turned towards him. We should then gradually make him come up close to us, in which endeavour it is well to use a whip in each hand, until we get him to rest his head against our back. We must, of course, regulate the direction in which to proceed; for we cannot do more in this case than to make the horse follow close behind us.

REARING AND WALKING ON THE HIND LEGS.

In a circus a horse is taught to rear by taking the snaffle reins over his head and jerking them, so as to hurt his mouth, and by touching him with the whip in front. Many animals are unintentionally taught to rear, by precisely similar treatment, outside of circuses. In a short time the circus horse will stand up on his hind legs and walk about in obedience to the mere flourishing of a whip. When a horse is trained to walk on his hind legs with a rider (generally, some misguided woman) on his back, the jerking of the reins, rather than the action of the whip, will have to be utilised. Such performances are as much opposed to the principles of true horsemanship, as they are stupid to look at.

\section{SEE-SAWING ON A PLANK, ETC.}

Employ the rope-twitch (see page II8) and Comanche bridle (see page 126). 
SHAKING HANDS.

Teach, as in "begging," q.v., the animal to advance his foot, by pulling it forward.

WALTZING.

Tie the horse head and tail (see page 155), and make him go round by flourishing the whip. As the animal obeys, gradually slacken out the cord, until it can be removed. For teaching two horses to waltz together, we may at first tie them together head to tail, and make them go round with the whip. 
I N D E X . 



\section{N D E X .}

Advitional school movements, 282

Admiration, love of, 19

Affection, 18

Aggressiveness, 27

"Aids," the, 48, 55, 58, 6I, 78

Amblers to trot, teaching, 320

Anger, 15

Angle of face to ground, 70-71, 78

Ape, II, 14, 16

Appuyer, 280

Arab horses, 10

Army horses, 33, 48, 31 2

Association of ideas, $3,7,35,38,4 \mathrm{I}$, 48

Attention, gaining horse's, 32

Australia, 236

Australian Blacks, ro

- horses, 32, 328

rough riders, 205

Automatic àctions, 2, 5

BACK, breaking pony's, 153

Balancing pole of body, 82

Ball, difficult to, 324

Ball's Bridge, 25 I

Banham, Mr., IO4

Banks, Irish, 240

Barroil, M., 87, 282

Bars of the mouth, $40,61,80$

Baucher, 79, 196, 233, 260, 26I

Bearing reins, 92, 169

Bearskin, 20

Beaucoup de jambes, etc., 78

Begging, 342

Behind work, heart, 32

Belvoir, 248
Bit, keeping behind the, 319

Biting, 38, 1 58, 329

Black Bess, 345

Blindfolding horse, 116

Boers, the, 161,162

Bolting, 318

Boots for jumping, 244

Boring, 185, 303

Bowing, 342

Breaker, danger of standing behind, 10 - requirements in the, $3 \mathrm{I}$

Breaking methods, selection of, 55

- - variety in, 55

Breaking, ordinary, 48

-

-

"Breaking" when wanted to walk or trot, 319

Bridle, Buonaparte, 121

__, difficult to, 323

—, keeping behind the, 76, 77, 319

- , twitch, 123

Bronchos, Io

Buckjumper, 44

Buckjumping, 328

Buckland, Frank, I I

Buonaparte bridle, I 21

Bushmen, Io

'Bus horse, 5

Cabmen, London, 91, 170

Camel, 20

Canter, 188, 223, 268

Cantering falsely, 223, 27 I

- , on three legs, 286

- with off fore, 223 
Cantle of saddle, rein under, I74

Capped knee, I I 4

Carriage of head and neck, 69

Carrot, I8, 4I

Castration, 52

Cat, 8, 18

Catch, difficult to, 323

Catching loose horse, Ior, 164

Cause and effect, Io, 89

Cavalry Drill, I99, 280, 294

Cavalry horse, I 5, 201, 293

—_ riding, 78

Cavesson, 40, 128, 24I, 343

Chance of doing wrong, not giving, 47

Change of pace, 278

- of leg in canter, 227, 270, 293

Charger, I 7

Chaser, the, 249

Chifney, Sam, 262

Children, I I, I4, 40, 66

China pony, I 53

Chucking up the head, 308

Circling at liberty, 342

- at the passage, $28 \mathrm{I}$

- horse, $8 \mathrm{I}$

Circular enclosure with jumps, 24 I

Circus, 42, 80, 82, 260, 287, 347 tricks, 34I

Civilisation, effect of, 4

Cold blood, jumping in. 33,248

Collecting horse, 72 221, 265-268

Colonel, 15

Comanche bridle, 126 , 196

Come up, making horse, 196

_- , teaching to, 105, 343

Companionship, horse's love of, 18

Conformation, 65

Consciousness, 2

Control, impatience of, I4

Corn, sieve of, 12

Counterchange of hand, 277

Courage, 23

Cow, I 8

— kicking, I Io

Crib-biting, I7

'Cross country horses, 49
Crosstrees, I 73

Cruiser, 5I

Crupper leading rein, 196, I98

Curbs, 79, 243, 264

Custance, 262

Cut and laid hedge, 240

Cuvier, II

DANGER of standing behind breaker, 96

Discipline, 45

Diseases, 52

Dismount from, difficult to, 323

Disunited in canter, 223

Dogs, 4, 8, II, I4, I6, I9, 21, 23, 54

Donkeys, I2, 20

Doorway, refusal to enter, 9

Double sheet bend, 138

Drench, difficult to, 324

Driving on foot, 175, 253

-_ pad, I72

Dublin, 25I

Dumb jockeys, 92

EARLY training, 32

Elastic reins, 94

Elephant, I2, I4

Emulation, I8, 42

Enclosure, breaking, 95

Ends of body, answering rein with both, 64

England, 222, 236

Entires, 19, 28, 39, 265

Epaule en dedans, 280

Esa, Mr., 125

Evening Standard, 160

Experience, 3

FACE, angle of, 72

Faintheartedness, 27

Fallon, 192

Falsely, cantering and galloping, 223 , 27 I, 289

Fanchion, 121, 198

Fatigue, 43

Feeling, sense of, 2I 
Fences, refusing, 246

- , running out at, 246

—_, rushing at, 246

Field, The, 337

"Fight," forcing horse to, 149

Figure of eight, 225, 271

Fillis, 20, 42, 265, 282, 285, 286, 287

Fire, unsteady under, 325

Fly, 38

Follow, teaching to, 105, I 27, 343

Foot, breaking on, 163

_- drawn back, 60

—, driving on, $\mathrm{I} 75$

Fordham, George, 262

Forehand, lightening, 66, 67

__, too much weight on, 32 I

_

Foreleg, extension of, 282

__, holding up, 111

_-, lifting up, I08

_-, noosing, 109

-_, tying up, I08, I I 2, I I4

Frasier, Mr., I 21, 343

Freedom, love of, 14

"Funk," 247

GAG, wooden, 38, I43, 329

Galway, 236

Gatacre, General, I 38

"Game" horses, 27

Geldings, 19, 39, 265

Gentling horse, 96, 148

— hind legs, 136

Germinal, 287

Gleeson, "Professor," I60

Goat, I8, 66

Grazing requirements, 65

Gregariousness, 17, 32

Groom, I 2, 54

Ground, keeping horse on, 149, 154, 166

Guards, leather, 9I

Gun, firing off, 344

HABITS, 3, 4, 55

Hack, park, 292, 295
Half hitch, I4I

Halt, collecting at the, 72, 77, 93 , 265

- the, $74,230,278$

- by word, 177

Haltering loose horse, IOI

Halter rope, 99

- twitch, I 6

Hamilton, 144

Handkerchief work, 343

Handle, difficult to, 323

Hands, shaking, 350

Hanging against pole, 322

- on headstall, 340 .

Harness, breaking to, 253, 295

-

_- falling in, I 54

- hanging against pole in, 322

- horses, 69, 93

jibbing in, 312

- , kicking in, 333

- lying down in, 340

_- plunging when starting in, 322

--, pulling away from pole in, 322

- work making horse pull, 305

Head and neck, carriage of, 69

- and tail method, 82, I21, I 55,

204, 208, 319

— pulled round on ground, I 50

— - shaking the, 342

- stall, hanging on the, 340

— stall, removing, 189

-- stall twitch, 132

__ throwing up the, 308

Hearing, sense of, I9

Heart behind work, 32

Heavy in front, 67,74

Hedge, cut and laid, 240

Heel, accustoming horse to, 325

--, unsteady when touched with, 325

High school, 80, 228, 260

- school horse, 201

Hill, zigzagging up, 13

Hilly countries, I 2

Himalayas, 4

Hind legs, gentling, 136 
Hind legs, lifting up, I 33

—, walking on, 349

- when jumping, injury to, 68, $230,243,320$

Hind-quarters away from us, teaching to turn, I64, 33 I

- sideways, carrying, $32 \mathrm{I}$

— , turning on, 272

— under horse, bringing, 66

Hippo lasso, 129

Hobble, 136

-..., improvised, $\mathbf{I}_{4} 2$

IIolding horse, 97

— horse on ground, I 53

—u up fore leg, III

Horse-breaking, objects of, 29

—_, ordinary system of, 6

—_, scope of, 29

—, 'bus, 5

- control, theory of, 29

-_ control, methods of, 95

— tamers, 48, 5I, 55, I 89, I 98, 208

- taming, 30

- taming machine, I6I

Horses, wild, 4

Humouring horses, 44

Hunters, 33, 20I, 246, 304, 33I

Hunting, 52, 53, 84, 306, 308, 332

Hurdle-racer, the, $25^{\circ}$

\section{IDEAS, 3}

Imitation, 17, 33, 42

Indian war bridle, 126

Initiative, depriving horse of, 73, 262

Instinct, 4, 56

Intelligence, 8, 22, 28, 35

Intensity of impression, 6,48

Ireland, 192, 222, 262

Irish outside car, 257

Islington, 236

IAMBETTE, 286

Jealousy, 54

Jennings, Mr. R., I 55

Jerking the reins, 4 o
Jibbing, 15, 16, 27, 33, 41, 51, 77, 309, 314

Jingle, a, 256

Jumper, show, 25I

Jumping, 74, 9I, 235

- competitions, 236, 25I

_. faults, 244

— over another horse, 344

—, strain on hind legs in, 68

Kемp, Mr., 308

Key to horse's mouth, 308

Kicking, 19, 68, I36, 158, 331, 334, 345

Kindness, 44

Kirby Gate, 248

Kissing, 345

Kneeling down, 345

Knights of old, 78, 26I

Knot which will not run, I 26

Knowledge of his own strength, 46, 50

LADIES' horses, 29I

Lamp-post, I 6

Language, horse understanding our, 35

Lassoing horse, 164

Laughing, 345

Laziness, 27

Lead, difficult to, 326

--, teaching to, I27, 195

Leading horse, 97, 199, 240

— off in canter, 224, 268

-- rein, crupper, I96, I98 with wrong leg, 32 I

Leather guards, $9 \mathrm{I}$

Le Bon, Dr., 6

Leg, changing, I88, 224, 226, 270

Leg strap, I I 2

Legs as an aid, 60, 220, 222

Leicestershire, 236, 248

Liberty work, 345

Lie down, making horse, 144, 319, 346

Lightening forehand, 66, 68

Light in hand, 74 
Limping, 246

Litter, pawing back the, 337

Long reins, $83,168,237$

Lunging horse, 81

Machine, horse-taming, 16I

Magic touch, 31

Magner, 198

Mahomet, the talking horse, 342

Mane of racehorses, plaiting, Io

- , scratching, 22

Mange provoking kicking, 337

Mares, 18, 28, 39, 177, 265

Martingale, running, 90

—_, standing, 87,190

Nemory, 2, 5

Mental qualities of the horse, I

Military exigencies, 49

— riding, 67,78

Miller, Capt. E. D., 295

Mind, I

Mitchell, Mr., 333

Monkey, I1, I4, 22

Moore, Mr. J. H., I93, 238

Morgan, Professor, 3, I 3

Mount, difficult to, 323

Mountain paths, 13

Mounted breaking, 20I

Mounting, Australian method of, 205 horse for first time, 202

Mouth, 48, 55, 59, 76

—, hardness of, 73

Mouthing, theory of, $5^{8}$

Mules, 12, 16, 296

NECK muscles, 70

- , stiffness of, 73

Nerves, I

- , over-stimulation of, 33

Nervousness, 24-26

- and vice, distinction between, 24

Nervous system, I

Newmarket, 185

"No!" 342

Noose țițch, 122, 165
Noose which will not run, I 21

Noosing fore leg, 109

Nose-bands, 90, 92

Nymphomania, 19, 163

Obedience, necessity of, $44,57,62$, 306 .

Obstinacy, 26

Off fore, cantering with, 227

Offett, Denton, I6o

Orders, making horse understand our, 35

Ourang-outang, II

Outside car, 257

Over-reaching, 244

PACERs to trot, teaching, 320

Pad, driving, I 72

Pain (see also punishment), $38,4 \mathrm{I}$

Pallin, Mr., 324

Park hack, 292, 295

Pas a' ecole, 267

Passage, the, 273, 278, 290

Passage, le, 267

Pawing at night, 337

- back the litter, 337

Peat, General, I 44

Permanency in breaking, 55

Personal influence, 53

Petting horse, 44

Phonograph, 3

Piaffer, 267, 287

Piaffer ballote, 287

Pigeon, tooth-billed, 4

Pillars, the, 92, 192

Pironette ordinaire, 273

- renverseé, 272

Plaiting mane of racehorses, Io

Plank, see-sawing on, 349

Pluck, 23

_—, spoiling, 46

Plunging in harness, 322

Points of the Horse, 78, 87, 186, 223, 228, 250, $25 \mathrm{I}$ 
Pole, hanging against, 322

- - pulling away from, 322

Polka, dancing the, 286, 348

Polo ponies, 91, 294, 317, 330

, Capt. E. D. Miller's book on, 293

Ponies, hill, 4, I 2

Pony mare, 16

Prancing, 319

Pratt, Mr., IO4, I21, I51, 198

Probasco, Mrs., 342

Pulling, 304

Punishment, 27, 37

Pushing man out of ring, 349

QUICK breaking methods, 7, 48

\section{RAABE and Lunel, I 29}

Racecourses, 27, 58, 84, 288, 3 I 7

Race-horses, Io, 39, 67, 185, 288

Railway lines, 82

Ranks, refusing to leave, 33

Rapid methods of breaking, see quick

Rarey, 30, 48, 51, 11 2, 144, I 59, I60

Rassembler, 79

Rawlins, Colonel, 108

Rearing, 68, 77, 314, 319, 349

Reason, 8-I I

" Refusing," 64, 237, 31 7

Rein-bearers, 173

Rein, getting tail over, 339

"Reining," 92

— back, 84, 185, 216, 290, 319

Reins, 59, $170^{\circ}$

- , bending to the, 77

- , elastic, 94

- , jerking the, 40

—, long, 83, I68

-

-

Removing gear, I 89 headstall, 189

Renz, Circus, 287

Repetition, 6

Revenge, 16
Reward, 37

Rideable and driveable, 47

Rider, timid, 36

Riding school, 17, 33, 235, 264

- the bridle, 222

River, 35

Rockwell, Mr., 198, 347

Rope-halter, 99

-_ , trailing, 20 twitch, I 20,165

Routiné, 226, 235, 263, 264, 27 I

Rubbing the tail, 337

Running away, 45, 304

- grounds, 82

— out, 317

——out at fences, 63,317 reins, 92

Rushing at fences, 246

SAdDLE, buckjumping, 210

- , difficult to, 323

Safety in breaking, 47

St. Petersburg, I6I

Salkeld, Colonel, 347

Sample, "Professor," 47, I44, I 55, I60, I6I, 347

Saunders, Mr., II 4

Savaging, 19, 28, 329

School breaking, 260

— horse, 264, 277

- instruction, course of, 28I

- movements, additional, 282

- walk, 267

See-sawing on plank, 349

Self-control, 8

- preservation, I4

Serpentine, 287

Sexual instinct, I9, 52

Shaking hands, 350

-. the head, 342

Sheet bend, double, I 38

Shires, the, 236

Shoe, difficult to, 45, 326

Shooting pony, 296

Shoulder-in, 280 
Shoulders fining down, 66

Show-jumper, the, $25 \mathrm{I}$

Shying, 5, 222, 316

Side reins, 92, 192

Sieve of corn, I 2

Sight, sense of, 20

Signals, horse understanding our, 35, 37,40

Sleeping standing, 338

Smell, sense of, 21

Smith, Mr. Norton, I60

Snafflẹ, 79, 168, 243, 264, 307

Snake, 20

Soldier, 67

South Africa, 28, 32, 161, 164, I65, 328

Spanish trot, 80, 26r, 285

— walk, 8o, 26r, 284

Speed when jumping, regulating, 244

Spiti, 4

Splinter bar, tying tail to, 334

Spoiled horses, 49, 54

Sprain of hind legs, 68, 230

Spurs, 232

Stall, hanging back in, 340

Standard, Evening, 160

Standing behind breaker, danger in 96

Stand still, making horse, 106

Star-gazing, 74, 91, 175, 308, 319

"Steady!" 36, I I8, 324

Stick, 59, 165

Stirrup leather for leg strap, I I 3

Stopping by word, 177

Strait-jacket, I29, I 54

Strength, knowledge of his own, 46, 50

Stubbornness, 5I, I5I .

Stumbling, 10

Submission to superior power, 22

Sulking, 26, 27, 32, 51, 149, 158, 166

Surroundings, 34

Sword, unsteady with, 325

TAIL, bandaging, 337

— over rein, 339
Tail rope, 145,152

_ , rubbing the, 337

- -, short, $14 \mathrm{I}$

__ to splinter-bar, tying, 334

with tape, tying, 337

" Taking off," when jumping, 244

Talking horse, 342

Tattenham Corner, 289

Temper, faults of, 323

Tent-pegging, 3 1 7

Tiger, 5, 23

Time required for breaking, 233

Touch with horse, keeping in, 76

Treachery, 22, 28, 51

Trooper, 20I, 293

Trot, the, 218, 266, 279

-Trying yearlings, 288

Turn, difficult to, 317

- hind-quarters away from us, teaching horse to, 164,331

- on forehand, 193, 212, 271

- on hind-quarters, 272

- on three legs, 286

Turning at liberty, 273

- horse, 63, 81, 179, 218, 220, 294

Tưrpin, Dick, 345

Twitch, bridle, 123

$\longrightarrow$, halter, 116

- - , headstall, 122

- noose, 122, 165

---, ordinary, I16, I18, 120, 125

—, rope, 118,165

" Tying horses up," 92

UNDERSTANDING our orders, horse, 35

Unharness, difficult to, 338

Uniformity of conduct, 22

Unsteadiness, 325

VARIETY in breaking methods, 55

Vice, 24, 50

Voice, effect of, 41, 42, 60

WAl.k, the, 71, 217

Waltzing, 350 
Wardrop, . Colonel, 192

Weaving, 17

Weight, distribution of, $63,66,187$, 218,32 I

- , rider's, 6o, 63, 64, 68, 227

Wells, 262

Whip, 39, I05, I81, 232

— , unsteady with, 325,326

Whipping round, 318

Whips, using two, 31 2
"Whoa!" I77

Woods, Major, 154

YEARLINGS, 288

"Yes," 342

Żebras, IO, 296

Zigzagging up hill, I3 

RETURN TO the circulation desk of any

University of California Library

or to the

NORTHERN REGIONAL LIBRARY FACILITY

Bldg. 400, Richmond Field Station

University of California

Richmond, CA 94804-4698

ALL BOOKS MAY BE RECALLED AFTER 7 DAYS

2-month loans may be renewed by calling

(415) 642-6233

1-year loans may be recharged by bringing books to NRLF

Renewals and recharges may be made 4 days prior to due date

DUE AS STAMPED BELOW

i. 25998 

